Lucia Oliveri

\title{
Imaginative Animals
}

Leibniz's Logic of Imagination 


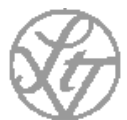

Franz Steiner Verlag 


\section{studia leibnitiana sonderhefte}

Im Auftrage der Gottfried-Wilhelm-Leibniz-Gesellschaft e.V.

herausgegeben von Herbert Breger, Michael Kempe,

Wenchao Li (verantwortlich) und Pauline Phemister

In Verbindung mit Stefano di Bella, Francois Duchesneau, Michel Fichant, Emily Grosholz, Nicholas Jolley, Klaus Erich Kaehler, Eberhard Knobloch, Massimo Mugnai, Hans Poser, Nicholas Rescher und Catherine Wilson

Band 57 


\section{Imaginative Animals \\ Leibniz's Logic of Imagination}

Lucia Oliveri

Franz Steiner Verlag 
Die Veröffentlichung dieser Publikation wurde durch den

Publikationsfonds der WWU unterstützt

\section{(9) $(\Theta \Theta \Theta$}

Dieses Buch ist eine Open-Access-Publikation.

Dieses Werk ist lizenziert unter einer Creative Commons Namensnennung -

Nicht kommerziell - Keine Bearbeitungen 4.o International Lizenz.

https://creativecommons.org/licenses/by-nc-nd/4.o/deed.de

Bibliografische Information der Deutschen Nationalbibliothek:

Die Deutsche Nationalbibliothek verzeichnet diese Publikation in der Deutschen

Nationalbibliografie; detaillierte bibliografische Daten sind im Internet über $<$ http://dnb.d-nb.de> abrufbar.

Dieses Werk einschließlich aller seiner Teile ist urheberrechtlich geschützt. Jede Verwertung außerhalb der engen Grenzen des Urheberrechtsgesetzes ist unzulässig und strafbar.

(C) Franz Steiner Verlag, Stuttgart 2021

Druck: Memminger MedienCentrum, Memmingen

Gedruckt auf säurefreiem, alterungsbeständigem Papier.

Printed in Germany.

ISBN 978-3-515-13049-3 (Print)

ISBN 978-3-515-13051-6 (E-Book)

https://doi.org/10.25162/9783515130493 
To my husband, Matteo Bozzon 
Franz Steiner Verlag 


\section{INHALTSVERZEICHNIS}

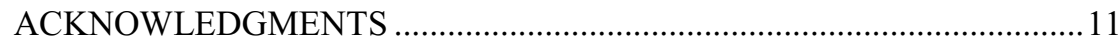

INTRODUCTION: THE LOGIC OF THE IMAGINATION:

SPACE, TIME, PREDICTIONS........................................................ 13

1. The Subject Matter of the Imagination ................................................. 15

2. Content Summary ..........................................................................25

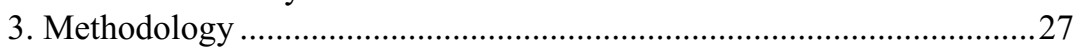

I. THE EXPRESSIVE POWER OF THE MIND

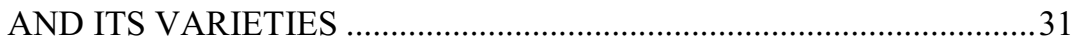

1. Ideas as Dispositions to Form Expressions ........................................... 33

2. Expression and its Interpretation....................................................... 35

3. Cognitive Desiderata for a Theory of Expression................................39

4. Expression and Blind Thought........................................................... 43

5. Expression and its Metaphysical Meaning............................................51

6. Is Cognitive and Epistemic Use of Expression Univocal? ....................53

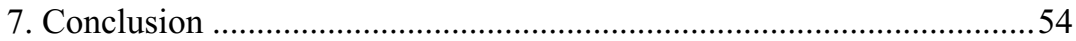

II. THE GROUNDWORK OF THE IMAGINATION ................................57

1. The Synthetic Work of Imagination.......................................................59

2. The Logic of the Imagination, its Cognitive Constraints......................6 67

3. Segmentation and Simplification ......................................................... 73

4. Confused Sensation and Distinguished Perception............................... 77

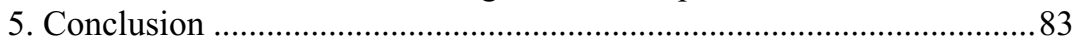

III. INTERLUDE: IMAGINATION AND REALITY ................................85

1. Segmentation, Simplification, and the Metaphysical Ground

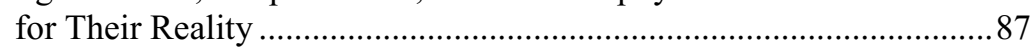

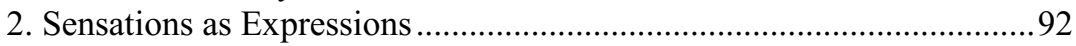

3. Segmentation as Expression................................................................... 95

4. Combinatoric of Elements vs Propositional Containment ..................... 98

5. Coherence, Motion, and the Metaphysical Constitution of Bodies .....101

6. Coherence and Distinct Perception ................................................... 110

7. Conclusion ................................................................................. 112 
IV. FIRST- AND SECOND-ORDER COHERENCE I:

TIME, SPACE, AND TYPES............................................................... 115

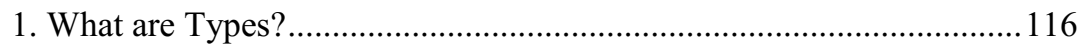

2. Nature as the Intentional Object of Types...........................................125

3. Space and Time: A First-Order Coherence..........................................129

4. Space, Time, Causation: Leibniz's Empirical Principle ........................133

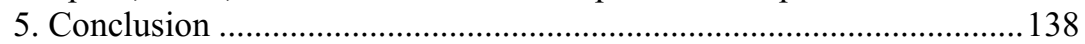

V. FIRST- AND SECOND-ORDER COHERENCE II: MODALITIES AND TYPES ...........................................................139

1. First-Order Coherence and its Limits....................................................141

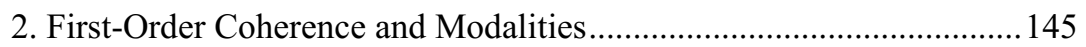

3. Second-Order Coherence and its Constraints ......................................152

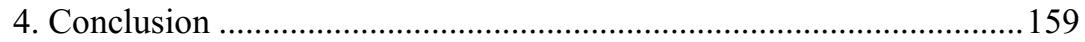

VI. SIMILARITY, MOVEMENT, AND THE INTERIORIZATION

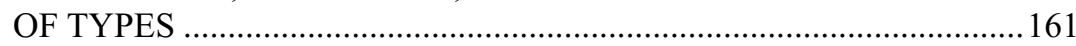

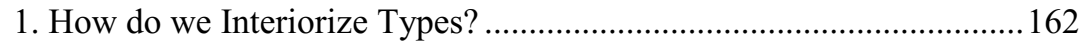

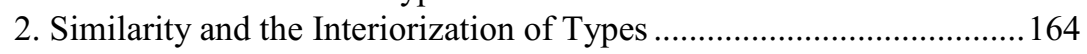

3. Similarity, Abstraction, and General Notions ......................................... 167

4. Similarity, Abstraction, General Notions in New Essays .....................174

5. Imagination as a Combinatoric Faculty ...............................................180

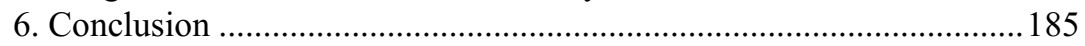

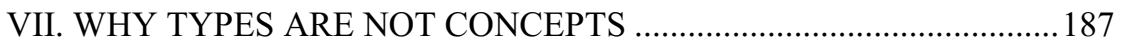

1. Types vs. Concepts - Extension vs. Intension ....................................... 189

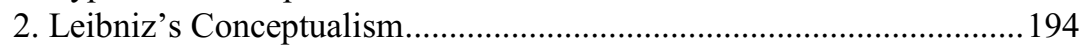

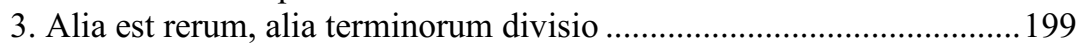

4. From Types to Concepts ....................................................................202

5. Types, Concepts, and Terms ………………………………….........205

6. The Conceptualist Response .............................................................211

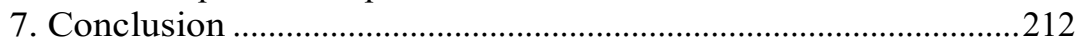

VIII. CONCEPTUALISM, REAL DISTINCTIONS, AND ERROR ..........213

1. Generalizations and Natural Languages..............................................214

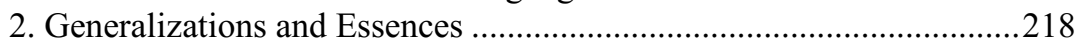

3. Logical, Metaphysical, and Physical Genus .......................................226

4. Mathematical and Physical Species …………………..................223

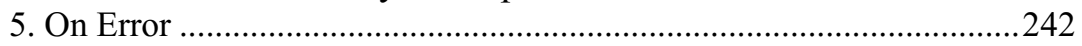

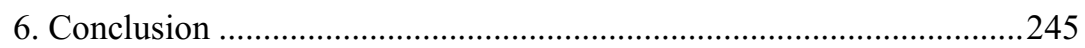


IX. LEIBNIZ'S INNATISM...............................................................24

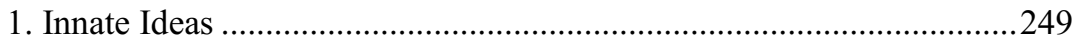

2. A Moderate Innatism.......................................................................256

3. The Mind as a Dark Room ...............................................................261

4. The Mind as an Architect...................................................................263

5. Two Desiderata for Leibniz's Theory of Innate Ideas ........................266

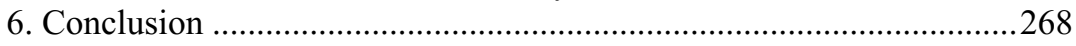

CONCLUSION: CONTOURING THE IMAGINATION .........................271

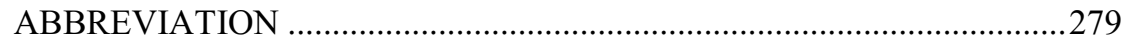

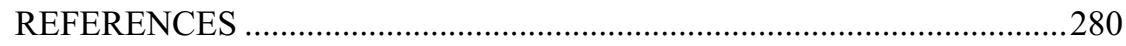


Franz Steiner Verlag 


\section{ACKNOWLEDGMENTS}

After completion of my dissertation "Imagination and Harmony in Leibniz's Philosophy of Language", my supervisor remarked that, given the title, he was expecting a chapter dedicated to the imagination. Good observations haunt you, and though I think that my enquiry into Leibniz's philosophy of language is an enquiry into the imagination, I could not ignore that there was more to say about the imagination before is tied to the use of signs (see introduction). I am first grateful to the person who made that observation (and many others), Stephan Meier-Oeser, for years of support and discussions.

The present book begun to take shape during a stay at Rutgers University (2017-18) and was completed during residence at Harvard University (2019-2020). Both stays were supported by funding from the DAAD (German Academic Exchange Service). I arrived at Rutgers with a short-term (six month) research fellowship and at Harvard with a one-year P.R.I.M.E. (Postdoctoral researchers international mobility exchange) Fellowship. I am grateful to Professor Thomas Leinkauf for supporting me during these years and for many discussion during his weekly research seminar and beyond. A special thank you goes to Martha Brandt Bolton and Jeffrey McDonough for sponsoring my stays at Rutgers University and Harvard University respectively. This work could not have found its way without their support and discussions both in private and public meetings, like the Harvard History of Philosophy Workshop, whose participants I thank. Thanks to Martha for inviting me to present this work at Rutgers and because I lost count of the hours we spent talking about Leibniz's philosophy between New Brunswick and Princeton. Thanks to Rafaella De Rosa, Enrique Chavez-Arvizo, and the participants of the NY/NJ Early Modern Philosophy Seminar for hosting a talk addressing parts of this work. Other people I had the fortune to meet during my stays in the USA contributed to this book as well: Richard Arthur, Santiago Echeverri, Ruth Hagengruber, Martin Lin, Samantha Matherne, Alison Simmons.

My research has been based at the Leibniz's Archive and the University of Münster since my PhD. During those years, I enjoyed discussions on Leibniz's Philosophy with Walter Mesch, Oliver Scholz, Niko Strobach, and the members of Leinkauf's research seminar and visitors of the Leibniz's Archive: Laurynas Adomaitis, Alexandra Alvarez Leon, Hannes Amberger, Laura Herrera Castillo, Marc Heimann, Pasquale Marino, Adrian Morreale, Christian Zeug, Dorothee Zucker, and many others. Thanks to the editor of Leibniz's philosophical writings and letters for their support with editorial issues: Gerhard Biller, Stephan Jenschke, Herma Klige-Biller, Stefan Lorenz, Henrik Wels. Thank you also to the technic and administrative support: Jörg Dieckhoff, Manon Dutz, Angelika Rüter. 
Besides the aforementioned venue, I presented the work at colloquia and to research groups at diverse Universities, among others: University of Milan, University of Osnabrück, and the Mathesis Research Group CNR Paris. Thanks to the people I met on my way, especially: Mattia Brancato, Matteo Favaretti Camposampiero, Valerie Debuiche, Vincenzo De Risi, Stefano Di Bella, Nora Gädeke, Stefano Gensini, Nikola Kompa, Martin Lenz, Cristina Marras, Massimo Mugnai, Enrico Pasini, Francesco Piro, Hans Poser, Mariangela Priarolo, and David Rabouin.

Achievement is void if you cannot share with family and friends. I am grateful to my parents, Nino and Palma; to my sister Chiara, her husband Giuseppe and little Ginevra; to Aldo, Paola and Rossella, and to my husband Matteo. Thank you to Louise Rebecca Chapman for proofreading the book.

Last but not least, thanks to the person who introduced me to philosophy, Maria Rita Abramo, and to my friends: Luca Anoé, Anna Battista, Stefano Porto and little Zaccaria Porto, Jonathan Bauerschmit, Angelo Matteo Caglioti, Francesco Campana, Davide dalla Rosa, Gianluca De Candia, Jonas Erulo, Nemanja Kostic, Iulia Ionescu, Herrissa Lamothe, Monja Reinhardt, Federico Sanguinetti, and Pia Schneider.

This book is published in Open Access thanks to the DAAD P.R.I.M.E. programme and the Publikationsfonds of the University of Münster. I owe a special thanks to Prof. Wenchao Li for his technical and philosophical support in the publication of the present work.

A final thank to Heinrich Schepers, sine qua non. 


\section{INTRODUCTION: THE LOGIC OF THE IMAGINATION: SPACE, TIME, PREDICTIONS}

I mindlessly leave my coffee cup on the edge of the table and my husband exclaims: "Look, it's going to fall". I turn on the TV and hear about what the future holds following the Coronavirus pandemic: how universities are going to change their inperson activities; how shops are unable to reopen until new hygiene norms are applied; how travelling, shopping, and eating out will be affected following the most unprecedented of events. My sister calls and my niece pretends to talk to me using a toy phone.

What these examples respectively emphasize is the extent to which we rely on our capacity to imagine past, present, and future states as connected. Indeed, it is through this capacity that we can anticipate, for example, how much influence one event bears on another, in both the immediate and distant future. This capacity is as various as the subject matter it concerns. My anticipation that the coffee cup will imminently fall differs enormously from predictions about the economic effects of a virus, which has put all quotidian activities to an end for months. The former is a quasi-sensory presentation of how the cup can change; the other is a survey of events and their potential consequences. ${ }^{1}$ Nevertheless, they have something in common: they connect a present or a past state with something that has not yet existed (and, indeed, may never), but which we nonetheless consider to be relevantly related to a present or preceding state of affairs.

This capacity to imagine or conceive of what is possible is normally thought to be the province of the imagination, a topic that this book tackles from a particular angle, viz. by unpacking Gottfried Wilhelm Leibniz's reflections on the cognitive dimensions of the imagination as it functions vis-à-vis human and non-human mental processes. It therefore expounds Leibniz's view that the imagination somehow permeates our cognitive life insofar as "human beings naturally tend (conantur) to explain through things that are subject to the imagination also those that they cannot imagine." However, in spite of its pervasiveness, the analysis of the imagination

1 This distinction is present in the contemporary literature, in which sensory imagining, such as when I imagine a flying pig, is counterpoised to conceiving of a "situation", that is, a conformation of objects and events, which verifies the truth of a proposition, such as when I consider which events might have been required for Germany to win World War II. Conceiving is nonsensory. On this topic, see, for instance, Yablo (1993: 1-42) and Chalmers (2005: 145-200).

2 De lingua philosophica (1687-88?), A VI 4 A 890. The full sentence is a remark about the use of prepositions. Leibniz remarks that prepositions seem to originally have spatial meaning. It is only through the use of tropes that they acquire metaphysical meaning, because these are less subject to the imagination. It follows a general claim about the imagination: "This should not 
in cognition has sparked little attention by scholars for several reasons. ${ }^{3}$ One of these is that, during Leibniz's time, the imagination was understood to be involved in the use and formation of signs (or any representative vehicles of thought), while today we do not think that the imagination has such scope. This caused scholars to overlook much of what Leibniz says about the use of signs, languages, and expressions more generally, viz. in their connection to the imagination and its broader function within cognition. ${ }^{4}$ Writing to Bayle, for instance, Leibniz claims:

Any time a human being reasons about abstract things that surpass the imagination, this does not happen without having in the imagination some signs that respond to them, such as letters and characters. There never is an understanding so pure that it is not accompanied by some imagination. So there always is in the body something mechanical that corresponds exactly to the series of thoughts that are in the mind of a human being insofar as what is imaginable is part of them, as a consequence the automaton of the body no more needs the influence of the soul, nor the supernatural assistance of God, than the bodies of non-human animals. (GP IV 541)

Indeed, the relation between the imagination and signs constituted my way into this topic. Thereafter, I realized that signs and languages were not the only domains presided over by the imagination. On the contrary, for Leibniz, the imagination is also relevantly involved in pre-linguistic and pre-conceptual forms of reasoning. More specifically, Leibniz's general claim that we have a natural tendency to imaginatively represent what is not in fact subject to the imagination must be interpreted, I argue, as the following claim: the imagination has the ability to transform subject matters that are - for various reasons - initially cognitively off-limits to finite, cognizant agents. This imaginative transformation renders those matters cognitively available to the agent. In other words, the imagination is the faculty responsible for what Leibniz calls expression, an activity through which a cognizant agent

surprise us, since 'homines etiam ea quae imaginari non possunt per res imaginationi subjectas explicare conantur." For a discussion of prepositions, see Oliveri (2014).

3 When I began my PhD thesis, "Imagination and Harmony in Leibniz's Philosophy of Language" (2016), the only work on the imagination known to me on this topic was Enrico Pasini's $\mathrm{PhD}$ thesis, later published as "Corpo e funzioni cognitive in Leibniz" (1996). Pasini's work has many merits, among others, its drawing attention to Leibniz's interest in the body understood as an organism. Other important works are De Risi (2007: Chapter 3) and a paper by Meier-Oeser (2011: 660-666), who explicitly connects the work of the imagination with the expression of sense-perceptions as bodies. Even in my $\mathrm{PhD}$ thesis, however, I neglected most of the cognitive work carried out by the imagination, focusing mainly on the function of signs for cognition. Indeed, as presented at the Harvard History of Philosophy Workshop - the first draft of a paper now developed into Chapters 3, 5, and 6 (2018) - there was little scholarship on the topic: papers by Garber (2015, although he does not explicitly link the geometrization of bodies to the imagination) and Leduc (2017). At the time, I did not know about some groundbreaking scholarship by David Rabouin (2013: 109-130; 2017; 2018), whose work on the role that the imagination has in cognition highly influenced my own, as can be seen in Chapters 3 , 4, 5, and 6. Recent scholarship on this issue has been advanced by Jorati (2019), Tropper (2019), and Weckend (2019).

4 Exceptions are Pasini (1996); Favaretti Camposampiero (2007); De Risi (2007), and MeierOeser (2011). 
extrapolates and processes information in order to form the idea of her world as composed of bodies, viz. four-dimensional objects whose respective states must be internally and externally compatible with the states of other, co-perceived (or coimagined) bodies. When they are not, these states are precluded from existence, although incompatible states may nonetheless be possible.

I further argue here that the idea of a world and the bodies populating it qua spatiotemporal unities are required for the anticipation and prediction of events. If this use of the imagination is evident in natural sciences, then it is also constitutive of social interactions. This book therefore advances the thesis that, for Leibniz, imaginative processes are required for developing forms of intentionality into what Leibniz calls "abstracta" or "essences". Through these acts, we constitute ourselves not merely as cognizant agents but as moral agents. Given the manifold role that this faculty plays in cognition, this introduction has the aim of unfolding the theoretical and historical context within which Leibniz developed his theory of the imagination, and, thereby, his relation to Thomas Hobbes (sect. 1). Through this short excursus, we shall set the stage for understanding how Leibniz transforms issues relating to the work of the imagination (sect. 2). I conclude with some brief remarks regarding my methodological approach to the history of philosophy.

\section{THE SUBJECT MATTER OF THE IMAGINATION}

Each faculty has its own, peculiar subject matter that distinguishes it from other faculties. For example, the senses are directed towards what is present in our perceptual environment, thereby making us aware of sensations (colors, smells, tastes, etc.). Memory, by contrast, presents to our minds something that was present in the past but now is not. Finally, the intellect is directed towards truth. The imagination makes present the absent, presenting to us what is possible but does not actually exist (and, most importantly of all, must not exist). The imagination is, therefore, the faculty of fiction. However, given its relation to what is possible (and so, its relation to the future), the imagination seems relevantly related to knowledge. This is not completely true for Leibniz, who assumes that the proper subject matter of the imagination is continuous quantity, sc. magnitude like space and time. Continuous quantity is something abstract and ideal; it is for this relation to ideal magnitudes that the imagination is relevantly connected to what is possible, and hence to fictions. However, in order to understand why Leibniz takes a different stance (as well as the import of this change), we need to establish a link between the imagination and fiction, which can be understood in the early modern sense as "that which does not exist". 5

5 Leibniz uses "fiction" in a technical sense. Fiction either refers to things that cannot exist because they are logically impossible, or to those things that cannot exist because a set of conditions precludes them from being part of the world, although it does not therefore imply the logical impossibility of that fiction. In the early modern period, a fiction was a product of the mind entertaining a non-obtaining state or event. More on this in chapter V. 
The aforementioned cognitive states (for instance, my husband's prediction about the falling coffee cup, causal connections between the virus and its effects, my niece's pretense in using her toy phone), are manifestations of a cognitive agent's reasoning, which furthermore relies upon imaginative skill. Some of these states result in new knowledge, as when we discover causal connections, while others do not. Still, they are all characteristic of a rational human being in her interactions with others. It seems that the same faculty is both constitutive of what we may define as "human rationality", but also the source of our most intimate, irrational responses to the world, insofar as that involves entertaining fictions. ${ }^{6}$

Early modern philosophers insisted on the Janus-faced quality of the imagination, which was easily singled out as the primary source of human error, but challenging to recognize as positively contributing to knowledge-acquisition. ${ }^{7}$ Recognizing the imagination's positive, cognitive role requires acknowledging its relation to what is possible. For, if the imagination contributes to cognition by making present the absent, then, it may also present to the mind's eye things that are not only likely to happen, but have not happened yet. Indeed, the imagination may even bring to cognition ideal objects from which we can extrapolate knowledge (as in geometry and mathematics). The imagination also causes us to entertain things as if they were true or existent, although they are not. Thus, the simple fact that we can imagine them may explain why we believe them to be true.

The irony here is that this line of argumentation is shared by those who view the imagination's work positively (like Spinoza or Leibniz). ${ }^{8}$ Hence, the role that the imagination plays in cognition is not just controversial, but elusive; an elusiveness still recognized in contemporary discussions. This is partly owing to the range of abilities the imagination allegedly controls. Contemporary accounts acknowledge the imagination's multitasking nature: it seems to be the "junkyard of the

6 Following on from this Janus-faced character, philosophers have recognized a puzzle: how is it possible to acquire knowledge from fiction? For a discussion, see Kind-Kung (2017). A different approach is adopted by Williamson (2017) who argues that the main business of the imagination is not to produce fictions: while it has this function, imagination is first and foremost devoted to the possible (understood as what can obtain).

7 A wide-spread view in the early modern period was the idea that the senses never err, owing to which the source of error must be either the imagination or the will. The senses simply present aspects of external objects and hence do not deal with truth, which consists in a connection of ideas. For Descartes, the senses are the source of material falsity, but not formal falsity, for which the will is responsible. Senses therefore never err (see Meditations AT VII 56/ CSM II 39; for a discussion of material falsity, see De Rosa, 2010). Leibniz thinks the work of the senses is a necessary distortion of the objects in order to render them available to the mind; they present some kind of illusion, as in optics, although they do not thereby deceive us (on this, see Favaretti Camposampiero 2016). Deception is the result of a judgment that lacks sufficient consideration about the causes or reasons that account for its truth. This topic was also discussed by Leibniz in a short conversation with Gottlieb Samuel Treuer. On this, see Oliveri (2019: 83-109).

8 On Spinoza, see Renz (2019); for a confrontation on Leibniz and Spinoza, see Leinkauf([2010] 2012). 
mind", 9 the place - cognitively speaking - where we can project any state of mind. However, to focus on early modern discourse, both negative and positive attitudes toward the imagination are manifested in early modern philosophers' vacillating between two extreme positions endorsed in order to exorcise the epistemic failings of the imagination. On this account, the imagination is either a useful capacity, albeit void of any epistemic role; or it is a pervasive power, whose tendency to lead cognizant agents astray needs accepting and, to whatever extent possible, managing.

Descartes veers toward the first extreme and, in the Meditations on first philosophy, denies that the imagination may be a source of knowledge. Despite early sympathy for the contribution of this faculty to knowledge (especially in the twelfth rule for the direction of the mind), knowledge is understood by Descartes as the evidence and intuition of intellectual items, viz. ideas, which differ greatly from the presentation of images, for which the corporeal imagination (phantasia) is responsible. ${ }^{10}$ Even if the imagination is relevantly involved in reasoning, Descartes unburdens it from any epistemic responsibility - or so argues Leibniz, as we will soon see. ${ }^{11}$ To do justice to the Cartesian stance, however, we need to add that the contentious point regarding the contribution of the imagination to knowledge is not about whether or not the imagination contributes to factual knowledge, as when we apprehend the distance between two objects or the shape of a book. Instead, the denial concerns the idea that the imagination may relevantly contribute to knowledge regarding the ideas we have about something, especially those ideas that are, on Descartes' view, innate, as the distinction between imagining and understanding in the VI Meditation proves. In there, Descartes makes clear that our capacity of representing extended figure is not tantamount to our capacity of understanding their constitutive properties and deriving truths from them, a task exclusive of the pure understanding. ${ }^{12}$ If Descartes denies this role to the imagination, then other figures

9 See Kind (2016: 1).

10 See Rule Twelve (AT X 414-416/CSM I 41-3) and Meditation VI (AT VII 74-5/CSM II 5054).

11 For a more accurate discussion of the role of the imagination in Descartes, see Sepper (2001), whose final analysis is that the imagination is an aid to truth. As Chavez-Arvizo (1997: 143-4) notes, the fact that it is "an aid" does not amount to seeing it as an epistemic faculty. Indeed, this is a consequence of Descartes' theory that truth depends on the intellect, which intuits ideas about objects. According to Bos (2011), this change of attitude towards the imagination is owing to Descartes' discovery of the application of algebra in solving geometrical problems. On the imagination, also see Fotì (1986).

12 AT VII 72/CSM II 50: "To make this clear, I will first examine the difference between imagination and pure understanding. When I imagine a triangle, for example, I do not merely understand that it is a figure bounded by three lines, but at the same time I also see the three lines with my mind's eye as if they were present before me; and this is what I call imagining. [...] Such a representation is useless for recognizing the properties which distinguish a chiliagon from other polygons. But suppose I am dealing with a pentagon: I can of course understand the figure of a pentagon, just as I can the figure of a chiliagon, without the help of the imagination; but I can also imagine a pentagon, by applying my mind's eye to its five sides area contained 
like Spinoza or Leibniz emerge as taking a more nuanced stance. In order to explain these positions, we first need to recall Hobbes' contribution, which veers towards the opposite extreme.

Hobbes considers any cognitive operation (except for sensation) as a form of imagination, generally defined as a "decaying sense", or the impression left on the mind by the object when it is no longer present to the senses. ${ }^{13}$ Besides this general definition, the "decaying sense" takes several forms: there is memory, or the recalling of past sensations; the "compounded" imagination, or the formation of fictitious entities; and understanding, or imagination by means of signs. ${ }^{14}$ To confirm this position, Hobbes rejects Descartes' notion of an idea as an intellectual item that presents itself to the understanding in a pure way, that is, deprived of a representative vehicle. ${ }^{15}$ Leibniz follows this lead, which we can deduce from his answer to Bayle (quoted above), as well as in a series of writings composed between 1675 and 1684, whereby he rejects the Cartesian notion of a pure intellection, which considers knowledge to consist in connections of ideas by means of representative vehicles, such as images or the words of a language. ${ }^{16}$ This Hobbesian sympathy, however, does not amount to an endorsement of Hobbes' ultra-nominalism, viz. that truth depends on names, a position that Leibniz criticizes in precisely the same years as when he was grappling with Descartes' philosophy. ${ }^{17}$ These are also the years in which Leibniz - through a confrontation with Descartes and Hobbes, inter alia $^{18}$ - settles on various matters relating to knowledge and cognition, as well as some metaphysical issues regarding the nature of the continuum and of mathematical fiction. ${ }^{19}$ Indeed, he does not change his position until being confronted with Locke's philosophy. This shakes Leibniz's epistemology to the point of prompting a book-length exposition (viz. New Essays on Human Understanding, published posthumously in 1765) of parts of his theory that had not yet been fully explicated nor adequately thought through. For this reason, it is worth contextualizing Leibniz

within them. And in doing this I notice quite clearly that imagination requires a peculiar effort of mind which is not required for understanding; this additional effort of mind clearly shows the difference between imagination and pure understanding."

13 Hobbes's definition of imagination is echoed in Definitiones cogitationesque metaphysicae, A VI 4 1394/LoC 237: "Imago est continuatio passionis in organo cessante licet actione objecti. Imaginatio est imagines perception. [An image is the continuation of a passion in an organ, despite the cessation of the action of the object. Imagination is the perception of the image.]"

14 Hobbes, Leviathan, I 2 "On Imagination".

15 See Objections and replies, AT VIII 184/ CSM II 129-30.

16 We will discuss these texts in Chapter I.

17 He broaches this subject already in his introduction to Nizolius' Antibarbarus (1671) and in Dialogus (1677; A VI 4 A 20-5), and then in Meditations on Knowledge, Truth and Ideas (1684; A VI 4 A 589-93/L 293-6). In Dialogus, Leibniz's spokesman rejects the view that truth rests on the connection of names.

18 They are not the only figures. We can moreover name Jungius, Plato, Aristotle, Thomasius, Spinoza, Malebranche, inter alia. However, Descartes and Hobbes are explicit points of reference in Leibniz's most important writings on epistemology and cognition, such as MKTI.

19 See Arthur (2018); Rabuoin - Arthur (2020). 
within Hobbes' discourse on the imagination, and especially the latter's remarks about the so-called "train of thought".

There are many parts of Leibniz's philosophy that evidence Hobbes' legacy. One such part is the idea that human beings are not alone in being capable of reasoning, a claim highly controversial at the time. ${ }^{20}$ Although Leibniz is certainly more cautious than Hobbes - for instance, he never explicitly claims that non-human animals are capable of reasoning - he nevertheless does not deny to non-human animals some form of empirical reasoning, or a shadow of reasoning, which consists in connecting experiential states to either expectations about the future or recollections of foregoing states. If we expect the sun to rise after night-time, then this is because we have had repeat experiences of day succeeding night. Since reasoning consists in connecting images or signs, non-human animals count as imaginative animals, just like human beings. The outstanding question thereafter becomes a matter of why human animals are capable of forms of reasoning precluded to other animals.

That this approach is Hobbesian in spirit can be proved with a passage of the Leviathan. Here, Hobbes explains why human animals are capable of developing other forms of reasoning that differs from (and may even be superior to) those forms that are proper to non-human animals. Reasoning is not exhausted by representational states of some sort, neither does it rest on a capacity for representing objects, nor their consciousness. Reasoning rather consists in the ability to feel a connection of quasi-dependence between images or representational states, such as when I see clouds in the sky and imagine that it is about to rain. In this way, Hobbes thinks we form a "train of thought". These are not random, as when we move haphazardly from one thought to the next. Rather, a train of thought may have a design, that is, a sort of certainty and necessity felt along with the connection between one thought (the clouds) and another (the rain); the latter being a consequence of the former:

The train of regulated thoughts can be of two kinds: one, when of an effect imagined, we seek the causes, or means that produce it; and this is common to man and beast. The other is, when imagining anything whatsoever, we seek all the possible effects that can by it be produced; that is to say, we imagine what we can do with it, when we have it. Of which I have not at any time seen any sign, but in man only; for this is a curiosity hardly incident to the nature of any living creature that has no other passion but sensual, such as are hunger, thirst, lust, and anger. In sum, the discourse of the mind, when it is governed by design, is nothing but seeking, or the faculty of invention, which the Latins called sagacitas, and solertia; a hunting out of the causes, of some effect, present or past; or of the effects, of some present or past cause. (Hobbes, Leviathan, I, 3)

20 The posthumous edition of Hieronymus Rorarius's essay, That animals use reason better than man (1539), and the entry "Rorarius" in Bayle's Dictionary of 1696 and then 1702, help to explain why the topic was intensely discussed. Another reason is the denial by Descartes and Cartesians that animals have a soul. Leibniz intervenes in the debate publicly with his comments on the entry Rorarius in 1702. 
What distinguishes human and non-human animals, then, are the kinds of connections between images that human animals are capable of producing, viz. through their cognitive activity, which is invoked in two discrete moments (although both can be said to result from the faculty of invention). One such moment proceeds from effects to recalling a cause (i.e., memory or recollection), while the other begins with the cause to imagining the possible effects. To borrow Hobbes' example, if I lose my keys, then I can recollect the places where I have been in attempting to retrieve them. In this case, I move from an effect to its cause. We can moreover imagine somebody doing something, e.g., my sister goes into the kitchen, and I can imagine what she is about to do, e.g., eat or cook something, talk to my mother, or innumerable other things. This act of imagining the future as having a link to a present state, and, more specifically, of deducing an effect through consideration of its cause, constitutes the anthropological difference between human and non-human animals. Why? Because, while recalling a cause by experiencing an effect does not imply that the subject has knowledge of the cause, the deduction of an effect from the cause implies both knowledge of what the cause is and an understanding that multiple effects can follow from the same thing, viz. one understands necessity and contingency - concepts not shared by non-human animals. The relation from the effect to the cause may be an extrinsic relation apprehended by circumstances, viz. habit and repetition, which fail to amount to knowledge, while the latter implies knowledge of the reasons why the effect follows.

Knowledge of the cause requires some form of abstraction, of which non-human animals are incapable. The idea that non-human animals do not develop skills identical to (or at least similar to) those of rational beings owing to their limited faculties for abstraction is reiterated by early modern philosophers, for instance Locke, with whom Leibniz concurs (NE 142). However, these words of Hobbes' are echoed and transformed in the writings of his eager readers, viz. Spinoza and Leibniz, and peculiarly too. Consider, for example, the first part of the Treatise on the emendation of the intellect. There, Spinoza explains what distinguishes the third from the fourth form of perception, viz. awareness of a connection as holding true. This insight is fairly Hobbesian insofar as the third form of perception consists in perceiving a connection from the effect to the cause, while the fourth form consists in the perception of the cause and what can follow from it. However, Spinoza also relevantly modifies Hobbes' words: only the fourth form of perception is knowledge of the essence, that is, what the thing is in se and per se. ${ }^{21}$

Leibniz, for his part, complicates Hobbes' thought with his notions of possibility and existence, on the one hand, and abstract essences and concrete beings, on the other. The difference between human and non-human animals does not consist in the direction of the connection (sc. from cause to effect, nor from effect to cause). It consists in the contents connected through the cognitive activity of the agent. Such connections are not entirely extrinsic to the kinds of states they relate. Non-

21 See Spinoza, TdIE II/9 20-35. Interestingly, the idea of forms, or "degrees of knowledge", is likewise picked up by Leibniz. On the differences between Spinoza's treatise and Leibniz's MKTI, see Leinkauf ([2010: 107-24] 2012). 
human animals, understood as sentient, imaginative, and non-rational, are directed towards concrete existing beings and their states. This means that they connect states because they experience them as temporally and spatially related, owing to which they are empirical. By contrary, human sentient, imaginative, rational animals have the capacity to conceive of "the pure possible", which, in Leibniz's jargon, means that they are capable of considering beings and their modifications in the abstract, viz. by isolating properties and considering them to be conceptual marks, which altogether constitute not the being but the essence expressing the being as a kind. This distinction is revolutionary when analyzed in the light of Leibniz's reformation of the modalities required to resist necessitarianism, as we shall see in chapters V and VI. In short, Leibniz's revolutionary metaphysics distinguishes between a notion of possibility as it is related to existence (according to which something is possible when, given a series of conditions, it can exist), and logical possibility (according to which something is per se possible when its essence does not imply a contradiction). For now, it is sufficient to claim that Leibniz distinguishes between two cognitive acts: first, the act of apprehending a being; and second, that of apprehending an essence. Remarkably, however, Leibniz does not think of either of these acts as independent of the imagination. In short, they should be understood respectively as varieties of intentionality or conceivability:

Terms are either simple or composite. Simple terms are those which cannot be made clear by more familiar terms, because they are given immediately to sense, that is they are themselves sensible qualities. That which has sensible qualities, or is perceptible, is called a being. So, with respect to us it can be said that the essence of a thing is for us the distinct conceptibility (or imaginability) of that thing, and the existence the distinct perceptibility (or sensibility) of it. Indeed, the compound of the qualities assumed simultaneously, that is conceptibility, constitutes the essence of a thing; perceptibility proves its existence (as evidently it is not a thing's fault that it is not actually sensed). (A VI 1285$)^{22}$

The incipit of this passage recalls Leibniz's claim that "terms" (that is, the words of a language) may either refer in concreto or in abstracto - a distinction that is, once again, Hobbesian. ${ }^{23}$ Terms may refer to concrete and so be analyzed into simples which are sensible qualities; or they may refer to abstracta, that is essences whose simple constituent are primitives. ${ }^{24}$ However, Leibniz attempts to couch this Hobbesian distinction within an ontological and epistemological framework that is

22 This passage is a revised version of Leibniz's Nova methodus discendae docendaeque jurisprudentiae (1677). Between 1695 and 1708, Leibniz produced three distinct revisions of his printed version of Nova methodus. Indeed, Leibniz remarks on several occasions, such as in a letter to Placcius (1695), that he wished to publish a new version of the text. (A II 3 51: "Ego ante multo annos cogitaveram de Methodo mea recudenda et augenda, quin et subinde corrigenda."). The quotations and translations here constitute the latest version of the passage, as reconstructed using the various manuscripts and notes present in the critical edition (A VI 1 285), which reproduce Leibniz's three textual revisions.

23 See Di Bella (2005).

24 An analogue distinction can be found in MKTI, where Leibniz says that primitives are constituents of notions that, in contrast to sensations, can be the object of an intuition. An example of primitives is mathematical unity (see Oliveri, 2020). 
decidedly non-Hobbesian, viz. within a distinction between beings and essences, the latter to be understood as connections of conceptual marks that do not depend on languages because they are ideas in God's intellect. Leibniz defines a being as a bearer of sensible qualities or what can be known through perception. A being, however, is not an essence, viz. a cluster of qualities that are altogether conceived as possible or without contradiction. The result of this distinction is a variegated ontology that is characterized by a denial that abstract entities can exist, because abstracta cannot be beings, that is, things that can mechanically interact with a cognizant agent's sense organs and thereby be possible objects of perception. The essence of a geometrical sphere cannot be a possible object of existence unless it is reified through expression, that is, transformed into a vehicle that can causally interact with a cognizant agent's sense organs, like a diagram, as Leibniz explains to Bayle. We will analyze the impact of this distinction at length. For now, we need to investigate the difference between two cognitive acts. The first being that through which an agent apprehends and predicts something's possible existence; the second being that through which one evaluates the possibility of an essence (as well as what can be deduced from it).

In other words, while nested within an eclectic nomenclature, "perceptibility", "imaginability", and "conceptibility", understood as kinds of conceivability, which will be exhaustively unpacked herewith, correspond with distinctions between kinds of cognitive act. Unlike Hobbes, however, Leibniz explains the distinction between various cognitive acts in terms of their respective dependence upon different faculties and not on the kinds of connections between cognitively-equivalent terms. Indeed, there is already a difference between the act of sense-perceiving a wolf and conceiving of (sc. conceptualizing) the essence of a wolf. The kinds of connection possible between sense-perceptual and conceptual states supervenes on this distinction. Sense-perceiving rests on principles analyzable into spatiotemporal constraints on beings that are apprehended as bodies, which simply cannot provide knowledge of essences, viz. clusters of conceptual marks that are joined by virtue of identity and contradiction. Prior experience of a wolf, for example, is required in order to recognize beings as wolves, although it is not sufficient for achieving knowledge of a wolf's essence as a cluster of conceptual requisites necessary for defining its essence. Experience alone, therefore, does not afford knowledge of a wolf as a mammal with four legs of the genus "canis", etc. As we will see in chapter IV, this claim is problematic insofar as Leibniz's metaphysics - which is based on the harmony between body and soul (sc. between bodily states and cognitive states) - implies that cognitive states are first and foremost about those things that can causally interact with a cognitive agent's sensory organs, that is, they are about beings. If this is the case, then how can minds conceive of essences, especially if essences are neither beings nor are they objects of possible sensory experience? The answer proffered by the present enquiry is that the work of the imagination fills the gap between perceiving and conceiving because both acts are in fact imaginative, and are therefore both relevantly related to possibility.

To anticipate the argument developed at length in this book, both beings and essences are expressed by a cognizant agent's imagination, which deploys innate 
ideas in performing those acts. Perceptibility is the construction of a being as a body changing within given spatiotemporal parameters. Indeed, because space and time (understood as continuous quantities) are innate notions of common sense and are the proper subject matter of the imagination (as shall be argued in chapter II), the expression of beings as bodies that undergo alteration in fact rests on the synthetic (viz. expressive) character of the imagination and its native spatiotemporal logic. Meanwhile, conceptibility is a capacity for ordering and connecting conceptual marks by means of imagistic vehicles, such as the words in a language, which combine to constitute definitions. To this act, the agent needs the expressive work of the imagination, which reassesses representative vehicles, that are subject to space and time, in order to express identity and contradiction between concepts. The synthetic work of the imagination in processing perceptual data and their organization results in types, to be understood as acquired abilities to interpret a being as having a nature common with other, similar beings. Types, I argue, constitute a necessary step in a cognizant agent's acquisition of concepts, which may in turn be couched as abilities to define abstract essences.

The constitutive chapters of this monograph textually support and expound this theory in detail. Herewith, I argue that the distinction drawn by Leibniz between types and concepts constitutes an attempt to distinguish soundly between "perceptibility" and "conceptibility". Leibniz's aim in arguing for such a distinction is the attribution of a kind of reasoning to non-human animals, which is similar to preconceptual forms of reasoning in human beings, owing to which it is a form of empirical reasoning. However, in spite of their similarities, non-human empirical reasoning differs from human empirical reasoning insofar as it is a "shadow of reasoning", as Leibniz writes in the NE. Animals lack the innate ideas possessed by human beings, which are required for the formation of more specific types, as well as abstract concepts. These innate ideas include the ideas of substance, unity, and identity, which are intellectual ideas that are not shared by non-human animals, and allow for the cognitive activity of abstraction (again, enjoyed only by human beings).

The distinction between perception and thought is furthermore relevant to explaining a tenet of Leibniz's theory of cognition that is, as demonstrated in chapter IV, intrinsically related to his theory of substance, viz. that both human and nonhuman animals are cognitive agents, although the latter cannot be moral agents. Forms of action based on empirical reasoning, such as going to bed because we expect the sun will rise after the darkness of the night, is not moral action. The development of such inductive responses is indispensable to animal survival and explains why human beings (in this respect like their non-human counterparts) act like empirics for three-quarters of their lives. All animal action begins with habitual expectations of what will occur in the future. Unlike non-human animals, however, rational-agential action is characterized differently. Their actions can be free, owing to which their actions can be evaluated morally, viz. as either good or bad, just or unjust, since rational agents can establish civil and moral peer relationships. Their capacity to understand pure possibility also turns out to explain why human animals 
are able to develop social and civil interactions, an intuition that we again find in Hobbes:

Which kind of thoughts [the thoughts that link the cause with the effect, L.O.], is called foresight, and prudence, or providence; and sometimes wisdom; though such conjecture, through the difficulty of observing all circumstances, be very fallacious. But this is certain; by how much one man has more experience of things past, than another; by so much also he is more prudent, and his expectations the seldomer fail him. The present only has a being in nature; things past have a being in the memory only, but things to come have no being at all; the future being but a fiction of the mind, applying the sequels of actions past, to the actions that are present; which with most certainty is done by him that has most experience; but not with certainty enough. (Hobbes, Leviathan, Part. I Of Man, Chap. 3)

The capacity to connect the present with the future is related to both the moral and civil domains of human action. For, in exercising this capacity, we are prudent; we foresee events and act providentially. ${ }^{25}$ These abilities ordinarily belong to the sphere of ethics and virtue. Why, then, is the capacity to imagine the future relevant to morality? To this, Hobbes proffers a perceptive reply: the future states imagined by human agents, as consequences of current states, constitute non-being, owing to which these states are a fiction; lacking certainty. While foregoing actions exist in the past - and the present obtains right now - the future does not and is not. Cognizant agents' acts of bestowing being upon imagined states of affairs is not only the source of anticipation (thanks to which we act in accordance with our expectations, such as when I see that the cup is going to fall and so I grab it): it is also constitutive of belief-ascription or mind-reading. This is at work, for instance, when I see my niece pick up the toy phone: I take this gesture as a sign that she believes to be talking to me through the phone.

Moreover, at the end of foregoing passage, Hobbes remarks that humans are prophets (viz. people who are good at guessing thanks to their acquaintance with a certain domain, owing to which they recognize signs of things to come). Indeed, this latter remark explains the early modern tendency to link the use of signs to the work of the imagination. Mastering a language is a capacity to predict what another is thinking. This begins with the signs used to express thoughts, which is a capacity for establishing a connection between what one thinks and what one says through the production of phonemes with phonatory organs. When our imaginative capacity is analyzed in relation to issues concerning the origins of language (for example, how it is even possible that we agree on what signs mean before we have any shared language) and its normativity (why we defer to linguistic conventions at all), ${ }^{26}$ it looks like our capacity to imagine the future - or guess others' actions and thoughts - must have played a decisive role in language development, through which we

25 What does it mean to be providential? By anticipating what is going to happen, and on the condition that I feel love or philia towards someone, then I will act so as to protect them. Interestingly, Leibniz does not exclude animals from being motivated by an instinctual apprehension of philia (see NE 93-4).

26 See the entries "Imposition" (Oliveri, 2020a) and "Obligatio" (in the Use of Language)" (O1iveri, 2020b). 
establish a social, civic bond. Indeed, these skills altogether constitute what we call rationality.

It therefore seems that the exercise of our intellectual skills goes hand-in-hand with our unique capacity for predicting what will happen next, viz. our tendency to imagine the future, even if (from the standpoint of the present) it is only a fiction. Our lower and higher cognitive abilities improve in tandem; a development to which the imagination contributes remarkably. However, Leibniz thinks that, in order to comprehend the work of the imagination, thereby providing a sound theory of human and non-human cognition, we need to reject the idea that the imagination is first and foremost a faculty of fiction.

\section{CONTENT SUMMARY}

In developing his theory of the imagination, Leibniz expounds two fundamental ideas. The first is that the imagination is unfree: it follows its own logic in forming connections, this being distinct from the logic of the intellect, which rests on the ideas of identity and contradiction. By contrast with the intellect, the imagination's logic is deduced from its peculiar subject matter. In fact, in believing that all reasoning constitutes an act of imagining, Leibniz takes the imagination to be an autonomous faculty, which has its own subject matter just like any other faculty, although it necessarily interacts with other faculties. For Leibniz, the subject matter of the imagination is continuous quantity or magnitude. Indeed, it is in virtue of its relation to continuous magnitude that the imagination is related to space and time, and thereby to possibility. Against this background, I shall argue that Leibniz is in a position to consider the imagination as both a cognitive and conative faculty. ${ }^{27}$ Indeed, through his exposition of the imagination, Leibniz is able to explain how agents can learn from fictions (to which end the imagination is functionally indispensable). This question necessarily arises when one assumes that the imagination is largely in the business of entertaining possible (but, as-yet, non-existent) states of affairs, although these are not (strictly speaking) fictional.

Moreover, Leibniz thinks that it is its relation to magnitude that makes the imagination first and foremost a synthetic faculty of what Leibniz calls expressions (otherwise describable as a combinatoric faculty, or a faculty of invention). Expressions are cognitive surrogates that make available to the mind an object of knowledge in a way that allows for easier extrapolation and connection of bits of information, which would otherwise remain off-limits to the cognizant agent. Expressions are Leibniz's Hobbesian response to Descartes' theory of cognition, as I will argue in chapter I. Both ideas - viz. the imagination having constraints derived from its peculiar subject matter (magnitude) and these constraints being active in the formation of expression-relations - constitute Leibniz's way of transforming the imagination's role within his broader theory of substance. 
We could not explain to what extent the imagination constitutes the expressive power of the mind were we not to explain what expressions are. To this end, chapter I constitutes an enquiry into the prevailing scholarship regarding the topic of expression. There, I also advance my own thesis, viz. that expression has the cognitive function of simplifying information that would otherwise be too complex or heterogeneous to be an object of human-agential (sc. finite) cognition. Expression is a relation between an exprimendum and an exprimens, whereby the exprimens translates and unifies pieces of information into a form accessible to a cognizant agent, who can thereafter cognitively elaborate upon it. Any act of cognition - from sensation to thought - is a form of expression. This has an enormous impact on the role of the imagination in developing other forms of expression.

Chapter II explores the groundwork of the imagination. To this end, I argue that this groundwork consists in synthetizing sensations afforded by the senses into perceptible wholes: extended shapes with sizes that are bearers of qualities. Perceptible wholes are confused expressions of variegated, discrete matter, which are transformed into perceptions of a distinguished kind through a process of comparison, resulting in the interiorization of concrete beings as types of bodies. As already intimated, types are rules expressing the common nature of similar beings, encoding information about a being's possible alterations qua type of phenomenon. Types are therefore rules for processing actually-experienced phenomena as similar to previously-experienced phenomena, thereby helping to anticipate and predict how things may or may not change. Chapters III-VI expound this theory.

Chapter III constitutes an enquiry into issues arising from the ideality of expressions. Although expressions are ideal and abstract, and so depend upon the imagination, they are not fictions. This is because expressions are partially grounded in metaphysical facts and partially grounded in cognitive facts, insofar as the cognizant agent is embodied. Chapter III explains the partial, metaphysical grounds of expression, while chapter IV constitutes an enquiry into their contrasting cognitive grounds. The latter presents an initial argument for types, as based on Leibniz's idea that the degree of clarity enjoyed by sentient souls depends on their capacity for constructing filters that are necessary for storing, elaborating upon, and utilizing information, thanks to which agents can deploy more specific responses to the world. Chapter 4 further introduces the idea that a heightened perception has within it a sense of coherence or implicit judgment regarding the existence and reality of an experienced phenomenon. Through experience, cognizant agents enhance their capacity for distinguishing between real and imaginary phenomena.

Chapter V and VI build upon the aforementioned Leibnizian notion of "coherence". There, I argue that coherence is to perception what identity and contradiction are to conceptual reasoning: ideal rules establishing possible and impossible combinations and successions of states. I further argue that we can distinguish between a first- and second-order coherence. In short, first-order coherence rests on space and time, thereby constituting what Leibniz calls "empiric reasoning", while second-order coherence rests on similarity and difference, which are required for interiorizing types. Chapter $\mathrm{V}$ defends the idea that there is a distinguished kind of knowledge based on perception (which I call types), that differs from a distinct kind 
of knowledge based on concepts. Chapter VI introduces a relation between the imagination and modalities, thereby proving that the imagination cannot conceive of pure possibilities. The logic of the imagination is distinct from that of the intellect, which relies on identity and contradiction. Consequently, necessary truths cannot be learned through experience.

The distinction between concepts and types is the object of chapters VII and VIII, whereby I link Leibniz's rejection of nominalist theories of universals (understood as "collective wholes") with his discussion about similarity and essences. Similarities between beings, construed by Leibniz as necessary for conceiving of concepts, are not thereby constitutive of concepts. The outcome of our analysis is an intensional interpretation of concepts. This keeps the extension of the concept (viz. the recognition of particular instances as instances of a concept) "outside" the concept of a concept. This means that extensional interpretations of concepts (which are based on recognition) falls under the purview of types. Chapter VIII proffers a more detailed analysis of the metaphysical implications of this logical theory. It further provides an error theory for explaining why, although we take the imagination to be pervasive in cognitive life, it is still the primary source of epistemic error.

In developing Leibniz's discourse on the imagination, I advance the thesis that each faculty has its own constraints, understood as limits on the extent of its possible operation. Chapter IX provides a full account of Leibniz's theory of innate ideas understood as such constraints, in particular on an agent's cognitive powers. On my unpacking, innate ideas are active tendencies of the mind to form expressions. This activity results in a bootstrapping process: expressions produced through the interplay of the imagination with a lower cognitive faculty are reassessed and reused by the imagination when interacting with a higher faculty - both for reasons of economy and normativity. The bootstrapping process, which is evident in the use of tropes for establishing new meanings for names, underwrites the Leibnizian learning process from experience and provides an answer to the question of why nonhuman animals do not develop skills similar to those of human animals, although they are capable of implementing lower forms of empirical reasoning. Chapter IX constitutes both the continuation and the conclusion of chapter I, providing thereby an answer to the issues raised in the present introduction.

\section{METHODOLOGY}

Leibniz does not use the word "type". This is language that I invoke as a proxy for different Leibnizian expressions (including "possibilities inherent in the resemblances", "nature", or "distinct perception"). In the spirit of Leibniz's teaching on languages - based on the idea that languages must be economical - I found a word that could express some of the features of "distinct perception" while not being a concept, with the aim of helping the reader to follow my reconstruction of Leibniz's theory. A "type" is not an image: it is related to the potential variations of a body 
apprehended qua general instance of a similarity class. Types are involved in forming expectations, but are not concepts. Chapters IV, V, and VI unfold the function of types in cognition, thereby assessing the extent to which reasoning based on types is imaginative in character.

The word "type" in this work refer thus to a degree of knowledge which lies between clear and confused sensations and clear and distinct concepts, viz. what Leibniz calls clear and distinct perceptions. Chapter III reconstructs Leibniz's theory of degrees of cognition by confronting Meditations on Knowledge, Truth and Ideas (1684); Letter on What is Beyond Senses and Matter (1702) and Letter on the Element of Geometry of the Duke of Burgundy (1705). I argue that there seems to be a missing degree in MKTI which is in turn present in both letters. This step is clear and distinct perception, that is the apprehension of beings as a perceptible whole having parts and attributes. A perceptible whole is the expression of a being as a shape having size and qualities and it is a spontaneous product of the senseperceptual activity of the sentient soul expressing the affections of the body it is attached to. Sense-perception has a physiological and a cognitive component upon which the soul has no control, although it can be said nonetheless to be active in the process of sense-perceiving. Perceptible wholes are the simplest product of this activity that is implemented by the cognitive agent's capacity to compare and so learn through experience. Chapters II to VI are devoted to explaining how the cognitive agent move from perceiving beings as perceptible wholes (appearances of shape with size) to recognize them as bodies of a certain type. Bodies, as we will argue, is a more complex expression of beings not simply as appearances of shapes, but as objects composed by states varying in compliance with space and time constraints. A type is a more sophisticated expressions of a particular kind of body based on the cognitive agent's capacity to recognize being's common nature. A survey of texts contemporary to MKTI in chapter III will show that Leibniz endorsed such a view on the mind already when he wrote the MKTI. Leibniz's theory remains coherent through the years.

These considerations bring us to a further issue. Leibniz scholarship is sensitive to distinguishing between different periods within his philosophical production, as marked by an apparent change of heart on certain matters within his intellectual production. As aforementioned, I argue that Leibniz's views about cognition settle around the time of his Meditations on Knowledge, Truth and Ideas (1684). Corroboration for this view consists in Leibniz's continuing reference to this text - even in his confrontation with Locke. As I will argue in chapter II, also the Letter on What is Beyond Senses and Matter basically reproduces the degrees of cognition exposed in MKTI simply adding what remained underdeveloped in MKTI but was already present in other texts. As a further proof of this unchanged core theory of cognition, consider that around the year 1695 Leibniz begins his project of revisions of his Nova methodus discendae docendaeque jurisprudentiae. The text was published by Leibniz in 1667 and contains a theory on how to teach and learn jurisprudence based also on matter concerning cognition and languages. Between the years 1695-1708 Leibniz carries on three major sets of revisions, partially published in 
the Academy Edition as footnotes signed with the letters D; E; F. ${ }^{28}$ As the Academy Editors report, Leibniz added pages to his copy of Nova methodus discendae docendaeque jurisprudentiae and reported on these sheets his changes of the text. The editors explains that notes marked with D refers to the first set of revisions Leibniz carried on the complete texts. Notes marked as E and F correspond to partial revisions of disparate parts. ${ }^{29} \mathrm{He}$ basically takes the published work and adds pages in the book on which he corrects the text. Most of the revisions concern terminology. Especially, Leibniz seems to consistently substitute "sensations" with "perceptions", where "perception" means a state of the cognizant mind that evaluate not simply the appearances of something, but the existence. Existence, as we will see, will consist in a distinct perception of a body as a type of body. The body is apprehended as a type when the cognizant agent recognizes the body as having a nature common to other bodies previously experienced and so forms expectation of how the body is going to change in agreement with its nature. This makes me think that while, over the years, Leibniz's core theory underwent various expansions and refinements, it remains - in spirit - unchanged.

The aim of this enquiry is to enable the emergence of Leibniz's theory of imagination through various loci within his metaphysics, epistemology, theory of cognition, and philosophy of language. The present introduction provides a synopsis of the range of abilities the Leibnizian imagination allegedly controls, while the task of each chapter is to present, through textual analysis, an accurate reconstruction of the topics addressed. It must be noted that Leibniz never dedicated a work to the imagination. However, this is not a reason to think that he did not have a distinctive theory regarding its role in cognition. As I have already stressed, the centrality given to expression, language, and perceptual processes all have links to the imagination, and especially to Leibniz's theory of substance.

Finally, allow me to make a remark about methodology. Philosophical reconstruction, which captures my approach herewith, means that Leibniz's writings should undergo a historically well-informed conceptual analysis, offering a coherent presentation of his views about a subject by linking them to topics or other issues which, while not directly addressed by the texts, nonetheless aid our understanding thereto. This work serves to tease out, and make explicit, conceptual distinctions which, for various contingent reasons, remain hidden, or implicit, within the text. This is moreover owing to the distinctive Leibnizian attitude (well-known to Leibniz scholars) for adopting terminology familiar to the addressee of a text, while using it without deference to the philosophical doctrine from which it stems. Leibniz's intention is to ameliorate his readers' comprehension of why a term should be

28 We know from different letters to Placcius June 25/July 51695 (A II 3 50), and a letter to Kettwig (June-October 1696), that Leibniz was working on the revision in those years, and, according to the Academy edition, he continued working intermittently until 1708. The edition in VI I lists three main revisions between the years 1691-1708. The revisions were so substantial that the edition in VI I simply reports some of them as footnotes. Loemker translates the text from 1667 and some of the footnotes present in the Academy edition in VI I.

See Introduction to A VI I, XVIII. 
understood differently from how it is presented according to prevailing philosophical doctrine. Hence, Leibniz aims mostly at imposing to the philosophical term his own concepts. The result is often a theoretical debacle, because it produces in his interlocutor (as well as in contemporary readers) a sort of lost in following the argument. This strategy is evident in Leibniz's use of the terms "idea", "perception", "substance", "extension", among others, which he adopts with the intention of imbuing them with new, philosophical meanings. This is often counterproductive insofar as it results in a misunderstanding of Leibniz's own arguments, which were of course read against the backdrop of prevailing concepts and definitions that he judged incorrect and erroneous, such as Cartesian categories. Conceptual analysis, on my view, aims at circumventing such pitfalls, not least as a direct consequence of sound philosophical praxis. 


\section{THE EXPRESSIVE POWER OF THE MIND AND ITS VARIETIES}

In virtue of different kinds of conceivability, the expressive power of the mind can either be directed towards concrete beings or abstract essences. As we pointed out in the introduction, on the one hand, perceptibility is the act by which the mind apprehends beings qua existent. On the other, conceptibility (or imaginability) apprehends essences qua possible. The metaphysical constitution of the mind (understood as a unity of an organic body and a bundle of cognitive faculties) determines the order in the manifestation of different kinds of directness: apprehension of beings' existence via perceptibility is spontaneously exercised by the mind before the mind can be directed towards possible abstract essences. In concluding the introductory chapter, we considered the heterogeneity of the concrete and the abstract of being and essence - , and asked how the mind is able to develop distinct knowledge of essences, if, given the mind's metaphysical constitution, it is foremost directed towards the existence of beings.

The question is more compelling when we consider that, on Leibniz's account, innate ideas do not function as representational devices that the mind simply apperceives $^{l}$ when there is a causal interaction with an object. Ideas are no objects of intentional acts; they are dispositions to form intentional contents or, as I am going to argue, to express what the cognizant agent tends to know. ${ }^{2}$ To borrow Leibniz's metaphor, the mind has the power of drawing Hercules (that is, a distinct conceptual content) from a marble block (the raw experiential material) thanks to it being a "block of veined marble", that is, disclosing its endowment of innate ideas (NE 82/A VI 6 82). This is not to say that Hercules is readily seen by the mind. To this end, his extraction needs work. Leibniz denies that a particular mental state is about something because the mind already possesses ideas that will themselves become objects of reflection and provide information about features of the objects ideas represent. ${ }^{3}$ Leibnizian ideas do not represent; they express insofar as they are powers or abilities to form expressions. A particular mental state is about something in

1 I use the term "apperceive" in this context as suggested by Barth (2011), that is as "noticing something" or "paying attention to something."

2 Most scholars endorse the view that ideas are for Leibniz tendencies or dispositions; they are not objects of thought themselves, see Ishiguro (1972: 23-7); Mugnai (1976; 1982); Bolton (2011a), Leduc (2011); Picone (2005); Poser (2016); Oliveri (2016; 2016a; 2016c). Most of scholars endorse as well that everything the mind can know is already inscribed in the mind as an idea. I reject this claim. I think that the mind has a set of necessary principles and ideas required to acquire concepts; these latter are only virtually innate; they are not innate as innate ideas are (see Oliveri, 2016: I.3.). I will address this topic in Chapter IX.

3 I think however that the mind can reflect on its innate dispositions and understands which principles and ideas are innate to the intellect in order for this latter to be the faculty of knowledge, see Oliveri (2016: I.3.). I will address this point in Chapter IX. 
virtue of the mind having ideas (understood as dispositions) to form expressions and expressions become objects of reflection. An expression is any cognitive surrogate - whether words, diagrams, images, etc. - that refers to either an existing being and its properties, or to an essence. The expression is an expression because it bears "a constant and regular relation between what can be said about one [the expression, L.O.] and about the other [the thing expressed L.O.]" (Leibniz to Arnauld, September 1687, A II 2 231/L 339). Expressions are cognitive tools deployed by a rational agent to attain knowledge of something. On this view, knowledge is acquired by virtue of ideas, viz. through inspection of those expressions formed in virtue of the idea. Knowledge is not, therefore, acquired through a direct inspection of innate ideas. Ideas are cognitive powers that allow the mind to form expressions, which are then used by the mind to reason about diverse kinds of intentional objects. $^{4}$

I am aware of only one passage in which Leibniz claims that ideas are "un objet immediat interne", "an immediate internal object" (NE 109/A VI 6 109). This definition could cause us to believe that ideas are themselves intentional objects. What follows this claim, however, dismisses this interpretation: an object is "an expression of the nature or of the qualities of the thing" (NE 109/A VI 6 109). Expression, in this context, refers to cognitive surrogates that the mind deploys in thinking, such as signs, diagrams, images, or anything that is sense-perceived and processed by the mind as related to something else with the aim of extracting and deriving pieces of information, which are about the thing expressed. Therefore, ideas are not direct object of thought; only expressions can become objects of thought. For expressions are products of innate ideas as causal mental powers, namely, when a rational agent actually considers an expression and has the power to correctly interpret it, the agent takes the expression as if she is operating with the idea or the thing expressed itself. For Leibniz, ideas, understood as objective contents, are essences present only in God's intellect (NE 256/A VI 6 256; Mugnai, 1990). They are that which we can only approximate by expressing the existing world using our God-given powers, our innate ideas.

A full disclosure of Leibniz's theory of ideas will find its place in chapter IX. The present chapter enquires into Leibniz's technical term 'expression'. To this end, it provides a survey of scholarly work on this notion, defending in turn the thesis that the mind has the power to be about an idea (i.e., an essence in God's mind). This is owing to its having recourse to resources (viz., innate ideas of the rational agent's mind) to invent expressions either of beings or essences. In outlining the cognitive dimensions of expressions, this chapter points to the decisive role of imagination in producing expressions, and so paves the way to our analysis of the logic of imagination in the next chapter. To this end, I shall begin by bringing in textual evidence such that, on Leibniz's view, ideas are dispositions to form expressions.

4 This distinction between ideas and concepts is a settled point in the literature. See, for instance, Mugnai (1990); Bolton (2006); Leduc (2011), in particular, insist upon this fundamental aspect of Leibniz's theory of cognition. 


\section{IDEAS AS DISPOSITIONS TO FORM EXPRESSIONS}

Scholars agree that Leibniz's text Quid sit idea? is a kind of manifesto for his theory of innate ideas as dispositions. "In my opinion", writes Leibniz, "an idea consists not in some act, but in the faculty of thinking, and we are said to have an idea of a thing even if we do not think of it, if only, on a given occasion, we can think of it" (A VI 4 B 1370/L 207). The text begins by equating ideas and faculties, concluding with the claim that the mind does not have ideas of complex objects. On the contrary, what we deploy in reasoning instead of ideas are expressions. As Leibniz remarks, "there must be something in me which not merely leads me to the thing but also expresses it" (A VI 4 B 1370/L 207). He elaborates as follows:

That ideas of things are in us means therefore nothing but that God, the creator alike of the things and of the mind, has impressed a power of thinking upon the mind so that it can, by its own operations derive what corresponds perfectly to the nature of things. Although, therefore, the idea of a circle is not similar to the circle [the expression, i.e. the figure or equation we deploy in expressing the idea, L.O], truths can be derived from it [from the expression, L.O.] that would be confirmed beyond doubt by investigating a real circle (A VI 4 B 1370/L 208).

This passage squares with a further passage, written some years earlier (1675), in a paper entitled On the mind, the Universe and God. It is difficult to underestimate the centrality of this text in the interpretation of Leibniz's theory of cognition. Although it is an early text, it nevertheless presents Leibniz's skepticism about the Cartesian theory of ideas as both dispositions and contents. ${ }^{5}$ The basic thesis of the text is that the mind cannot intuit complex ideas, those ideas having more than one requisite. ${ }^{6}$ Therefore, the Cartesian theory of ideas as immediate objects of a mind's perception is false. The only alternative to the Cartesian theory is to argue that ideas are "what is necessary to think of" a particular kind of essence (for instance, a square), because the mind can invent surrogates - like images or signs - which function as tools for deriving truths (Leduc, 2011). Here, Leibniz uses the same example of the idea of a circle, claiming that we do not have any idea of the circle, but only expressions of the circle and "anything necessary to think of a circle":

We do not have any idea of a circle, such as there is in God, who thinks all things at the same time. There is in us an image of a circle, and also the definition of a circle, and there are in us the ideas of those things that are necessary for a circle to be thought. We think about a circle, we provide demonstrations of a circle, we recognize a circle: its essence is known to us, part by part. (A VI 3 463/DSR 5)

The passage is complex and so requires a detailed analysis, which will be offered in our chapter on innate ideas. For now, however, we need to bear in mind that, if ideas are faculties, then they cannot do the work of being representational devices

5 As noted also by Belaval (1990), Bolton (2006; 2011a; 2011b), Picone (2005), Mugnai (1976), and Leduc (2011).

6 On the notion of "requisite" see Di Bella (1994: 33-48 and 2005). 
that the mind attentively considers and "observes with its mind's eyes". ${ }^{7}$ This cannot be the way in which Leibnizian ideas represent. Leibniz's ideas indeed express the nature of things, and they do so owing to there being something (an expression) that takes the place of the thing. The mind can then operate with the expression as if the mind was dealing with the thing itself. ${ }^{8}$ If this is correct, then the mind is directed either to concrete beings or to abstract essences in virtue of an expression taken as referring either to a being or to an essence. This is because the mind has ideas that allow it to form expressions, which refer either to concrete beings or abstract essences.

Looking at the problem of directedness from this perspective, I claim, suggests that intentional states develop gradually. Whether this is the right understanding can be assessed through an analysis of the way in which we develop our expressive devices - languages, diagrams, and anything that can count as an expression - because all that the mind can be about is mediated through kinds of expression. Unless the mind is dealing with what Leibniz calls "simple notions" - that is, notions composed of a single requisite (such as the concept of unity), representing a simple essence - the mind cannot have intuitive knowledge of complex notions, viz. notions composed of more than one conceptual requisite (such as the notion of a circle) whose essence is complex. The mind has no direct inspection of essences without expressions playing a mediating role (see MKTI A VI 4 A 590/L 291).

To fully appreciate the import of addressing the problem of intentionality in terms of a development of intentional capacities of the cognizant agent, which go hand-in-hand with a development of expressive devices, we should look into the

7 I am following Leibniz in making a comparison with Descartes' philosophy, at least as Leibniz understood it. For Descartes, ideas are dispositions "to see a content" and also the object of the content. This ambiguity lead to a famous controversy between Malebranche and Arnauld on the very nature of ideas: are they modifications of the mind or are they objects of the mind? Arnauld claimed they are modifications; Malebranche argued they are not, and that they should be thought of as objects that only an infinite mind like God can possess. Leibniz studied this controversy, criticizing Malebranche and Arnauld, and was evidently puzzled by the nature of ideas: if they are dispositions, then they cannot be objects (High 2008; Jolley 1988: 71-91; Perler 1996: 207-32; Oliveri 2016: I, 1) His solution was to argue that they are faculties or dispositions to form expressions of things and essences; the expressions can become the objects of thoughts, and hence, indirectly, they stay for ideas, i.e., essences, in the mind of God, thereby becoming objects of thought. To argue in this direction, Leibniz had to convince the Cartesians that what minds perceive are not ideas themselves, but expressions. Therefore, many of his writings on the topic of ideas begin with a denial that the mind enters in direct contact with ideas. His standard argument for denying that we possess ideas is that we talk and believe we have ideas of things, which turn out to be impossible, like the most rapid movement. See, for instance, the beginning of "On mind, the universe and God" (A VI 3 462/DSR 5); "What is an idea?” (A VI 4 1370-1/L 207-9); and MKTI in A VI 4 A 590/L 292-3).

8 This formulation is typical of Leibniz's description of an expression: an expression allows a subject to abstract or infer truth about another thing that remains in an expressive relation with the object of analysis, whereby the truth achieved is as valid as if we had known it through direct knowledge of the thing itself. See MKTI in A VI 4 A 590/L 292. 
concept of expression. This will help us to understand what kind of relations expressions are and, more importantly, which cognitive functions expressions exercise within mental processes. Leibniz's distinction between natural and arbitrary kinds of expressions seems to hint at the same order of development of diverse kinds of intentionality. In short, the idea seems to be that when we conceive of essences, the mind does so thanks to its ability to invent arbitrary kind of expressions, viz. signs composing into a language. Nonetheless, if the mind can invent arbitrary kinds of expressions, then it is because the mind already knows natural kinds of expressions and can extend them to other knowledge domains. ${ }^{9}$ To argue in this direction, then, we first need to make clear what an expression is and why intentionality rests on the human capacity to form expressions.

\section{EXPRESSION AND ITS INTERPRETATION}

The notion of expression permeates Leibniz's philosophy: the mind expresses the body; the world expresses God; the individual mind expresses God and the world; and language expresses thought. Expressions are also multidisciplinary. We find them in mathematics, metaphysics, epistemology, the philosophy of language, and the theory of cognition. Expressions hence seem to theoretically unify these disparate disciplines. If this is correct, then we should be able to univocally define and model the notion of 'expression'.

A broad way of defining 'expression' is as of a relation that occurs between two relata ${ }_{2}$ such that one relatum preserves information that structures or characterizes the other. Scholars have defined a relation of expression as a kind of mapping of parts of the exprimendum (what must be expressed) onto parts of the exprimens (what expresses). The mapping allows for the "data mining" of relations and information characterizing the exprimendum by means of the exprimens. An example of this is the relation between a geographical region and a map. The map is not the region, but by analyzing relations internal to the map (such as the distance between two dots on the map), we can infer distances between two places within the region (Swoyer, 1995). In so doing, we gain knowledge about the region that would have been very difficult (if not impossible) to acquire without the use of the map. The expression is a surrogate of the exprimendum, owing to which this kind of reasoning has been named "surrogative reasoning" (Swoyer, 1995).

This analysis of the notion of expression, to the extent that it focusses on the epistemic force of the notion, is vouched for by some of the most cited Leibniz texts on the topic:

One thing expresses another, in my usage, when there is a constant and regular relation between what can be said about one and about the other. It is in this way that a projection in perspective

9 I argued for a developmental view of our expressive devices in Oliveri (2016: III.1-2), Oliveri (2016b) and Oliveri (2014) this latter with special focus on prepositions. The topic of language evolution is addressed also in Gensini (1991). 
expresses a geometric figure. Expression is common to all the forms and is a genus of which natural perception, animal feeling, and intellectual knowledge are species (Leibniz to Arnauld, September 1687, A II 2 240/L 339).

Even if the definition of expression seems to be complete, I want to pay attention to what follows this definition:

In natural perception and feeling, it suffices that what is divisible and material and found dispersed among several beings should be expressed or represented in a single indivisible being or in a substance endowed with true unity. The possibility of the representation of several things in one cannot be doubted, since our soul provides us with an example of it. (Leibniz to Arnauld, September 1687, A II 2 240-1/L 339)

I invite the reader to bear in mind throughout the rest of our analysis that the classical passage, in which Leibniz defines expression, is normally construed as a kind of mapping, which continues by stressing that, in order to have an expression, it is sufficient that there is a kind of unity represented in the expression. This is so, for instance, in the case of simple sensations of sensory qualities, like colors. Colors appear to cognizant agents as simple and without parts, even if they are expressions of the causal changes of particles of matter interacting with the sense-organs of the perceivers. Because of harmony, the material changes are reflected or mirrored at the level of the cognizant agent as minute perceptual changes. The appearance of a color is a simple, confused notion that expresses the unification of minute perceptions changing in the perceivers (NE 53). On this understanding, the notion of color is simple and unanalyzable, whereby no mapping of parts onto other parts is possible. And, even if it were possible, there would not be the salient trait of this kind of expressions. Simple notions do not express because cognizant agents are aware of a mapping of parts of the expressions onto parts of the things expressed; they express because they present a multitude into a simpler unity available to the mind. ${ }^{10}$ We will return later to the notion of unity. For now, we ought to focus on some scholarly work on expression.

The overall assumption at work in the debate is that, in order to capture the epistemic force of expression, one needs to determine what kind of relation the expression-relation is. More specifically, what makes a relation between two items an expression relation?

The literature on the topic has a venerable tradition, beginning at least with Menke (1925) and Cassirer, although the idea of focusing on epistemic force and capturing it by means of formal tools - modelling the kind of relation that expression consists in - was established by Kulstad (1977: 55-76). His analysis has given a welcome twist to the debate, provoking much scholarship on the notion. In short,

10 On an interesting interpretation of monadic expression as a form of phenomenology, Poser (2000: 19-41), who insists on the synthetic/unifying activity of the monad resulting in various forms of phenomena. As it will result from the rest of the chapter and the inquiry in the next chapters, we will tackle the evolution of various degrees of the cognitive agent's expressive power. 
Kulstad argues that the expression relation may be understood as a mapping relation/function between two sets associated to the exprimens and the exprimendum, respectively. The claim, "one thing expresses another" is an elliptical proxy for a five-place relation: there is a relation between two things such that there are two sets associated to the things that allow for a mapping of their items thanks to a certain relation that needs spelling out (see formulation D of the principle of expression in Kulstad, 1977: 70-76).

Kulstad's study has been criticized by Swoyer (1995), who highlights an aspect of the notion of expression which, I think, is decisive in understanding Leibniz's account. Swoyer first notices that a mapping relation of this sort must be bijective, which may be possible for some kinds of expression, but not for just any kind of expression. Consider the circle and the ellipse that expresses it: the ellipse does not have all of the qualities of the circle (Swoyer, 1995). Swoyer's central objection concerns the notion of mapping between sets: mapping loses its grip on Leibniz's notion of expression since it misses the idea of what is preserved in the passage from the thing to the expression, viz., a structure that is reproduced by the exprimens, which is the same as, or similar to, that which characterizes the exprimendum. Recently, however, this conception of structural preservation has been criticized by Jorgensen (2019: 101-25), who sharpened Swoyer's worry that there may be expressions where no structure is preserved, as in the case of an equation and the circle it expresses on a Cartesian plane.

In analyzing the notion of expression, I will argue that expressions are devices of the human mind to apprehend the unity of one thing through the unity of another thing. Insistence upon the unity of the thing apprehended via the unity of the expression will turn out to be decisive for grasping both the nature and the cognitive function of the expression. And yet scholars seem to have paid less attention to the fact that what characterizes an expression-relation is not simply a certain relation between the parts of the exprimens and of the exprimendum, nor the structure, or information-preservation. Even if structure, mapping, and information-preservation are relevant to answering the question about what tools the mind has for finding expressions, they do not answer the question of why one thing expresses another.

The epistemic force of an expression lies in the fact that the unity of the thing expressed is both produced and made available to a finite mind thanks to the deployment of devices that present some cognitive advantages over the thing itself, which remains beyond the bounds of being grasped by a mind unless it is expressed. ${ }^{11}$ As I shall argue more extensively in chapter IV, the productive power of

11 See for instance De Risi (2007: Chap. 3) who insists on the notion of unity; see also Debuiche (2013: 409-39) who insists on the dialectic between unity and multitude, finitude and infinitude, which is intrinsic to the notion of expression - especially in mathematics. As she convincingly notes, however, despite the variety of models of expression that we find in mathematics, none of these captures the notion of expression as a metaphysical relation. I am in agreement with Debuiche on this point, who thinks that discourse about expression in metaphysics must be taken as a sort of infinitesimal approximation to the most perfect kind of knowledge we can reach about God, substance, and the totality of the universe. In this sense, 
the mind bestows unity, and so being, onto the thing expressed, although the reality of the thing expressed may be mind-independent since there are metaphysical reasons why the mind can conceive of that thing as singular and one. Expressions are mind-dependent, for there are no expressions - not even natural expressions - if there is no mind to take one thing as if it were another. The reality of the thing expressed, nonetheless, is somehow grounded in nature, an aspect that locates Leibniz's epistemology beyond the categories of idealism/realism (more on this in chapter IV). In any case, the theoretical achievement of this chapter is that the cognitive advantages offered by expressions rely heavily on the fact that expressions make available the unity of the thing expressed. Moreover, the unity of the expression is simpler (which may mean it is more abstract) than the thing itself, although it presents relations characterizing the thing in a way that makes them more comprehensible (überschaubar) and more easily visualizable (anschaubar) for the mind.

This discussion of the notion of expression is a propaedeutic to both understanding why sense-perception and thought are species of the genus expressions (as Leibniz explained to Arnauld), and for better focusing on the former species. Expressions concern any level of human cognitive capacity, the most basic form of which is the expressions of the world as if it had been made of bodies determined by shapes and sizes situated in space and time. As we will see from this and the next chapter, what Leibniz calls perceptibility is not only the work of sense-perception: it is the joint work of the imagination and sense-perception. Through its work, the mind gives unity to percepts. Moreover, in performing the spontaneous work of sense-perceiving the world, the mind expresses the world as made up of bodily phenomena in space and time, which is the reason why it can move to conceive of the body as a body of a certain type.

In what follows, I will reconstruct the theoretical kernel of Kulstad's, Swoyer's, and Jorgensen's positions respectively in order to integrate them with aspects of the notion of expression highlighted by other scholars, for instance, Debuiche (2011: 88-117; 2013: 409-39). However, before proceeding to that analysis, I want to clarify that what I am going to say about expression is not a challenge to the strategy of capturing the epistemic force of expression through a formalization of the kind of relation that constitutes expression. Rather, I think of my analysis as concurrent with those strategies, especially to that recently offered by Jorgensen (2019), but also as a way of improving upon them, especially by clarifying the cognitive role played by expressions. Indeed, it is in virtue of their cognitive function that expressions can exercise their epistemic force. In short, it is not simply the kind of relation that accounts for the epistemic force of expression relations, but rather a list of desiderata that an expression must fulfil, which rests on the structure of human cognition.

the notion of expression is used as an expression itself, as a kind of reflexive and metaphorical meaning based on an analogical translation of the word from the epistemological domain to the metaphysics domain. 
By insisting on these desiderata (most of which are already highlighted in the debate, albeit not systematically), I hope to draw a conclusion of extraordinary importance for the present enquiry. Expressions are productive tools (Bolton 2011b; Jorgensen 2019) that are either naturally or arbitrarily invented by the mind as means for selecting and translating information from one domain into another, in order to improve and facilitate the mind's efforts in information-storage, processing, and extrapolation. To some extent, I shall align my analysis with that recently propounded by Jorgensen (2019: Chapter 5). However, I shall also modify that discussion to a different end: expressions are not tools of information-preservation; they preserve information and make them available to a cognizant agent insofar as they produce a loss of information in favor of the re-assessment of salient traits characterizing the thing expressed from a perspective that, ontologically, does not directly inhere with the thing expressed in itself. Signs, for instance, allow for distinct knowledge of things via concepts since they allow for a loss of perceptual concreteness while permitting a gain in conceptual distinctness. Signs per se are not distinct knowledge and do not bear any necessary relation to essences per se. Nonetheless, by transfiguring the material aspect of signs, i.e., their being composed of imagistic parts that can be sense-perceived by the human mind, into a symbol of something else, viz., the essence that exists as an idea in the mind of God, signs become an informative placeholder for the essence. This transfiguration permits to express rapports ${ }^{12}$ that are abstract and, henceforth, not immediately inferable from sensory presentation of the being as it is apprehended by sense-perception. I do not 'see' Socrates's "being a musician" in the same way as I 'see' Socrates's being white. Nevertheless, I can make the property of Socrates "being a musician" available to the mind through deploying signs. In so doing, the syntactic and semantic aspects of languages permit for the expression of what has rapports and yet not bodily parts, as thoughts, ideas, or individual substances, into a unity in the multitude that expresses some or the totality of the rapports characterizing what the stream of sign is about. Drawing a list of cognitive desiderata will help to make my position clearer.

\section{COGNITIVE DESIDERATA FOR A THEORY OF EXPRESSION}

Leibniz defines a relation of expression as a relation between parts and/or predicates (that is, what can be said) of the exprimendum and the exprimens. Thus far, Kulstad's formal analysis tells us that this relation must be intended as a mapping relation between sets that hold for parts of the things respectively expressed. In commencing our discussion, let us begin with Kulstad and then move to Swoyer.

12 Following Leibniz, I prefer to use the French word "rapports" instead of "relations" because a "rapport" means also ratio (proportion), similitude, resemblance, and connection. "Rapport" is more than a relation. 
Kulstad analyzes the expressive relation as a mapping or function of ordered sets respectively associated with the exprimendum and the exprimens. By specifying the relation, namely the mapping relation between one set and the other, we can capture the way in which one thing expresses another, while also clarifying the epistemic force of the expression. For, by knowing the law that governs the mapping, we are able to infer what characterizes the exprimendum from an analysis of the exprimens. It is important that what properly makes a relation an expression-relation between two things is a peculiar kind of relation between two sets associated with the exprimens and exprimendum respectively: that is, a mapping relation. Only this mapping relation between associated sets corresponds to Kulstad's formulation (D) of expression that escapes the objection formulations to which (A) and (E) are subject (Kulstad 2001: 414-5; Jorgensen 2019).

I myself doubt that this mapping relation captures the nature of an expression. This is not because anything can be an expression-relation, but because even if the mapping relation puts some constraints on what can count as an expression, it still permits relations that should count as expressions because they respect the formula, but we would not ordinarily take them to be expressions. Consider two cases: (i) there may be two things associated with two sets that map onto one another, and yet there may be no proper relation of expression; (ii) expression is not always a symmetrical relation (Debuiche, 2011). One thing expresses another, but the other is not thereby an expression of the former. To argue for point (ii), we need to appeal to the cognitive functions of expression. Something can be an expression because it has some qualities that go beyond its capacity for mapping onto another thing.

Let us start with (i). Consider a cactus and me. Suppose that my figure at the moment $t_{1}$ of the universe presents the same colors as the cactus at the moment $t_{1}$ of the universe. My hair and eyes are dark like the earth; my clothes are green like the cactus, and my skin is of the same color of the cactus's vase. Following Kulstad, we may say that there are two things associated with two sets (parts of the things divided by colors), and that there is a law of association between the sets, a similarity of colors (i.e., we are fulfilling Kulstad's criterion of spelling out in what respect the two things are similar, and not making a vague claim about general similarity), such that one set maps onto the other (Kulstad, 2011: 411). Can we say that the cactus is an expression of me or that I am an expression of the cactus? I do not think so. Why? The answer to this question echoes Swoyer's objection to Kulstad: there is no preservation of structure (Swoyer 1995: 85). The cactus does not express me because there is no intra-relation between the parts of the things preserved by the mapping.

To better grasp the notion of structure, consider the relation there is between parts of a map and parts of the region it depicts. The map preserves not just the correspondence between parts of the map and parts of the region, but also intrarelations between the parts of the maps and parts of the region. The cactus fails exactly on account of this correspondence of intra-relations, which must be similar to the intra-relations between parts of my body. 
As appealing as the idea of structural-preservation may be, Swoyer and others (Jorgensen 2019, for instance) note that there may be expression without the preservation of any structure, as in the case of an algebraic equation, such as $x^{2}+y^{2}=1$, and the circle it represents on a Cartesian plane. Strictly speaking, the parts of the equation do not map onto the circle. Yet, Leibniz says that the equation is an expression of the circle (Jorgensen 2019). In discussing this problem, scholars have pointed out that, if it is true that the equation does not map onto the circle, then the set of its solutions, as an expression of the equation, does. So, when we say that an equation expresses a geometrical figure, we are referring to the set of solutions that maps onto the figure.

Consider a further example of a flag and the country it represents. Leibniz tells us that arbitrary signs are expressions insofar as there is a habitual relation by which the sign becomes the sign for something else (see Quid sit idea, A VI 4 B 1370). It is an established habit that colors distributed on a rectangular surface through straight lines and other signs are used as symbols of countries. I would say that there is no mapping between the country and the parts of the flag. But the flag nevertheless counts as an expression of the country. Why? In short, the flag can become an expression of the country, although there is nothing in the structure of the flag that univocally refers to that country. The flag can express the country because it expresses the unity of the country, meaning, the flag refers to only one country, albeit only conventionally. A flag is one thing (in having its own unity), referring as it does to one thing, a region. Stressing the unity of the expression aligns with what Leibniz says in what follows about the definition of expression in the letter to Arnauld (September, 1687). In having an expression, it suffices that some kind of unity is represented by the expression.

This point may sound trivial. However, if we now compare the example of the cactus and the example of the equation, we can see the convergence: in the case of the cactus, we have two things. The mapping, however, does not refer to the unity of the thing, only to parts of it and their correspondence. Therefore, although there is a mapping between sets, we do not thereby have an expression. In the case of the equation, the equation is a semantic and syntactic algebraic unity referring to the unity of that circle and only that circle. Therefore, we have an expression, although there is no mapping between the equation and the circle. The set associated with the equation is a natural expression of the equation because the equation is the principle of generation of all possible bits of information that are blindly expressed by the equation. I shall elaborate upon this below.

"Blind thought", cognitio caeca, is a terminus technicus of Leibniz's philosophy. A cognitio caeca is an expression that has some cognitive advantages when deployed in reasoning because it is simpler than the thing we have to reason about, and yet more informative than the thing itself. The cognitio caeca is more informative because it translates the information onto a level - and onto a format - that is 
easier to apprehend by the mind and, therefore, cognitively clearer than the thing itself. $^{13}$

These ideas about blind thought will ultimately provide the key for deriving the respective cognitive desiderata for a theory of expression. Before pursuing this further, however, I want to point out that my analysis is sympathetic to that of Jorgensen, who recently argued that we should reread Kulstad's and Sowyer's proposals as a way of pointing to the fact that an expression is a relation that, given a model, $\mathrm{M}$, (i.e., the model according to which we can interpret the expression), we can extrapolate information about one thing to another. I would like, however, to add some constraints on this definition since it is too liberal in its current form. After all, not every system preserving information about another thing is about that thing. As in the example of the cactus, the cactus may preserve information about me (such as the colors I am wearing), but it is not for that reason about me. Something may be about parts of a thing and not be about that thing. Therefore, the relation of similarity between me and the cactus is not an expression of me or, indeed, of the cactus. On the other hand, a flag may carry very little information about the country, but in seeing the flag, and recognizing it as a flag, we know at least that it is associated to one country, that is a territorial, political, and cultural identity; and yet, on account of its flag, we learn nothing more specific about the country. Still, the flag is about that country. Unless I have a way to relate any part of the expression to one thing, that part of the expression is not telling about that thing.

For this reason, I think that what truly characterizes an expression as an expression of one thing is the fact that it preserves the unity of the thing and the multitude characterizing the thing in the sense that allows us to extrapolate and relate all the bits of information that we can achieve from analyzing the expression as ordered information about one thing. Moreover, if one thing is an expression of the other, this does not mean that the thing expressed functions as an expression of the exprimens: countries can exist even if flags do not, for flags are arbitrary kinds of expressions. On the other hand, expression may also be symmetric. For, the equation is an expression of the circle because it is simpler than the circle and the circle may express the equation because it makes visible all at once the relations of the points derivable from the equation. I shall elaborate on this shortly.

To make my point about the desiderata of a theory of expression stronger, I will analyze the cognitive advantages offered by cognitio caecae. Any sagacious reader, however, will immediately notice that my analysis is tendentious: not every expression is a kind of cognitio caeca. The world expresses God; the mind expresses the universe; such expressions are unlike blind thoughts. Thus, I will offer a way of extending my analysis to cases of expressions that are not blind thoughts. I shall argue that Leibniz's use of the term "expression" in a metaphysical context is analogical, and, with this, I refer to medieval theories of analogy. The transposition of

13 See MKTI in A VI 4 A 590/L 292. For an accurate analysis of cognitio caeca or symbolica in Leibniz's philosophy, see Meier-Oeser (1997); Favaretti-Camposampiero (2007). 
the use of the term in a non-cognitive and non-epistemic context, such as metaphysics, is grounded in two basic functions of the expression: it is a combination and unification of a multitude of rapports in one thing which transfigures those rapports onto a different ontological plane. Therefore, the monad expresses the universe and God; the universe expresses God. Decisive to my analysis is the remark that expression requires not just the preservation/production of unity, but also its transposition/transformation of one genus into another kind of being, viz., a "metabasis eis allo genos" (a change to another genus, which does not imply a category mistake; see also Debuiche, 2013). While this metabasis causes a loss of information, it also creates new relations, like the reflection of something in a mirror.

\section{EXPRESSION AND BLIND THOUGHT}

So far, we have highlighted how 'expression' is a kind of relation that extends from metaphysics to epistemology and the theory of cognition. I shall use Leibniz's discourse on blind thought to uncover the desiderata for a theory of expression, that is, what makes a certain relation expressive. My analysis, thus far, has not excluded the thought that there may be a form of mapping (or information-preservation) entailed by the notion of expression. My analysis simply highlights what must be added to a mapping relation in order to fully disclose what makes an expression an expression of something. To this end, we shall look at a particular kind of expression: blind thought.

The notion of blind thought or cognitio symbolica appears in the Meditation on Knowledge, Truth and Ideas in the context of Leibniz's discussion about degrees of knowledge. ${ }^{14}$ It refers to the kind of thinking permitted by distinct knowledge, as in the case of definition and/or algebraic formulae. The case of an equation, for instance, falls under this category. Therefore, cases of blind thought are cases of expressions, although not all expressions are cases of blind thought.

To understand how blind thoughts express, we need to bear in mind the distinction between clear and confused notions, on the one hand, and clear and distinct notions, on the other. Clear and confused knowledge rests on the apprehension of sensory qualities (colors, tastes, but also magnitude and figure), while distinct knowledge is knowledge that, once grasped, vouches for a decomposition of predicates in conceptual marks, and hence in the formation of propositional structures usually known as definitions: $\mathrm{G}$ is $\mathrm{F} / \mathrm{G}$ has F. If this kind of knowledge, although clear and distinct, is inadequate, then this is owing to the fact that, in decomposing distinct concepts, such as the concept GOLD, we cannot avoid meeting with sensory qualities, which are clear and confused, and therefore not subject to a perfect analysis. $^{15}$

14 For a reconstruction of the reception of the notion, see Meier-Oeser (2019).

15 For a more detailed discussion of the degrees of knowledge, see Bolton (2011b). 
Despite the characterization of the degrees of knowledge, what is relevant for us is that Leibniz ties distinct knowledge to definition, as well as to symbolic cognition or blind thought. The use of definitions depends on their systematic formation via signs, which are blind. This is because, in deploying the sign, we refer to the thing without needing to grasp all the marks and relations characterizing the concept of the thing. Indeed, we assume that we know them and/or, on occasion, have the capacity for recovering our knowledge. As Leibniz puts it:

\begin{abstract}
Yet for the most part, especially in a longer analysis we do not intuit the entire nature of the subject matter at once but make use of signs instead of things, though we usually omit the explanation of the sign for the sake of brevity, knowing or believing that we have the power to do it. Thus when I think of a chiliagon, or a polygon of a thousand equal sides, I do not always consider the nature of a side and of equality and of a thousand (or the cube of ten), but $I$ use these words, whose meaning appears obscurely and imperfectly to the mind, in place of the ideas which I have of them, because I remember that I know the meaning of the words but that their interpretations is not necessary for the present judgment. Such thinking I usually call blind or symbolic; we use it in algebra and in arithmetic, and indeed almost everywhere. When a concept is a very complex, we certainly cannot think simultaneously of all the concepts which compose it. [A VI 4 A 590/L 292; my italics]
\end{abstract}

The reason why the mind must deploy blind thought is that it is structurally unable to consider (i.e., have an intuition of) the "entire nature of a subject matter". To be more precise, the entire nature of the subject matter cannot be thought by the mind unless the mind uses surrogates, viz., blind signs, which stand for the entire nature of the subject matter. However, the mind can neglect to bring to bear a perfect analysis upon the subject matter (assuming that it in fact wields such powers of analysis, albeit imperfectly).

I want to stress two points made in the above quotation. The expression (the sign, definition, etc.) refers to "entire nature", that is, its unity. Nature is made available to the mind thanks to the expression being simpler and more affine to the mind, in a way that its unity qua entire nature is not. In other words, the expression functions as a kind of trans-latio: a transposition of the exprimendum (the entire nature) onto a level that does not ontologically inhere with the thing per se, but which is accessible to the knowing mind. Notice that this translation is also appropriate to mathematical examples: even if the ellipse and circle belong to the same genus "curves", they are two different species of curve. ${ }^{16}$ When the ellipsis expresses the circle, it does so because it is not the circle. Signs, on the other hand, carry "the nature of a thing" to the level of thought because they are not the thing; and, in so doing, become placeholders for that thing. What's more, however, without signs as a system ruled by syntax and semantics which allow us to form definitions - the "entire nature of the thing" is cognitively offline or unavailable - even unfathomable - to the mind. For, all that we can grasp of a thing's nature are parts of the rapports characterizing it, owing to which we need a system of signs. Thus, nature

16 Compare this passage with NE 308, where Leibniz talks of infinite homogeneous transformations that translate one figure into another but do not make the figure of a different genus. 
is grasped by finite minds through its expression into conceptual networks (Bolton 2011a). I will elaborate on this claim shortly.

For now, let us turn to an early text of Leibniz, On Mind, the Universe and God. Here, Leibniz explicitly claims that the mind cannot conceive of "the entire nature of a thing" unless it deploys signs. The text is quite interesting, for its content and structure is reminiscent of Quid sit idea? and Meditations on Knowledge, Truth and Ideas, although the technical vocabulary of Leibniz is not yet at play. Indeed, there is no reference to either expression or symbolic knowledge. However, what Leibniz has in mind are exactly these two concepts, which he will formalize in the later texts, whereby "expression" and "blind thought" become technical vocabulary and pivotal concepts within Leibniz's theory of human cognition. Leibniz declares that the human mind can by no means have knowledge of ideas because it cannot intuit one idea: the mind is not capable of grasping all the rapports defining the idea as the idea of a circle, for instance, in a single moment. For this immediate grasping of the entire nature is beyond human powers, the finite mind grasps the idea "part by part", representing to itself those rapports by means of surrogates, which may either be symbolic or imagistic. The echoes of blind thought and of expressions become more explicit when one looks at Leibniz's further remarks:

If we were to think of the whole essence of the circle at the same time, then we would have the idea of a circle. Only God has the ideas of composite things; in the meantime, we know the essence of a circle by thinking of its requisites part by part. The deficiency of the idea that we have is made good by some sensible image, or by a definition; that is, by an aggregate of symbols, in which there is no need of similarity. The place of an idea is filled on each occasion by some phantasm, the whole of which is sensed at the same time. Images excite the senses, symbols excite thought; the former are more suitable for action, the latter for reasoning (A VI 3463 in DSR 6-7; my italics and bold)

The "phantasm" the human mind can sense-perceive and use as a surrogate for an absent idea or essence clearly hints that, although the mind can extrapolate only bits of information, those bits are about one essence because the mind has resources to understand the unity of the whole essence. Definitions or images are ways to express the multitude of rapports into either a semantic or syntactic unity (given by definitional formats) or otherwise in the form of images. Such definitions or images constitute blind thoughts, for they present the thing "uno obtutu", sc. all at once. Nevertheless, this is not a true intuition of the essence: it is merely a gloss.

Thus, unity is not merely represented but produced in the expression. On one hand, it may be the case that the thing expressed has unity per se, as in the case of an essence, but this may not be available to the mind. On the other hand, when the thing has no unity per se, as in the case of a body (that for Leibniz is an aggregate per accidens), unity is nonetheless bestowed by the mind upon the thing. In each case, unity is produced by the mind, and, in producing it, the expression becomes a generative order of information about that thing. Hereby, the mind even creates new rapports, viz. rapports that are not in the world unless there are minds endowed with expressive rational power. Symbols, signs, and languages, for instance, become parts of the world; things that materially exist. This creates new meanings, 
and even imposes false ideas, ${ }^{17}$ producing new associations, for instance between terms that refer to abstractions. These invented objects also create new relations.

I would like to stress that it is in virtue of the unity of the expression that the expression can fulfil its task of making something available to an epistemic subject. To emphasize the creative and productive powers of the mind, Leibniz writes: "A most perfect being [...] is capable of ideas and of thoughts, for this multiplies the variety of things like a mirror" (DSR 9/A VI 3 464). Indeed, considering that Leibniz defines monads as "living mirrors", rational monads multiply the variety of the created world thanks to having a limited power to produce new rapports exercising their expressive power.

The pivotal point of the passage quoted above, however, lies in the unity of the multitude produced by the expression. The "whole of the phantasm", as Leibniz writes there, it is sensed at once, and this is the reason why the "phantasm", which nothing is but what later is called "expression" or "blind thought", is better suitable for reasoning. Expressions, I insist, function as cognitive tools if and only if they present an entire nature "uno obtutu", "all at once", supplementing the mind's lack of intuitive power. ${ }^{18}$ If the nature and multitude of rapports characterizing that about which we want to gain knowledge is neither straightforwardly available nor cognizable by the human mind, then the expression makes it comprehensible and visualizable. ${ }^{19}$ In so doing, the mind amplifies its epistemic and cognitive power, increasing the degree of clarity of its knowledge. In a text dated to 1685 , entitled "On the combination (complexione) of the varieties of all cognizable at once" (De totae cogitabilium varietatis uno obtutu complexione), Leibniz defines exactly the act of beholding a multitude "all at once" as the greatest moment of knowledge: "The greatest moment in thinking is when we can connect all at once the totality of the conceivable things that our minds are used to observe more frequently" (A VI 4 A 595). So, in this way we understand comparisons and connections among things; we discover the proposed thing; and we compare one given thing with others. He concludes affirming that the discovery of a lingua characteristica - comprised of true definitions - will serve this scope greatly (see A VI 4 A 595).

All this points to the fact that the expression is a tool that produces and generates new information. A diagram describing a decrease of natality in Europe, for instance, may lead the mind to discover new facts, simply by connecting known data from which an improvement in knowledge can arise, which would not occur simply by reading the same data listed on a sheet of paper. The expression, moreover, must allow for the extrapolation of pieces of information in an ordered way.

17 See the encyclopedia entry "imposition", Oliveri (2020a).

18 Belaval reads Leibnizian formalism as a substitute for Cartesian intuitionism and makes it the mark of the distinction between Leibniz's and Descartes' theories of cognition. If, for Descartes, the mind intuits ideas, however complex they may be, Leibniz utterly rejects such a claim, arguing that the only thing minds can do is invent signs as if they allowed for the intuition of an idea. For a more detailed and accurate distinction, see Belaval (1960: 23-83).

19 See also Leduc (2011: 582-90), who explains the role of expressions as cognitive tools. 
The best order would be the respective relevance of pieces of information for grasping the nature of something.

Let us consider the case of definitions. Definitions, claims Leibniz, are "une expression distincte de l'idée de la chose" (A II 1 877), "a distinct expression of the idea of the thing". In a different letter, he remarks that definitions are "pricipes de l'expression des veritez, c'est-à-dire les definitions sont principes des propositions" (A II 1 424), "principles of expression of truths, that is definitions are principles of propositions." While later he claims that equations are a kind of definitions (A II 1 424).

I am intrigued by the word "principes", meaning principles for the expression of truths. When we have a distinct expression (an expression that refers to the essence of the thing in its totality), we grasp a principle for the extrapolation of bits of information according to a certain degree of relevance for that thing: we do not extract bits of information randomly, nor do we simply differentiate between true and false propositions; we order them on the basis of their pertinence for defining a certain essence. ${ }^{20}$ To use Leibniz's metaphor, each definition is like a view on a city; a real definition equates to see the combinations and compositions among those views like on the city map. The real definition, hence, allows to derive the other views. ${ }^{21}$ We may even say that such a hierarchy of pieces of information constitutes the "abstract" structure of rapports. This structure preserved and made

20 A VI 6 293-4/NE 293-4: "L'essence dans le fonds n'est autre chose que la possibilité de ce qu'onpropose. Ce qu'on suppose possible est exprimé par la definition, mais cette definition n'est que nominale quand elle n'exprime point en même temps la possibilité, car alors on peut douter si cette definition exprime quelque chose de reel, c'est à dire de possible; jusqu'à ce que l'experience vienne à nostre secours pour nous faire connoistre cette realité a posteriori lorsque la chose se trouve effectivement dans le monde [.]" [Essence is fundamentally nothing but the possibility of the thing under consideration. Something which is thought possible is expressed by a definition; but if this definition does not at the same time express this possibility then it is merely nominal, since in this case we can wonder whether the definition expresses anything real - that is, possible - until experience comes to our aid by acquainting us a posteriori with the reality (when the thing actually occurs in the world).]

21 That perfect definitions give us a way of deriving other definitions is proved by the fact that non-perfect or merely nominal definitions do not provide us with a principle of definition, see A VI 6 267/NE 267: "l'or est un metal qui resiste à la coupelle et à l'eau forte, c'est une idée distincte, car elle donne des marques ou la definition de l'or. Mais elle n'est pas accomplie, car la nature de la coupellation, et de l'operation de l'eau forte ne nous est pas assez connue. D'où vient que lorsqu'il n'y a qu'une idée inaccomplie le même sujet est susceptible de plusieurs definitions independentes les unes des autres, en sorte qu'on ne sauroit tousjours tirer l'une de l'autre, ny prevoir qu'elles doivent appartenir à un meme sujet et alors la seule experience nous enseigne qu'elles luy appartiennent toutes à la fois. [Gold is a metal which resists cupellation and is insoluble in aquafortis; that is a distinct idea, for it gives the criteria or the definition of 'gold'. But it is not a perfect idea, because we know too little about the nature of cupellation and about how aquafortis operates. The result of having only an imperfect idea of something is that the same subject admits of several mutually independent definitions: we shall sometimes be unable to derive one from another, or see in advance that they must belong to a single subject, and then mere experience teaches us that they do belong to it together.] 
available to the mind in a blind way because of the expression taken as a real definition. This hierarchy consists in the relevance and importance of bits of information in relation to the essence or nature that the expression is about.

Considering things from this perspective, we can harmonize the interpretations offered by Jorgensen, Kulstad, and Swoyer by understanding "structure" not as imagistic, but as an abstract organization of rapports among parts, where "part" refers to something very abstract, such as informative sentences that we can formulate within a language, which are about the nature of a thing. Using Leibniz's words: we learn to put the nominal essences of a thing in perspective order, just as we learn to discern from which vantage point a city is best represented. We learn to not simply express but compose such points of view. Only by representing nature via nominal definitions, which stand in an ordered relation to each other thanks to a definition that must be "real", we reach the best-informative point of view. Any true or real definition, hence, is a definition that, like an equation, allows for the derivation of the set of what can be said about the thing expressed. In this sense, both a kind of mapping and a structuring among pieces of information is preserved in the expression.

Leibniz indeed says that an essence may have an infinite number of nominal definitions, just as a city can be expressed from different viewpoints. ${ }^{22}$ These essences, however, are not epistemically equivalent. In any case, they are all subordinate to a real definition, something that remains beyond human powers. ${ }^{23} \mathrm{~A}$ real definition will give the very essence of the thing; its generation. If the construction of figures on a geometrical plane comes close to a real definition, then, when dealing with other sorts of beings, such as natural kinds, real definitions are unavailable to the human mind. ${ }^{24}$ And yet, the human being is not without resources. The human subject can come close to real definitions because they can discover expressions referring to "the entire nature of a thing", or they can ameliorate and re-assess definitions in a continuous process of approximation to the true nature of things.

If this is correct, then some definitions are better expressions than others, even though they are still nominal and not real, and even if their relevance depends on the "series of thoughts" in which they occur. Consider the following example.

$\left(\operatorname{def}_{1}\right)$ A human being is a rational animal.

$\left(\mathrm{def}_{2}\right)$ A human being is capable of laughter.

22 A VI 6 294/NE 294: "Pour mieux distinguer aussi l'Essence et la definition, il faut considerer qu'il n'y a qu'une essence de la chose, mais qu'il y a plusieurs definitions qui expriment une même essence, comme la même structure ou la même ville peut estre representée par des differentes Scenographies, suivant les differens costés dont on la regarde." [To reinforce the distinction between essence and definition bear in mind that although a thing has only one essence, this can be expressed by several definitions, just as the same structure or the same town can be represented by different drawings in perspective depending on the direction from which it is viewed.]

23 MKTI A VI 4 A 591/L 293.

24 A VI 6 30/NE 30; A VI 6 148/NE 148; A VI 6 295/NE 295. 
According to the Aristotelian tradition, which Leibniz endorses, $\left(\mathrm{def}_{1}\right)$ defines the essence of what it is to be a human being, while $\left(\mathrm{def}_{2}\right)$ defines a proprium of man: something only human beings are capable of, but which does not fully capture the essence of man. Leibniz considers the definition, "human being is a rational animal", a kind of real definition, for, "[in] the case of man, I believe that we have a definition which is at once nominal and real" (NE 313). The former definition, Leibniz tells us, is more informative than the latter, and hence is an expression of the essence, not simply because it pinpoints a trait that only human animals are supposed to have (reason), but because it allows for the extrapolation of other pieces of information that characterize human beings, which cannot be extrapolated by analyzing the attribute "capable of laughter". If I grasp that a human being is rational, and furthermore grasp what "rational" means, then I can infer that a human being is capable of speaking, laughing, singing, and many other things, which are not straightforwardly derivable from other, merely nominal expressions, like $\left(\mathrm{def}_{2}\right){ }^{25}$

Something is an expression, then, when it is about the entire nature of the thing, or when it is a partial expression, like any nominal definition, that is apprehended as expressing a part of an essence. Real definitions are in addition sources or principles of partial expressions of the thing, or of propositions (whether true or false), which are about the thing.

In the same spirit, an equation is an expression not because there is a mapping of the equation onto the circle, but because it is about the unity of the circle: it expresses the multitude of rapports into a simple formula, which is of a completely different kind to the circle (viz., composed of algebraic signs as opposed to points and lines). Yet, it is more informative, telling us something more about the circle, information that remains hidden from us absent its formula. The equation, then, preserves the circle's unity, and is productive of information about the circle because it allows to derive numbers that represent points that, altogether, belong to the circle and retain its peculiar relations about a focal point.

The foregoing analysis is not intended to contrast with any existing, formal account of expression. My aim is simply to highlight that, in order to have an expression, the following desiderata must be fulfilled:

25 Leibniz is however aware that $\left(\operatorname{def}_{1}\right)$ is not always the best definition. Its suitability depends on the context in which the definition occurs. One example is "Socrates is a musician. He can sing well" and "Socrates is a white-man. He can sing well". The former definition of Socrates is better suited to extrapolate the property that Socrates is a good singer. Being a white-man is not straightforwardly a sign of being a good singer. See Di Bella S. (2004, 39). The passage Di Bella is referring to is a note to Temmik presented in Vorausedition (VE 1082) which says: "Albus Socrates, et Musicus Socrates, sunt unum idemque nam etsi Socrates qua Musicus bene canant, et qua albus non canant, verum tamen est album Socratem canare et quicquid de Musico Socrate, etiam de albo dici potest, nisi quod praedicationes hic excludimus reduplicativas, quibus formales rationes praedicatorum albedo scilicet et Musicae peritia distinguuntur. Et sane revera Socrates qua Musicus bene canit est enuntiatio praegnans constans ex his Socrates canit, Socrates est Musicus, et Nisi Socrates esset Musicus non bene caneret. Itaque non semper alius est Musicus et alius albus, ac proinde non sunt disparata." 
(i) There must be unity in the multitude. An expression must preserve the unity of the thing, meaning that it both refers and produces the unity of the exprimendum, while expressing the multitude of rapports that characterize the exprimendum;

(ii) There must be simplicity. It is a transformation and re-assessment of a multitude in a simpler unity;

(iii) There must be composition or connection (viz., the "uno obtutu" principle). The expression must allow for a better grasp of relations, which becomes a quasi-form of intuition;

(iv) Expression must be capable of translation. Expression transposes one thing onto something of a different kind; a kind that does not ontologically belong to the exprimens;

(v) There must be productivity and an ordering of information. The expression must allow for extrapolation of information in an ordered way;

(vi) The expression must, finally, be available to the mind and taken up proactively as an expression of something else.

We have already argued for points (i) - (v). Point (vi), however, states that expressions are cognitive tools insofar as a rational agent invents them and recognizes them qua expressions of something else. ${ }^{26}$ To be recognized as expressions, expressions must be available to the cognizant agent and therefore subject to cognitive constraints. A long string of signs, or an enormous figure, may function as expressions of something else. If, however, the figure is so big, or the string so long, that the mind cannot perceive them as one figure, or one string, then they will not be available to the mind and are therefore not expressions.

Moreover, in the case of equations or real definitions, these are merely ideal cases of expression. Expressions that are not as informative about the nature of the thing as real definitions, such as a flag or a nominal definition, still have cognitive functions that may serve diverse aims, like making available the unity of one thing through the unity of another owing to the latter's cognitive availability to the agent, thanks to which information can be transposed on a level ontologically different from the thing expressed. Expressions are ways of transforming one thing into another. This is the minimum condition of having an expression. All other expressions are particular and more complex cases of how one thing expresses another: transformations, mappings, and projections are all cases in which the unity is preserved and we are capable of ordering what is true about one, and what it is true about the other, in an abstract order of rapports between what can be said of the one and what can be said of the other.

26 In NE, Leibniz distinguishes truths which express God's ideas and their relations from the expressions we, finite minds, use to think of them, a distinction already stated in Dialogus (1677, A VI 4 24-5). A VI 6 397/NE 397: “C'est donc dans ce rapport qu'on doit placer la verité, et nous pouvons distinguer entre les verités qui sont independantes de notre bon plaisir, et entre les expressions, que nous inventons comme bon nous semble." 


\section{EXPRESSION AND ITS METAPHYSICAL MEANING}

Now we need to tackle the question of whether our analysis of expression is limited to cognitive surrogates or whether it can also be extended to metaphysics. In what follows, I will simply gesture to an answer, leaving the issue for a future, more extensive study.

Despite the cognitive and epistemic value of the notion of expression, as well as the fact that Leibniz analyzes it in epistemological terms, scholars report that expression, when used in a metaphysical context, cannot be reduced to either mathematical models - often deployed by Leibniz to describe expression - or to a simple mapping function. Despite the varieties of expressive models that we can find in mathematics, none of these captures expression as a metaphysical relation. This analysis is offered by Debuiche (2009: 88-117; 2013: 409-39), for instance, with whose account I am sympathetic. Discourse about expression in metaphysics must be taken as a sort of infinitesimal approximation to the kind of knowledge we can reach about God, substance, and the totality of the universe. In this sense, the notion of expression is used as an expression itself, a sort of reflexive and metaphorical meaning based on an analogical translation of the word from an epistemological domain to a metaphysical domain. It is a way of talking that blindly allows the human mind to understand the kind of relation there might be between God and the universe, or between the mind and God. It is a human being's attempt to approximate the relation between God, the universe, and the mind. If we follow this lead, then we can extend the cognitive analysis already conducted about expression to its metaphysical nature, at least when we understand the term "expression" to signify analogically within metaphysical discourse.

By 'analogy', I am here referring to those medieval theories of a word's analogical reference. Briefly, the medieval theory of semiotics posits the question of how it is possible that we can use the same term, for instance "being", to refer both to creatures and to God, when (evidently) creatures and God are not beings of the same kind. The medieval solution was to argue that terms may be used either: univocally, i.e., with the same meaning; equivocally, i.e., with different meanings; or analogically, i.e., with related meanings (Ashworth, 2017). As regards analogy, there are three different forms: analogy of proportion, such as when we say that both a spring and a point are "principles", because a point is to a line what a spring is to the river. In this case, the word "principle" is used with different, but related meanings. Another form of analogy is that of attribution, such as when we use the adjective 'healthy'. On one count, 'healthy' describes the physical status of a living creature, while in describing food, we might say "fruit is healthy." What we really mean is that this food makes a person healthy. Therefore, the person is healthy; the food is healthy on account of a secondary, derivative meaning. The third form of analogy is that of likeness: a creature is said to be good because it bears similarity to God. ${ }^{27}$ 
Among the three different forms of analogy, the first seems particularly useful in understanding how the word 'expression' is used in metaphysics, which is proportional to the use we make of it in the theories of cognition and knowledge. There is a core semantic meaning - a sort of genus - that relates metaphysical and epistemological tokens of "expression", so that "expression" may have different species and yet be related thanks to belonging to the same genus. This core semantic meaning is given by the notion of the preservation of unity and its transposition into a different and better kind of being, which we argued lies at the core of this notion.

Let us bring in some examples in order to improve clarity. When Leibniz says that "the mind expresses the universe or God", the term 'expression' is transposed into metaphysical discourse because the relation and connection between those things mirrors certain aspects that characterize the cognitive aspects of the notion 'expression' in epistemic discourse. The universe expresses God not because it is simpler than God, but because it is a complexion of the infinite nature of God. In this sense, the universe expresses God because there is a "metabasis eis allo genos" of God into something of a different kind that is certainly not identical to God, but which preserves the nature of God by being the effect of the cause (Jorgensen, 2019). The universe expresses God, moreover, because the universe is, in part, available to the mind in a way that God is not. Although God is beyond direct knowledge for the human mind, knowledge of the effects of God's infinite power, i.e., what exists in the actual world, can provide insight into God's nature.

The mind expresses God because (to repeat Leibniz's words), "it has thought and ideas, and this multiplies the variety like in a mirror". This means that the mind expresses God not simply by being an effect of God's power, but by being similar to God and by presenting, albeit on a finite scale, some of the cognitive capacities that God has on an infinite scale. ${ }^{28}$ In this latter sense, the third form of analogy, that of likeliness, is also involved.

I cannot pursue these ideas further here. However, the aspects of unity, simplicity/finitude, and of a "metabasis eis allo genos" seem to form the grounds for why we may use the notion of expression in metaphysics analogically. In claiming that there is a relation of expression between two beings, we transpose the core of the epistemic notion (viz., its being a cognitive tool) and focus on those aspects of the expression that may also be called a metaphysical relation, viz., qualities like unity, ontological difference in existence, yet dependence among states and properties of the two things. ${ }^{29}$

28 A VI 6 397/NE 397: "Il vaut donc mieux placer les verités dans le rapport entre les objets des idées, qui fait que l'une est comprise ou non comprise dans l'autre. Cela ne depend point des langues, et nous est commun avec Dieu et les Anges. Et lors que Dieu nous manifeste une verité nous acquerons celle qui est dans son entendement, car quoique il y ait une difference infinie entre ses idées et les nostres, quant à la perfection et à l'etendue, il est tousjours vray qu'on convient dans le même rapport."

29 The most extensive work that tries to isolate the peculiarity of the metaphysical notion of expression is Debuiche (2011: 88-117; 2013: 409-431). 


\section{IS COGNITIVE AND EPISTEMIC USE OF EXPRESSION UNIVOCAL?}

Thus far, we have seen that, as a concept pivotal to both metaphysics and epistemology, "expression" has sparked scholarly work that focuses on giving a general and formal analysis of the relation that expression consists in. Moving from the most accurate definitions of expression in Quid sit idea (1677), but especially in the letter to Arnauld of 9 October 1987, scholars have attempted to isolate the structure of expressions, as well as their metaphysical and epistemological roles. Such scholars are persuaded that an analysis of the term must lead to a univocal definition, which is ipso facto valid and preserved in any kind of expression.

The final passage of my analysis, however, points to an analogical use of the term 'expression' by Leibniz, which may even gesture towards a pluralistic interpretation of the term. In line with Kulstad's remark (2011: 412), expressions must present some common features, although there may be different kinds of expressions that do not rest on a univocal definition. The preservation of structure and mapping may be relevant to certain kinds of expression, such as perspectival projection on a geometrical plane, or expressions based on similarity, which are not essential to all kinds of expression, such as in the case of the equation and the circle. A derivative kind of mapping between "what can be said of one thing and what can be said of the other", however, depends on the cognitive function for which the expression accounts.

The idea of a pluralistic ground for expression may be desirable insofar as it permits us to move towards a plurality of reasons for why expressions are invoked, and how they can be developed into more abstract kinds. To be more specific, more imagistic traits, such as similarity of structure, may be the reason why the mind learns to take one thing as the expression of something else. Once the mind learns that there may be a substitution in reasoning of one thing through another, and that the latter amplifies the epistemic power of the mind, the mind learns to isolate other, more abstract traits that may serve to establish expression-relations between dissimilar things. To this end, other tools like continuous transformation (such as between perspectival figures), or the analogical mapping of pieces of information (as in the case of equations) may serve as the basis for developing expression-relations, where the preservation of a unity in the multitude of rapports becomes a minimal trait for having an expression, even if it must be coupled with other desiderata, as listed above. Quid sit idea distinguishes expressions into natural and arbitrary expressions:

It is also clear that some expressions have a basis in nature, while others are arbitrary, at least in part, such as the expressions that consist of words or characters. Those which are founded in nature, either require some similarity, such as that between a large and a small circle or that between a geographic region and a map of the region, or require some connection such as that between a circle and the ellipse which represents it optically, since any point whatever on the ellipse corresponds to some point on the circle according to a law. [...] That the ideas of things are in us means therefore nothing but that God, the creator alike of things and of the mind, has impressed a power of thinking upon the mind so that it can by its own operations derive what corresponds perfectly to the nature of things. Although, therefore, the idea of a circle is not 
similar to the circle, truths can be derived from it which would be confirmed beyond doubt by investigating a real circle (A VI 4 B 1371/L 208).

Given the "natural" character of some expressions, I wonder whether natural expressions are developed before arbitrary kinds of expression. I think that there are reasons to argue that Leibniz thinks that natural expressions are acquired before arbitrary expressions and serve as a preparation for the development of these latter. As I will argue in the next chapter, the denial of ideas as objects of the minds goes hand-in-hand with the theory of ideas as dispositions to form expressions. These dispositions, however, proceed in an ordered way from the natural to the arbitrary, even allowing for a plurality of grounds in the establishment of expressions.

The next chapter will defend this claim at length. What we have gained through the present analysis is our having been given a key for understanding the importance of the synthetic power of the mind in cognition, i.e., the mind's capacity to express a multitude of rapports into the unity and simplicity of cognitive surrogates. This power is already explicated in sense-perceiving, insofar as sensation consists in the unity in the multitude of minute perceptions. Moreover, in sense-perceiving, as we will soon see, the mind deploys expressions. In experiencing the world, minds experience bodies, i.e. simple notions, like colors and tastes, united into a shape, which is a form of expression of the variety of the world through something simpler and finite, and, therefore, available to the finite mind. ${ }^{30}$

Minds, as I argue, first express the world as made up of bodies: determined shapes and sizes that undergo spatio-temporal variations. This apprehension is the groundwork of the imagination. If this is correct, then sense-perception expresses the world because it is the unity in the multitude of rapports that are made available to the human mind by translating the world into figures of a certain size, which change continuously through space and time. This translation of the world as if it is made up of bodies is the first productive operation of a cognizant agent in senseperceiving beings. This operation is the basis for any further development of more abstract and arbitrary expression-relations.

\section{CONCLUSION}

I have argued that the notion of unity is central to the notion of expression. Both Jorgensen and Kulstad overlook the idea that unity production and preservation are proper to expression. Swoyer sees this element as central, although the idea of structural-preservation may lead us astray, for it is too tied up with an imagistic understanding of structure, whereby parts of the exprimens map and are ordered in a way similar to the exprimendum.

If we understand the notion of structure in this imagistic way, then we face problems, as in the case of the equation as an expression of a circle. If, on the other hand, we tied structure to the idea of unity of a multitude of rapports among pieces 
of information, produced and preserved by the expression, we remain both faithful to the peculiarity of the expression-relation as presented by Leibniz, while also potentially accounting for the epistemic force of the expression-relation in a non-imagistic way. An expression is anything that produces the unity of a thing, thereby rendering it available to the mind, producing some cognitive advantages in extrapolating and ordering pieces of information about the thing to be expressed. What we further need to stress is that expressions of things that are per se not subject to the imagination (for instance, an equation) are presented by means of imagistic surrogates. Expressions are signs, images, diagrams, sounds; indeed, anything that can be the object of sense-perception and imagination. Only in this way is an expression a cognitive surrogate that makes available the unity and multitude of the thing, permitting the extrapolation, storage, and attribution also of pieces of information that characterize things, which, per se, are neither the subject matter of the senses nor the imagination. Thought, for instance, is subject neither to the imagination nor the senses. However, by being expressed through signs and language, thought becomes thereby subjected to those faculties, and moreover available to other minds. Expressions, furthermore, are tools for selecting and ordering pieces of information that are more salient than others, depending on the context in which the expression is deployed by a rational agent.

This analysis of expression will enable us to argue for a developmental story from sense-perceiving beings to conceiving essences. The mind is naturally capable of imagining existing beings it experiences via the senses as bodies in space and time. The unity and coherence that the mind detects in phenomenal bodies is grounded in the fact that the mind can express bodies through quantitative qualities, viz., as shapes of a certain size undergoing continuous variation in space and time. Once the mind apprehends bodies of this sort, the mind spontaneously compares and gathers them in classes of similarity by interiorizing what we call types. Types are interiorized by the imagination, which operates on perceptual presentations. Only when the mind learns to consider a present, existing being as a being of a certain type can it ask the question of what makes those similar beings beings of the same type. Based on this first task of categorization, led by what Leibniz calls the logic of imagination (A VI 4 A 513), rational agents can direct their attention to the nature of things. In so doing, they learn to conceive of essences and form concepts. In reconstructing the story of how minds form concepts from the perspective of how the human mind's faculties work, we can thereby highlight the fundamental role the imagination plays in human rational processes.

Imagination, so I shall argue, is the faculty mediating and synthetizing the basic activity of substances, viz. perceptions and endeavors, with innate ideas. The final result of this mediation is thought, while its various manifestations through a system of signs is what we call language. 
Franz Steiner Verlag 


\section{THE GROUNDWORK OF THE IMAGINATION}

The primary work of the imagination is commonly taken to consist in the reproduction of mental representations of things not presently perceived. ${ }^{1}$ While sense-perception provides epistemic subjects with data about what is presently happening in their perceptual environment, the imagination enables them to mentally entertain possibilities rather than presently-obtaining actualities. For example, I sense-perceive the keyboard I am typing on, but I can only imagine that I am now playing the piano, while in truth I am writing this text. In short, sense-perception deals with what is real, the imagination with what is fictional.

Leibniz rejects this clear-cut distinction between sense-perceiving and imagining. He subscribes to a tradition that takes the imagination to be essentially involved in sense-perceiving the external world: the imagination is a schematic and synthetic faculty constructing phenomena on which the intellect can operate. ${ }^{2}$ At the perceptual level, its synthetic work consists in processing sense-perceptual information

1 Philosophers' attention to the powers and limits of the imagination has intensified over the last two decades. Much scholarly effort has been devoted to isolating the role and function of the imagination with regard to other capacities of the human mind, such as sense-perceiving, makebelieve, decision-making, and reflection. The problem of delimiting the object and function of the imagination emerges from the fact that this power seems to be related to each of these capacities. Imagining seems to be a sensory presentation of objects or events in the mind, and yet it is distinct from sense-perceiving. Indeed, the capacity of presenting the mind with possible objects and events seems to play a central role in belief-acquisition and decision-making, and yet imagining something does not imply believing what, or acting as, one imagines. It is furthermore unclear whether the act of imagining extends to the non-sensory conception of objects and events, as in the case of evaluating the possibility of counterfactual propositions. This, in turn, bears on the role imagining plays in acts of reflection. For an introduction to the topic within contemporary philosophy of mind, see Liao - Gendler (2020).

2 It is commonly thought that imagination qua schematic capacity of the mind is a theory first put on the philosophical stage by Kant. As Rabouin (2018) explains, the idea of a schematic imagination is to be found already in Proclus, where "schema" refers to the Greek "figure". Imagination is therefore the faculty by which the intellect projects geometrical figures onto perceptible and material forms by using points, lines, and surfaces organized in continuous space. This theory of imagination is seen in opposition to Aristotle's theory of imagination as a faculty of abstracting homoiotes, similarities, among perceptible beings, producing thereby a first-level abstraction (Aristotle, De Anima, 2-3; for comment, see Schofield 1995: 250-79). The intellect operates on the general image produced by the imagination and abstracts a concept. Aristotle's theory is delivered to early modern readers through an incredible number of interpretations, which proliferated during the Middle Ages, both in Western and Arabic worlds. Various commentaries on De Anima have both revised and transformed the original Aristotelian doctrine. The relation between the imagination, memory, the active and passive intellect, and the apprehension of "intentiones" (meanings) is a complex story whose main figures may be individuated in Avicenna, Averroes, Albertus Magnus, and Thomas Aquinas (see Black 
and performing a certain groundwork for cognition: the imagination segments and synthetizes (or, in Leibniz's jargon, expresses) the multitude of sense-perceptions into perceptible wholes and, in so doing, interiorizes rules for simplifying senseperceptual data. Through this, the imagination produces an initial generalization of particulars into similarity classes, which I call 'types', and for which Leibniz uses the phrase: "possibilities inherent in the resemblances" (NE 323).

It is worth specifying that the kind of imagination we are dealing with here is pictorial, i.e., a cognizant agent's capacity to entertain quasi-sensory representations of objects and events. The pictorial imagination differs from both conceiving and understanding insofar as, in the latter case, we do not entertain the scenario in a quasi-sensory way: rather, we canvass the conditions of a specific proposition's being true or false. Even if this notion of conceiving still sounds obscure, the upshot of the present work is to show that the idea of a schematic imagination offers a framework for distinguishing between the pictorial, or iconic, imagination, and conceiving, while also offering a unifying account of imagination as a specific mental power. Both imagining and conceiving rest upon the schematic imagination, despite depending on different "constraints": similarity characterizes imagining; identity characterizes conceiving.

The major contribution of the imagination with regard to the sensory apprehension of bodily phenomena is to interiorize what I call types. Types are shorthand for what Leibniz calls "distinct perceptions". Types are rules for how various worldly phenomena may or may not be, although this knowledge still remains tied to sensory and imagistic cognition. In this regulative function, types enable acts of simulating and tracking sensory-motor apprehensions of bodies in space and time. This is because the mind apprehends them as bodies or sensory properties of certain types.

The interiorization of types marks a decisive moment in a cognizant agent's life because it grounds the initial expression of things' common nature: once types for body or property are interiorized, the subject learns both to recognize a particular body as an instance of a type, and thereby to reproduce images, which are used as expressions of the type. When the mind takes the image of a Labrador not as similar to any particular Labrador, but as a surrogate expressing the type of body dogs, the mind makes an (initially-confused) reference to a possible essence.

From now until chapter VI, we will work through the idea that types are a prestage of imaginative knowledge. Indeed, types are required for the acquisition of conceptual knowledge. There are two basic moments in the interiorization of types.

2000 on the active and passive intellect; also see Hasse 1999). The complex analysis that imagination undergoes in cognition during the Middle Ages makes it difficult to isolate a unique tradition to which Leibniz may have subscribed. Nevertheless, the analysis of Leibniz's texts offered in this chapter hopes to provide a reliable basis for arguing that both the idea of the imagination as synthetic/schematic power, and as a faculty that recognizes similarities among beings, constitutes his theory of imagination. Imagination, moreover, seems to play the role of conciliating empiricism with an axiomatic theory of truth (as Leibniz claims in the letter to Burnett 1700 A I 18 373). For commentary on the letter to Burnett, see Oliveri (2016a: 177). 
The imagination segments unities of multitudes of parts by synthesizing the impressions received by each sense into coherent wholes that are comprised of parts: a shape of a determinate size bearing various secondary qualities. Through this geometrical expression of particular beings as body-shapes, the imagination tracks bodies' spatiotemporal variations as variations of the same bodies. Only when the imagination is dealing with unities can it further compare perceptual wholes based on qualitative and quantitative similarities. The result is the interiorization of types of bodies and/or properties corresponding to similarity classes.

The second moment consists in the apprehension of a relation of coherence among phenomena. This is based both on the type of phenomena we interiorize and on the habitual circumstances in which we apprehend them. Through this, we construct the idea of "nature", or of "a world", learning thereby to isolate the circumstances that variously allow for or impede the obtaining of phenomena's changes based on knowledge of the types of phenomena they are. Thus far in the story, types are not yet conceptual knowledge. They nevertheless allow the subject to track bodies and their properties, enabling predictions and expectations for how they behave based upon an unconscious activation of the type of body/property that they are.

The remainder of this chapter fleshes out the first moment of the imagination's work by reconstructing Leibniz's argument for the claim that the imagination is involved in the sensory apprehension of bodies. In sect. 1, I shall introduce the synthetic work of the imagination as presented in a letter to Sophie Charlotte, "On What is Independent of Senses and Matter". In sect. 2, I will expand this analysis by putting the letter into the context of Leibniz's Meditations on Knowledge, Truth and Ideas and other texts on mathesis universalis and the logic of imagination from around the same time. Based on this analysis, sections III.1 to III.3 enrich our discussion through the analysis of Leibniz's "Letter on the Element of Geometry of the Duke of Burgundy" (1705). There, the imagination's synthetic work is presented peculiarly as a sort of segmentation of confused sensations into perceptible wholes. The three subsections provide a full account of what the work of segmentation consists in.

\section{THE SYNTHETIC WORK OF IMAGINATION}

The senses provide information about particular beings: the cup in front of me; my coworker, Peter; my hands. These are all known by me insofar as I can sense-perceive them. Beings as sense-perceived are collections of primary and secondary qualities, as we argued in chapter I. In what follows, we are going to revise this thesis somewhat. Sense-perception alone does not provide the mind with a representation of one being. All that the senses provide are collections of sensations waiting to be organized into perceptible wholes (toutes entiers or totum). By "wholes", Leibniz means a totality of parts apprehended as belonging to the same body. At the sense-perceptual level, the body is nothing more than a shape enclosing parts of the body, detaching it from other perceptible wholes, which surround it. As argued in Chapter I, a certain kind of unity characterizes expressions as cognitive tools in 
reasoning. The act by which the mind encloses parts into a whole, thereby producing a relation of parthood characterizing a body, is therefore an expression of the imagination that enables the cognizant agent to move forward in her path towards knowledge of essences.

Perceptible wholes consist in confused notions of sensations, on the one hand, and clear and distinct notions of the imagination, on the other (Letter to Sophie Charlotte, 2 May 1702, A I 21328 - 346/LSS 220 - 247). More specifically, the imagination's clear and distinct notions roughly correspond to what are traditionally called primary qualities, that is to say, notions of sensations are akin to secondary qualities.

It is worth noting at this point that primary and secondary qualities are not properly parts of a whole. Given that a whole is a body, its parts are those that have some sort of function within the body, which primary and secondary qualities simply help us to track. Thus, a human body may be distinguished into arms, legs, a head, eyes, and so forth, although these parts do not necessarily present disparate secondary qualities. To clarify the point, it would be instructive to focus on how secondary and primary qualities help us to detect bodies, leaving the topic of proper parthood for Chapter III. There, we will also be preoccupied with the role of motion in the interiorization of types.

For now, let us focus upon secondary qualities. These are impressions originating in each sense: colors, tastes, smells, sounds, and tactile qualities. Primary qualities, by contrast, are measurable qualities such as the shape and size that are the subject matter of what Leibniz calls "common sense" or "imagination". The apprehension of a combination of primary and secondary qualities, like the sense-perception of a billiard ball, is what we call a perceptible whole. Its spherical shape is detectable through both touch and sight. The fact that this quality is both sensorially perceived and measurable makes it both an object of the senses and of the imagination. ${ }^{3}$ Imagination is the faculty that tracks quantity and quality. It is therefore naturally directed towards measurable qualities (indeed, to anything that can be reduced to a continuum divided into contiguous parts). The imagination is therefore sensitive to the distinct side of primary qualities, even if it does not yet apprehend them conceptually: in sense-perceiving wholes, the mind does not apprehend shape and size as clear and distinct geometrical figures, which bear a certain proportion or have certain geometrical properties. Rather, it is only when it begins to abstract and perform geometrical operations that the mind can acquire clear and distinct knowledge of such properties. Thus, the spherical form I perceive in seeing a billiard ball is, on this level, no more than my capacity to trace the border of the ball, and, in so doing, "detaching" the ball from the perceptual environment in which it is embedded. This enables its differentiated apprehension, that is, perceiving the billiard ball as different from, for instance, the rectangular green table upon which it rests. The secondary qualities borne by the billiard ball (its being black and white,

3 See, for instance, A VI 4 513, a text that we will discuss in more detail below. For an analysis of the text, see Rabuoin (2017). 
its bearing the number eight, its being smooth and cold) may help us in detecting it $q u a$ body as a unity separate from the rough, green table it sits upon. However, as will emerge in Chapter III, the ultimate proofs of bodily unity and parthood are given by observing their movements through space and time. ${ }^{4}$

Let us stress, for now, that we are dealing with a developmental story of how the mind arrives at perceiving bodies as complex objects (composed of parts) bearing diverse qualities. For instance, at an early developmental stage, we cannot say that a child has a notion of spherical shape distinguished from the sensory apprehension of its colors or tactile qualities. ${ }^{5}$ The apprehension of perceptible wholes is, at this stage of development, confused owing to its being merely a brute amalgam of qualities. Nonetheless, the imagination's (albeit hampered) attempt to track shape permits the apprehension of basically-differentiated bodies.

Thus, at the very beginning of the human being's experience of bodies, the cognizant agent has neither the power to isolate nor abstract sensory qualities as qualities of a body. What seems to us a very simple and basic capacity of the mind is something that requires a great deal of cognitive practice, which begins with our capacity to analyze a complex sense-perceptual environment. Owing to the mind's tendency to express the body, the senses (at least when they are working properly) afford an abundance of phenomenal provisions, which are sorted into simple and finite shapes of a certain size. When the imagination fixes a shape, it brings it to the foreground of other sensory perceptions, thereby helping to focus our attention, and, in so doing, allowing for the abstraction of information. The detection of shapes is, for Leibniz, the spontaneous work of the imagination. Indeed, as we shall soon see, because sense-perceptions of primary qualities are more distinct than other second-

4 We will return to this point extensively later. For now, see A VI 3 28: "Manifestum est corpus aliquod constitui definitum, unum, particulare, ab aliis distinctum, motu quodam suo vel conatu particulari, quo si careat, non erit separatum quoddam corpus, sed unum continuum cum eo cohaerens cuius solius motu movetur. Et hoc est quod alibi dixi cohaesionem esse a conatu motuve, ut quae uno motu moveantur, inter se cohaerere intelligantur."

5 Leibniz often compares the human infant's degrees of knowledge to that of non-human animals, as in A VI 1 269: "Cum autem primis annis infantes parum à brutis differant (ratione sese ob defectum experientiae tanquam materiae in qua exerceatur, linguaeque seu symbolorum per quae exercentur, parum adhuc exerente), et pueri quoque adolescentesque (ne quid de viris dicam) sensibus affectibusque ad instar brutorum plurimum regantur [...]." A similar conception is again located by Christian Thomasius: "Nach der Geburt ist ein jedweder Mensch [...] gantz unwissend, sogar, daß wenn er in diesem Zustand von denen Menschen abgesondert auferzogen werden solte, würde er ja so wenig, wo nicht weniger Vernunfft von sich spühren lassen, als manche Bestien" (see Christian Thomasius, Einleitung zur Vernunftlehre, Halle 1691, reprint Hildesheim 1968, p. 95: quoted and commented upon in Meier-Oeser (2007, 218)). Moreover, Leibniz distinguishes between the order of discoveries, which begins "par les idées plus composées et plus grossieres" (A VI 6 83/NE 83), and the order of nature, or the logical order of notions, which, on the contrary, begin with simple notions and eternal truths, constituting a proof of the dependence of our order of discoveries on what is simple and therefore already inscribed in the mind. For discussion, see Oliveri (2016: 234-252). 
ary qualities, they are more distinct insofar as they are potential objects of mathematics and geometry. As sense-perceived, however, primary qualities are also confused. A child can see a square-form, but it cannot as-yet abstract it from all other sense-perceptual qualities, which such a form appears alongside. For the child, the square is not something distinguished from other qualities: it is not differentiated from the colors or tastes that the body appears with. ${ }^{6}$ Despite this confusion, the detection of shape is a fundamental operation of the imagination because it is an initial cognition of the unity of a multitude. ${ }^{7}$ This reduction of the multitude of the sense-perceptual magma into discrete unities (what Leibniz calls "perceptible wholes"), as demarcated by shape and size, is, in Leibniz's view, that which allows the mind to interiorize types based on similarity, moreover producing a kind of 'mixed mathematics', or what Leibniz calls mathematization of the natural world. I shall elaborate on this below.

This line of argumentation is presented by Leibniz in two texts devoted to the distinction between degrees and kinds of knowledge: Letter on What it is Beyond the Senses and Matter (Letter to Sophie Charlotte, June 1702, henceforth abbreviated as BSM); ${ }^{8}$ and Letter on the Element of Geometry of the Duke of Burgundy (Letter to Sophie 31 October 1705, henceforth abbreviated as EGDB). ${ }^{9}$ It is worth noting that both letters share a common topic with Leibniz's published paper on epistemology, the Meditation on Knowledge, Truth and Ideas (1984; henceforth MKTI), while also presenting a remarkable departure. In these texts, an analysis of the cognitive role of the imagination takes center stage, thus contrasting with MKTI, which conceals this aspect, limiting symbolic cognition to expressions through language.

As anticipated in the foregoing chapters, in MKTI Leibniz marks out a distinction between the kind of knowledge the senses provide, i.e., clear and confused knowledge, and the kind of knowledge the intellect provides, i.e., clear and distinct.

6 As will emerge later, the capacity for abstracting is, for Leibniz, related to the operation of analyzing something composite into its constituent parts, rather than purely generalizing. By analyzing, the mind fixes constituent parts, or attributes, as something distinct from the thing they are a part/attribute of. In so doing, the mind fixes the nature of the part/attribute as such. This will become clearer in 3.3., when we will analyze distinct perception. For textual references, see both the passages quoted in $\mathrm{n} .5$ of this chapter, where Leibniz explicitly says that cognition begins with composite notions, and a passage from NE, where Leibniz denies that animals have abstraction. On his view, this is because they cannot have representations of sensations distinct from the bodies they inhere in. Thus, an animal cannot have a representation of whiteness distinct from chalk or snow (see A VI 6 142/NE 142).

7 Leibniz's fundamental definition of perception is an exact expression of the many in the one. See, for instance, Specimen inventorum de admirandis naturae generalis arcanis, A VI 4 C 1625 .

8 There are three different versions of the letter $\left(\mathrm{L}^{1} ; \mathrm{L}^{2} ; l\right)$ edited in A I 21 N. $224328-346$ and translated in LSS $220-47$.

9 We have four different versions of the letter (one is lost). Three versions $\left(\mathrm{L}^{1} ; \mathrm{L}^{2} / \mathrm{L}^{3}\right.$, dated 31 October 1705) are edited in: A II 4 N. 110 336-54/LSS 322-32; Leibniz drafted other two shorter versions on October 31, 1705 but finished them on November 24, 1705 (sent to Sophie for Elisabeth Charlotte of Orléans). These are published in: A II 4 N. 112 360-67/LSS 340-43. 


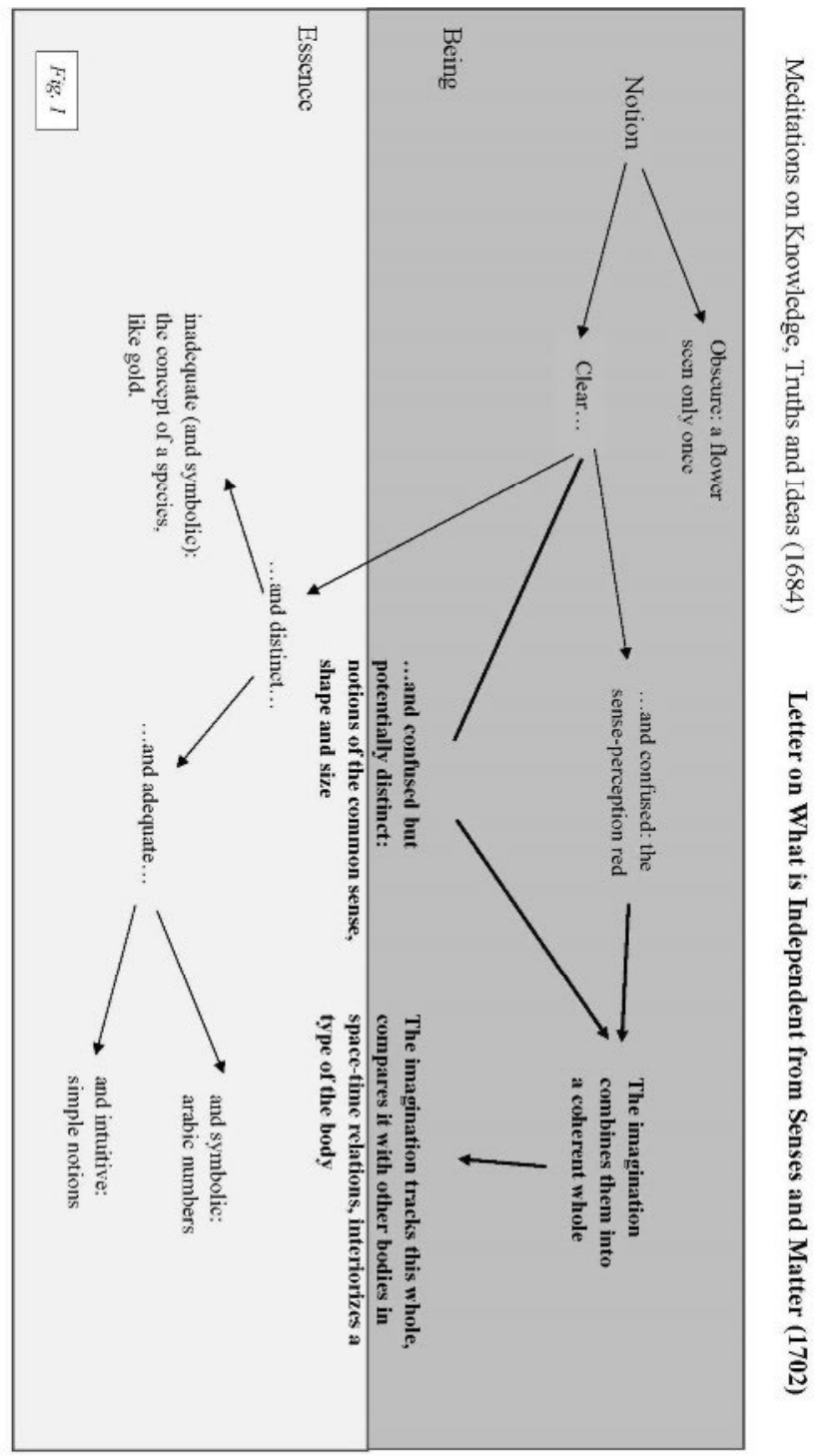

Fig. 1: Above described are those additions presented in BSM. The degrees of knowledge are those articulated in MKTI, while those in bold are what Leibniz adds in BSM. NB that the background demarks the distinction between beings and essences, as analyzed in chapter I. To remind the reader: perceptible wholes, which are composed of clear and confused notions of the senses and by distinct notions of the imagination, mark out a substantial step towards a midpoint between beings and essences: types. 
The former concerns sensory qualities as delivered by each sense; the latter concerns distinct, conceptual knowledge, which takes a propositional form, as expressed by definitions into language. In MKTI, however, Leibniz's target is simply to contrast different degrees of knowledge, rather than giving an account of how minds move developmentally from one stage to the next. The question of how a mind expresses not just sensory qualities, but more specifically perceptible wholes, e.g., the appearance of a body as the computer in front of you, remains hidden in MKTI. This issue bothers Leibniz in the letters dated 1702 and 1705, almost twenty years after MKTI. There, remarkably, something substantial is added: a midpoint between clear and confused notions, and clear and distinct concepts. This stage consists in clear and distinct notions of the imagination, which allows for the apprehension of bodies as shapes of a determinate size in space and time, or, better yet, shapes and sizes situated in spatiotemporal relations. This expression of bodies allows the subject to move from sense-perceptual to the conceptual knowledge of essences (see Figure 1 above).

Let us analyze BSM more closely in order to specifically address the work of the imagination. Here, Leibniz offers a distinction between three kinds of notion. Notions can be sensible, imaginable, and intellectual. The former are notions of the senses, such as colors, while imaginable notions are those that are subject to the imagination, such as shapes, sizes, or numbers. Meanwhile, intelligible notions are those of metaphysics and morality, such as substance and justice, which the mind apprehends as "objects of the understanding alone." 10

Leibniz begins the letter by stressing both the importance and limits of the senses, which we use as a blind person uses a stick. This analogy simply means that secondary qualities provide some 'first aid' in orienting the cognizant agent in their knowledge of existing bodies, although they do not present things as they really are. While each sense can provide sensory notions peculiar to it - colors are expressions of changes in the eyes, tastes of changes in our mouth and tongue, etc. (more on this in sect. 3) - these qualities are clear but confused. The reason for their confusedness lies in the simple nature of the qualities themselves, which allows for recognition, but not for an analysis. Our acquaintance with red bodies allows for our ability to recognize red when we see it, an ability that cannot be provided by any definition of the simple notion "red". I can say that "red is a color" or "red is a variation of light-rays of the frequency such and that", but none of these definitions are sufficient to enable the subject to recognize a body as a red body. By contrast, distinct notions are thus insofar as they allow one to know something in virtue of those definitional marks that characterize the notion. While a blind person can never recognize the color red, she may nevertheless have clear and distinct notions of the imagination, as in the case of geometrical knowledge. Shapes and sizes are qualities apprehended multimodally, that is, through a diversity of senses. Until this point, the text does not explicitly contrast with the claims of MKTI, except insofar as Leibniz introduces what seems to be a further, fine-grained distinction between 
clear and confused notions of sense-perceptions, on the one hand, and clear and distinct notions, on the other. This further level consists in our representation of perceptible wholes, a task carried out by the imagination. ${ }^{11}$

Leibniz clarifies that, despite the "occult" nature of secondary qualities, they can become subject to scientific explanation when unified in the imagination and analyzed by virtue of other distinct notions: numbers and shapes. Our notions of number and shape belong to the common sense because they are not proper to any single sense: we detect them through touch and sight, owing to which there must be something common to those notions. As Leibniz immediately clarifies, however, even if we were talking about an analysis of common-sense notions through the more refined lens of distinct notions, shapes and numbers (as experienced by the common sense) are not distinct per se, for "in order to conceive numbers and even shapes distinctly, and to form sciences of them, we must arrive at something which the senses could not provide, and which the understanding adds to the senses" (LSS 239). Leibniz's remark here is important because it underlines that, at this level, we are not dealing with conceptual knowledge: numbers and shapes, as perceived by the common sense, are particular manifestations of numbers and shapes, not concepts. The imagination deals with presentations of particular shapes - material that only the senses can provide. Indeed, like our notions of secondary qualities, these presentations are necessarily clear and confused, since they denote only the senseperception of a shape. (Suppose you are presented with a 5-cube, a cube in 5-dimensional space: you see a shape, but you have no clear and distinct notion of that figure (assuming you are not an expert mathematician). You nonetheless see a determinate shape.) Shapes and numbers can, however, become the objects of clear and distinct knowledge since the understanding can "add" something to them.

Having delineated the distinction between clear and confused notions of the senses, and clear and distinct notions of the common sense, Leibniz proceeds to argue for the necessity of the synthetic work of the imagination. Each sense can receive impressions proper to its nature. Certain other kinds of impressions (for example, primary measurable qualities) can be detected multimodally, to use a contemporary term. In any case, we need a common sense that elaborates on those impressions. On their own, impressions are unconnected and disorganized. However, we may assume that there is a faculty, namely the imagination, whose work is to coherently organize impressions of the common sense and of the senses into "one whole". A perceptible whole is an appearance; an image of one particular being. It could be, for example, the image of a book-shaped body in front of you, or of an apple-shaped body, or indeed anything perceptible to your senses in your surroundings, with such-and-such a quality, which is perceived as singular insofar as it is detachable from other appearances in the perceptual field. The apprehension of such wholes constitutes the commencement of acts of abstraction, as well as of recalling and comparing shapes, sizes, and properties.:

11 For a more detailed argument regarding the relation between MKTI and BSM, see Oliveri (2020). 
Therefore, as our soul compares (for example) the numbers and shapes that exist in colors with the numbers and shapes that are found by touching, it must be the case that there is an internal sense in which the perceptions of these different external senses are reunited. This is what we call the imagination, which includes both the notions of the individual senses, which are clear but confused, and the notions of the common sense, which are clear and distinct. And these clear and distinct ideas which are subject to the imagination are the objects of the mathematical sciences, namely, of arithmetic and geometry, which are pure mathematical sciences, and of the application of these sciences to nature, which makes mixed mathematics. (LSS 239/A I 21 339)

Towards the end of this passage, Leibniz says something remarkable about this process: the synthetic work of the imagination allows for the mathematical accountability of concrete bodies and the properties we confusedly apprehend. That is, the expression of concrete beings in terms of shape and size renders them objects of the quantifiable sciences. Owing to this, clear and confused qualities, such as the secondary ones, can thereby also find clarification, themselves becoming objects of the natural sciences and mathematics. ${ }^{12}$

Shape and magnitude constitute a 'middle way' between what can be senseperceived and what can be conceptually apprehended: we see something as square even if we do not know what it is or how to define it, i.e., when we, as-yet, lack the relevant conceptual knowledge. Being both imaginary and conceptual, elements of both geometry and mathematics (as detected in bodies) allow us to reduce particular apprehensions of bodies to wholes, which accounts for the first stage of abstraction and generalization based on similarity, which is not as-yet of a conceptual kind. When I say that this generalization is not of the conceptual kind, I mean that it is not of a clear and distinct kind: it does not provide a definition of a whole, and it is yet a degree of knowledge potentially more distinct than simple sensation, as we are going to see in the rest of the chapter.

While this stage is missing in the MKTI, Leibniz does bear witness to it in his writings on geometry and mathematics that are contemporaneous with MKTI. Clearly, something occurred between 1684 and 1702-4, likely something relating to Leibniz's confrontation with Locke's empiricism. This confrontation compelled Leibniz to work out a more sophisticated and detailed account of the relation between sense-perception and conceptual knowledge, on the one hand, and of the acquisition of the latter as occasioned by the senses, on the other. ${ }^{13}$ As Leibniz himself puts it, the senses do not give us conceptual knowledge of necessary truths: they

12 For commentary, see also Rabouin (2013); Leduc (2017).

13 Leibniz had already claimed in MKTI that experience provides the human mind with a posteriori knowledge of the possibility of empirical concepts. Even if I can conceive of gold and its properties, and, in so doing, I am not capable of detecting any contradiction, I cannot have certainty of the real possibility of gold unless I experience something that I can categorize as gold, which proves the consistency of my concept (see MKTI in A VI 4 590/L 293). In Oliveri (2016: 1.1), I argue that Locke's philosophy compels Leibniz to face a new body of problems: harmonizing his theory of human cognition with the fact that human non-conceptual and conceptual apparatuses develop and change throughout an individual's ontogentic and phylogenetic life (see, for instance, A VI 1 656). 
provide the occasion for the mind's coming to know them. ${ }^{14}$ Without sense-perceptual knowledge of the world, the mind would not develop conceptual knowledge of essences, although this knowledge ultimately depends upon the intellect's contribution. Locke's account of abstraction causes him to confront this body of issues. Indeed, it is at this stage, in my opinion, that Leibniz forges the link between how the imagination works in the apprehension of mathematical and geometrical entities, and how it functions in apprehending sense-perceptual appearances. The result is the idea that human cognition has a geometrical and mathematical core, whereby innate knowledge constrains the imagination. The constrained (and schematic) imagination is activated in sense-perceiving worldly phenomena and allows for their categorization, an operation that Leibniz calls "mixed mathematics": the reduction of beings to geometrical-like wholes, or, what he calls, "the mathematization of the natural world". The imagination, namely the faculty that traditionally mediates between sense-perception and intellectual knowledge, therefore becomes in Leibniz a synthetic faculty constituting human sense-perceptual apprehension of those phenomena that have a body. Beings, as we argued, are first represented as bodies, which have a certain shape and size, and bear various sensory qualities, which change depending upon spatiotemporal conditions. Our capacity to see one perceptible whole (the phenomenal appearance of a single being), however, is not given to the senses; it is rather a product of the joint work of faculties that are active in the cognizing agent.

To summarize thus far, in BSM, Leibniz emphasizes the synthetic work of the imagination. If we can compare colors, shapes, and whatever else is apprehended through the senses, then this is on account of the imagination first synthetizing sense-perceptions into unities. Even though the letter does not elaborate on this synthetic work, by further exploring EGDB and certain other early texts on geometry, we can demonstrate that the Leibnizian imagination's synthetic work consists in segmenting the multitude of sense-perceptions into perceptible wholes.

\section{THE LOGIC OF THE IMAGINATION, ITS COGNITIVE CONSTRAINTS}

BSM offers a substantial link to Leibniz's analysis of the work of the imagination in algebra and geometry, as in other early texts dedicated to geometry. It is here that Leibniz claims that the imagination has its own logic, governed by spatiotemporal constraints. ${ }^{15}$ Remarkably, such attention to the imagination is raised in a period following Leibniz's most important discoveries in geometry and mathematics, in-

14 Leibniz to Sophie Charlotte (August - November 1702; in reply to John Toland: A I $21667-$ 76/ LSS 257-277, for commentary, see Oliveri (2016: 240-270)). For a thorough analysis of Leibniz's claim that the senses simply give occasion to knowledge of necessary, general truths, see Bolton (1996; 2011a; and 2017).

15 The topic of a 'logic' of imagination has attracted scholars like Rabouin (2017). 
cluding analysis situs, i.e., the attempt to reduce geometry to a calculus of situations, ${ }^{16}$ as well as his infinitesimal calculus, in which the infinitesimal is presented as a fiction. ${ }^{17}$ To be more specific, Leibniz defines the work of categorization in the natural sciences as a mathesis generalis or a "mixed mathematics", which expresses his idea that the mechanisms governing the imagination in fields like geometry and algebra is a model for understanding how the imagination underpins and "prepares" expressions of the natural world through concepts. The mathematical imagination uses mechanisms according to which we acquire knowledge, and which we likewise spontaneously deploy in the apprehension of the external world as presented in sense-perception. Therefore, the work of these mechanisms is more evident and explicit when the human mind deals with objects of pure mathematics, which is why analyzing how the imagination works in mathematics allows us to abstract models for a mathesis generalis (A VI 4 A 513; Rabouin 2017).

The texts we are about to consider sees the emergence of an imaginative faculty that is not anarchic for Leibniz. By 'anarchic', I mean that it is not a faculty devoted simply to fictions or to the reproduction of what is not present to the senses. ${ }^{18}$ The imagination is first and foremost responsible for tracking regularities and similarities in perceptual presentations, and for expressing those regularities through an ideal order. Hence, it does not operate independently from various principles of order that are, for Leibniz, innate, as he writes to Locke years later in NE:

These ideas which are said to come from more than one sense - such as those of space, figure, motion, res - come rather from the common sense, that is, from the mind itself; for they are ideas of the pure understanding (though ones which relate to the external world and which the senses make us perceive), and so they admit of definitions and of demonstrations. (NE 128/A VI 6 128)

Space, figure, motion, and rest are notions belonging to common sense, and come together to form what Leibniz calls the "logic of imagination". The topic of a "logic of imagination" emerges very early on in Leibniz's logical investigations. In the paper "Elementa Nova Matheos Universalis" (Summer 1683?, written less than a year before MKTI), Leibniz defines "mathesis universalis" as a science whose task

16 According to the most extensive contribution on this topic (De Risi 2007), Leibniz's definitions of space and time as ordering relations appears in 1677, the same year as Quid est idea, in which the relation of expression acquires a technical meaning.

17 Leibniz to Antoin Verjus, Hannover 1698, A I 16375.

18 This is also evident in Leibniz's use of the term "fiction". This term is not synonymous with "made up" (as in "fabricated"), which may result from a combination of parts to form notions of nonexistent objects, as in the case of Descartes' fictitious ideas. To the contrary, fiction, for Leibniz, is the act of "fingere", imagining. It is an act performed in compliance with various modes of conceiving. It is true that what we conceive in the act of "fingere" is something that does not actually exist, or that may be impossible. Nonetheless, the fiction may help to clarify a concept or solve a problem. We will return to the meaning of fiction later. For now, it is worth noting that Leibniz's theory of imagination allows him to positively assume arguments based on fictional objects or propositions, such as in the case of jurisprudential fictions or mathematics. 
is to provide the tools for an inquiry into those "things" that are properly subject to the imagination. This is what makes it a "logic of imagination" (A VI 4 A 513). ${ }^{19}$ In a contemporaneous paper (A VI 4 A 509: De arte combinatoria usu in scientia generalis), Leibniz defines "mathesis universalis" as a "science of imaginary things", which is distinct from both logic, as a general science, and from metaphysics, considered as "the science of intellectual things". ${ }^{20}$ While in Elementa rationis (1686, A VI 4 A 722) Leibniz warns that the imagination in metaphysics does not proceed as beautifully as when it concerns objects that are subject to it, as in the case of mathematics, a long passage there argues for the possibility of using an algebraic calculus to analyze intellecual notions:

The science of similarities and dissimilarities, and of the combination of formulae and signs, as well as that generally accepted of the equal and unequal, can be taught by demonstrations; and it is spread out to such a point that it not only supports the mathesis, but it rules also the arts subject to the imagination (nor is it sufficiently observed in those either, although the same algebra has derived everything from it), but it also paves the way for the sensory expression of those things that seem to be not subject to the jurisdiction of the imagination, as will be achieved by our science. (Elementa Rationis A VI 4 A 723)

Imagination, and especially the science of similarities and dissimilarities, of equality and inequality "praebeat viam", will provide a way to handle intellectual notions. ${ }^{21}$ In short, even if notions such as substance, unity, being, and so on are not imaginable, their imaginative surrogates - what we have been calling a perceptible whole - put minds on track for conceiving of those notions that are the proper subject-matter of the intellect alone. Imaginative surrogates play the role of necessary intermediaries in the mind's progress towards metaphysical knowledge. They operate through a mechanism that appears, albeit not problematically, to bootstrap the mind from a lower to a higher level of distinct knowledge. How? This mechanism relies on there being distinct notions implicit within the expression of those surrogates, albeit in a "blind" way (we will return to this claim in Chapter VI). For now, let us turn to the text, Elementa Nova Matheos Universalis (1683?), which concerns the "logic of imagination", and analyzes similarities and dissimilarities.

19 On this aspect of the imagination see Pasini (1996: 179); Rebouin (2018: 4751-83) remarks that the notion of a theory of imagination, as a kind of projection of intellectual knowledge in order to make this kind of knowledge visible to the mind by providing material anchoring, can be seen as a homage to Proclus's theory of imagination and his analysis of Euclid's Elements. On the topic of a logic of imagination and its role in mathematics, also see Leduc (2017).

20 On the concept of mathesis universalis in Leibniz, see Rabouin (2009: Chapters 5 and 6).

21 In describing his project of finding a universal characteristic, Leibniz writes that only few have tried to advance in other sciences a language that permits reasoning as if we were using an algebraic calculus, relying on the example given by the imagination in abstract mathematics ("Equidem fuere quanmquam pauci, qui quod princeps in logica fecit Aristoteles, in aliis quoque scientiis ab imaginatione abstractis mathematicorum exemplo tentarent." Elementa rationis A VI 4 A 719). 
According to this text, things are imaginary insofar as they are modes of matter, ${ }^{22}$ which have parts. Owing to this, they are subject to the categories of quantity and quality (A VI 4 A 514). ${ }^{23}$ Leibniz makes explicit that what is purely intelligible, i.e., metaphysical notions of the intellect, is not straightforwardly subject to the imagination, as we have just seen. On the contrary, material bodies are subject to the logic of the imagination. Therefore, geometry is simply a special branch of the mathesis generalis, whose scope is wider than pure geometry since it concerns the apprehension of the naturally-existing world. But why does Leibniz think, in processing perceptual presentations, that human minds appeal to the imagination and to its constraints? There is both a natural and theoretical answer to this question. The natural explanation goes as follows: since minds are embodied, attention and memory, which are necessary for all cognitive processes, are first and foremost controlled by sense-perceptual modifications (more on this in chapter IV). The imagination plays a central role in directing those two faculties in processing perceptual presentations, for it is the only faculty that shares a common subject-matter with the intellect: distinct notions. The theoretical explanation for this is that, through the imagination, we learn to construct relations between exprimens and exprimendum as based on similarity, just as through geometry we learn to conceive of perspectives or of one thing as proportionally related to another. ${ }^{24}$ Let us examine more closely this work of the imagination:

The imagination in general is directed towards two [notions]: quality and quantity or magnitude
and form, according to which things are said to be similar or dissimilar, equal or unequal. It is
also true that the consideration of similarities, and of equalities too, belongs to a general math-
ematization; it follows that special mathematization, such as geometry, always investigates the
similarities of figures. Similar are those things which cannot be distinguished per se one by one
(singulatim); qualities or forms are what distinguish things per se. Similar things are nonethe-
less distinguished in an act of comparison, which consists both in the coperceptibility (coprae-
sentia) of the things to be compared, and in the coperceptibility (copraesentia) of a third thing
with both. (A VI 4 A 513)

According to this passage, the imagination is sensitive to two modes of material being: quality (viz. shape), and quantity (viz. size (magnitudo)). We should bear in mind that these two notions are the same invoked in the letter (BSM, 1702) that the

22 I prefer here to say modes of matter, rather than extension. This is because, as we will see below, the two are different for Leibniz: matter qua existent is always discretely determined to the least of its parts; extension, as a continuum of uniform matter, cannot exist in reality. It is therefore a distinct notion of the imagination. I will discuss this in the next section. For detailed insights into this distinction, see Arthur (2019: Chap. 2).

23 Rabouin (2018) acknowledges that this claim about quality is very significant. It bears witness to Leibniz's project of renewing geometry: it is not simply a science of quantity, but of qualities among situated points, lines, and surfaces. The notions of congruence and of similarity become central to this reformation. On Leibniz's theory of analysis situs, see De Risi (2007).

24 As De Risi (2007) shows, the concepts of space and geometry, understood as the science of the projection of figures, is developed during the Renaissance thanks to the work of authors like Patrizi. However, geometry is, for Renaissance authors, a science of figures in space, whereas for Leibniz it becomes a science of the order of situations. 
imagination uses to organize perceptual presentations. After having delineated that the study (considerationem) of similarities and equalities is proper to both general mathematization and particular mathematics, such as geometry, Leibniz defines as "similar" those things that cannot be distinguished per se when taken one by one (singulatim), but only when they are put in a relation of co-presence with other things. To this end, "compraesentia" simply means that two numerically distinct bodies can be simultaneously perceived by a cognizant agent, owing to which she can also entertain spatiotemporal relations. On this view, two bodies can co-exist (that is, they are simultaneous) as distinct wholes that are related spatially (that is, they are a certain distance from one another). Note that this "compraesentia" corresponds to what Leibniz calls "comperceptibilitas" in other passages, such as in Nova Methodus (A VI I 684). Indeed, it is the reason why he invokes the synthetic work of the imagination in BSM. For, unless the cognizant agent has the ability to detect unities, she will not have the capacity to compare them.

Coperceptibility, then, is the act by which the mind compares bodies. Through comparison, the mind distinguishes bodies through the categories of shape and size. Leibniz's idea seems to be the following: shape per se can distinguish one body from another, as in the case of a sphere and a cube. When one co-perceives a spherical and a cubical body, in coperceiving them, she sees that they are different. In a second moment, the cubical and the spherical body need not be coperceived to be distinguished: they can be distinguished in virtue of shape alone. Let us change scenarios and conceive of two spherical bodies of different sizes. When two objects have the same shape, we can still distinguish them in an act of co-perception, even if we cannot distinguish them when perceived separately. Coperception of similar bodies enables minds to apprehend other bodily determinations, as that they have similar shapes but different sizes, for instance.

In the rest of the paper, Leibniz analyzes cases in which shape and size cannot help in distinguishing between two objects, owing to which we need to appeal to other criteria. One case involves two spheres of the same size: one made of gold, the other of silver. In this case, they differ thanks to some property of matter, for instance, the color of their surfaces. When properties of matter cannot help, such as in the case of two perfectly congruent spheres of gold, an epistemic criterion for discerning both things consists in putting them in a space-time relation, that is, to coperceive them. In this case, things are congruent and can be distinguished "solo numero". Leibniz specifies that the question regarding whether two perfectly identical objects can exist is a question for metaphysics. He seems not to deny that two things can appear perfectly congruent to us, and yet we use situation as a sufficiency criterion for the distinction of phenomena. ${ }^{25}$ The fact that they cannot occupy the 
same space at the same time is a valid epistemic criterion to consider them similar, but nevertheless not identical. ${ }^{26 ; 27 ; 28}$

The way in which Leibniz's examples are organized suggests an attempt to deduce the fundamental relations that permit the tracking of bodies and their alteration. If the similarity of qualities and quantities is the most evident, then, by stripping away differences, the only phenomenological criterion left available is the situation of bodies in two different spatial positions at the same time.

In summary, the text analyzes the way in which things are compared in the imagination. The condition of possibility for the comparison is the human capacity to co-perceive coexistents. The co-perceptibility of things is the act by which the imagination apprehends diverse perceptible wholes simultaneously as occupying different situations in space. This act allows the apprehension of quality and quantity. When there is a perfect congruency between bodies, what remains for their distinction is their relation in space and time. Space-time relations are therefore prior and more fundamental to the apprehension of differences and similarities. For, comparison between bodies rests on the cognizant agent's capacity to apprehend wholes that occupy different positions simultaneously. Therefore, we imagine things of different shapes and sizes as occupying a determinate situation in space, and as occupying different positions in time. We imagine bodies as bearing spacetime relations. ${ }^{29}$ These modes of conceiving bodies structure the work of the imagination in the act of perceiving things simultaneously.

26 Leibniz indeed considers the sameness of appearance and the identity principle $(\mathrm{A}=\mathrm{A})$ as two distinct, primitive truths, A VI 3 508: "Primae apud me veritates quae probari non possunt, ut: Ego habeo apparentias tales vel tales. Item: A est A, et definitiones."

27 A VI 4 514: "Numero differunt quae ne quidem comparatione inter se discerni possunt, sed referenda sunt ad externa locum scilicet et tempus, an autem possibile sit dari res solo numero differentes in natura, hoc solo scilicet quod revera non sunt unum, sed plura, non est hujus loci, sed ad Metaphysicam pertinet; nobis sufficit talia reperiri posse, quae imaginatione, sive sensuum apparentia discerni non possint."

28 Congruentia is, for Leibniz, a special case of similarity. Similarity is a spatial and metrical difference known through the coperception of two geometrical figures, as when we compare a larger circle with a smaller one. In case the two circles are perfectly similar, i.e., the same shape and size, they can be taken as two different figures only on account of our coperceiving them as being situated in a different space at the same time (Debuiche, 2013: 17). Congruentia is a decisive relation for constructing Leibniz's analysis situs as an algebraic relation between situated points: points are, in this case, congruent and space is not the container of points, but constitutes the order of all possible situations of points. For more on this, see De Risi (2007). The notion of congruentia is fundamental for arguing that the imagination cannot provide any notion of identity: no matter how similar two things are, all the senses can offer us is a coperception of them at the same time. However, if we can coperceive two congruent bodies, then we take them to be two, and hence distinct, not identical. Only the intellect can provide knowledge of identity as $\mathrm{A}=\mathrm{A}$. In chapter VI we will return on this point. For a discussion of the role of identity in Leibniz's project during these years, see Rabouin (2013).

29 A VI 4 A 893: "Omnis relatio rerum exprimitur quodammodo relatione situs corporum." 
Thus far, we have seen that the imagination is active in the sense-perceptual processing of bodily expressions. Its synthetic work consists both in coherently unifying information provided by each sense, or by the common sense, into one perceptible whole such that it can make possible comparisons between perceptible wholes. This synthetic work is nothing more than giving a position to two bodies apprehended simultaneously, i.e., it simply consists in coperceiving them as next to one another.

Two further points deserve clarification. First, space and time, at this stage, are not concepts of which the subject is aware in dealing with her sense-perceptual environment. Perceptibility and coperceptibility must be available at an early developmental stage when conceptual knowledge has not yet burgeoned. Owing to this, children and animals must be capable of this kind of apprehension. Therefore, Leibniz must intend that space and time, as well as similarity and dissimilarity, function as kinds of constraints upon the spontaneous imagination in acts of early cognition. ${ }^{30}$ Second, the synthetic work of the imagination, as described thus far, is rather thin: a normal sentient subject is never in the presence of any single, perceptible whole, but is instead constantly surrounded by perceptibles. Owing to this, we need to further revise this interpretation, integrating it with what Leibniz says in his other letter: EGDB (October 31, 1705). There, the work of the imagination is presented as a kind of segmentation and simplification of the external world. Integrating these insights into the picture developed thus far will finally allow us to broach the theoretical core of Leibniz's logic of the imagination. On this more refined reading, the imagination is not a reproductive but a productive faculty. To this end, the imagination expresses the overwhelming variety of the externally-perceived world through the simpler medium of what we may call 'mental images'.31

\section{SEGMENTATION AND SIMPLIFICATION}

The Letter on the Element of Geometry of the Duke of Burgundy is the most succinct and explicit of Leibniz's texts to tackle issues regarding (i) the role of imagination in perceiving bodies, and (ii) how clear and distinct notions of shape and size relate to the real world. Daniel Garber (2015: 231-54) sheds light on the core thesis of the text in a paper entitled "Leibniz's transcendental aesthetics". He explains that concrete, real bodies - that is, what exists independently of the expression of the human mind - are non-geometrical and non-mathematical. Nevertheless, their expression in human cognition is geometrically and mathematically construed: what the mind does in perceiving what we are calling "perceptible wholes" is to reduce concrete matter to its expression in a space-time continuum, which is not real but ideal. Continuous space-time magnitudes do not exist "outside the mind"; they are ideal and are used to express contiguous discrete matter because, being continuous and ideal,

30 Various passages of NE argue in this direction, see NE 204/A VI 6204.

31 See also Pasini (1996: 169-78). 
space and time can receive any possible or actual modification of matter, transforming it in modifications of extended homogeneous bodies delimited by points, lines, and surfaces. To put it more crudely, concrete beings do not exist as extended geometrical entities (viz., shapes and sizes, and their modifications through a spacetime continuum). Rather, the mind idealizes and renders geometrical and mathematical concrete beings. More precisely, the imagination is accountable for this cognitive feat. The idea of an idealized or mathematized natural world is the core idea of the letter, EGDB, which we shall now probe in greater depth.

The distinction between discrete matter and continuous magnitudes provides the backdrop that enables us to point to a false belief that human agents tend to form, viz. that the concrete world is exactly as we perceive and conceive of it. For, we cannot but conceive of bodies spatiotemporally, that is, as continuous magnitudes, we believe that space and time are something existent outside of the mind, as absolute containers of things. Leibniz argues that this representation is misguided. Space and time are orders of situations deployed by the human mind in order to organize beings' appearances (about which we will say more soon). ${ }^{32}$ To this end, Leibniz proffers the following argument. Space and time are continuous and ideal orders of all possible situations. Space, imagined as geometrical, can receive all kinds of figure and, qua continuum, can be divided ad infinitum. If space were a container of existing things, then matter would likewise be divisible ad infinitum, a condition that would lead to the labyrinth of the continuum. But how can we conceive of unity as an indivisible component of things if space qua continuum implies that anything can be infinitely divided $?^{33}$ The answer: space and time (as abstracts) are not real, but ideal, imaginary orders of expression. We will return to this issue in section $4 .^{34}$

Leibniz's view is that our cognitive apprehension of being rests on a translation of concrete beings into measurable, ideal, and continuous quantities (shapes and sizes as the modifications of ideal space and time). Concrete beings qua concrete, by contrast, are modifications of matter whose nature is discrete, that is to say, they are actually divided and determined to the least of their parts. Beings are not, therefore, in space and time; our human, finite minds adopt notions of idealized quantities and qualities in order to apprehend them. Indeed, their expression through an ideal system is cognitively advantageous. Expression simplifies the determinacy of the concrete world by reducing matter to simple and detectable, (quasi)perfect

32 EGDB in II 4 342-43/LSS 328-29. For discussion, see Arthur (2013).

33 Arthur (2019) heeds Leibniz's reflection on atoms (as evidenced in his early to late writings), arguing that Leibniz's thread out of the continuum is the idea that extension as a continuum does not exist. What does exist is matter divided to infinity. The notion of infinity is syncategorematic because there is no end to it: each part is further divided, and each part is "nested" in other parts while an entelechy diachronically (and not synchronically) provides unity to corporeal substance (a real aggregate).

34 According to Leibniz, "Tempus est Ens imaginarium, quemadmodum, locus, qualitates, aliaque multa." [Time is an imaginary being, such as space, qualities, and many others.] (Definitiones notionum metaphysicarum atque logicarum, A VI 4 A 629). "Locus ordo coexistendi, Tempus ordo mutationum." (A VI 4 A 632). 
geometrical lines, curves, and points. Reducing matter to shape and homogeneous surfaces, which are nothing other than the extremities of perceptible wholes/bodies, enables the mind to coperceive bodies as situated, i.e., bearing relations of similarity and congruency, as well as of distance and magnitude to other coperceived bodies. As Leibniz puts it:

I reply that $[. .$.$] space must be distinguished from matter. Space, or unchanging place, is an$ ideal thing, as is time, and concerns the possible as actual. This is what constitutes Quantum continuum (a magnitude in which there is no separation at all), which is indifferent to all possible divisions, just as number is in relation to all the fractions one can make from it. But matter, which is real, is Quantum discretum (a magnitude already divided), just as a whole number is in relation to unities, from which there results the divisions which can be made in matter by successive operations, being actually already made there from the outset by nature, which has distinguished from all time what will be able to be detached from another, and is different from it, whether one thinks of and notices the separation or not. It is this difference between space and matter which had not been well observed, and which had diverted men from the knowledge of unities, that is, of the true elements and principles of substance. (LSS 342/II 4 364)

What does it mean to say that nature is determined to the least of its parts? What this means is that there are actual divisions in matter everywhere. If we fail to notice them, then this is because our sense-organs are limited and cannot receive modifications in a manner sufficiently-differentiated for the imagination's purposes. For example, I cannot see a bottle of water placed too far away from my eyes, and my eyes do not have the power to detect its discreteness, which is, in this case, too distant to be seen. If we could implement our sight, for example, by using a microscope or telescope, we would realize that nature is determined and organized everywhere to the least of its parts. ${ }^{35}$ As a consequence of the full-determination of nature, bodies (those perceptible wholes that we can detect through the imagination, owing to information provided by the senses) are less determined than that which acts upon the senses. Nonetheless, the simplification the imagination operates, in an act of enclosing those bodies into a shape, constitutes the act by which the mind apprehends bodies as situated in space and time. More precisely, following Leibniz's notion of relational space, bodies are not individuated by their position in absolute space, but by bearing ordered relations to other bodies. It is only when we undergo a segmenting of sense-perceptions into wholes that we can coperceive wholes simultaneously as close to one another. Before this act of segmentation, our sense-perceptions remain at the level of confused sensations: there are colors, tastes,

35 A leitmotif in Leibniz is that, if we had a microscope, then we would see that every part of nature is replete with small animals, i.e., there is organization. In fact, Leibniz invokes this very example in EDGB: "Ainsi dans la matiere et dans les realités le tout est un resultat des parties, mais dans les notions ou dans les possibles le tout entier indeterminé est anterieur aux divisions, comme la notion de l'entier precede celle des fractions pour mieux concevoir les varietés et divisions actuelles et deja determinées, de la matiere. Car qu'on prenne un morceau de pierre, on le trouvera composé de certains grains, et prenant le microscope, on trouve que ces grains sont comme des montagnes, où il y a mille varietés, et si la force de nostre veue estoit tousjours augmentée, elle trouveroit tousjours de quoy s'exercer. Il y a là partout des varietés actuelles, et jamais une parfaite uniformité en tout, ny deux pieces de matiere entièrement semblables l'une à l'autre, dans le grand comme dans le petit." A II 4 342/LSS 327. 
and other secondary qualities, but these are as-yet undetectable by the human mind. We shall elaborate on this shortly.

If this is correct, then the act of apprehending a body in space does not result from a simple act of sensation, but of co-perception: the mind can perceive one body because it "segments" the continuum of perception into wholes that are presented as neben-ein-einder (contiguous). Leibniz calls this expression of concrete beings via continuous magnitude, the "mathematization of the world". As Leibniz writes:

There are actual varieties everywhere and never a perfect uniformity, nor two pieces of matter completely similar to each other, in the great as in the small. Your Electoral Highness knew this well when she told the late Mr. D'Alvensleben in the garden of Herrenhausen to see if he could find two leaves whose resemblance was perfect, and he did not find any. Therefore there are always actual divisions and variations in the masses of existing bodies, however small we go. It is our imperfection and the shortcomings of our senses which make us conceive physical things as mathematical entities, in which there is indeterminacy. (LSS 328/II 4 352; my emphasis)

These so-called "mathematical entities", which bear "indeterminacy", correspond to mathematical essences or species in NE (about which we will elaborate in chapter IX). We take general essences of natural kinds to be fixed and unchangeable because the slightest change in them causes a change in the very essence of the species in question. For example, if I take two leaves to be identical, then I consider the species LEAF and neglect the particular phenomenology characterizing two leaves as distinct particulars. LEAF is a mathematical notion and contains indeterminacy because, as we saw in chapter I, it expresses an essence, and essences qua possibilities are indeterminate. Thus, the essence LEAF is indetermined about being an oak leaf, an apple tree leaf, or a birch leaf. This indeterminacy makes LEAF incapable of existing, for this is only possible for concrete things (which are determined to the least of their parts) (see chapter I).

The point Leibniz is making in this passage, namely by confronting the indeterminacy of LEAF to the full determinacy of any leaf in the Garden of Herrenhausenn (which resulted in Mr. D'Alvensleben's inability to find two identical concrete leaves), is that the apprehension of particulars (as provided by the senses) runs in a different direction with respect to intellectual apprehension through essences. This is because two similar birch leaves, as presented to the senses and imagination, will always appear (provided that they are coperceived) as two distinguished leaves, even if we experience a perfect congruency between them (as Leibniz had argued in Elementa Nova Matheos Universalis). Although sense-perception is directed to what exists and is therefore particular, the very expression of bodies as shapes and sizes in space and time, which allows for the coperception of beings, constitutes a first step towards conceiving of mathematical essences, such as the essence LEAF. This is because mathematical essences are, structurally, a first-level simplification and abstraction from the discrete and complete determinacy of anything existent. This permits the comparison and apprehension of resemblance: birch leaves look similar between themselves, but different in the presence of maple leaves. And yet, we arrive at the unified essence LEAF, as anticipated by our capacity to recognize 
any leaf as a type of body. If we are to fully comprehend the extent to which the individuation of collective bodies constitutes a first step towards essences, then we need to understand in what sense the imagination's segmentary work constitutes a first level of simplification and abstraction from concrete matter.

That concrete beings are discrete and therefore actually divided and determined to the least of their parts amounts to saying that the appearance of an apple-shaped, green body on a homogenous, smooth, wood-colored, rectangular surface (such as this table) is an imaginative expression of concrete matter. The real table may present further divisions that my senses do not have the power to detect, but which would appear to me if I looked through a microscope. Neither the surface, nor the contours of the table, are as smooth and clear as they appear in perception. If, however, they appear in this way to me, then it is both owing to the limitations of the senses and because the imagination segments and translates the imperceptible determinations of matter into an organized and uniform collection of points, lines, and extended surfaces bearing colors and/or other secondary qualities. But how does this segmentary work operate in detail? Moreover, how does a subject see a green apple on a desk, for instance? To answer these questions, we need to understand a passage from clear and confused sensations to clear and distinguished perceptions.

\section{CONFUSED SENSATION AND DISTINGUISHED PERCEPTION}

Before beginning the analysis, let us clarify a terminological point. I will use the term 'sensations' exclusively for simple sense-perceptions of colors, tastes, and whatever else the senses present to us. Under this rubric, clear and distinct sensations of shape and size also count as sensations because, when sense-perceived, they initially present themselves as simple and confused. Sensation is moreover opposed to perception, i.e., the appearance of a whole or body that can be distinguished into parts. Moreover, I have chosen to use the adjective distinguished instead of distinct in conjunction with perception to keep clear and distinguished perceptions separate from clear and distinct thoughts. Leibniz occasionally employs the Latin "distincta perceptio", and sometimes the French, "distinguée" (NE 53). We will soon see that this distinction will turn out to be useful in tracking degrees of perception according to Leibniz.

Besides this terminological choice, the dialectic between various degrees of perception is a decisive aspect of Leibniz's epistemology. Indeed, the soundness of his theory rests on constructing an account of a continuous change with regard to degrees of perception. ${ }^{36}$ Leibniz indeed thinks that sensitive rational and non-rational souls are omniscient insofar as any single change in the outer world bears an

36 Jorgensen (2009) has sparked scholarly attention to the issue of the continuity principle. For Leibniz, Jorgensen contends, any scientific theory must conform to the principle of continuity, the claim that nature does not make any leaps. This means that there cannot be a change that is not the consequence of an infinitesimal one. Jorgensen uses this criticism to show that most of 
influence on a substance's organs. ${ }^{37}$ As a consequence of this plenum thesis, and of Leibnizian harmony, the soul actually expresses single affections through minute perceptual modifications. Because the soul is not capable of expressing any minute change distinguishedly, there must be a gradual change at the perceptual level, and, when the change reaches a certain level of unity or confusedness of minute perceptions, the soul has more conscious sensations. As already argued in the introduction, my aim is to track Leibniz's theory of the phenomenology of cognition apart from his theory of consciousness. It may be that the analysis we offer bears some consequences on the latter debate as well, but that is not my target in this study. So, without entering into the intricate debate regarding Leibniz's theory of consciousness and self-consciousness, the minimum assumption I will make is that a sensation's being conscious means that it can be perceived attentively by the mind. ${ }^{38} \mathrm{We}$ will soon see what this implies.

The sensitive soul is capable of minute perceptions of all changes that occur in the world, but it forms confused sensations of qualities of bodies that impress the senses in the right way (e.g., the body is not too far a distance from the sense organs, it is under the correct lighting or atmospheric conditions, etc.). Only objects that affect the organs in the right way are consciously expressed at a psychic level. This happens through an involuntary and spontaneous unification of the soul's minute perceptual activity. ${ }^{39}$ This unification renders minute perceptions more intense and heightened, and, in so doing, produces a clear and confused sensation: a sensation that stands out and makes itself either "visible", "audible", "testable", "touchable", or "smellable" - in a word, sensible. The external world appears to us qua merely sensible: a multitude of simultaneously co-sensed sensations. Clear sensations of shapes and sizes are, at this stage, sensations of a confused kind because they present themselves as potentially distinct, but not yet as such. In this process, there is a loss of information. Indeed, this is made explicit in Leibniz's example of the color green (NE 53): the green we sense is composed of innumerable, minute yellow and blue parts, and, owing to a paucity of power in sight, a "visible" and homogeneous

the scholarly work on Leibniz's conception of self-consciousness rests on the idea that selfconsciousness is self-reflective and so consists in a kind of higher-order state that violates the aforementioned continuity principle. In recent years, scholars have tried to resist this criticism, for instance, Simmons (2011), who openly affirms that self-reflective consciousness must violate the principle.

37 See, for instance, the letter to Sophie (February 6, 1706) in A I 25 572-77/LSS 344-51.

38 I follow the proposal of Barth (2011), who argues that "s'appercevoir de", at least in the NE, is a non-technical term simply meaning that when the mind apperceives, it notices changes presented via the senses.

39 We can say that the unification of minute perceptions is a consequence of harmony: the complexity and major degree of nestedness of the animals composing the organism is the ground for their functional organization in the body; any change is then nested within other changes, and this "nestedness" is reflected at the psychic level with a first unification of minute perceptions: sensations. On the concept of nestedness, see Nachtomy - Shavit - Smith (2002). On this view, a high degree of nestedness and complexity in the body implies a high degree of clearness and distinctness in the cognition of the soul (Duchesneau 2013). 
green color appears. Thus, a loss of perceptual information is nonetheless a gain in sense-perceptual distinguishedness: without this loss, the mind would not be capable of noticing something distinguished. The physical limits of the sense-organs represent the first constraint on what can become perceivable by the imagination.

Now, Leibniz claims that homogeneous colored surfaces, which also bear other sensible qualities as detectable by other senses, are not the object of the imagination unless they are enclosed and segmented by the imagination into wholes. His idea seems to be that, unless the imagination analyzes the complexity of sensations into unities, the mind is not capable of coperceiving what is put before the senses. If the mind cannot coperceive anything, then it cannot apprehend relations, nor can it move forward in the process of knowing. What does it mean, then, to segment?

The way in which I understand segmentation is not completely at odds with the analysis of synthesis, as advanced in BSM. The idea is that, in focusing on one part of the perceptual field, the imagination is spontaneously attracted to what is more affine to its nature, viz. shapes of a certain size. In focusing on shape, the imagination encloses some clear and confused sensations (such as colors) into a shape, and thereto provides unity to the multitude. This unity is nothing more than the emergence of a body from the backdrop of an amalgam of clear and confused, and clear and distinct, sensations. Before the imagination focuses upon something, and segments various sensations into coherent wholes, the mind does not perceive bodies. Indeed, a body simpliciter is not perceivable by the senses alone. If you like, think of your imagination as a camera that is zooming in on diverse parts of the plenum of the scene representing your sense-perceptual environment. In so zooming, certain bodies become sharper than others, rendered more distinct from the confused backdrop. The imagination permits the emergence of what the senses present, and, in so zooming, it encloses a portion of the scene into a shape representing one body and, thereby, it constitutes the body as one: the imagination has an active part insofar as the shape attracts it over other aspects because it is "more affine" to its notions. Moreover, until the imagination zooms in on and segments the scene into unities, whatever sensations there are are available only confusedly to the mind. Only when they are embedded into a whole can the mind move onto a more distinguished perception of whatever is put forth by the senses. Therefore, in zooming in on the green apple on the table, its shape appears before me. It may not be as smooth and linear in reality as it is presented to me, but I nonetheless present it in this way.

Leibniz seems to refrain this idea of "zooming in on", or focusing on, bodies in a short text entitled, "On distinguished (distincta) perception". In clarifying the difference between having a confused sensation, on the one hand, and a distinguished perception, on the other, he draws upon several examples. Among these is that of seeing a human face: we have a distinguished (distincta) perception of the face insofar as we apprehend it as part of a man, i.e., insofar as the face is, for us, part of a larger whole, viz. a human body. Otherwise, when our eyes glimpse a crowd of people, while we see faces, none is apprehended as distinguished from others, or as clearly belonging to one body over another in the amalgam of bodies that compose the crowd: 
We perceive in a distinct way that whose parts or attributes we perceive as pertaining to it, e.g., when a man, of which we perceive the face, shows up, and we simultaneously think the face pertains to this man. Otherwise, when we direct our eyes to a crowd, we perceive men, and the faces of them singularly appear, although confusedly. And when we hear the water flowing from a distance, in fact we hear the crash of multiple waves, thus there is no reason why we hear one rather than the other; and, if there were none [i.e. no waves], surely we would hear none. In any case, this perception is confused. (A VI 4 A 58)

While this text is short, it is nevertheless extremely dense. Here, the contrast between the apprehension of a crowd and its analogy with the apprehension of the sound of waves (one of Leibniz's classical examples of confused sensations (see NE 53)) provides us with a clue regarding the role that segmentation plays. While a confused sensation (like those of waves) presents itself as simple, i.e., not further distinguishable into parts, no matter how much I concentrate on the sound of it, the confused perception of a crowd may become more distinguished. For instance, if I zoomed in on one part of the crowd, then I would be capable of distinguishing whose face belongs to whose body. This imaginative work of segmentation is, therefore, a first step towards a distinguished perception of bodies as wholes, respectively composed of parts, properties, and attributes.

To sum up, both primary and secondary qualities appear to the mind as confused, simple sensations because it is beyond the senses' powers to further distinguish them into parts. However, the loss of information that renders a sensation confused is nonetheless a gain for the imagination insofar as confused sensations of primary and secondary qualities provide the material for the more distinguished perception of beings. Indeed, the imagination segments the amalgam of simple sensations into wholes that express the shape and size of the body. Wholes constitute distinguished perceptions insofar as the imagination can further divide them into parts and attributes, which are considered as parts of the whole. Let us stress that, at the beginning of a cognizant agent's experiential life, segmentation provides clear and confused perceptions of wholes, which are as-yet undistinguished. For instance, a perception of a billiard ball is, at first, like that of a crowd: the mind needs time to analyze it into parts and attributes. In the conclusion of the passage we have just read, after Leibniz makes a contrast between confused sensation and distinct perception, he glosses the role of distinguished perception thus:

A perception is distinguished (distincta) in this way, insofar as we attribute something similar to our substances, we indeed know we are the subject of various attributes, so in a similar way we consider objects as if they were certain substances or things (res). And a distinct perception is that which is done with a judgment without negation or affirmation. A thought is a distinct imagination. (ibid.) ${ }^{40}$

40 For commentary on thought as distinct imagination, see Oliveri 2020. There, I argue that the end of this passage offers a clue for understanding the passage from clear and distinct perception to clear and distinct thought as one of degree. In Chapter V, we will unpack this distinction in greater detail. 
The end of this passage is rather demanding. What Leibniz seems to be arguing is that we apprehend a similarity between our being and perceived beings. In acknowledging a similarity, we confer onto what we perceive a kind of unity. This similarity consists in the property of being a corporeal substance: a bearer of diverse attributes. In this sense, even if the green apple is not a substance as I am, I nevertheless consider the apple as if it were substantial, and, in so doing, I understand that the apple is a bearer of attributes and parts, such as those that I experience in myself.

Thus, a distinct perception seems to have the following three attributes: (i) it is a perception of something composite, viz. a whole; (ii) the subject has an implicit judgment that what is perceived is a whole composed of parts, or attributes that belong to, or constitute, the whole; and (iii) there are some further implicit judgments about the whole, which are implicit insofar as they do not have a propositional form, that is, they do not put forth any kind of assertion or negation requiring assent or denial by the intellect. What Leibniz here calls a "judgment" seems to be a spontaneity on the subject's part, whereby she unavoidably assumes that the outer unities she detects at least share with her the property of being corporeal substances. The end of the above passage may sound obscure for now, but it is very informative for the analysis we are going to lay down in chapter IV. It says that, when I focus on the table and see the green apple in front of me, the green apple is an amalgam of sensations of the clear and confused, and clear and distinguished kind. That is to say, unless I am capable of distinguishing different parts of this whole (the peel from the flesh, the petiole from the core), as well as the various attributes that parts of the whole may have (the different colors and tactile sensations as aspects of the peel, for instance), our perception of the apple remains at the level of confused and clear sensations. This capacity, however, is not knowledge the mind has ready-tohand, nor knowledge that the mind simply abstracts from the perceived being. What one is first able to detect are unities that are themselves clear and confused perceptions. Rendering a whole a distinguished kind of perception requires great efforts of observation, and moreover involves various kinds of assumptions (judgments that fall short of assertions), such as the temporal permanence of the body although it is changing and moving. Among the fundamental assumptions are various substantive aspects of the perceived unity, which are derived through acquaintance with our own selves. ${ }^{41}$ The further stages of distinguishedness nonetheless begin with the capacity to detach a certain shape from a background amalgam of confused sensations.

As we will see in chapters V and VI, perception only becomes distinguished when it is accompanied by an interiorized type, which allows for the perceptual coherence of bodies. A clear and confused perception of some sort of unity becomes

41 In NE 51/A VI 6 51, Leibniz says that we have certain ideas, as of substances, for instance, because we are substances, and because we are innate to ourselves. This expression simply means that we have an acquaintance with our own nature through which we know what does and does not belong to ourselves. This immediate acquaintance to ourselves is a filter through which we analyze the world, as we explain in the last chapter devoted to the question of how innate ideas operate in cognition. 
a perception of a distinguished kind when the subject develops some form of acquaintance with different types of bodies and their mereological relations (viz. whole-part constitution), as well as with the type of movements and alterations they may or may not undergo. These changing aspects of the newly-distinguished perception are based on a first-order coherence, consisting in spatiotemporal constraints, as well as a second-order coherence, which is based on the interactions of various types of phenomena.

If what we have said thus far is correct, then what we have called 'segmentation' is just perception of a clear and confused kind. Although it is only as-yet clear and confused, it constitutes an indispensable first step towards achieving clear and distinguished perceptions. To help the reader keep track of the degrees of perception we have analyzed thus far, we can revise Figure 1 by adding those degrees proffered in EDGB:

\section{DEgREeS OF PERCEPTION}
MKTI (1684)
BSM (1702)
EGDB (1705)

\section{Obscure notions}

\begin{tabular}{cc}
\hline Clear and confused & Clear and confused \\
sensations & sensations
\end{tabular}

Clear and distinguished

sensations of shape and

size

\section{Clear and confused per- Segmentation}

ception of a whole

\begin{tabular}{cc}
\hline Comparison of wholes & $\begin{array}{c}\text { Coperception of } \\
\text { wholes }\end{array}$ \\
\hline Clear and distin- \\
guished perception
\end{tabular}


of whole-part rela-

tions as in space and

time

Clear and distinct

concepts, like the

concept GOLD
Mathematical inde-

terminacy of es-

sences

Now that we laid down the groundwork of the imagination in the chapter to come we will tackle it in more details grappling with problems and issue the theory raises. We begin with a metaphysical interlude dealing with the reality of segmentation. While it is true that there is no one-to-one correspondence between the ideal body and concrete divisions, nonetheless, in EDGB, Leibniz is adamant that our representation of bodies is neither a fiction of the mind, which tracks something nonexistent, nor something ideal. It is not a mere fiction because it is an expression of actual modifications of substantial forces (Garber 2015: 232-36), which are expressed by the mind on a space-time continuum. In explaining why segmentation is not a fiction, the role of space and time for coherence of phenomena emerges.

\section{CONCLUSION}

The imagination has its own subject-matter: continuous magnitude that can be divided and organized in whole-part relations through the apprehension of shapes and size. It is in virtue of its nature that the imagination is spontaneously activated in the process of sense-perceiving bodies and responds to its own logic, which rests on relations of shape and size, and is governed by the spatiotemporal relations of situations. If this is correct, then the contribution of the imagination in sense-perception is to segment the amalgam of confused sensations and, in so doing, to express the discreteness of matter into the continuity of space and time. In segmenting, the imagination simplifies the perceptual surroundings into perceptible wholes, which are spontaneously coperceived and compared so that we may detect commonalities with regard to shape and size. The reason why the imagination is attracted to similarities rather than differences lies in the fact that its natural subjectmatter are elements of geometry and mathematics; objects that appear more distinguished to it when they are compared to other perceptible properties of bodies, such as colors or tastes.

The respective payoffs and pitfalls of the imagination's segmentary work will preoccupy us in the next chapter. For now, though, let us stress that, in the light of the conducted analysis, we can understand why the imagination must perform this synthetic work. The imagination is the faculty of continuous magnitudes of two kinds: the continuum of space, and the continuum of time, which can receive any possible determination. Space and time qua infinite magnitudes are not objects of 
the imagination, but of the pure understanding; only their positive and limited determination can be the subject-matter of the imagination. Indeed, shapes and sizes, as bearers of similarity and equality, are apprehended imaginatively. Our senses are constantly affected by sensorial impressions of secondary and primary qualities (viz. shape and size). The imagination produces a first-order simplification by segmenting the actual divisions of concrete beings in compliance with the degree of distinguishedness that can be detected through our limited senses. This work of segmentation, which amounts to tracing the boundaries of concrete beings and their parts, constitutes a primary and necessary step towards the mathematization of reality, for it translates discreteness on an ideal space and time continuum, thereby preparing the application of mathematics and geometry onto nature. This application is very poor at the beginning, for it consists simply in the capacity to detect discrete wholes, which appear to us as being of a determinate shape and size. 


\section{INTERLUDE: IMAGINATION AND REALITY}

The concrete determinacy of existing beings eludes the eyes of the mind which see existing beings as shapes delimited by homogeneous surfaces, lines, and points, bearing secondary qualities. We called the appearance of a shape bearing qualities a perceptible whole and argued that it is an expression of the imagination that synthesizes the multitude of what is sensible - - clear and confused, and clear and distinct notions - - into perceptible wholes: unities despite the multitude of their parts. This synthetic work must not be understood as a collection of parts into a whole, but rather as a segmentation of whole-parts units which is necessary for apprehending concrete modifications. Despite I will focus on shape, perceptible wholes may be also non-spatial. ${ }^{1}$ The relevance of this operation is that the capacity of fixing wholes presents cognitive advantages over other confused sensory qualities because, as I argue in this chapter, wholes express a certain unity of whatever acts upon the body of the cognizant agent: forces underlying bodies. In this way, we will show why what appears to a cognizant agent as a perceptible whole is real, in the sense that something in the world corresponds to the appearance, although it is at the same time imaginary.

To understand the issue at stake, consider that the act of segmenting shapes translates concrete modifications into a format that is accessible to a finite mind. As an expression of the mind, the segmentation work of the imagination simplifies discrete matter through the continuum of space and time. To the mind, bodies appear as continuous parts enclosed by a shape, and henceforth as unities that are contiguous with other bodies. The shapes are not exactly discrete and determined as the things existing "outside" the mind and expressed through its constant activity. We can even say that bodies - -as we see them - - do not exist anywhere but in the mind that expresses them. If this is correct, what is the difference between real and imaginary bodily phenomena? In light of what we have said, all phenomena are to some extent imaginary insofar as their appearances hinge on the work of the imagination. And yet, they are not imaginary in the sense of fictional. I see my dog and play with her; I assume that she exists and that her bodily movements express her excitement when playing with me, that she is healthy, and happy. But I can be far away from home and nevertheless still imagine playing with her. I can evidently tell both situations apart and infer that in the first case the dog is real in the sense that I am expressing actual modifications of my sense-organs accounting for her existence, whilst in the second case the phenomenon is fictional, in the sense that I

1 Let's specify that when I use the term "imaginary" I refer to non-pictorial sensory presentation, like sounds or tastes, as well. An imaginary whole can be a piece of music unified by a certain duration that the mind perceives as one. Duration, however, is something complex that the mind must learn to sense-perceive. 
am reproductively imagining something which does not actually affect my senses. Therefore, when Leibniz asks about the imaginary status of phenomena, he is not asking the question of whether or not phenomena are ideal, that is cognitively dependent on the simplification operated by the imagination. He is asking the question of whether phenomena are fictional, i.e. corresponding to anything existing in the actual world. When phenomena are both ideal and fictional, they are not real. But what are real phenomena?

Real phenomena are ideal expressions of the mind partially grounded in metaphysical facts about bodies and in cognitive facts about the mind. When there is this double ground, I contend, our expressions of perceptible wholes track something real and existent. Coherence, the subject matter of this chapter, provides for the reason as to why expressions of bodies as wholes are neither merely ideal nor fictional, albeit their dependency on the work of the imagination. Phenomena can be said real insofar as they are well-grounded in metaphysical facts about the constitution of bodies. These facts are expressed by minds as a coherence of bodily movements. Coherence is a relational property of our expressions of bodily phenomena and concerns how bodies can move and change through space and over time. ${ }^{2}$

The enquiry begins by introducing a distinction between perceptible wholes and concepts, arguing that the question about the reality of bodily phenomena amounts to the question of what corresponds to what appears as a whole. (sect. 1). Granted that expressions are always ideal and imaginary, we delineate two strategies to argue that they are not fictional. The first strategy is to show that expressing external changes as perceptible wholes varying in the spatio-temporal relation between their parts and properties yield knowledge as result. The second strategy, completing the former, is to show that expressions of bodies as perceptible wholes respond to criteria determining their possible existence that are grounded in metaphysical facts about the constitution of bodies. We will explain the different reasons by which sensations and segmentations of wholes are non-fictional. The chapter concludes with an excursus on how Leibniz modifies his view on bodily composition and coherence over the years: from being a property of the ontological status of bodily composition, he eventually treats coherence as a property of the appearances of bodies to the mind (sect. 5). It is this relation to the minute perceptual activity that correlate coherence to motions and forces, and makes it a property of our expression that tracks what is persistent in bodies: forces. From here it follows

2 As Mugnai (1992) argued, relations are not merely ideal for Leibniz insofar as they are grounded in the ontological constitution of beings, although they do not represent a being, i.e. something existent in the world, and are therefore mind-dependent as well. If the name "tree" for instance refers to a being possibly existing in the world, "being-father-of" is a relation between two beings that supervenes to their existent correlate, which is so because there is a mind perceiving it. Relations are syncategorematic and are expressed in languages through prepositions or other particles (Oliveri, 2014). Leibniz defends the idea of the reality of relations and of phenomena in several texts and especially in NE, where the idea of "phaenomena bene fundata" is decisive to resist Locke's (and any ultra-nominalist) view on the mere arbitrariness and conventionality of categorization. See for instance Mugnai (1976); Oliveri (2016: 2.1. - 2.3.; 2016a; 2016b); Bolton (2017). 
that coherence is grounded both in facts about the constitution of bodies and facts about the constitution of minds (sect. 6). We start with some consideration of the metaphysical ground of, what we call, the segmentation of wholes.

\section{SEGMENTATION, SIMPLIFICATION, AND THE METAPHYSICAL GROUND FOR THEIR REALITY}

The first reason why phenomena are real is that our expressions of them yield knowledge as result. When the mind expresses anything at the ontological level as a body possessing shape and size and which is situated in space and time, the expression is the reason why the cognizant agent's states are more distinguished than simple sensations. Distinguished perception is also the requisite to acquire other forms of distinct knowledge. In compliance with Leibniz's distinction between the sensory apprehension of beings and the conceptual apprehension of essences, distinguishedness concerns bodily appearances as in perception, while distinctness is a property of the conceptual cognition of essences. ${ }^{3}$

Let me devote a few words to the distinction between distinguished perception and distinct thought, which I introduced in chapter II. Textual support for this distinction can be found in, for instance, NE 53, where Leibniz uses the French term "distingué" to refer to sensory qualities that can be recognized (apperceived) by the mind, ${ }^{4}$ while in texts dealing with conceptual knowledge he uses the adjective clear and distinct, a combination which has epistemic significance both for its Cartesian roots and for Leibniz's intent of reforming it - which he explicitly declares in MKTI. Precisely in MKTI, he uses the term distinct notion to refer to knowledge of the conceptual kind: distinctions of conceptual marks represent an essence and are expressed as definitions in propositional form. Even if the distinction between "distinguished" and "distinct" is not altogether common in the literature ${ }^{5}$ I think that it cannot be ignored for it is of significant technical import. As we will see soon, Leibniz claims that there is knowledge of a non-propositional kind, and that, therefore, cannot per se be distinct, not even to a minimum degree, because it does not have the proper form to actually be distinct: it is not conceptual. This difference has to do with the nature of perceptible wholes: perceptible wholes are homogeneous wholes because they are subject to a continuum which is both spatial and temporal.

3 Bolton (2011a and 2011b; 2021) is the scholar who insists the most on making a distinction between sense-perception and thinking within Leibniz's cognitive architectonic.

4 Following Barth (2011a), I understand the term "apperception" to be synonymous with "paying attention to" or "noticing something", and not as "reflection".

5 Simmons (2002) draws this distinction, but explicitly says that it is not a relevant one. Brandom (1981) already argued that to be consistent with Leibniz's degrees of knowledge, one should distinguish between distinct perception and distinct concept or thought. According to his view, this distinction will help in understanding why non-human animals possess knowledge, on Leibniz's account. I am following Brandom's lead here, and have already argued in favour of it in Oliveri (2016). For more on this distinction see also Bolton (2011a) 
Conceptual wholes are homogeneous because they are subject to identity and contradiction, as we will see in chapter VIII. ${ }^{6}$ To be more specific, in Conspectus libelli elementorum physicae (Summer 1678/winter 1678-9?), Leibniz writes:

Extended is what has size (magnitudinem) and situation (situm). Size is also a way to determine every part of the thing or those things with which the thing can be conceived (intelligi). The situation is the way of determining with which further things the thing can be perceived. The size of the thing cognized exactly is the cognition of the number of the parts congruent to the measure. We should treat of numbers both as determined (certis) or defined, as in arithmetic, and as undefined, as in algebra. This latter deals with equality and proportion (ratio). In fact, equal are those things that can be made congruent. Proportion is to equality what number is to unity. The situation of the parts of a thing among themselves is said shape (figura). From here originate similars which cannot be discerned unless we perceive them simultaneously. Homogeneous are those things that can be made similar. Any thing similar and equal is congruent. (A VI 4 C 1987)

The imagination deals first with wholes which have shape and size, i.e. which are extended. Although in the passage size is specified as a distinct quality, something congruent to a measure expressed by numbers, as we saw in the last chapter apprehension of distinct qualities can also be confused: in being presented with two spheres, I see one bigger than the other. Extended means that wholes have parts that are extended, that is are homogeneous, i.e. they can be made similar through constant and continuous transformations. Take, for instance, a circle: infinitely small changes can be made to the circle such that it can eventually be made into a square. This is a proof that the square and the circle belong to the same genus of extension. Conversely, no matter how many changes we make to one hour, an hour can never be transformed into a meter, i.e. spatial and temporal extensions are of a different kind. ${ }^{7}$ Parts are thus always contiguous to other parts that have a situation within the whole.

Massimo Mugnai (2017) has shown that in the years 1686-89, Leibniz was developing a mereological calculus based on the notions of "homogeneity", "parthood", "similarity", and "containment". Leibniz's studies were so advanced that he had developed, what Mugnai calls, following Varzi (2016), a "core mereology." Mugnai further argues that the proper objects of this core mereology seem to be extended things and not concepts, even if Leibniz wanted to extend his mereological

6 In A VI 4 394, Leibniz defines "cogitans" and "intelligens" as follows: "Cogitans (seu agens intra se). Concipiens id est cogitans aliquid. Imo videtur conceptus esse notio formata sponte ita ut ab alio possim discernere. Intelligens id est distincte concipiens, ita ut possim distincte considerare rei notas." Another definition of "body" in A VI 4180 says: "Corpus est substantia in qua partes intelligi possunt."

7 Leibniz uses this example in NE 63/A VI 6 63. We will discuss this extensively in Chapter VIII. As it appears from the example, the work of the imagination is involved in determination of being's genus and species, and is therefore involved in conceptualization as well, but other rules are implied: logical rather than spatio-temporal constraints. 
calculus to a treatment of conceptual containments. ${ }^{8}$ This observation is very interesting for our enquiry, first because it provides further proof that there is a logic of the imagination that deals primarily with extended whole-part unities. This means that there is a difference between how beings are apprehended in sense-perception, i.e. extended shapes with size, and how they are conceived via concepts, even if mereology may be used to understand logical containment: a concept is not a whole with parts, because it is not extended; however, it may be conceived as if it was a whole with parts where the parts are understood as conceptual marks. The concept of parthood in this respect is, nonetheless, different. In the case of concepts, we use the notion of parts in a metaphorical way, as there is some convenience in representing concepts as wholes. ${ }^{9}$

Leibniz's awareness of a distinction between a logic of the imagination and an inferential logic of the intellect further points to different principles that govern them. As Mugnai shows, for instance, the logic of mereology rests on a distinction between sameness as identity and sameness as coincidence (congruency) in opposition to difference. The separation between sameness and identity has a huge impact on the inference allowed by perceptible wholes and concepts. We reserve our effort to appreciate this difference to chapter $\mathrm{V} .{ }^{10}$ For the present chapter, the distinction between wholes and concepts as well as the different logic to which they are subject bears relevance for the notion of coherence.

Coherence is first connected with presentations of whole-part unities in senseperception. Any part that we distinguish in a perceived body is not a conceptual mark that defines its essence: "[...] If those things that inhere to homogeneous things are those things that are contained [in it], we call them parts and the container a whole (totum)" (GP VII, 245); that is, a part is something extended, which occupies a certain situation in the perceptible whole of which it is a part. This kind of knowledge cannot be distinct, but it can be distinguished, insofar as it allows to distinguish parts within a whole that vary with an order determined by spatio-temporal constraints. As a further proof of this distinction, recall Leibniz's motto that "alia est rerum, alia terminorum divisio", ${ }^{11}$ and his comment on Dalgarno's Ars

8 On the development of this logic in light of Leibniz's Analytica Generalissima Humanorum Cognitionum project, see also Rabouin (2013).

9 In Oliveri (2016: 3.2 and 2016b), I argue that metaphors and tropes in general are cognitive tools for Leibniz used by human minds to expand languages from one knowledge domain to another. Linguistic references proceed from the signification of things which are the most concrete and closest to the senses, to the signification of notions of things that are the most abstract and, therefore, non-sensible. If this is correct, the capacity to sense-perceive shapes with parts as whole-part relations is a pre-stage of knowledge that is later used analogically by the mind to express what is not subject to the senses and the imagination: concepts. This is also interesting because in these same years Leibniz was developing a diagrammatic calculus for conceptual containments based on lines.

10 Rabouin (2013) also highlights this distinction and tracks the impact that it has on Leibniz's logical and mathematical project.

11 The motto is part of a manuscript edited by Mugnai (2000) and then discussed by Di Bella (2015). 
Signorum: "one thing is to dissipate parts, another to consider them distinctly" (A VI 3 174-5), the latter act amounting to the apprehension of a being through a concept. ${ }^{12}$ Despite this distinction between spatio-temporal apprehension of beings and non-spatiotemporal apprehension of concepts, the act of distinguishing parts which are coherently arranged according to spatio-temporal laws and to the nature of a body is a decisive step towards the distinct consideration of concepts and is itself a kind of knowledge, as we will see soon.

Bearing the distinction of perceptible vs. conceptual wholes in mind means to be aware that when we ask the question of the reality of phenomena this very question may be interpreted in different ways. One way is to wonder whether our conceptual apparatus track real distinctions in nature, a question we reserve for chapter VIII. Another way is to ask whether there is correspondence between perceptible wholes and bodies existing independently from the mind. We deal now with this latter question and we notice that when declined in these terms, it seems that in light of Leibniz's account there is no correspondence between perceptible wholes and whatever is external to the cognizant mind. Leibniz seems to deny that bodies exist as we sense-perceive them. Whatever exists independently from cognizant agents' expressions is discrete and infinitely divided to the least of its parts, as we saw in the previous chapter. Bodies are like flocks of sheeps, lacking true unity. This chapter argue that even if bodies lack true unity per se, they do not lack unity altogether.

If bodies lacked any form of unity, they could not be expressed by the mind. If we insist hence on the fact that the expression of discrete matter as perceptible wholes is an epistemic achievement of the cognizant mind with respect to giving up determinacy and concreteness, we have a first argument in favour of the reality of phenomena, which reads as follows: phenomena are real because they allow the mind to acquire knowledge of the world that would otherwise remain precluded to finite minds. In simplifying and synthesizing concrete bodies into whole-part relations the cognizant agents acquire distinguished knowledge: the limitations of the senses make perceptible or noticeable minute changes that would otherwise remain unnoticeable to the mind if they were not united and synthesized in the expression of a homogeneous surface, a line, or a certain auditory frequency. ${ }^{13}$ As a result, real changes are far more complex at the material level, but we perceive them as simple and uniform. ${ }^{14}$ The uniformity of sensible qualities makes them both perceivable to the imagination and homogeneous to their subject matter - continuous magnitudes - and therefore noticeable for memory and attention. Only that which possesses limits, but which is complex can be perceived or imagined by the finite human mind

12 For an introduction to Dalgarno and Leibniz, see Maat (2005). For a discussion of the passage, see Oliveri $(2016,190-92)$.

13 For an extensive phenomenological analysis of auditory perception in Leibniz, see Sieroka (2015).

14 Leibniz argues in favour of the complexity of simple notions of the senses against Locke in NE: what appears simple to us may be complex in itself, see NE 120/A VI 6 120. Already Pasini (1996: 162-179) points to this power of the imagination. 
(with the infinite being an object of the understanding) ${ }^{15}$ if matter is actually infinitely divided, as Leibniz argues, ${ }^{16}$ then only the reduction of actually infinitely divided matter into, what appears to be, a finitely divided whole can turn discrete matter into an intentional object of the finite mind. In sense-perceiving a whole with parts, like the appearance of a billiard ball, the mind has already carried out a decisive cognitive performance. The simple act of isolating the ball from the rest of the perceptual environment and tracking its motion or change of colour with light variations is a very complex cognitive act that requires considerable experience to be performed.

By expressing bodies as perceptible wholes, moreover, cognizant agents move toward distinct knowledge because of the segmentation work of the imagination. By taking the perceptible surfaces and lines as the extremities of shapes, this effort simplifies the complexity of the world and allows for comparing wholes and recognizing similarities among them. This comparative process will eventually result into interiorizations of types. Types are interiorized rules and the capacity of the mind to track the common nature of different phenomena. In a nutshell, when the mind interiorizes a type based on the similarity of bodies, the mind considers a particular apprehension of a body, for instance the billiard ball in front of me, as a round-type of body and - in virtue of this association - expects certain behaviours from that body; for instance, the tendency of a ball to roll rather than to stay in place when left on an inclined surface. We will extensively show how we interiorize types, what they are and how fine-grained they can be in chapters IV and V, but from what we have said up until now it is clear that the detection of bodies as shape is the beginning of the story of how types are interiorized.

The second reason why phenomena are real is that the mind cannot make any arbitrary and imaginary distinctions in nature, or, put otherwise, that any division made by the mind is made by nature as well (NE 309). Any division that the mind can make in nature is the result of a change in matter that bears an influence on human beings' sense organs. As the mind mirrors the body, only a change on the bodily side can provide the reason for a distinction on the cognitive side. Because any change is grounded in forces at the metaphysical level, any cognitive change bears a relation of expression with the formal causes of those changes. It is this relation, as I will argue, that allows Leibniz to attribute a certain degree of reality to secondary qualities and to avoid the consequence that phenomena as we perceive them are misrepresentations of some real modifications. To argue for this point, we turn our attention to NE.

15 Bolton (2006) argues for the impossibility of perceiving that which does not have parts. On the infinite, see also Rabouin (2018).

16 Arthur (2018) extensively reconstructs Leibniz's rejection of the notion that the continuum exists as the sum of parts, for small they may be. There is no minimum and maximum in material composition. Matter is actually infinitely divisible, in the syncategorematic sense of infinite. 


\section{SENSATIONS AS EXPRESSIONS}

In his Essay, Locke objects that God could indifferently establish a connection between our sensation of, say, pain, and both the motion of particles in a piece of steel and in our flesh. In other words, our sensations have no resemblance with exterior changes in the object or in the subject's senses, lacking so a unique ground. Leibniz, after summarizing Locke's position, rejects this conclusion. He writes in NE:

PHI L. $\S 13$. Now, when certain particles strike our organs in various ways, they cause in us certain sensations of colours or of tastes, or of other secondary qualities which have the power to produce those sensations. 'It being no more impossible, to conceive, that God should annex such ideas [as that of heat] to such motions, with which they have no similitude; than that he should annex the idea of pain to the motion of a piece of steel dividing our flesh, with which that idea hath no resemblance.'

THEO. It must not be thought that ideas such as those of colour and pain are arbitrary and that between them and their causes there is no relation or natural connection: it is not God's way to act in such an unruly and unreasoned fashion. I would say, rather, that there is a resemblance of a kind - not a perfect one which holds all the way through, but a resemblance in which one thing expresses another through some orderly relationship between them. Thus an ellipse, and even a parabola or hyperbola, has some resemblance to the circle of which it is a projection on a plane, since there is a certain precise and natural relationship between what is projected and the projection which is made from it, with each point on the one corresponding through a certain relation with a point on the other. This is something which the Cartesians have overlooked; and on this occasion, sir, you have deferred to them more than is your wont and more than you had grounds for doing. (NE 131/A VI 6 131)

A hyperbola and a circle differ, and yet, as we know, one can express the other through a ruled relationship. Likewise, secondary qualities are not arbitrary; they are not misrepresentations of some "real" bodily modifications as there is a constant and ruled relationship between secondary qualities as minds perceive them and their correlated causes, namely, motions as expression of forces. Despite sensations are not arbitrary, we need to keep in mind that we can use them simply in the way that "a blind person uses a stick" (to Sophie Charlotte (June 1702) A I 21 337), that is acknowledging that they have a ground in the object won't change their being a confused kind of knowledge. Secondary qualities do not provide us with access to what is stable and constant about bodies. They are, nevertheless, inherently connected with bodies such that they can be starting points for reaching a more stable kind of knowledge.

A few pages later in NE, Leibniz argues that since a warm object appears cold when one's hands are cold, so even primary qualities can be subject to deception, as when a sphere is touched in a certain way it appears double. This "shows [...] that warmth is not a sensible quality (i.e. a power of being sensorily detected) of an entirely absolute kind, but rather depends upon the associated organs; for a movement in the hand itself can combine with that of warmth, altering its appearance" (NE 133/A VI 6 133). And he concludes:

So, from the fact that something does not always appear the same, it does not follow that it is not a quality of the object, or that its image does not resemble it. As for warmth: when our hand is very warm, the lesser warmth of the water does not make itself felt, and serves rather to 
moderate the warmth of the hand, so that the water appears to us to be cold; [...] So there is a sense in which the warmth can be said to inhere in the water in a bath, even if the water appears cold to someone; just as we describe honey in absolute terms as sweet, and silver as white, even though to certain invalids one appears sour and the other yellow; for things are named according to what is most usual. None of this alters the fact that when the organ and the intervening medium are properly constituted, the internal bodily motions and the ideas which represent them to the soul resemble the motions of the object which cause the colour, the warmth, the pain etc.; or - what is here the same thing - they express the object through some rather precise relationship; though this relation does not appear distinctly to us, because we cannot disentangle this multitude of minute impressions, whether in our soul or in our body or in what lies outside us. (NE 1323/A VI 6 132-3, my emphasis)

The expression-relation between changes in discrete matter and our representation of bodies has metaphysical significance. Since the mind needs to experience a certain similarity among distinguished phenomena more than once in order to notice them - or at least this is how Leibniz argues for a distinction between obscure and clear and confused knowledge in MKTI - , if the mind notices a modification and classifies it as a type of modification, this is because there are forces to which material effects in the body and cognitive effects in the mind correspond. Since sensations consist of changes in minute perceptions that do express external changes through their interaction with the organs of the body attached to a soul (more on this in chapter IV), the water may feel cold despite its being warm because the state expresses also the interaction with the organs. Despite this instability of sense-perceptions, they do track something in the body. If a cognizant subject recognizes a sensation as a type (warm rather than cold), there must be a certain type of power or formal cause active in nature, which bears some similarity to other formal causes that produced similar effects in the past. In this sense, we can say that the water is warm even if through a certain period it feels cold to someone whose sense-organs have underlying conditions that are reflected in the activity of minute perceptions. That is also why a cognizant agent whose sense-organs have been damaged will not have the same kind of sensations as a subject whose organs are well functioning. ${ }^{17}$ Leibniz makes his point clearer in another passage, where he says that a formal cause must corresponds to our sensations:

However, no matter what rules men make to govern how things are to be named and what entitlements go with names, provided that the system of rules is orderly (i.e. interconnected and intelligible) it will be founded in reality, and men will be able to imagine (figurer) only such species as have already been made or distinguished by nature - nature which even encompasses possibilities. As for what is inner: although every outer appearance is grounded in the inner constitution, it can nevertheless happen that two different constitutions result in the same

17 A VI 6 132/NE 132: "La lumiere encor ne paroist point à des yeux mal constitués, et quand ils sont remplis eux mêmes d'une grande lumiere, une moindre ne leur est point sensible." A VI 6 137/NE 137: "Effectivement ce seroit quelque chose de fort curieux et même d'instructif de bien examiner les idées d'un aveugle né et d'entendre les descriptions qu'il fait des figures." This means that a person who is born deaf and dumb, and who is therefore incapable of speaking, cannot develop the language required for forming abstract notions (i.e. notions without shapes). And yet she would be probably capable of forming analogies, as we do between Latin and Chinese characters. 
appearance; yet there will be something in common, and that is what philosophers call the 'immediate formal cause'. But even if that were not so, e.g. if M. Mariotte were right (I think he is wrong) in saying that the blue of a rainbow has an entirely different cause from the blue of a turquoise, with no common formal cause; and even if we agreed that some of the apparent natures which lead us to name things had nothing in common internally; our definitions would nevertheless be grounded in real species, for phenomena themselves are realities. It can be said, then, that whatever we truthfully distinguish or compare is also distinguished or made alike by nature, although nature has distinctions and comparisons which are unknown to us and which may be better than ours. (NE 309/ A VI 6 309, my emphasis)

Leibniz's heavily loaded metaphysical assumption here is the last piece of his theory that he utilizes to warrant the reality of phenomena: layers of similarities among (i) forces or formal causes that are inferred from (ii) similarities among phenomena experienced both by (iiia) a single perceiver, $x$, and (iiib) any other perceiver, $y$, who is acknowledged by the perceiver $\mathrm{x}$ as being similar to herself guarantee the reality of the phenomena. ${ }^{18}$ The similarity between $\mathrm{x}$ and $\mathrm{y}$ allows one to infer that similar causes affecting $\mathrm{x}$ and $\mathrm{y}$ 's bodies will correspond to similar cognitive effects both in the $\mathrm{x}$ and y's minds (unless one of the perceiver's organs is malfunctioning), such that from observing the causes affecting $\mathrm{y}, \mathrm{x}$ has reasons to infer what $\mathrm{y}$ 's cognitive states are about, at least at the moment in which y's body is affected by the cause. ${ }^{19}$ Through $\mathrm{x}$ 's reflection upon her own nature, $\mathrm{x}$ can infer what other embodied perceivers can or cannot do. If the causes affecting y are signs of a language - which, recall, are also bodies apprehended by the imagination - , then we begin to get a glimpse of the importance of these layers of similarities and this intricately baroque mirroring game, to which we now turn our attention. The first thing to notice is that it corresponds to an analysis of what Leibniz calls reality defined as the harmony among a perceiver's own states and those of other perceivers. ${ }^{20}$ We will now proceed to explain the first part of this claim, aware that explaining the mechanisms by which cognizant agents process minute perceptions and so express changes in discrete matter is the key to understand how there can be harmony among different perceivers' perceptual states. They express similar changes in similar ways.

18 Acknowledgement is not transitive: that's why a mind - for instance a human mind - can acknowledge a non-human soul, a dog for instance, as similar to itself under some respect i.e., both are capable of sense-perceiving - and yet only the human mind can have reflective knowledge of itself and of the knowledge the animal can have - the human can think, according to Leibniz, that the animal is feeling pain, while the animal feels the pain, but cannot think that "I am feeling pain". Lacking reflection, an animal is not capable of acknowledging the human being as similar under a certain respect. In Oliveri (2016: 1.5.) I argued that this acknowledgement is what constitute Leibnizian conscientia.

19 I argue extensively for this structure in my doctoral thesis, Oliveri (2016: 2.3. and 3.1.); a shorter version of this thesis can be found in Oliveri (2016a and 2016b).

20 Leibniz to Burchard De Volder, 30 June 1704 (A II 4 252/ LDV 306-7). 


\section{SEGMENTATION AS EXPRESSION}

Leibniz has a special attitude towards categories constructed through opposition or as being mutually exclusive, such as arbitrary and natural: ${ }^{21}$ he analyses the reasons for holding either of each category to be true, and then looks for a third way to reconcile what is valuable about each, with the minimum loss of explanatory force possible. He manifests this aptitude - I think - in his definition of reality as harmony among perceivers' states and the role that he attributes to coherence.

We have seen so far that part of Leibniz's explanatory effort with his theory of the imagination is to avoid the following consequence, namely, that if bodies experienced are in fact idealizations of the imagination, that what we believe to be real about them are merely mind-dependent properties of bodies. The first strategy for testing the thesis that the world minds experience is only an ideal construction, and yet that there is no reason to doubt the reality of phenomena can be found through the notion of expression: if sense-perceptions of bodies are expressions of forces, this is because matter is actually infinitely divided. As the world is like a plenum, any actual division of matter bears an influence on neighbouring material divisions and so changes propagate to any discrete part of matter for far it can be. This constant affection of matter on the organic body is reflected in the mind through its minute perceptual activity. Variations of minute perceptions are in harmony with actual affections of divisions in matter on the body. This harmony warrants a ruled and analogical correspondence between what there is at the ontological level and what we experience at the phenomenological level, despite the change in kind between ontological and phenomenological levels. It is exactly this change in kind that by which the ontological level is knowable by a finite mind, insofar as it assimilates it to categories (continuous magnitudes) which the mind can apprehend: if discrete matter divided to infinity cannot be an intentional and conscious object of the finite mind, finite bodies (wholes with parts) as caused by changes in infinite minute perceptions can. If there would have been no change in kind, no transfer of levels, the mind would simply not have known what there is in the actual world.

What does this imply? There are bodies that we see as round. Spotting the roundness of the body functions as an explanation as to why that body can roll. We can use the same example to explain categorical vs. dispositional properties of bodies, the intuition being that we can understand that a round body will roll without assuming metaphysically that the body has the power or disposition to roll; the capacities of a body supervene upon its categorical properties. I think that this view

21 This was already noted in Zimmermann (1834) who argues that Leibniz tried to overcome the distinction between nominalism / realism about essences. The same tendency can be observed when he tries to settle the controversy between arbitrary and natural signs: the names of a language are arbitrary, for there is no necessary relation between a name and a concept; but they are natural insofar as there were reasons to choose one name over others. See Oliveri (2016: 3.2. and 2016b). 
is sympathetic to Leibniz's conception of reasons, according to which the properties that we can identify as properties of a body or of an entity in general can serve as reasons for explaining why the body or the entity can undergo certain changes and states. Properties, however, must be reduced to forces and substances, but without identity: that is the role of expression. ${ }^{22}$ The fact that a body can roll is metaphysically grounded in substances and their forces; the fact that I see the body as round can serve as an explanation of why that body roles; but from my seeing the body as round I cannot infer that the force or the (Leibnizian) substance is round or that a power to roll exists in the body and this is the cause of the rolling. At a more fine-grained metaphysical analysis, bodies cannot be ultimate subject of activities; although properties we can conceive of them can serve as explanations for changes. In this respect, when we observe a change, all we can say is that there is a force correlated to the phenomenological appearance of being round and rolling, and that is so the reason for changes of the body, even if we may have no way of reducing the property of the body to the force:

\begin{abstract}
it must be borne in mind above all that the modifications which can occur to a single subject naturally and without miracles must arise from limitations and variations of a real genus, i.e. of a constant and absolute inherent nature. For that is how philosophers distinguish the modes of an absolute being from that being itself; just as we know that size, shape and motion are obviously limitations and variations of corporeal nature (for it is plain how a limited extension yields shapes, and that changes occurring in it are nothing but motion). Whenever we find some quality in a subject, we ought to believe that if we understood the nature of both the subject and the quality we would conceive how the quality could arise from it. So within the order of nature (miracles apart) it is not at God's arbitrary discretion to attach this or that quality haphazardly to substances. He will never give them any which are not natural to them, that is, which cannot arise from their nature as explicable modifications. (NE 65-6/A VI 6 65-6, my italics)
\end{abstract}

The quality we detect may simply be a gloss that we use as an index for predicting bodily behaviours due to the expression-relation between body and mind, even if the real body can only be said to have that property analogically. The body may be not as round as we conceive of it, since it undergoes constant modifications. Despite those modifications, there is some actions the body produces in its own way, through mechanical interactions, that we express as motion or a change correlated to observable properties.

This distinction within attribution, hence, can help to determine what actually can serve as an explanation for the finite mind, even though the reconduction of that explanation back to its proper metaphysical ground will remain obscure to the finite human mind. As I will argue in chapter VIII, this warrants the autonomy of natural sciences from metaphysics. And yet this is exactly the force of what Leibniz calls expression, as we analysed in chapter I. Expression is the unification and synthesis of information insofar as it is translated and encoded into a format which (1) bears an ontological difference with the thing of which the expression is an expression and (2) makes the information available to a finite mind. Concrete material changes

22 Already De Risi (2007: 329-30) notices that the relation between exprimens and exprimendum is not isomorphic but homomorphic. 
might not be round as we conceive of them, but roundness is a property that allows us to predict some bodily changes (more on this in chapter V).

The analogical correspondence between ontological and phenomenological levels guarantees that the imagination carries out segmentation and synthesis in a way that mirrors real divisions in nature, however undetermined and vague they might be. This theory of natural divisions does not imply that only "one order of nature is possible"; on the contrary. It does not exclude the fact that what we call nature may be divided in a variety of other ways, and which may even be inconsistent with the actual divisions we make because of the limits of our cognitive and sense-perceptual capacities. And yet, our divisions can be said to be arbitrary and natural at the same time. There are two ways, based on what we have said so far, in which this claim can be interpreted.

First of all, divisions are proportional to our body because segmentation depends on spatio-temporal relations; that is, on the proportion of our bodies to other bodies. ${ }^{23}$ If the dimensions of my body's sense organs were to somehow drastically change, as if I suddenly shrank to the size of a bacterium, I wouldn't be able to see a book. A bacterium, as a living organism, perhaps has the capacity to distinguish between different bodies in its environment - even if these are unimaginable to the human mind because of a lack of similar organs between the human body and the bacterium. If the bacterium could categorize and use names for those things, it would have categorized a completely different set of natural entities. Nevertheless, the bacterium's categorization would still be in accordance with natural divisions, even though those divisions are unimaginable to human minds (more on this soon). ${ }^{24}$ Why? Because nature is actually divided to infinity in a way that always expresses forces or substantial forms, as Leibniz says in NE quoted above. To Sophie Leibniz writes the following:

At any rate, I conceive all natural things, even the invisible and those far away, just as one conceives those which are visible and nearby, the difference being only in the degrees of grandeur and perfection. This makes my system very straightforward, since everything is understood in proportion to what we see. (LSS 331/II 4 347)

The second way in which the divisions are not arbitrary is that there may be many criteria available to categorization. I can, for instance, organize my library by sorting my books out in either alphabetic order, by which it is easier to find books, or by colours and shapes, so that they fit nicely into my living room. If I choose one order over another, it is because classifications depend on both pragmatic and contingent reasons (I attribute more importance to the atmosphere they produce in my living room, rather than the easiness alphabetic order provides for finding books).

23 A VI 6 58/NE 58: "Cette connoissance des perceptions insensibles sert aussi à expliquer pourquoy et comment deux ames humaines, ou autrement d'une même espece, ne sortent jamais parfaitement semblables des mains du Createur, et ont toujours chacune son rapport originaire aux points de veuë, qu'elles auront dans l'univers."

24 See Tahko (2012: 405-24) for an echo of these kinds of problems in contemporary metaphysics. 
The fact that I choose one order over another does not rule out the fact that I could have chosen the other, i.e. that nature may be divided in different ways. I cannot choose, however, the fact that I see book-shaped bodies bearing similarities to one another. $^{25}$

Despite the possibility of classifying phenomena in many ways, the divisions actually made by the mind through the imagination are not fictional either. We can certainly imagine divisions which are not actually given in our perceptual environment, and indeed we even have the power to conceive things that we will never experience, like monsters or unicorns. ${ }^{26}$ As a proof of its reliability, though, the imagination spontaneously develops a sense or capacity of drawing a line between real and fictional phenomena. This "capacity" is the result of perceiving a certain phenomena's coherence. Coherence is a feeling of possible existence accompanying the phenomena; it does not concern truth, as we point out in the next section.

\section{COMBINATORIC OF ELEMENTS VS PROPOSITIONAL CONTAINMENT}

Knowledge concerns either what is true or false, or what can or cannot obtain. True or false knowledge concerns propositions which are nothing but the connection of a subject and its predicates, as expressed by a categorical sentence in the form of "a is F". When we say that expression of beings as bodies having a shape with size provides distinguished knowledge about phenomena, we do not intend knowledge of what is true or false. We are claiming rather that they allow the subject to expect states of affairs as likely or unlikely consequences of a cluster of phenomena: to predict their possible existence. Coherence, we argue, is a pre-propositional stage of knowledge, which concern how something may or may not change. Leibniz argues for a pre-propositional stage of knowledge in a passage of NE, specifically at the beginning of book 4, chapter 1, in response to Locke's claim that knowledge consists in the agreement of ideas as given in a proposition:

Knowledge can be taken even more generally, so that it is involved in ideas and terms before we come to propositions and truths. If someone looks attentively at more pictures of plants and animals than another person, and at more diagrams of machines and descriptions and depictions of houses and fortresses, and if he reads more imaginative novels and listens to more strange stories, then he can be said to have more knowledge than the other, even if there is not a word of truth in all that he has seen and heard. That is because the practice he has had in portraying in his mind a great many actual, explicit conceptions and ideas makes him better educated, better trained, and more capable than someone who has seen and read nothing - provided that he takes nothing in these stories and pictures to be true which really is not so, and that these

25 See Mugnai (1976; 1982); Bolton (2017). I myself have argued for how the diversity of categorization does not make it completely arbitrary and conventional in Oliveri (2016: 2.2. and 2016c).

26 And it is exactly this capacity of conceiving possible species that Leibniz considers a resource for doing science. See A VI 6 242/NE 242; more on this in Chapter V. 
impressions do not prevent him in other context from distinguishing the real from the imaginary, the existent from the possible. (NE 355-6/A VI 6 355-6)

A pre-propositional stage of knowledge consists of the imagistic modifications of bodies and their entertained properties whether they be sensory, i.e. when the imaginative act begins with a modification of the sense-organs due to a material change affecting the senses (e.g. we see a fortress, a house, a plant, and so on), or imagery, i.e. when the imaginative act begins in the imagination as an input of nonpictorial vehicles or words (e.g. cases like when we read a novel or when we are asked to mentally picture a scenario). The pre-propositional stage of knowledge is close to the manipulation of images where the images are taken to be images of certain types of bodies. It also possesses a further characteristic: the more one trains the imagination to imagine many bodies and changes simultaneously (at once, to use Leibniz's jargon), the more prompt and prepared the mind will be to picture whether a certain combination of traits or parts is or is not coherent, or, to use another of Leibniz's peculiar philosophical terms, compossible.

Coherence implied in the evaluation of reality concerns the (com)possible existence of a phenomenon in the world of which the epistemic subject is a part. Training the capacity of imagining, as Leibniz claims at the end of the aforementioned passage, provides the mind with knowledge even if that which is imagined is simply fictional; that is, if it refers to facts or entities which do not belong to the actual world. Why? This is because mere training enhances the mind's capacity to understand what is possible and because this capacity rests on a combinatoric of elements or the parts of a whole.

In line with the distinction between propositional and non-propositional kinds of knowledge in NE, in "On the Method of Distinguishing Real from Imaginary Phenomena" (1683), Leibniz distinguishes between two different ways of acknowledging the coherence of phenomena: (i) we form hypotheses about the phenomenon (a propositional understanding of coherence); and/or (ii) we see it as conform to the "customary" nature of a phenomenon:

Let us now see by what criteria we may know which phenomena are real. We may judge this both from phenomena itself and from the phenomena which are antecedent and consequent to it as well. We conclude it from the phenomenon itself if it is vivid, complex, and internally coherent (congruum). It will be vivid if its qualities [...] appear intense enough. It will be complex if these qualities are varied and support us in undertaking many experiments and new observations. [...] A phenomenon will be coherent when it consists of many phenomena, for which a reason can be given either within themselves or by some sufficiently simple hypothesis common to them; next, it is coherent if it conforms to (consuetudinem servat) the customary nature of other phenomena which have repeatedly occurred to us, so that its parts have the same position, order, and outcome in relation to the phenomenon which similar phenomena have had. Otherwise phenomena would be suspect, for if we were to see men moving through the air astride the hippogryph of Ariostus, it would, I believe, make us uncertain whether we were dreaming or awake. (L 363-4/ A VI 4 B 1502; my italics)

Coherence is an intrinsic and extrinsic relational property of phenomena. It can either involve one single phenomenon (as a coherence among its internal parts); or coherence between different concomitant phenomena. In both cases a comparison 
(i) to previous experiences of phenomena that we apprehend as being similar to a present one; (ii) or/and with concomitant co-varying phenomena constitutes our capacity to sense-perceive the phenomenon as coherent. The coherence of a phenomenon with previous or concomitant phenomena may be of two kinds: it can be of a propositional kind, i.e. reasons we detect which serve to devise a hypothesis for why a phenomenon is expected to behave in a certain way; ${ }^{27}$ or it can be of an imagistic form, i.e. it is a "feeling" 28 or a sort of "consuetudo" accompanying the imagistic presentation of the experienced phenomenon. This feeling depends on experiencing the phenomenon in conformity with previously experienced phenomena of the same type and/or to the way the present phenomenon reacts to concomitant phenomena. The mind expects what it considers to be typical behaviour of the phenomenon based on past behaviours of similar phenomena.

The imagistic kind of coherence, Leibniz tells us, consists of apprehending an order between a phenomenon and the position of its parts, as well as of some outcome they can produce. This order is sense-perceived because it concerns extended parts that are actually perceived as though they are in space and time, and that we spontaneously apprehend as similar to those of previously experienced phenomena. To argue for this spontaneous comparison between actual and past phenomena, Leibniz introduces an ambiguous case: suspicious phenomena, i.e. phenomena which do not behave as they would typically and/or as we are used to them. If coherence is a sort of feeling (sentiment), a subject realizes that coherence accompanies any perception when it does not perceive it because the phenomena are incoherent. We are used to seeing men walking on the street and we expect hippogryphs to appear in fairy tales; if I suddenly saw a man riding a hippogryph in the sky, I would infer that something has gone terribly wrong either with me or with the world. Consequently, I would start to look for causes of that phenomenon. To construct an analogy, we can say that coherence is to sense-perceived phenomena what contradiction and identity are to truth.

The pre-propositional form of coherence as described in the aforementioned passage is limited to, what we referred to as, perceptible wholes as shapes with size. The coherence of a phenomenon, in this case the sensory appearance of a body, depends on the organization of its parts as having a position into a whole. Consider a human body: one expects the feet to bear a certain distance from the head and the hands to occupy a certain position between the torso and the head. If one was to

27 In Specimen hypotheseos demonstrativae (A VI 3 3), Leibniz defines a hypothesis as follows: "Hypothesis est causa Phaenomenorum possibilis. Et cum causa sit id quo posito aliud (Effectus scilicet) existit, Hypothesis erit id quo posito phaenomena consequentur."

28 As Simmons (2011) argues, "feeling" or "sentiment" refers to a degree of cognition that involves working memory: feeling is a sensation associated with a previous experience whose memory is spontaneously triggered by sense-perception. A dog that was beaten by its master so Leibniz's example goes - will remember the pain when seeing the stick. Feeling is therefore a certain connection between states. For a definition of "sentiment", see PNGR § 4/L 637 and also Oliveri (2016: 68). 
find the hands having the position of the feet while the body is standing, she would be surprised, and the phenomenon would appear suspicious.

The working hypothesis we will follow is that, to fulfil the task of discriminating between imaginary and real phenomena, coherence must rest on principles that are partially grounded in metaphysical facts about the constitution of bodies and cognitive fact about the mind. While the next two chapters analyze the cognitive ground for coherence, showing it depends on the continuity of space and time, the rest of this chapter argues that coherence can have this function of distinguishing real and imaginary phenomena because it tracks something persisting in bodies, forces expressed in motion.

\section{COHERENCE, MOTION, AND THE METAPHYSICAL CONSTITUTION OF BODIES}

Let us linger on the notion of coherence a bit and retrace its role within Leibniz's theory of bodies. When talking about coherence, scholars commonly stress how it grounds the appearances of bodies, leading them to see coherence as a trait of mental representations of bodies. However, if we trace the evolution of this notion within Leibniz's system, we can also tell a different story. Leibniz first introduces his discourse about coherentia (coherence) in relation to bodies and their composition. In Specimen quaestionum philosophicarum (1666), a very young Leibniz who already thinks that matter is infinitely divided ${ }^{29}$ - distinguishes between efformation and composition. Efformation, he writes, is proper to a body endowed with only one form, while composition concerns bodies that are composed by various kinds of matter. ${ }^{30}$ This distinction seems to reflect what will later become a distinction between true unities and mere aggregates, but even more interesting are Leibniz's further distinctions of the notion of "composition".

There are two ways of composing bodies: either through a conjunction of parts, i.e. when the parts are coherent; or through a commixtion of parts, i.e. when the parts do not cohere. Compositions of the first kind are masses of bodies, like the body of a man. This type of composition is similar to when we drop ink into water: we still see the ink and the water, but we cannot really separate them. This is an example of a coherent composition because our mind can distinguish different parts of what looks like a whole. Conversely, a commixtion is a composition without distinguishable parts. When we mix wine and water, there are parts, but we, observers, cannot notice them. ${ }^{31}$ Both kinds of compositions are confused, but in the latter we cannot identify different parts like in conjunction. This is an important distinction because it maps onto what Leibniz says in the text On Distinct Perception, which we analysed in the previous chapter where simple sensations, like colours, are confused and cannot be further distinguished into parts. Coherence hence seems to be

29 See Arthur (2018: 88).

30 See A VI I 80.

31 See A VI I 81. 
a relational property among the parts of a whole, that is the reason why bodily commixtion cannot be said coherent. The physical mixture of wine and water seems to provide a rudimentary intuition of what would later be transferred into the soul as its internal distinctions: minute perceptions. Minute perceptions are indeed endeavours too minute to be sensed as distinct by a cognizant agent, and nevertheless are they distinguished. Their being confused is not a limit, since they produce great effects when they are compacted and fused together. Besides speculation, we need to fix that only composites of noticeable parts can be coherent.

A few years later, Leibniz revises this distinction and relates the notion of coherence to that of continuity and contiguity arising from the endeavour of indivisible points. Leibniz writes to Oldenburg (28 September 1670):

Without a doubt Aristotle in the most correct way defines contiguous things as those things whose boundaries are at the same time, and continuous those things whose boundaries are one. Those things whose boundaries are one are hence connected or coherent in themselves, as long as the unity of the terms persists. But how can the bounds of two bodies be made one, and how on the contrary can two bodies be made from that indivisible one (the boundaries of things are indeed indivisible), connecting as much as dissolving in things? This depends on the subtle contemplation of the nature of points or indivisibles, from which originates many miracles in natural things. I claim therefore: those things are moved in this way that one endeavours to enter another place (locum), so during the endeavouring those things cohere. The endeavour (conatus) in fact - as Hobbes correctly observes - is the beginning of the motion, or endeavour is with respect to motion, what the point is to the line. If therefore one endeavours to enter into the place of the other, the other (since there is no penetration of dimensions) is expelled by that, it follows that in the first moment of time it already is in the place of the first point, it enters it through the extreme point of entrance; two points or extremities of bodies, expelling and impelling (impellere), penetrates each other (there is penetration of points, not of bodies) and therefore are one. (Leibniz to Oldenburg, 28 September 1670, A II 164 , partially translated in Arthur, 2018: 131, fn. 24) ${ }^{32}$

During these years, coherence is a property of the minute and invisible composition of bodies. Bodies are composed by infinite moving points that interpenetrate because they push and expel each other; this is what produces the unity of the thing as long as the composition of the endeavours persists. Unity rests on the continuity of the points which, in striving and pushing against each other, share their boundaries. Consequently, if a perceiver sees the body as continuous, as Leibniz held in these years, it is because the body is continuous or coherent. The body is the ultimate subject of attribution, since when we say that the body is continuous, continuity is a property of the external body. As he writes in A Demonstration of Incorporeal Substances (A VI 3 78-79):

We experience that we see bodies also at a great distance only if they are big enough and bright enough and illuminated, and there is nothing in between. It is also necessary therefore that their parts, for they might be so small so that we do not see them distinctly, nonetheless act and gather in the vision of the whole, since every body however big (magnum) is an aggregate of parts however small, by which means that if no part acts, we won't see the whole, since nothing

32 I would like to thank Richard Arthur for help in translating this passage. 
however assumed remains nothing. It is also necessary that the parts whenever they push each other cohere.

Indeed, what pushes endeavours (conatur) to enter in another place, per def. What endeavours to enter, begins to change its place, i.e. begins to be in a new place (locum), and ceases to be in the prior [place], i.e. there is a moment in which it is in both places. Ergo their extremities [i.e. of the two points pushing L.O.] are one or are in the same place (eodem loco) since one cannot impel without the other being in the same place, therefore they cohere. Bodies: Agents and patients, cohere or are sympathica. In fact, the bodies of which one acts on the other, of those one impels, since every action of the body is a movement def. 2. So, those that impel, cohere, per prop. 1. (A VI 3 78-79)

If the body is seen as internally coherent and contiguous to other bodies that are internally coherent, this is due to the conatuses of the points endeavouring to enter each other, which thereby produces an actual continuum. The body, though being an aggregate of points, is coherent, which is why we see it as coherent. In another text he writes:

Proposition 14. Any body is a grave distinct from a general mass moved under the parallel and meridian through its proper motion and conatus. It is evident that any body is constituted, defined, one, particular, distinct from the other bodies through a certain motion or particular conatus of its own, since if it lacked [motion or conatus], it would not be a certain separated body, but one continuous coherent with the other [bodies] which moved with it of one sole motion. And this is what elsewhere I said to be cohesion from motion and conatus, for those things that move of one motion, those things are conceived (intelligantur) as internally coherent. Further, any body through its proper motion influence (turbat) the motion of the general mass. (Specimen hypotheseos demonstrative (1672), A VI 3 27-8)

There is something intriguing about these passages. First of all, Leibniz intends for coherence of bodily apprehension that refers to a property of bodies grounded in conatus or motion which makes a body be and, therefore, appear one and distinct from any other bodies. The reason why a body is conceived as distinct is that its parts cohere and that it is detached from a general mass through "one motion". In this way, the body simultaneously acts on the general mass that, while being acted upon, is also contiguously actually divided into other coherent bodies. Notice that even if Leibniz assumes that there is extension and continuity, he already thinks that extension is not the substance postulated by the Cartesians, since it is grounded in aggregates of points that constitute it. However, this is not the notion of coherence that Leibniz adopts later on. As Arthur (2018: 124) notices:

In any case, by 1676, Leibniz had "become a geometer", and had abandoned his earlier theory of continuous bodies being composed of overlapping points. For once he has rejected his previous interpretation of the infinitely small as actual infinitesimal points, this explanation of original cohesion, and with it his theory of neo-Scaligerian mixtion, is in ruins. But he does not for this reason abandon atoms. Indeed, as we have seen, in numerous fragments he gives voice to a theory of spherical atoms whose solidity is now attributed directly to its containing a mind: "the solidity or unity of the body comes from mind" (16 April 1676; A VI 3 509/LLC 117).

According to Arthur, during this period, Leibniz provides a solution to the issue of the labyrinth of the continuum: because the continuum is abstract, bodies cannot exist as actually continuous. Without the pretence of reconstructing all the passages, 
we can say that at some point in 1676 Leibniz changes his mind: bodies are not continua; continuous things are abstract and cannot exist. The years around 1676 are decisive for Leibniz's philosophy of mind and epistemology as well. In these years, he writes several important texts, notably some against Descartes (e.g. De Summa Rerum 1675) and particularly Quid sit idea (1677?), where he turns the notion of expression into a technical term. From here my hypothesis: What if the theory of continuity Leibniz held before 1676 - that is of points as endeavours penetrating each other to produce continuity, coherence, and bodily unity - is transferred from being a physical theory of how bodies are composed materially to a cognitive theory of how minute perceptions compose in sensations and then perceptions of wholes? What if this kind of composition is assumed as the ground of expressing appearances of bodies as shapes enclosing homogeneous surfaces having sizes? More precisely, ideal and non-extended points cannot produce concrete existing things, but if they are ideal and immaterial - like minute perceptions - , why can they not explain the way in which the mind changes internally, co-varying with the actually infinite divisions in actually discrete matter established by harmony? After all, these are also the years of Leibniz's Elementa de mente, which was his attempt to write a theory of the mind that is analogous to Hobbes' Elements of Philosophy. And almost fifteen years later, in NE, Leibniz writes to Locke:

In short, insensible perceptions are as important to pneumatology as insensible corpuscles are to natural science, and it is just as unreasonable to reject the one as the other on the pretext that they are beyond the reach of our senses. Nothing takes place suddenly, and it is one of my great and best confirmed maxims that nature never makes leaps. I called this the Law of Continuity when I discussed it formerly in the Nouvelles de la republique des lettres. ${ }^{33}$ There is much work for this law to do in natural science. It implies that any change from small to large, or vice versa, passes through something which is, in respect of degrees as well as of parts, in between; and that no motion ever springs immediately from a state of rest, or passes into one except through a lesser motion; just as one could never traverse a certain line or distance without first traversing a shorter one. [...N] oticeable perceptions arise by degrees from ones which are too minute to be noticed. To think otherwise is to be ignorant of the immeasurable fineness of things, which always and everywhere involves an actual infinity. (NE 56-7/A VI 6 56-7)

A huge implication emerges, which characterizes this change in Leibniz's conception of coherence: bodies cannot be the ultimate subject of attribution. If we see the body as coherent, it is not because matter is coherent and continuous. The appearance of a body as coherent is an expression in minds of the infinite and constant divisions taking place in discrete matter as expressed by minute perceptual changes.

33 Leibniz refers to his "Letter of Mr. Leibniz on a General Principle Useful in Explaining the Laws of Nature..." (see GP III 52/L 351-354) where he writes that: "On le peut enoncer ainsi [the law of continuity L.O.]: Lorsque la difference de deux cas peut estre diminuée au dessous de toute grandeur donnée in datis ou dans ce qui est posé, il faut qu'elle se puisse trouver aussi diminuée au dessous de toute grandeur donnée in quaesitis ou dans ce qui en resulte, ou pour parler plus familierement: Lorsque les cas (ou ce qui est donné) s'approchent continuellement et se perdent enfin l'un dans l'autre, il faut que les suites ou evenemens (ou ce qui est demandé) le fassent aussi. Ce qui depend encor d'un principe plus general, sçavoir: Datis ordinatis etiam quaesita sunt ordinata." 
While constant divisions result from forces acting within matter, unification of minute perceptions results for compositions and strivings that in unifying, make themselves sensible or confusedly present to the cognizant agent. Our incapacity of being aware of all of these divisions because of the finitude of our mind is the source for apprehending changes in a clearer way, since the successive act of the agent is to unify sensations into wholes having shape and size. Shapes express bodies and what persists in them through spatial and temporal variations: forces. In the next chapter, we will enquiry into the cognitive advantage of this simplification in detail. What is relevant for us now is that the ultimate subject of those changes, hence, cannot be only matter; what persists must rather be the force, the unity, or the substance. And yet, that which attributes the changes cannot be an identity: force is not round, does not have speed $x y z$, and does not have a shape. Nor actually is the body as round as we conceive of it, nor accelerated exactly as we measure it. Our expressions of bodies is an approximation or, as we said, an idealization that translates what there is at the ontological level, namely, discrete matter actually divided according to forces inherent in substances, into intentional states that can serve as explanations for the human finite mind. Bodies are hence undetermined or vague ${ }^{34}$ because they are not as determined and divided as they are in their actual changes; and yet our divisions, though neglecting some of those changes, makes them homogeneous and uniform surfaces enclosed by borders that the agent takes as one for advancing in her knowledge, the errors (viz. neglecting changes) be too small to harm the kind of knowledge she can achieve with this idealization. ${ }^{35}$

In what follows, I try to flesh out this idea and provide an answer to the question why Leibniz position cannot be described as idealist about bodies or as merely phenomenalist. ${ }^{36}$ As Arthur shows, bodies are actually infinitely divided (in the syncategorematic sense) and, only after 1676 does Leibniz maintain that they are unified by minds over time. Within this context, a question then arises: bodies are internally divided to infinity and therefore are not true unities. At each moment, the infinite divisions in matter express forces. If bodily changes consist of divisions which express forces, bodies do not persist across moments of change. What then

34 See (Kostinen \& Repo, 2002: 83-99); also Arthur (forthcoming) in private correspondence.

35 Cf. Letter on the Elmenent of Geometry of the Duke of Burgoundy, 1705.

36 Useful for our discussion is Rutherford (2008) who describes four forms of matter realism, claiming that three are hidden forms of matter idealism, while one is not. The three forms of matter idealism are: (1) phenomenalism claims that bodies are nothing over and above their being contents of harmonious perceptions among perceivers; (2) divine phenomenalism holds that bodies are God's perceptions; the third position (3) holds bodies to be aggregates of monads. The only form of matter realism (4) is that which holds that matter is constituted by monads which means that we need to operate a reductionism from an ontological plane to a metaphysical plane in which only monadic changes and states are admitted. Recently, Arthur criticised Rutherford by arguing that matter realism so presented is a hidden form of monadic aggregation (the third types of matter idealism) rather than a genuine account to matter realism in which matter is constituted by monads, which means that matter has its own status and is unified by monads (see Arthur, 2018: Chapter 3). 
makes the body persist? To answer this question, Leibniz changes his view on composition: Discrete divisions in bodies express forces that are inherent to true unities, i.e. substances, which are not homogeneous parts of the bodies; they constitute bodies. ${ }^{37}$ What minds express, so I argue, is not just the force, but the confused union of the forces acting within the constant changes. They do so by expressing shapes that persist through their changes over space and time. So Leibniz writes to Sophie (19 November 1701) that even if it is correct to say that bodies are constituted by true unities, which in turn do not have the same properties as bodies, there is a relation between those unities, the properties of the body, and what we perceive:

Now what has neither parts nor extension also has no shape, but it can have thought and force, or effort, the source of which we also know cannot come from extension or shapes. ${ }^{38}$ Consequently we must look for this source in unities, because there are only unities and multitudes in nature. Or rather there is nothing real bar the unities; for every assemblage is only the mode and appearance of one being, but actually it is as many beings as it contains true unities. And just as in a flock of sheep, the beings are the sheep while the flock itself is only a mode of being, it can be said that in rigor of the truth the body of each sheep and every other body is itself a flock, and that being itself is only found in the perfect unity which is no longer a flock. It can be concluded from this that there are unities everywhere, or rather that everything is unities. And every unity has a mode of life and of perception, and can have only that. But in the regular assemblages of nature, that is, in the organized bodies like those of animals, there are dominant unities whose perceptions represent the whole; and these unities are what are called "souls," or what each person means when he says "I." And just as the body of an animal can be composed of other animals and plants, bodies have their souls or their own unities. It is clear that these animals, these unities, or these primitive forces, are dominant in their little sphere, although they are subjugated in the larger body in which they work together to form the organs, and from which they can be detached, because bodies are in a continual motion and flux. However there are grounds to think that every soul always retains a sphere that is fitting for it. (Leibniz to Sophie, 19 November 1701 LSS 208-9/A I 20 72-4)

Bodies as we see them are composed of other parts, like in a flock. However, bodies are unities that for a limited duration are united by forces that constitute them. While these forces always persist and are indestructible, bodies constantly change and eventually are destroyed. Cognizant agents express the transitory unity in bodies constituted by forces or soul by detecting properties of bodies that are transitory, that is they persist for a certain amount of time and are taken as causative of other properties. A phenomenon like water, for instance, is a bulk of discrete material divisions that is unified by forces that cognizant agents express as a homogeneous transparent fluid liquid. But as soon as we analyze its bodily constitutions from a metaphysical point of view, we must observe that any part of water is composed of yet further bodies. This will lead to an infinite regress unless we assume that there are true unities, which cannot be minimal material parts; they are not homogeneous to bodies and are indeed simple, immaterial, and without parts. Unities or substances, as I understand them, are requisites of bodies in the sense that as soon as we can conceive of something as one, like a human body or a bacterium, or water 
molecules, we have to assume that unity cannot be provided for by matter or changes in matter; matter is like a flock, always discrete and constantly changing, but always organized. Matter always exists together with some form that makes it a particular kind of matter, with its own organization and structures - a mineral, a muscle, a lever cell, a water molecule, an atom of hydrogen - and, in this respect, it cannot be the mere composition of parts distinguished solely with respect to shape, size, and motion. The organization of matter is provided for by the unities, forces, or forms present within it. The more complex a given material organization is, as in, say, organisms, the more a unity is given by a multitude of other unities, accounting for the organization of each part, all of which are unified by a dominant substance; that, as Leibniz says, is subjugated by other unities, which account for its organs. The unification of changes provided for by organs on the mechanical level is reflected in the mind via minute perceptual changes.

So even if these forces unify matter in - for us - mysterious ways, when sensible and rational souls express forces as shapes that persist through changes, they express both the material changes and the forces in the body even if, in rigore metaphysico, we cannot attribute shapes, sizes and motions to anything existing as a true unity simply because a true unity does not have parts and therefore does not have a shape; nor does the body have the ideal properties as we detect them because what there is are the discrete divisions. The fact that we track a ball as round hence can be used as an explanation for us of why the ball roles and we have epistemic reasons grounded in coherence to think that this is sufficient. However, as soon as we ask for metaphysical reasons for why the ball rolls, we need to provide a different explanation. However, roundness remains a valid explanation because of its expressive relation to what we think there is at the metaphysical level. To conclude when tracking the properties of bodies and motion we track the forces acting within material changes. Without this transfer of information because of harmonious correspondences between changes in forces, body-body interactions, and changes in minute perceptions, the external world and other substances will remain precluded to us, since we cannot directly know what is per se active.

From what I said, does it follow that only forces are real in what cognizant agents apprehends as bodies? I do not think so. If forces were not embodied, that is reflected by actual changes in matter, then cognizant agents could not express forces; but what cognizant agents express is matter constituted by substances and their forces. As I clarified, even if there is a gap of attribution such that the way we conceive of phenomena are approximations of actual changes, both in their active and passive constituents, we are not allowed to say that only forces are real. So I agree with Garber that the idea of coherence is a turning point in Leibniz's conception of bodies because it establishes bodily phenomena as "well grounded"; I slightly disagree with him that since they are mind-dependent, only forces are real in bodies:

Leibniz very carefully remarks that if anything is real in body, it is just the force of acting and suffering. If there really are bodies on the other side of our sensations, Leibniz argues, then they must be thus and so. But we can't know for certain that anything is real, as he noted earlier 
in the essay. And if they are not real, then bodies are just the phenomena of minds: real phenomena, coherent phenomena, phenomena that allow for the prediction of the future and the regulation of life. But phenomena nonetheless. (Garber, 2009: 284-5)

Garber calls this kind of phenomenalism extended-mind phenomenalism and it is characterized by a scepticism towards the existence of bodies. As Garber notices it has an epistemic dimension insofar as we cannot know by metaphysical necessity if bodies, as we know them, exist. Garber sees this form of phenomenalism as different from aggregate phenomenalism which is a metaphysical position claiming that bodies we detect as unities actually are composed by corporeal substances. I do not see these two forms as two distinct kinds of phenomenalism, but rather as two complementary stances. ${ }^{39}$ What I have argued for so far is a form of aggregate phenomenalism, since, as I said, what we take to be one body is constantly many. Coherence is the ground of aggregate phenomenalism since "coherent appearance" simply means that, metaphysically speaking, bodies are actually divided down to their smallest parts and constantly change, and therefore the body does not retain all of its parts through momentaneous changes. Therefore bodies are "apparitiones coherentes", coherent appearances.

When cognizant agent, for reasons grounded in the continuity of space and time, as we will see in the next chapters, keeps the borders of the shape constant and persistent through changes, she tracks the changes and recognizes them as changes of the same body and hence of a same substance. The force is the only thing that persists over time because bodies constantly change. Therefore, if we consider matter per se, independently of any substance, the conjunction of parts is what identifies a body as a whole. This criterion cannot suffice to determine the identity of any given body over time, because the body loses and acquires new divisions constantly. Coherence first of bodily motion is the reason why we consider the body as the same. Coherence, even when analyzed in terms of continuity of motion, gives us epistemic certainty but not metaphysical knowledge that extension or continuity exists. Following my line of argumentation this leads, as Garber suggests, to epistemic scepticism about whether bodies as extended homogeneous shapes, exist. If bodies are expressions, well the thing expressed can differ greatly from our expression. Therefore, the fact that there is coherence among our perceived phenomena and the fact that our expressions agree with expressions by other perceivers; as well as the fact that I apply a mathematical calculus to a certain phenomenon and it yields truth, all this is not sufficient to provide a cognizant subject with metaphysical necessity that any of the properties detected exist. But, I contend, this doubt does not concern that (1) something corresponds to bodies; (2) that this must be matter or something changing trough mechanical principles and a principle of activity.

These two points, however, cannot be deduced from observational quality of bodies because we would make a category mistake. Therefore, I think that Garber is right to claim that Leibniz in texts like On the Distinction Between Real and 
Imaginary Phenomena does not provide a metaphysical argument for what corresponds to bodies; what I contest is that we can take those texts as representative of Leibniz's metaphysical positions about bodies. I think we cannot because what he is apt to, as it will result in chapter VIII, is to provide epistemic criteria for the temporal existence of bodies and their states which are not grounded in knowledge of what bodies metaphysically are. He tries to divorce metaphysics and the sciences by distinguishing epistemic criteria for existence of phenomena distinct from metaphysical arguments for their constitutions. Coherence alone is no ground for ruling out the hypothesis that bodies may be merely imaginary like an ordered dream. It does not mean that Leibniz has no absolute resources to argue for the reality of body, but for this he needs to introduce metaphysical reasons, like harmony and the constitution of sentient soul, as we will see in the next chapter; metaphysics is not the main concern of On the Method of Distinguishing Real from Imaginary Phenomena (and is, again, an attempt to criticise Descartes' sixth meditation, where Descartes thinks to be capable of deducing the existence of bodily phenomena from epistemic facts about extension).

So even if our seeing a shape does not allow us to infer that the body exists exactly as we see it - continuous, homogeneous, with smooth surfaces; but the fact that I am not allowed to say that the body exists as I see it does not allow me to infer that nothing exists or that only the force exists. It simply means that matter alone is nothing, a philosophers' fiction, because matter alone, pure extension or pure passivity, could not produce any change. What does not act, does not exist. To act, however, matter needs a principle of action, a formal cause that determines matter to be something definite and what cognizant agents express is this something definite, that is its being attached to a formal cause.

Cognizant agents express the unity of material changes and forces because they express their bodies modified by contiguous bodies. In conclusion, if actual modifications in discrete matter correlated to forces did not act upon the body associated to the soul, cognizant agents could not express anything. The unity bestowed by expression to being is not imaginary; it simply tracks something different respect the constant material divisions; and yet correlated to it: the force or the persistence and change in bodies. That is the reason why coherence does not concern instantaneous change, as we will see; it is an evaluation about the consistency of spatiotemporal change expressed through the law of continuity, as we argue in the next chapters.

I insist that, for Leibniz, expression is a cognitive capacity that allows the mind to acquire knowledge of notions and things that are constitutively beyond our cognitive reach if it otherwise did not express them. The idea of a chiliagon is as out of reach $^{40}$ as the soul or the substance of my husband working next to me. And yet the movements of his body express changes in his soul. I can infer that he wants to eat when he approaches the fridge, or that he is happy when he laughs. I can also infer

40 MKTI A VI 4 590/L 292, where Leibniz says that we cannot know the idea of a chiliagon via intuition; we can only represent it part by part (DSR 5), either through definitions or through images. 
what he thinks through his use of words or even a particular expression of his face. But I cannot infer that the force or the soul laughs, or that it wants to eat. The corporeal substance, the union of the organic body and a soul, wants, thinks, laughs. By the same token, the constancy that we experience in a body, like the fact that my body remains the same size throughout constant changes, is an expression of what forces can do; but I cannot say that the force as such has a size. The perception of one perceptible whole changing through space and time is a confused apprehension of the union between matter and form. True substances and their forces are not of the proper ontological kind to be bearers of those properties, although intentional properties may be reduced to material changes and these further to substances and forces, even if only by an omnipotent mind like God.

In other words, there was a Copernican turn in Leibniz's conception of bodies that compelled him to give up his theory of cohesion and continuity as properties of material bodies. Matter is never one and continuous. The constitution of bodies is grounded in substances and their forces. As a consequence, that which metaphysically exists is not continuous and coherent, but rather discrete matter that is actually infinitely divided and only unified by forces inhering to substances. The body appears continuous and coherent. In detecting a shape, like my husband's face (the homogeneity of his skin, the distance between his eyes, and so on), and in keeping this whole-part relation constant through space and over time, the mind bestows coherence to the phenomenon, which serves as proof of its reality analyzed as existence. Coherence is now a property of the phenomenon as apprehended by the mind, but it has a ground also in what can persist: whatever force acts and produces the appearance of a homogeneous movement of one body independent of other bodies. If motion can be used as proof of coherence, it is because in the plenum of what exists, any change bears an influence on the organic body of the perceiver which is reflected at the level of the soul in the minute perceptual activity internal to the cognizant agent.

[H] [God L.O.] made bodies in advance so that, following their laws and natural tendencies to movement, they will come to do what the soul will ask at the appropriate time; and he also made souls so that, following the natural tendencies of their appetite, they will also always come to the representations of the states of the body. For just as motion leads matter from shape to shape, the appetite leads the soul from image to image. So the soul is made dominant in advance, and is obeyed by bodies inasmuch as its appetite is accompanied by distinct perceptions, which makes it think of suitable means when it wants something; but it is also subjected to the body in advance in as much as has confused perceptions. For our experience is that all things tend to change, the body by the motive force and the soul by the appetite which leads it to distinct or confused perceptions, depending on whether it is more perfect or less perfect. (Leibniz to Sophie Charlotte, 8 May 1704 LSS 316/II 4 236-7)

\section{COHERENCE AND DISTINCT PERCEPTION}

As we saw in discussing On Distinct Perception in the previous chapter, a perception is distinct or distinguished when we can separate parts within the body object 
of the perceiving act, and the perception is accompanied by some judgments without negation or affirmation, that is of the non-propositional kind, in the sense that they are not about the truth of the phenomena. The analysis conducted so far provides textual evidence that the implicit judgment may be the sense of coherence that accompany our experience of bodily phenomena.

For Leibniz aggregates, insofar as they appear to us continuous bodies or wholes composed of parts, are not true substances. They are rather expressions of corporeal substances because we sense-perceive and cognize them as something persistent, as a unity (a substance) made up of a multitude of parts. This attribution is based on the implicit acquaintance of embodied minds to their bodies and the changes that bodies undergo in spite of remaining the same in appearance. Minds therefore assume that in detecting the shape of a thing, that thing is considered a substance - a unity with a multitude of parts that can change and act. With this simplification, the mind does not track the body; rather, it tracks and expresses the constitution or the force that actually divides matter such that what we experience or conceive the body as being capable of doing is an expression of what the force(s) acting in the world can do. Since the infinite is no sums of parts, nor something that the mind can access, we cannot experience forces directly, but God gave us a way to translate them into formats that are accessible to our finite minds: an organic body endowed with senses and an imagination. So Leibniz writes in another relevant text, Distintiones cogitationesque metaphysicae (1677-83?):

The unity of a thing persists as long as it can salva multitudine; this makes possible that we understand (intelliguntur) bodies as bending rather than dividing, as when a shaking chord is considered one, even though any part in it has a particular motion. Those who understand this proposition in a correct way will laugh as vane any question about the seat of the soul (A VI 4 B 1401/LoC 251 translation slightly changed)

My arm can move while my body remains at rest. If I consider the arm to be a moving part of a whole, and therefore bending rather than being divided from the rest of the body, this is due to the coherent way in which whole-parts move and the cohesion among them expresses the force in the mind. Therefore, it makes no sense to think of the soul as something located either in the brain, the heart, or the pineal gland. The unity of a body is the coherent co-moving among its parts.

The boundaries of bodies are therefore both bona fide boundaries and fiat boundaries, to use a contemporary terminology. ${ }^{41}$ Bona fide boundaries are natural demarcations of bodies, like the actual boundaries of the apple sitting on my table. Fiat boundaries are human demarcations that are arbitrary and conventional, like the political borders of a country. Using this distinction, we can say that the distinctions between bodies, my seeing the chord as though it is bending, is both a bona fide and a fiat boundary: it is a bona fide because it is grounded in nature and tracks what persists in bodies; it is a fiat boundary because its contour, its border or demarcation is one that the mind makes and uses for convenience. Because it is not independent from nature, it is both real and ideal. The body as a whole with parts 
becomes the expression of a natural change for the mind, which is grounded in forces and is therefore a division grounded in nature. Even if there is no one-to-one correspondence between the expression and the thing, we have grounds for seeing a chord as one thing, a lion as different from a cat or a table as similar to another one. $^{42}$

However eternal truths based on limited mathematical ideas are still useful to us in practice, in as much as it is acceptable to set aside the inequalities too small to be able to cause significant errors in relation to the proposed purpose; just as an engineer who draws a regular polygon on the ground is not bothered if one side is longer than another by a few inches. (Leibniz to Sophie, 31 October 1705, LSS 338/II 4353 )

The ideal [unities] represent a whole which is not a perfect unity, but which our understanding takes as one thing, even though it is an accumulation of several, in order to have the convenience of reasoning about several things all at once, and that which is common to them and which has a connection not only to nature but also to existence. (Leibniz to Sophie, 31 October 1705, LSS 328/II 4 344, my emphasis)

Coherence is therefore a form of knowledge of the mind that rests on bodily movements and is therefore connected to the apprehension of spatio-temporal changes of the body. And since spatio-temporal changes must be in accordance with the logic of the imagination, as shown in the previous chapter, our apprehension of bodies has one foot in the metaphysical constitution of bodies and one in the cognitive constitution of minds. This ground makes the harmony between world-mind states and mind-mind states less obscure: reality is the harmony among a perceiver's own perceptual states, and other perceivers' perceptual states. Since human minds share a world through their perceptual states and are likely subject to the same cognitive constraints, human minds will cognize the world in accordance with changes that are mediated by the way bodies acts on their own organs. ${ }^{43}$ Therefore, you may represent a chord as moving in an undulatory way if you look at it lengthwise while it is in motion, and I will express it as going up and down if I look at the chord from the front. Nevertheless, we have ways of agreeing that the same chord is moving.

\section{CONCLUSION}

Despite their being ideal, expressions of bodies as shapes with a given size are neither merely ideal, nor fictional. There are two main reasons why they are not so. First, as expressions of the mind, shapes simplify whatever there is at the ontological level in a way that allows the human finite mind to acquire first distinguished, and then distinct knowledge. What we refer to as distinguished knowledge is a pre-

42 A VI 6 325-6/NE 325-26; we will come back to this topic in chap. VI.

43 I first defended this thesis in Oliveri (2016 and 2016c) where I used the expression that minds categorize in "analogically similar ways", meaning that even if categorization may vary from mind to mind due to differences in experiences and their points of view on the actual world, similarities among cognitive mechanisms and the fact that minds share a world guarantees an analogy among states of minds. 
propositional and pre-conceptual type of knowledge. The second reason why expressions of bodies in the mind are not fictional is that they track changes in forces and are, therefore, grounded in nature.

The analysis of expression conducted in chapter I turned out to be decisive for understanding why phenomena are real. Expression is a cognitive performance of the mind that transfers changes from one level (in our case the ontological level of substances and forces in matter) into changes inherent to a vehicle of a kind different from the thing to be expressed (in our case, extended shapes divided into parts). Whatever there is at the immaterial ontological level is not continuous, does not have shape, and does not have sizes, and yet changes in shapes, sizes, and motions can be taken as expressions of something else. Cognized phenomena do not present things as they are, but they are confused expressions of matter and form; discrete changes and forces. We have completed our analysis of coherence, how it changed within Leibniz's theory of bodily composition. From being a property of continuous bodies, coherence become a property of phenomena. The link to this change lied in Leibniz's theory of minute perceptions as expression of the constant affections in the organic body attached to a sentient soul. In the next chapter, we will move from here to explain what it is the cognitive ground for coherence: our innate capacity to spatio-temporal relations. 
Franz Steiner Verlag 


\section{FIRST- AND SECOND-ORDER COHERENCE I: TIME, SPACE, AND TYPES}

It is on account of the coherence of phenomena that cognizant agents are able to distinguish between what is real and imaginary. Coherence is partially grounded in metaphysical facts, and partially in facts regarding how the human mind cognizes phenomena. The foregoing chapter concluded that we need to postulate a form of knowledge that is not based on concepts and definitions, but rather on types. A type is an ability to track phenomenal appearances of bodies - shapes enclosing parts comoving as parts of a whole. Based on the sensory presentations of bodies, types encode rules regarding how phenomena behave.

This chapter and the next seek to explain what types are and how, by inquiring into how spatiotemporal constraints serve to fix typical or habitual ways in which bodies behave when acting upon one another, we interiorize them. Types are interiorized through our experience of bodies and their movements through space and time. The main result of this enquiry will be to prove that the intellect and imagination have their own, different constraints, which govern distinct logics underpinning different forms of inference. A survey of Leibniz's texts will help us to deduce those constraints innate to the imagination, which are different from innate ideas that are proper to the intellect. This enquiry is divided into two moments, which respectively constitute this and the following chapter. The two moments articulate the notion of coherence in first-order coherence, constituted by space, time, and associative causation, and second order coherence, constituted by an apprehension of things' common nature. First-order coherence provides a definition of body as an ability interiorized by cognizant agents to express beings as four-dimensional extended objects: the three dimensions of space and the diachronic dimension of time. Once a cognizant agent apprehends beings as bodies, she can distinguish more specific types within the general type "body". More specific types are acquired abilities of the cognizant agent to express the common nature of phenomena, and they correspond to a first attempt to categorize beings into similarity classes.

Focusing more specifically on the present chapter, this completes the analysis undertaken in chapter III. There, we argued for a metaphysical partial ground of coherence: forces expressed by discrete divisions in matter. These changes are expressed by cognizant agents as perceptible wholes having parts co-varing in an orderly way with the whole. Coherence is a state accompanying sense-perception of wholes that tracks how perceptible wholes move in accordance with both spatiotemporal constraints and then with the internal constitution of the whole and its parts. Coherence is hence a pre-conceptual confused expression of the unity of matter and form and can have various degrees.

To this end, our analysis of types begins with a consideration of the cognitive necessity of a pre-conceptual form of knowledge, necessity derived from the constitution of the cognizant agent as a bundle of cognitive abilities associated to an 
organic body. By focusing on the constitution of the cognizant agent, we will explain why types are necessary: (i) they produce simplicity and control the analysis of ever-incoming sensory information; (ii) they give order to sensory information. This general argument for why cognizant agents need types will provide a thread guiding our analysis insofar as it establishes a link between coherence and the development of cognitive attitudes by the agent - particularly suspicion - in processing sense-perceptual states (sect. 2). In section 3, we shall probe Leibniz's Metaphysical Definitions and Thoughts (1677-1681? in A VI 4 B 1392-1410). This will corroborate the claim that types are interiorized by experiencing changes of bodies that are primarily changes in the bodily states of motion and rest. From this textual survey, we will find that first-order coherence is grounded in the logic of the imagination and involves space, time, and associative causation. It tracks bodily motion through spatiotemporal changes, which is how bodies and their parts consistently co-move through space and over time. The text furthermore highlights the importance of associative causation as a notion of the imagination that is involved in sense-perceiving bodily motion (sect. 4). I argue that space, time, and associative causation are necessary to what Leibniz calls the empirical principle: "what has happened will happen again in the same way" (NE 51). In section 3, I articulate five rules defining the principle and argue that they are necessary to express beings as bodies, but they are insufficient to ground the sense of reality required for distinguishing between real and fictional phenomena; second-order coherence is moreover required. Second order coherence is the subject matter of chapter V.

\section{WHAT ARE TYPES?}

The best way to understand what types are is to understand what function they exercise in cognition. This function is importantly related to the metaphysical constitution of cognizant agents/souls. ${ }^{1}$ Through chapters I-III I have sought to highlight Leibniz's theory of imagination and its relation to sensation and perception. I argued that his view on cognition settles around the time of MKTI and stays unvaried

1 Leibniz's metaphysics is in search of a correspondingly sound and detailed cognitive theory. Yet scholars have overall neglected or underestimated the importance of cognitive and epistemological issues for metaphysics. Bolton (writing about Kant and Leibniz (2021)) notices scholars' general tendency to consider Leibniz's theory of epistemology and cognition as bearing little import with regard to his metaphysics. Meier-Oeser (2019) shows - through a careful and detailed reconstruction of the reception of Leibniz's MKTI and epistemology - that, immediately after Leibniz's death, scholars tended to diminish the importance of Leibniz's epistemology or considered the latter of marginal interest, to be subordinated to more relevant metaphysical questions, a claim that is evidently refuted by the extensive number of papers dedicated to cognitive and epistemic issues in Leibniz's own papers and letters. On my understanding, metaphysical and cognitive issues are intertwined to offer a theory of cognition that is capable of explaining human and non-human agents' complex and sophisticated skills. On this topic, see also Leinkauf ([2002: 125-43] 2012). 
in its core, solely refined by issues raised by other contemporaries, like Locke. In this chapter, I want to complicate my thesis by arguing that the cognitive function attributed to imagination is required also by Leibniz's metaphysics of substances. To this aim, I will survey his most significant text, Monadology, and compare it to Leibniz's confrontation with Toland in 1702. The link to this exchange is relevant because the confrontation with Toland is contemporary to the letter On What is Beyond Senses and Matter (1702) and establishes thus a link between Leibniz's theory of cognition and its late metaphysics. ${ }^{2}$

Leibniz holds the thesis that everything is full of living beings or small animals, that is, organic bodies are endowed with simple substances that are capable of perception and appetite (Monadology $\S \S 66-9$ ). While they are all cognitive insofar as they have perceptive and appetitive powers, simple substances differ from soul-like substances on account of the latter uniquely having the power to manifest heightened and distinguished perceptions. As we saw in Chapters II and III, heightened perceptions correspond to modifications in the sense-organs expressed in a soul's cognitive apparatus through the unification of appetitive and perceptual changes. These result in sensations (Monadology $\S \S 7-17$ ), such as the perception of color, and are transformed by a cognizant agent into more distinguished forms of perception insofar as the agent is capable of distinguishing parts and properties of what they sense-perceive as parts and attributes of one being (see On Distinct Perception). We want to show that this distinction is present also in Monadology.

Leibniz refers to the basic perceptual activity of soul-like substances as "minute perceptions", regularly stressing that those minute perceptions constitute higher degrees of perceptions, i.e., heightened or distinguished perceptions. Moreover, souls can take three different forms: vegetative; sensitive; and rational. Their kind is determined in virtue of their intrinsic properties, which Leibniz frames in terms of changes that depend upon cognitive powers. Heightened perceptions, conscious perceptions, thoughts, and conscious thoughts, insofar as they are modifications of the minute perceptual activity of a soul, depend on the different types of cognitive power possessed by the soul (Monadology $\S \S 18-20$ ). If the soul is capable of selfconscious thought, for instance, then it must be endowed with intellect and rational powers. In Leibniz's terminology, this kind of soul is a "spirit". However, if it does not have self-conscious thought, but has heightened sense-perceptions, then it has sense-perceptual powers and is, therefore, a sensitive soul (Monadology $\S 29$ ). ${ }^{3}$

2 De Risi's work (2007: chapter 3 Phenomenology) masterly argue that there is a tight link between the metaphysics of monads and Leibniz's theory of idealism about bodies in Monadology. Although I agree with De Risi and this general link, and I feel myself in tune also with his almost Kantian approach to cognition, I dissent with him on two points. The first is that the idealization of bodies is peculiar of Monadology. As I have argued so far it was a turn already present at the end of 1670. I also dissent that the idealisation of bodies corresponds to a denial of reality to matter and phenomena.

3 The question of what the conditions are for the emergence of conscious thought has been greatly debated by scholars, although it is now commonly held that, when a sense-perception involves 
On Leibniz's account, different kinds of soul afford cognizant agents' different degrees of perception, and this difference in degree explains - still within the framework of Leibnizian metaphysics - why rational souls are more perfect than their vegetative and sensitive counterparts, but still less perfect than higher spirits, such as angels and God. In short, the degrees in perception of which a soul is capable determines the position that the soul occupies on a spectrum that moreover reflects their degree of knowledge: obscure knowledge lies on one side of the spectrum, while perfect knowledge is on the other. Clear and distinct knowledge lies in the middle, representing what human rational agents can do (MKTI A VI 4 A 589; Monadology $\S \S 20-25)$. If the soul is capable of clear and distinct knowledge, then it means that it has intellectual powers. If it lacks thought but can nonetheless senseperceive, then it bears sensitive apparatus. The more the soul approaches perfect knowledge, the closer it is to God (Monadology $\S 60$ ).

The idea of souls that differ in degrees of perfection is a hallmark of Leibniz's metaphysics, owing to which it is intertwined with issues concerning individuation and a distinction of souls' cognitive powers. More specifically, if this framework requires criteria for the individuation of cognitive powers, then a relation between powers and their manifested effects seems the logical way to structure a rigorous enquiry into souls' kinds. Monadology, Principle of Nature and Grace, as well as other texts from around the same period, sketch an argument from introspection that - although it may sound unconvincing at first - reflects this strategy. ${ }^{4}$ In introspecting about their own mental states, rational agents can experience a great variety of changes. From here, Leibniz argues, rational agents need to assume that similar changes are likely to occur in other, lower substances. Even if we cannot directly experience other substances' internal states, we can nevertheless infer from what other substances do or do not manifest through their states, specifically what kinds of cognitive powers they must possess. If a dog runs in front of its master holding a stick, and the dog was beaten in the past, for instance, one may infer that the dog does this because it is capable of making various natural inferences and expectations, which are not logical. ${ }^{5}$ The dog's running must be related to internally-represented variations of the dog's soul, and because perceptual variations cannot be

memory and attention, it is conscious, while conscious thought moreover requires self-reflection, i.e., consciousness of the first-personal perspective: "I think that". For a summary and overview of this distinction, see Simmons (2011). What remains debatable for many scholars are (i) what sorts of change in minute perceptual activity reflection consists in, and (ii) whether it leads to an inconsistent theory insofar as it is at odds with Leibniz's principle of continuity (Jorgensen 2009).

4 In a Letter to Samuel Gottlieb Treuer (after June 1 $1^{\text {st }}, 1708$ ), Leibniz writes: "Porro omnis substantiae est agere; et quidem intime ex natura sua seu actu interno (quemadmodurn demonstrari potest), et actus rei internus quatenus ad multitudinem refertur, qualis in externis reperitur[,] repraesentationem eorum continet, atque hoc ipsum est quod perceptionem appello, repraesentationem nempe multitudinis in uno seu in Monade. Talem experimur in mente nostra, talem in omnibus aliis Monadibus ponere necesse est, etsi conscientia et ratio non adsint." ( $\mathrm{LBr}$ 939, B1. 3 ed. and trans. In Oliveri (2019)).

5 See GP VI 600. 
caused on account of mechanical changes (Monadology $\S 17$ ): they must instead hinge upon the dog's cognitive powers. Much ink has been spilt by scholars regarding the soundness of the foregoing argument. ${ }^{6}$ What concerns us, however, is a corollary of these claims. If there are a variety of more or less perfect souls, then there are souls that do not manifest any powers; they are in a state of deep sleep, i.e., dormant. This, for instance, characterizes the status of souls after death (Monadology $\S 20)$.

Dormant souls are metaphysically and cognitively interesting. They do not manifest any form of knowledge whatsoever, nor do they have any power besides the capacity for basic perceptions and endeavors. Leibniz nevertheless calls them souls and distinguishes them from simple substances ${ }^{7}$ insofar as souls seem to have the power of awakening from their sleep and ascending to a higher degree of perfection. They are souls that can be transformed into different kinds of souls. ${ }^{8}$ However, if higher degrees of perception result from modifications in the basic activity of souls (endeavors and perceptions), and dormant souls indeed possess this basic capacity, then the explanatory burden regards why dormant souls do not manifest higher cognitive states. Leibniz's answer is that sleeping souls are not capable of higher forms of knowledge because they are constantly stupefied. ${ }^{9}$ Understanding

6 To be more precise, there are two different arguments involved here. One infers the existence of perceptual states in other substances from mental introspection (for discussion, see Bolton (2011b)). The other, which is based on the thought experiment of the mill, claims that mechanical changes cannot bring about perceptual changes. One therefore needs to postulate causal relations that account for perceptual states, which are not mechanical and material. For a reconstruction, see Bobro and Lodge (1998); Lodge (2014).

7 Monadology $\S \S 19-20 \mathrm{GP} / \mathrm{L}$ 644: "19. Si nous voulons appeller Ame tout ce qui a perceptions et appetits dans le sens general que je viens d'expliquer, toutes les substances simples ou Monades creées pourroient être appellées Ames; mais, comme le sentiment est quelque chose de plus qu'une simple perception, je consens, que le nom general de Monades et d'Entelechies suffise aux substances simples, qui n'auront que cela, et qu'on appelle Ames seulement celles, dont la perception est plus distincte et accompagnée de memoire. 20. Car nous experimentons en nous mêmes un Etat, où nous souvenons de rien et n'avons aucune perception distinguée, comme lorsque nous tombons en defaillance, ou quand nous sommes accablés d'un profond sommeil sans aucun songe. Dans cet état l'ame ne differe point sensiblement d'une simple Monade, mais comme cet état n'est point durable, et qu'elle s'en tire, elle est quelque chose de plus."

8 Discourse de Metaphysique A VI 4 1541-2/AG 42: “[...]qu'aucune substance ne sçauroit commencer que par creation, ny perir que par annihilation. Qu'on ne divise pas une substance en deux, ny qu'on ne fait pas de deux une, et qu'ainsi le nombre des substances naturellement n'augmente et ne diminue pas, quoyqu'elles soyent souvent transformées."

9 Monadology $\S 21$ GP VI 610/L 645: "21. Et il ne s'ensuit point, qu'alors la substance simple soit sans aucune perception. Cela ne se peut pas même, par les raisons susdites; car elle ne sauroit perir, elle ne sauroit aussi subsister sans quelque affection, qui n'est autre chose que sa perception: mais quand il y a une grande multitude de petites perceptions, où il $\mathrm{y}$ a rien de distingué, on est étourdi; comme quand on tourne continuellement d'un même sens plusieurs fois de suite, où il vient un vestige qui nous peut faire evanouir et qui ne nous laisse rien distinguer. Et la mort peut donner cet état pour un temps aux animaux." 
what "stupefied" means will give us a grip on the function that types have within Leibniz's theory of cognition.

Being "stupefied" means that sleeping souls are in a constant state of stupor, which is an affection connected to other cognitive attitudes of the soul, like simple attention in non-human animals, and inspection (consideratio) in rational agents. When a cognizant agent perceives something new, or too intently, the result is stupor. The healthy cognitive reaction to stupor is consideratio (inspection, consideration). Inspection is the cognitive attitude with which the mind seeks to normalize, or make sense of, the stupor. If one saw a man riding a hippogryph in the sky, for instance, one would be stupefied, owing to which one would begin to seek a reason for that phenomenon. Inspection is of course essential to scientific discovery because it diverts the mind's attention to the cause of the stupor.

In a text analyzing passions and their cognitive and conative functions in determining human minds to act, ${ }^{10}$ De Affectibus. Ubi de Potentie, Actione, Determinatione, Leibniz defines stupor by quoting Descartes' Article 73 of The Passions of the Soul. On that account, stupor is "an excess of wonder (admiratio)" (A VI 4 B 1411, cf. CSM I 354/AT XI 383). Consideratio is meanwhile defined there as a state combining memory with an attendance to a preceding state of soul. This previous state is recalled in order to be intellectually inspected:

Inspection seems to be any more attentive thought to what must be thought thereafter what is searched. Or inspectioin is an attention of the soul to what must be contemplated. Or it is attention of the soul to what must be discovered and judged. (A VI 4 B 1414)

If the soul cannot exercise its conative/cognitive power, and so move from what causes a change (the passion of stupor) to the activity of inspection, then the soul will be permanently stupefied, as if in a state of sleep or death. As Leibniz writes, "[there] would be no will (voluptas), but stupor [...] if we persisted in the same state, however honorable it may be" (De mundi perfectione continuo augente, 1689-90, A VI 4 B 1642). Having delineated the cognitive/conative function of stupor, we can now attempt to explain why a constant state of stupor characterizes dormant souls.

$[\ldots][\mathrm{A}]$ confused aggregate of many little perceptions, containing nothing elevated that excites attention, induces a stupor. (Dutens 232/RSB § 10)

Since every present state of a simple substance is a natural consequence of its preceding state [...] since we perceive our perceptions when awaking from a stupor, it follows necessarily that we have had these perceptions immediately before, even though we did not then perceive them [...]. From this we can see that if we had nothing distinctive in our perceptions, and nothing lifted out, so to speak, and of a higher flavor, we should always be in a state of stupor. (Monadology $\S 21-24 / \mathrm{L} 645)$

10 For a discussion of affects and actions, see Roinila (2015) and Oliveri (2016: 1.5). Schepers (2014: 170-90) considers the text to be a turning point towards Leibniz's theory of substances and possible worlds. See also Di Bella (2006). 
While stupor is a cognitively-healthy passion of the soul, at least when it is transitory, it constitutes cognitive death when it is constant. Constant stupor bespeaks a paralysis of the soul insofar as it is incapable of moving onto other states in virtue of changes in cognitive/conative attitude. What, then, is required for something to be "distinct and lifted out" and hence accountable for changes in the soul's conative/cognitive condition? The answer of Monadology is a well-formed organic bodies.

Leibniz already provided an answer to this question to John Toland, explaining that, when souls are attached to living organic bodies, which are endowed with functioning sense-organs, the soul awakens from its preceding state of stupor. ${ }^{11} \mathrm{He}$ writes to Toland that he never denied

that we need sense-organs in order to have our thoughts [...] I believe that even the most abstract thoughts are represented by some traces in the brain [...]. The soul can never be without organs more or less expressive, in order to be more or less sensitive according to its different states" (Leibniz to Sophie Charlotte for John Toland, 9 December 1702, LSS 272/A I 21 718).

In describing what the soul's death consists in to Toland, Leibniz associates it with the privation of functioning sense-organs. Organic dysfunction - equivalent to death - causes states comparable to "étourdissement", that is, when a sentient being is affected by prolonged, overwhelming noise:

if the noise were always to continue in our ears, if we were to hear nothing else, and even if the rest of our organs and also our memory were to provide us with nothing more to notice, the noise itself would no longer be noticeable and we would be completely stupefied, even if the confused perception were nonetheless to continue: it is in this way that a person is stunned by a shot from a cannon, dazzled by a bright light, or seized by epileptic convulsions, the violence multiplying too much and confounding the motions of the organs. [...] Now when this confusion of perceptions is universal and of some duration, during which nothing can be distinguished, it passes in common opinion for a complete cessation of functions, and even for an extinction of the animal (Leibniz to Sophie Charlotte for John Toland, 9 December 1702, LSS 273/A I 21 719)

In summary, then, constant stupor constitutes a cognitive death that corresponds with the cessation of normal bodily functions. ${ }^{12}$ It does not, however, correspond

11 Leibniz expresses the same concept in Reflections on the Souls of Beasts (1710, Dutens 232/RSB): "Sed, inquies, corpus organicum posse destrui. Respondeo, etsi destrueretur corpus aptum ad sensionem; non ideo tamen anima destrueretur, maneret enim massa animata \& anima continuaret agere intus \& extra, etsi minus perfectè, seu non cum sensione. Et talem perceptionem in somno profundo, apoplexia, \& aliis casibus retinemus, licet sensus cesset. Sensio enim est perceptio, quae aliquid distincti involvit, \& cum attentione \& memoria conjuncta est. Sed aggregatum confusum multarum perceptionum parvarum nihil eminentis habentium, quod attentionem excitet, stupore inducit."

12 Leibniz to Sophie Charlotte for John Toland, 9 December 1702 A I 21 719/LSS 273: “Ainsi quoyqu'elle se puisse trouver dans un Estat d'assoupissement elle ne laissera même alors d'avoir quelques sentimens, et quelque usage de certains organes, les quels ne recevant pas des impressions assez fortes, ny assés ordonnées, l'ame aura aussi seulement des perceptions ou embrouillées, ou trop petites et presque egales ou balancées entre elles, ou il n'y aura rien qui ait du relief, et qui se distingue assez pour attirer de l'attention, et dont par consequent on se puisse 
with a cessation of minute perceptual activity. Even when stupefied, the soul perceives. This can only mean that the soul has neither knowledge nor any "distinguishing" power when faced with an incessant stream of perceptions. Anything can cause a stupor. Conversely, if the soul is not stupefied, it means that it is capable of some heightened and distinguished perceptions, i.e., ways of filtering and ordering ever-incoming information.

From this analysis of stupor and dormant souls we can conclude that heightened and distinguished perceptions require the presence, on the side of the body, of fullyfledged and functioning sensory apparatus (viz. organs connected by a nervous system to the brain, where they converge). As we will see, however, the mere existence of organs is not enough. Substance also requires fully-fledged cognitive apparatus present on the side of the soul (attention, memory, imagination, and, in human animals, intellect). The cooperation of organic bodies and cognitive apparatuses through harmony affords the mind the capacity to acquire knowledge of actual and possible world(s). Consider this metaphor of Leibniz's:

Mariotte says that the human mind is like a bag: when you are thinking you are shaking the bag until something falls out of it. Hence there is no doubt that the result of thinking depends to some extent on chance. I would add that the human mind is more like a sieve: when you are thinking you are shaking the sieve until some minute things pass it. When they pass, the spying attention (ratio speculatrix) catches whatever it seems relevant. (On the Art of Discovery, A VI 3 N. $49 /$ C 170$)^{13}$

Following the metaphor of the sieve, the state of constant stupor, which typically characterizes dormant souls, corresponds with a lack filtration between minute perceptions and cognitive faculties, such as memory and attention. This absence of filtering causes the mind to attend persistently to changes in the soul. Since these changes are many and varied, without filters the mind is in a constant state of stupor. On the other hand, if the mind thinks, imagines, make-believes, or, in short, exercises its conative and cognitive attitudes, then this is because there is a well-structured sieve, composed of layers, that fine-tunes and orders what can get through its holes, thereby becoming objects of memory and attention. Once something moves into the space of attention, the soul processes it through other filters and ordering principles, as afforded by two further psychic faculties, viz. imagination and intellect.

But how does this metaphorical sieve work? Each faculty provides its own mode of filtration. Correspondingly, well-functioning sense-organs are the barrier of which bodily modifications can catch an agent's attention, as said in Monadology:

But a soul can read within itself only what it represents distinctly; it cannot all at once develop all that is enfolded within it, for this reaches to infinity. Thus, although each created monad

souvenir. Tel est l'estat de l'enfance ou du temps qui la precede. C'est aussi l'estat d'un profond sommeil, de l'etourdissement et même de la mort."

13 In Wilson (2006). I thank Laurynas Adomaitis for making me aware of this passage. 
represents the whole universe, it represents more distinctly the body which is particularly affected by it and of which it is the entelechy. And as this body expresses the whole universe by the connection between all matter in the plenum, the soul also represents the whole universe in representing the body which belongs to it in a particular way. (Monadology $\S \S 61-2 / \mathrm{L} 649$ ).

If, for instance, I have heightened sense-perceptions of the space and books in the library in which I am working, but I cannot sense-perceive the railway station that is half a mile away from here, this is because the organs of my body are interacting appropriately with what is in the vicinity, under proper sense-perceptual conditions. These bodies are not too far away from my own body. They are, moreover, under the right lighting and atmospheric conditions: I can see forms and colors; I can hear people talking at the reception. Whatever exists beyond my perceptual environment (that which my sense-organs cannot reach) only affects my body indirectly and therefore falls into the shadows of my heightened perceptions. As Leibniz explains:

We too have minute perceptions of which we are not aware in our present state. We could in fact become thoroughly aware of them and reflect on them, if we were not distracted by their multiplicity, which scatters the mind, and if bigger ones did not obliterate them or rather put them in the shade. (NE 134/A VI 6 134)

"[Bigger] sense-perceptions" are those that are united because they mirror the channeling of bodily impressions by organs through nerves up to the brain. A soul capable of distinct knowledge uses the body as a filter for information. The body functions as a point of view on the world to which the substance belongs. We have thus laid the foundations for Leibniz's mental sieve.

Other cognitive filters, such as memory and attention, are then put to work in enhancing the mind's point of view. The logic of the imagination is constituted by space and time, as well as other constraints that ground our apprehension of firstand second-order coherence. As we will soon see, the latter constitutes a further filter insofar as it regulates memory and attention. The joint work of the imagination, memory, and attention provides the soul with associations that are pre-propositional, as we have hitherto claimed, which merely mimic reasoning. This further layer explains why minds are able to focus on the cause of a stupor, "locating" it within the broader corpus of knowledge:

Memory provides a kind of consecutiveness to souls which simulates reason but which must be distinguished from it. Thus we see that when animals have a perception of something which strikes them and of which they have had a similar perception previously, they are led by the representation of their memory to expect whatever was connected with it in this earlier perception and so come to have feelings like those which they had before. When one shows a stick to dogs, for example, they remember the pain it has caused them and whine or run away. (Monadology, Prelim., Sec. 65.)

The strong imagination which strikes and moves them comes either from the magnitude or from the number of the perceptions which preceded it. For often one single strong impression produces at once the effect of a long-formed habit or of many frequently repeated ordinary perceptions. (Monadology $\S \S 26-27 / \mathrm{L} 645$ )

Let us highlight the role that imagination plays in this passage. The imagination filters what the senses permit passage of in the remit of attention, owing to a natural 
attraction. This can either be owing to a more puissant impression, such as when something in dog's body causes intense pain, thanks to which the dog is forced to pay attention, or because the regular occurrence of the same stimulus forms a habit, consisting in an established connection of successive events, such as when, in witnessing a sunset, I expect nightfall to follow. I shall elaborate on these thoughts shortly. For now, we should understand the activation of memory and attention as the reason why information can be stored and readily recalled whenever the imagination processes new sense-perceptual data bearing similarities to previous data.

With this picture now in mind, I will argue in the following chapter that the imagination functions as a kind of telescope that enhances the viewpoint and cognitive filters of an agent. Leibniz often draws a parallel between formal procedures - as in geometry and mathematics - and the role that telescopes or microscopes play in enhancing our sense-organs. Just as those lenses improve the power of the eye to capture those details hidden in nature, so too formal means enhance human beings' rational power to achieve more stable and higher forms of knowledge ( $E l$ ementa Rationis, A VI 4 B 717). ${ }^{14}$ For, the imagination subsumes sense-perceptions under its own kind of geometrical logic, thus I think we can compare it to a kind of telescope insofar as - at least metaphorically - it crucially permits rational agents to see into the future, viz. by anticipating and predicting the behaviour of phenomena.

As we have already argued, the first basic operation of the imagination is to synthetize sensations into complex unities (what Leibniz calls "perceptible wholes", which are nothing more than an expression of presently sense-perceived beings, viz. as shapes with sizes bearing sensory qualities, as argued in chapter II). In so doing, the imagination - interplaying with memory and attention - begins a process of comparison and information-ordering that enables cognizant agents to acquire similarity classes for phenomena. When phenomena are processed as similar to previous one, it is because the cognizant agent has formed a type for that phenomenon that it is activated by some features of the perceived body, for instance the shape, and in be activated memory and attention are controlled to pay attention to salient aspects, i.e. typical aspects, of the phenomenon. In this way, the cognizant agent forms expectation about how the phenomenon is likely to change, or how it cannot change, entertaining so counterfactual reasoning or contemplating possible worlds (entertaining what if something happened). Through the imagination, cognizant agents are not simply subject to what the senses present to them: they learn

14 In a letter to Herzog Johann Friedrich (April 1679), Leibniz presents his universal language, and art of discovery, as follows A I 2 168: "Car mon invention contient l'usage de la raison tout entier, un juge des controverses, un interprete des notions, une balance pour les probabilités, une bous-sole qui nous guidera sur l'ocean des experiences, un inventaire des choses, un tableau des pensées, un microscope pour eplucher les choses presentes, un telescope pour deviner les eloignées, un Calcul general, une magie innocente, une cabbale non-chimerique; une écriture que chacun lira dans sa langue: Et même une langue, qu'on pourra apprendre en peu de semaines, qui aura bien tost cours parmy le monde". 
to command attention and memory, taking voluntary control of their cognitive processes, and making forecasts into futurity.

Thus, even though I cannot sense-perceive what is happening at the railway station while I am sitting at the library, I can still imagine what might be happening there: I imagine entering the station hall, seeing people coming and going, getting onto the train, greeting their loved ones. Indeed, I can even distinguish imagining from sense-perceiving: I know that what I imagine about the railway station does not correspond exactly to what is happening there. And yet, the fictional entertainment of situations and events lies at the core of the sense of coherence constituting real phenomena - the same is, to some extent, at play when I perceive a train at the railway station, and I can imagine one. Mental entertainment of both real and imaginary phenomena rests on types, as I will argue, and is the reason why cognizant agents learn to connect states of affairs and events.

Let us summarize what we have argued thus far. If a soul is permanently stupefied, then this happens because it has no cognitive resources available to order the constant stream of information, which is afforded through its minute perceptual activity. On the contrary, when the soul has cognitive resources, it can identify what causes a stupor, "locating" it within a broader corpus of knowledge by connecting it with other phenomena and their alteration. Types - themselves as forms of cognitive filters - reduce the amount of information cognizant agents need to process when experiencing bodies. Types do this by instilling in the cognizant agent a sense of how the body may change from $\mathrm{t} 1$ to $\mathrm{t} 2$. To give an intuitive example, if I see a piece of paper five feet away from a fire, I do not expect the paper to burn, although paper per se can burn. Types afford an ability to recall and cognitively call upon stored information about things' habitual changes and are a cognitive necessity within Leibniz's metaphysics and theory of cognition. They are necessary insofar as they contribute towards the construction of our telescope. To this end, types enhance the cognizant agent's point of view in their acts of anticipation, inference, and are moreover crucial to making predictions about physical phenomena. Thus, for the remainder of this and the next chapter, my primary goal is to flesh out Leibniz's theory of how types' interiorization is related to space and time. I shall moreover clarify the imagination's peculiar cognitive constraints, distinguishing these parameters from those of the intellect.

\section{NATURE AS THE INTENTIONAL OBJECT OF TYPES}

If we return to the topic of coherence, especially considering it from the perspective of our foregoing analysis, then we can say that, at any time when we have an experience and do not feel any form of suspicion or surprise caused by a phenomenon's behavior, we are actually processing and ordering that phenomenon as cohering with "its customary nature", as Leibniz puts it in On the Method of Distinguishing between Real and Imaginary Phenomena. That is, we are processing that very phe- 
nomenon in compliance with certain filters that we have refined through acquaintance with the external world. Indeed, these filters enable cognizant agents to express phenomena's common nature.

We can label these filters "types". Types are the result of the joint work of imagination, memory, and attention regarding the data furnished by sense-perceiving what Leibniz calls "perceptible wholes" (analyzed in chapter II). They correspond to the capacity of considering the phenomenon as having a nature common to other phenomena. Types are ways of imagining phenomena and their interaction through bodies. The body, as argued in the previous chapter, is itself an expression of substances' respective forces. The idea that we are going to work out in more detail is, roughly, that if, from similar effects we can infer similar formal causes, as Leibniz writes in NE 309, then from bodies' resemblances we can infer those bodies' common nature.

More specifically, what Leibniz calls "nature" is distinct from a thing's essence, although it remains importantly related to an essence, and can be inferred from the typical, observable physical states of bodies (NE 309). It is an expression of what a body, qua type of body, can or cannot do, and is based on inferences relating to a phenomenon's resemblance to other phenomena. Phenomenal resemblance is grounded in the outer appearance of phenomena. Types, qua interiorizations of common nature, collect and store observable states and properties of phenomena, which are considered similar and therefore of the same type. Types are therefore knowledge of a general kind since nature constitutes a midpoint between what pertains to something owing to what it is (its essence), and what pertains to it thanks to its existence, i.e., the context in which the thing exists:

That is how the matter is viewed by philosophers, too, when in their often-repeated distinction
between what pertains to essence and what to existence they associate with existence
everything which is accidental or contingent. Very often one does not even know that a
universal proposition which is known only through experience may not be accidental too, for
our experience is limited. For example, in a country where water never freezes, they would
arrive at the proposition that water is always in a fluid state; but this is not essential, as is
discovered by coming to colder lands. However, we can take the accidental in a narrower way,
so that there is a kind of middle ground between it and the essential: this middle ground is the
natural, meaning that which does not necessarily belong to the thing but which nevertheless is
inherently appropriate to it if there is nothing which prevents it. Thus someone could maintain
that fluidity is not really essential to water but is at least natural to it. One could maintain this,
I repeat, but still it is not something which has been demonstrated, and perhaps the inhabitants
of the moon, if there were any, would have grounds for believing that they were just as entitled
to say that it is natural for water to be frozen. (NE 433-4/A VI $6433-4$ )

Types can be understood as "possibilities inherent in the resemblances" (NE 323/A VI 6323 ), as well as interiorized rules that enable the expression of a phenomenon's nature. Phenomenal resemblance serves as a ground for the first categorization of concrete beings into similarity classes, which are not essences, and their knowledge rests on experiencing beings. As Leibniz notes, "a great deal of care and experience is needed if one is to mark out genera and species in a manner which comes fairly close to nature" (NE 310). Types are not expressions of essences because, as we 
will soon see, the necessity they imply is physical rather than metaphysical, or so I will argue.

Taking types to be the cognitive performance owing to which souls are able to distinguish between beings on account of resemblance hints at the idea that types are highly complex interiorizations of phenomenal behavior. This behavior is so complex and dynamic that types cannot be considered as images, nor indeed as any kind of mental representation of phenomena that is explicitly entertained by the mind and employed to compare presently perceived phenomena, in order to apprehend whether the phenomenon conforms to the type. Although types process the sensory presentation of bodies and their sensible properties, they are not therefore images. The argument for this is well-known, but worth remembering (Bolton, 2017).

Types are related to the observable changes of things, as well as to their sense perception by sensory beings. If this is correct, then the type is first involved in the tracking of a body's movement. However, the type is not an image of the body as entertained by a cognizant agent. Any image of a phenomenon can be taken by the mind as an exemplification of a phenomenon's type. For instance, I can draw a human body and tell you that the type we are after - human body - looks like my drawing. The problem with this explanation is that, however far-removed from particular properties and traits the drawn image may be, it will necessarily represent one and only one position that the whole and its parts can occupy at the same time in space..$^{15}$ The hands cannot at once be placed over the head as well as dangling down the sides of the body. Most existing human bodies can assume these postures (albeit at different times), and the coherence we thereby develop of the relevant type does not merely concern one mode of presentation between the relations of whole and parts, but any possible position that the whole and its parts can take. These changes do not preclude taking a body, postured thus-and-so, as similar to previously-experienced bodies, whether or not they are positioned similarly. Moreover, these different representations are, no less than one another, actualizations of the type in question. In short, a type is the capacity to consider various postures of a whole-parts as possible states of the whole-parts; each state is moreover taken as produced by previous states and generating successive states. We will elaborate on this soon.

At root, a type concerns whole-part relations of a certain body. This is true of relations within the body, as well as being in virtue of experiencing and observing bodies' behaviors, which affords knowledge of relations between the body-type and other previously-experienced, contiguous body-types. For instance, we learn that paper behaves differently when soaked in water than when it is near a fire. So, if a drawing is able to be taken by a subject as exemplifying a type, then this must be on account of the mind already having a type that accounts for any presentation of the class of things falling under it. The class of things related to a type is, therefore, determined thanks to a cluster of sensory presentations, the most relevant of which 
is, as I shall argue in chapter $\mathrm{V}$, the body-shape as divided into its constitutive parts. To foreground that discussion, I shall make one prefiguring remark. On Leibniz's account, shapes are detected multimodally. Owing to this, even though vision seems to dominate in our experience of bodies, there can be types of non-visual sensory presentations, such as sounds, tastes, or smells, and these can be ordered on a scale that varies with regard to different measures of quantifiability, including intensity and duration, frequency, and so on. However, as we are going to see, the interiorization of property-types is parasitic upon the interiorization of body-types insofar as they rest on the capacity for distinguishing parts into a body. This is the reason why, for now, we will focus on the apprehension of body-types.

When a type is active during the processing of sensory presentations, all this means is that the mind has learned to see the actual presentation of a particular body (say, a cup) not simply qua a shape with sensory qualities; it is seen as a type of body, cups, because (i) the actual shape and parts of the cup bear similarities with previously-experienced cups; (ii) the sensory presentation of the cup is coperceived along with other bodies that are typically associated with the cup. Furthermore, conditions (i) and (ii) activate certain expectations and predictions regarding the cup's behavior in contexts in which the body of the perceiver may form a relevant part. In short, we do not mentally entertain types as kinds of general images; we simply learn to see bodies qua types of phenomena manifested through an acquired, habitual acquaintance with body-shapes, sizes, and qualities. Thus, types are $d y$ namic rules of tracking phenomena's behavior, as interiorized through experience. These rules are unconsciously active when we experience new phenomena and allow us to take the new phenomenon as a habitual one. Our typical and habitual acquaintance with phenomena renders attention and memory selective, shifting their respective focus from common traits among bodies, as based on similarity, to what distinguishes phenomena as being of a certain type.

A type is thus an interiorized ability to express the nature of the body qua a general kind of body. It is manifested as a recognition of the body as belonging to a similarity class; a prediction of how the body changes internally, i.e., its parts move coherently given the type of body, as well as how it changes externally, i.e., coherently with the nature of other, surrounding bodies. And yet, given the complexity of types (despite the fact that types are not consciously entertained) it is hard to make them adequate to the cognitive demand that types must produce a filter for reducing and diminishing an array of information, thereby ordering and controlling the amount of information that would otherwise overwhelm the cognizant agent, rendering them stupefied. Thus, in order to argue that types are filters, we need to focus on the role that spatiotemporal constraints play in the sense-perception of bodies. The connection to space and time will allow us to argue that in processing wholes we do not entertain all possible outcomes that a given arrangement of the whole and its parts can have; we rather assume a general framework provided by space and time that allows to estimate whether the whole changes in a coherent way. 


\section{SPACE AND TIME: A FIRST-ORDER COHERENCE}

We ought to consider how minds form general notions of space and time in order to show that space and time act on the level of the sensory apprehension of bodies, that is, before minds acquire explicit notions of them. Owing to this, space and time act as constraints on the imagination in tracking sensory presentations of beings as perceptible wholes. In so doing, they serve as rules for interiorizing the first-level coherence of bodies, that is, how parts of a whole move in relation to spatial and temporal constraints. First-order coherence also serves as the basis for interiorizing second-order coherence. This is based on the way that bodies (qua types of bodies) move and change. The parts of a human body, for instance, move differently to those of a dog-body or snake-body. Nonetheless, both types of body move coherently with spatiotemporal rules. Second-order coherence hence constitutes more specific knowledge of how a body qua type (whether canine, human, or ophidian) can or cannot change. To better understand the relation between first- and secondorder coherence, let us analyze how general representations of space and time are learned.

Across a diversity of papers and passages, Leibniz describes the process by which human minds learn to conceive of space and time. While the most wellknown text is a passage of the fifth letter to Clarke, ${ }^{16}$ I prefer to discuss an earlier text, Definitiones cogitationesque metaphysicae (1677-1681?). There, Leibniz not only proffers the conception of imagination that interests us here (indeed at an early point in his philosophical career): he also begins to draw an important connection between time, space, and the human capacity to perceive bodies. A body in this text is not simply the appearance of a whole, but a more complex expression of the perceptible whole as subject to space and time.

According to this text, physics is said to be connected to geometry, arithmetic, and metaphysics: "Physics is subordinated to arithmetic or algebra insofar as it cocerns magnitude, to geometry insofar as it concerns situation; to metaphysics insofar as it concerns resistance, i.e. action and passion" (A VI 4 B 1394/LoC 237). In each of these domains, claims Leibniz, cognizant agents rely on different principles of certitude. The principle of certitude in physics is that phenomena have a certain "consensentia vera", i.e., they are co-sensed together as true. Physics moreover has its own categories: body; world; time; space; and individual (A VI 4 B 1396). In short, the human capacity for distinguishing individual bodies moving through space and over time - as well as the capacity for organizing them into a world distinguished into successive temporal states - is the object of the physical

16 Leibniz's Fifth Letter to Clarke, $\S 47$, GP VII 400/ed. by R. Ariew (2000: 45-6). The beginning of the text is of interest to us: "Voicy comment les hommes viennent à se former la notion de l'espace. Ils considerent que plusieurs choses existent à la fois, et ils y trouvent un certain ordre de coexistence, suivant lequel le rapport des uns et des autres est plus ou moins simple." Furthermore, in the letter to Clarke, the act of co-perception constitutes the starting point for any possible development of a conception of space. 
sciences, permitting the distinction of dreams from actually-obtaining states (A VI 4 B 1396).

Within this framework, the perception of a moving body is a phenomenon of the imagination and its constraints insofar as these phenomena appear situated. The body has a situation when we perceive it as an image: "an image is the continuation in the organ of the action of the object even when it has ceased. Imagination is the perception of an image" (A VI 4 B 1394/LoC 237). The perception of an image is what we named "the groundwork of the imagination" in chapter III, i.e., the senseperception of bodies as shapes with sizes. This groundwork explains how we can perceive phenomena as consensentia vera, viz. coperceiving their truth. But what does it mean to say that we can coperceive phenomena as true? What Leibniz means here is more or less what he writes in On the Method of Distinguishing Real from Imaginary Phenomena. Consensentia vera involves the perception of phenomena as coherent or as being in agreement. When we sense-perceive phenomena, we tend to accept our perceptions, for those perceptions do not generate in us any affection of suspicion. The fact that Leibniz outlines an argument for why we need to believe in the existence of that which we sense-perceive suggests that we should read the foregoing text in accordance with Leibniz's better-known On the method:

The causes of the phenomena, too, must be outside you, and also outside any other conceiver, since they appear co-sensed by many, and, with your nature being limited, no reason can be provided for so many new appearances cohering among themselves. Hence now there arises the consideration of a certain generic space whenever certain particular situations are assigned to the phenomena, and one observes the distance and angles of things, which do not change without a cause. Thus if we posit something in a fixed and enclosed place, we do not doubt to find it in that very place, unless some force or another event (casus) do not supervene. Also this space is common to all things, and those phenomena themselves we call them bodies to which we can assign a situation (situ), like a star; there is no body which is not cognized as being in that general space and which has some distance from other bodies. [...] But since changes occur, which varies the situation assigned [to the body], in this case, to avoid confusion, we devise a mode of distinguishing those things which happen prior or posterior or simultaneous, by referring everything to changes of those things which are apprehended as uniform, such as the movement of the stars. And this consideration of the things with each other is called time, which is also generic, and comprises the whole of everything nothing can happen which is not prior or posterior or simultaneous to any other given thing. (A VI 4 B 1396-7/LoC 242-3 translation slightly modified)

The passage addresses the same body of problems of "On the Method of Distinguishing Real from Imaginary Phenomena”. Its philosophical claim is that there must exist other perceivers, as well as causes of the phenomena we experience. For, if we assumed that such causes did not exist, then we would not be able to provide an explanation for anything that appears to us as internally coherent. Space and time are used as criteria to explain why phenomena are coherent and why supervening causes - things that occur independently of our existence and will - can make sense of the order of succession and relations among the phenomena we experience. However, space and time are no existing framework outside the cognizant agent; they are a categorical framework that agents develop from appearances of wholes. What is first available to the cognizant agent is the appearance of a shape bearing a certain 
size. The cognizant agent assigns a situation to the shape (that is, she renders it a geometrical object subjected to the logic of the imagination) by putting it in a relation to other appearances in her perceptual environment. Indeed, following the quoted passage, Leibniz continues by saying that

Now with the aid of time and place we can also distinguish individuals, and decide which are the same and which are different; if I have two eggs in front of me that are similar or equal throughout... (A VI 4 B 1397/LoC 243).

Thanks to the analysis conducted in chapter II, we are already familiar with the claim that the mere situation of two bodies constitutes a sufficient criterion for their apprehension as two distinct bodies, in spite of their congruence. We now know, furthermore, that the body is situated through the act of expressing it as a finite shape. As we have argued, detecting unities into an amalgam of sensory perceptions is the groundwork of the imagination, and explains why the imagination can proceed to compare shapes. The final, relevant aspect of the passage is the role thereby given to causation. If no external cause supervenes, then the object stays in the same position (situ); if a cause supervenes, then it moves. The notion of cause, like those of space and time, however, is not an explicit concept that the mind as-yet applies to bodily apprehensions. Such notions are rules for constructing sense-perceptions as appearances of bodies, which permits their tracking across space and time.

The text is relevant not only because it explains how we form a representation of space and time: it introduces the notion of bodies (corpora) as more structured phenomena than mere individuations of a shape. Bodies are phenomena that cannot but be conceived as shapes occupying a position in space (situs), thereby bearing relations to other shapes/bodies that likewise occupy a position in space (distance), whose changes transpire either before, after, or at the same time as other changes, i.e., in time. Bodies do not, therefore, undergo alterations without explanatory, etiological grounds. Our finite human minds depend upon the imagination, owing to which we cannot detach our conception of bodies from spatial and temporal relations. Even if the concepts of space, time, and causation were explicitly learned after the mind had experienced bodies, this would mean that space, time, and causation already actively functioned as constraints upon the imagination, i.e., as conditions of possibility for the appearance not of shapes but of more complex phenomena, viz. bodies. As we will see in chapter IV, by "innate ideas" Leibniz means those constraints on the imagination and intellect that are always active in cognition, but are only known explicitly by rational minds following a great deal of experience, abstraction, and reflection.

Bearing in mind that space and time are rules rather than concepts, we can further clarify the kinds of rules they are. Definitiones cogitationesque metaphysicae (1677-1681?), which we cannot survey analytically, offers five rules that determine how bodies can appear to the imagination, which change in accordance with space and time:

(i) A body is in space and time iff, in an act of coperception, it appears as having spatial relations to other bodies (simultaneously situated at a certain distance from other bodies). In short, it is near other bodies; 
(ii) Whatever is in space is either a whole or a part. It is a whole if it has parts; it is a part if it belongs to a whole; ${ }^{17}$

(iii) The body has parts iff they are both extended and continuous. This means that the parts "bend" rather than "divide", moving apart from the body; ${ }^{18}$

(iv) Movements of parts and wholes are continuous and homogeneous, i.e., they trace ideally what appear to perceivers as continuous lines, constructed in ideal space over time;

(v) Movement qua change, while a body is at rest, depends upon a supervenient cause: a state occurring in accordance with (i-iv).

The first upshot of these rules is that the Leibnizian notion of body is not Cartesian: bodies are not comprised of one, sole property - extension - because they are not three-dimensional. Bodies are in fact four-dimensional: they have length, depth, breadth, as well as temporal extension. A body is whatever appears to the imagination as having extension in both spatial and temporal respects. It is hence a bundle of states changing continuously in compliance with space and time. As we will see in the next chapter, spatiotemporal continuity is all-important to the notion of a world and is moreover required for constructing more structured expectations between states, viz. causal relations.

Rules (i)-(iii) result from what we have already argued from chapter II until now. Rule (iv), in turn, derives from what Leibniz says in the text quoted above. There, the apprehension of the spatial alterations of the same body depends on the continuity of the body's movement. This homogeneous change, as we will see in chapter $\mathrm{V}$, is the reason why the imagination is capable of keeping track of the body and its changes, and why it takes them as changes of the same body. The apprehension of temporal duration as the same body changing place does not result from a comparison of different images of the body apprehended at different times. This kind of tracking is a spontaneous activity of the imagination, because such an activity is affine to the imagination's own logic. The appearance of homogeneous, linear movement of the body inclines the mind to take it as the same body changing: the body does not disappear in one place and then reappear in another; it moves in what appears to us as continuous, linear movement. This homogeneity of movement reduces bodies' movements to the representation of an ideal continuum through which the body must move in order to reach a different position. This continuum is called space and it is imagined as an underling substratum of bodies. There might be different ways in which a body can move from position A to position B: it might be a direct, straight line, or a curved line. In any case, the body must trace a continuum. That bodies are homogeneous means that, independently of their peculiar shape or size, they are similar insofar as they change coherently with (i)-(v).

17 Leibniz's main claim in this paper is that coherence leads the mind to form an idea of "mundus", understood as the totality of phenomena. A world, however, is not an actual whole (something we can sense-perceive) but a regulative idea regarding the kind of phenomena that can and cannot exist in the world.

18 The example of a moving chord, used by Leibniz in Metaphysical Definitions and Reflections (A VI 4 B 1401/LoC 251) and discussed in chapter III, shows this point. 
Why is the foregoing relevant? These clarificatory remarks are important because this ideal continuum grounds the first-level coherence of bodily movement, and thereby governs our expectations regarding how bodies may move. Independently from the nature of the body, viz. whether it is a tree or a hyppogryph, any movement traces what appears to us as a homogeneous, continuous passage between two locations. For instance, a body cannot disappear at position A and at the very next moment appear at another distant location. A body moving in this way would appear as suspicious to the cognizant agent.

Homogeneity of motion, as afforded by space and time, provides an initial answer to the question regarding how the imagination's own constraints, which are active in coperceiving bodies, control incoming sensory information. Homogeneity establishes expectations regarding phenomenal alteration. If, in order to move from position $\mathrm{A}$ to position $\mathrm{B}$, a body needs to move past all points between $\mathrm{A}$ and $\mathrm{B}$ (which necessarily lie on a continuous line of whatever shape), then locating the body at time A permits certain expectations I have of its forthcoming move. If I see someone walking, for instance, then I am able to track her movement owing to her legs moving in a certain way. If the right leg is in front of the left leg, then I expect the left leg to move gradually to the front of the right leg. The salient point here is that linear, homogeneous motion, the perception of which is afforded by our expression of beings as bodies on a space-time continuum, limits the combination of possible alterations that a body can undergo from $t 1$ to $t 2$. This requires that, in seeing a body, I do not simply see a shape: I see a phenomenon related to other phenomena insofar as they all adhere to certain rules. What the interiorization of a type 'body' allows to predict thus is not how a body will actually change from a certain arrangement of its parts: its parts can vary in too many different ways. What it will predict is the mode of change: independently from the direction of the part or the whole, the change must be linear and homogeneous.

Therefore, when a cognizant agent interiorizes a type for 'body', the type consists in an ability to take any experienced body as similar to any other body, at least with respect to their being subject to space and time. 'Body' is hence also a type. It is a type insofar as it corresponds to the cognizant agent's capacity of expressing what is common to all beings as perceptible wholes: their being subject to spatiotemporal rules. Bodies' common nature is their similitude with respect to space and time. This general framework of bodies as four-dimensional objects is required to interiorize more specific kinds of bodies and so more specific rules of how bodies recognized as having specific natures changes. This furthermore allows cognizant agents to predict and expect certain kinds of bodily behavior. In the next section, we will further probe the grounds for these kinds of expectations, focusing on rule (v) and associative causation.

\section{SPACE, TIME, CAUSATION: LEIBNIZ'S EMPIRICAL PRINCIPLE}

Spatiotemporal rules ground those causal changes that see bodies in motion and at rest. The causal relation involved, however, is based on the principle (often stated 
by Leibniz) that what has happened will happen again in the same way (NE 49 and NE 51). This is important because, as I shall argue here, this kind of causation does not imply necessity, only association. Owing to this, non-human minds are too capable of its apprehension.

In NE, the aforementioned principle is used to distinguish between analytic reasoning, which is based on the isolation of requisites for something's existence, and mere association. ${ }^{19}$ More specifically, associative causation is, at this level, a mere connection between two states that repeatedly occur either together or successively. The cognizant agent simply expects state B whenever state A occurs; they do not cognize state A as a cause, nor as that which produces the existence of $\mathrm{B}$. It is mere expectation. This is also the way in which non-human animals, and "simple empirics", connect and predict events:

While men are capable of demonstrative knowledge [science], beasts, so far as one can judge, never manage to form necessary propositions, since the faculty by which they make thought sequences is something lower than the reason that occurs in men. Beasts' thought sequences are just like those of simple empirics who maintain that what has happened once will happen again in a case which is similar in the respects that they are impressed by, although that does not enable them to judge whether the same reasons are at work. (NE 51/A VI 6 51)

In Reflections on the Souls of Beasts, a short text written in 1710 and already published in Dutens (1768), Leibniz writes more explicitly:

Since this point has not until now been very well explained - while some remove even sensation from beasts, others ascribe even reason to them and report many cases in which beasts seem to connect certain consequences - it should be known that there are two completely different sorts of inferences, empirical and rational. Empirical inferences are common to us and beasts, and consist in the fact that on sensing those things that have on several occasions been experienced to be connected we expect them to be connected again. Thus dogs having several times been beaten when they have done something displeasing, again expect a whipping if they should do the same thing and so they refrain from acting; this they have in common with children. (RSB $\S 14 /$ Dutens 232)

Leibniz was aware that induction may have different sources and that the simple repetition of events, which are temporally proximal, may lead a cognizant agent to create a connection between the two events. The connection is tantamount to expecting B whenever A occurs, as when a dog expects to be beaten if it has already been beaten. The expectation, however, does not amount to an awareness that state A produces $\mathrm{B}$ : it is not yet a notion of causation. Indeed, Leibniz thinks this is why empirics are easily fooled by experience:

But as it often happens that such things are only connected accidentally, empirics are often deceived by this, just like beasts, with the result that what they expect does not happen. Thus, if I give food to a dog doing something, this indeed happens accidentally as a result of my free will; but as soon as the dog has become habituated to the action I wished to teach it, I no longer give it food when it acts correctly, although until then it may expect this to happen. (Ibid.)

19 For a detailed account of the notion "requisite", see Di Bella (2005: 67-93). 
Human beings are furthermore inclined to empirical expectations, as it emerges with unexpected violence when they move to another country, where social expectations result from a different set of protocols and habits:

Likewise, if some Dutchman boarding a ship is carried off to Asia, and taken to a Turkish city looks for beer in an inn just as he would at home, he will in this way be deceived, for he will expect something from the inn which is connected to it only accidentally, and is not found in the same way in Turkish inns as in Dutch ones. However, a human being, insofar as he does not act empirically but rationally, does not rely solely on experience, or a posteriori inductions from particular cases, but proceeds a priori on the basis of reasons. (Ibid.)

The inference that I can find beer in an inn (so lifesaving in the Netherlands!) becomes a deception in another country, whereby I realize the non-necessity of the connection between inns and beer.

Years before Hume, Leibniz had already addressed the distinction between mere connection and causation, rejecting the idea that connection is all there is to causation. However, connection brings about an associative causation, that is, a link between two events based on habitual experience. This is a remarkable feat for cognizant agents because it serves to instill stability and order both into nature and the cognizant agents' own cognitive processes. As yet, however, this order is not rationally grounded. If we return to the passage from Metaphysical Definitions and Thoughts, in which Leibniz claims that we do not expect a body to move without a cause, then we will see that the notion of causation there involved is merely associative, based on acquaintance with the past.

Let us, for now, return to movement. Alterations in states of motion and rest typically require temporal succession and an event that causes the change. It is only typically thus owing to the frequency with which we experience the event. Experience furnishes expectations given what has happened thus far. This comes down to the frequency with which one state succeeds another. In normal cases, the status of a body at rest, A, is anticipated by the movement of another body, B, as it approaches A. Thanks to the logic of the imagination, the typical scenario experienced by cognizant agents is that a body, A, changes its situation immediately after another body, B, appears so close that the cognizant agent cannot perceive any distance between A and B, although they do suddenly perceive a change in A's state of rest and in B's motion. The imagination takes this type of change as typical because it is, besides its frequency, affine to its logic: it is the most consistent with those spatiotemporal, continuous changes (as presented in (i) and (iv)) insofar as the imagination can coperceive two bodies that move coherently within the spacetime continuum. What is important here is that this causation rests on a mere association between state $\mathrm{A}$ and $\mathrm{B}$, as based on time, and, to this extent, involves the imagination:

The thought sequences of beasts are only a shadow of reasoning, that is, they are nothing but a connection in the imagination - a passage from one image to another; for when a new situation appears similar to its predecessor, it is expected to have the same concomitant features as before, as though things were linked [liaison] in reality just because their images are linked in the memory. It is true, moreover, that reason counsels us to expect ordinarily that what we find in the future will conform to long experience of the past; but even so, this is no necessary and 
infallible truth, and it can fail us when we least expect it to, if there is a change in the reasons which have been maintaining it. (NE 51/A VI 651 , my italics)

As Leibniz notes in the Monadology, "we are all mere empirics in three-fourths of our actions [...] when we expect daylight tomorrow, we act as empiric, because this has always happened up to the present" (Monadology $\S 28 / L$ 645). However, while connections between events and expectations - as afforded by experience and forged through the imagination - is a tremendous boon to practical beings who need to navigate the world, it is nevertheless vulnerable to error. However, in spite of its potential fallibility, it is far from being an impediment to achieving truths, at least when exercised correctly. As I argue in the next chapter, if cognizant agents did not first exercise their tendency to be "empiric", they could not attain to more stable knowledge. Expectations grounded on the principle, "what has happened will happen again", may be vital for pragmatic purposes or "fast reasoning", but mere expectations cannot reveal the "necessity" for why something happens as a consequence of something else. Indeed, even if association could lead us to knowledge of necessary truths accidentally, we would still not be entitled to say that the truth achieved through empirical means is of a necessary kind (RSB $\S 14$ ). For, necessity requires something more than mere connections forged in the imagination. What is required is the input of intellect. ${ }^{20}$

Once we turn our attention to the question of how the foregoing principle functions in the apprehension of motion, we will recognize that its fallibility rests on the fact that no change vis-à-vis states of rest/motion occur mechanically, that is, by way of bodily collisions. A human body, for instance, can self-move independently of any observable change in its surrounding. Indeed, in the passage from Metaphysical Definitions and Thoughts, Leibniz leaves it an open question what kind of causation is here involved: whenever we see a change, we think a cause supervenes. This does not mean the cause cannot be internal, such as when my will moves my body to fetch some water.

The foregoing observation is important because this notion of causation can also be extended to things that we neither observe nor experience in the same way as we experience bodies. Consider, for instance, the way in which rational agents ascribe thoughts to others. ${ }^{21}$ I see you grabbing a glass of water and therefore judge that you are thirsty. This inference rests on a more basic assumption that a change needs a cause. Consequently, if I see a change (viz. your body moving and reaching for some water), and I do not perceive anything that moves your body coherently with the movements you produce, I do not thereby abandon my assumption that there is a cause. This is because my assumption rests on the ultimately stable principle that "what happened will happen again in the same way". ${ }^{22}$ I rather assume

20 See also Oliveri (2016: 2.3); Bolton (2017).

21 See Oliveri (2016: I.5) and Roinila (2007).

22 The argument from introspection of Monadology $\S 16$, which infers the existence of other perceiving souls, rests on PSR. Leibniz writes: "Nous experimentons nous mêmes une multitude 
that there must be a cause moving your body - a substance that moves your body through your being thirsty. The reason for not revising the principle is hence more subtle than blindly assuming the principle's invariant truth: I have resources to find a cause for your grabbing the glass; a cause that affords preservation of the principle. I can observe, for instance, that my body too moves without external influence, but rather through internal strivings, as when I feel thirsty. Henceforth, I generalize and assume that your body - being similar to mine - can also move for the same reason.

This argument coheres with that which Leibniz gives in "On Distinct Perception", as outlined in chapter II. We claimed there that we implicitly judge other bodies to be substances because we attribute to them the status of substance that we likewise experience in ourselves. ${ }^{23}$ Without broaching metaphysical questions regarding body-mind interactions (which constitutes a further step in a rational agent's process of discovery, which leads rational agents to revise their notion of efficient causation, giving way to varieties of causation), the relevant point for us is that space and time, as constraints, support the apprehension of causal relations between moving bodies. These spatiotemporal parameters can serve the imagination as further constraints in its activity of determining and interiorizing types.

Associative causation leads the mind to believe that changes in bodily states of rest and motion require contact between two bodies. We expect that material bodies do not move without a cause of their movement, i.e., if movement is produced, then we presuppose a cause. At this level of explanation, we are not making hypotheses. We simply expect movement when we witness body-body collision owing to those rules grounding the "coherence" in accordance with which phenomenal change is possible. By "coherence", Leibniz simply means the cognitive state of the agent that, in sense-perceiving worldly phenomena, carries certain expectations and predictions regarding how bodies behave. Expectations rest on spatiotemporal rules and they underpin the interiorization of the type 'body'. That cognizant agents have a type for body simply means that, if they see a material body at rest, occupying a place, then they expect that the body will continue to occupy that very same spot unless something happens. This is because they already expect that, when a cause supervenes, a body changes. Time is therefore a further dimension of bodies. All

dans la substance simple, lorsque nous trouvons que la moindre pensée dont nous nous appercevons enveloppe une varieté dans l'objet. Ainsi tous ceux, qui reconnoissent que l'Ame est une substance simple, doivent reconnoitre cette multitude dans la Monade" (GP 6 609/L 644). The driven premise to conclude the existence of other perceiving monads is the assumption of introspective knowledge of our own mental states as proof for a variety of phenomena. For bodies act and interact with our own body, there must be other perceiving souls.

23 We should recall the passage we read in chapter II: "Distincta itaque perceptio fit, dum aliquid nostri simile rebus attribuimus, nos enim scimus esse subjectum variorum attributorum, itaque similiter objecta consideramus tanquam substantias quasdam sive res. [A perception is distinguished (distincta) in this way, insofar as we attribute something similar to our substances, we indeed know we are the subject of various attributes, so in a similar way we consider objects as if they were certain substances or thing (res)]" (A VI 4 A 58). 
that the type requires is an inculcated attitude to expect a further state, consistent with how bodies move in space and time from one state to another.

\section{CONCLUSION}

Cognizant agent are bundles of organic and cognitive functions, whose harmonious cooperation results in an ability to bring order to a vast amount of sensory information. To this end, a cognizant agent's faculties - memory, attention, and imagination - interplay in learning how to predict and expect phenomenal behavior. Having outlined this general framework, in this chapter we focused on how space and time contribute to structuring sense-perception, viz. by interiorizing a type for "body". For any single body to be coherent, and therefore real, it must behave consistently with those spatiotemporal constraints described in (i) - (v).

In the next chapter, we shall add certain qualifications to this first-order coherence, which alone cannot account for how cognizant agents interiorize more specific types. While first-order coherence is a necessary condition for the cognition of certain types, it is inadequate for distinguishing between phenomena that exist in the actual world and fictional phenomena of possible worlds.

The most succinct way of explaining why first-order coherence is necessary but not sufficient for grounding the sense of coherence that can distinguish real from imaginary phenomena is to elaborate on the example of suspicious phenomena deployed by Leibniz in On the Method. A hippogryph moves coherently with space, time, and associative causation. But if coherence only depended on space and time, then coherence would still not explain our suspicion were we to see a hippogryph. This suspicion must hinge upon an implicit assumption that what we perceive cannot exist in, or is not a phenomenon of, the actual world.

The next chapter fleshes out this argument through an analysis of what Leibniz considered to be the relation between imagination, the kinds of conceivability it accounts for, and the kinds of modalities to which it affords access. This will prove that types are interiorized through experiential acquaintance with the real world. 


\section{FIRST- AND SECOND-ORDER COHERENCE II: MODALITIES AND TYPES}

Space, time, and associative causation act as rules for determining the first-order coherence of phenomena. First-order coherence concerns how bodies can or cannot move and change in compliance with spatiotemporal constraints. When cognizant agents apprehend perceptible wholes as embedded in the ideal continuum of space and time, the imagination performs an act more complex than the work of segmentation described in chapter II. Our sense-perception of bodies is more structured than simple apprehensions of perceptible wholes (shapes with sizes) because the cognizant agent forms expectations regarding how bodies change state (for example, between motion and rest). Bodies move homogeneously and linearly across what appears to us as a continuum. Moreover, they do not change without cause. Hence, in experiencing perceptible wholes, cognizant agents learn the nature common to all bodily phenomena, independently of their specific type. For, while snakes, human beings, imaginary hippogryphs, and indeed the moon, are each examples of bodily phenomena, and each moves in its own peculiar way (celestial bodies revolve, human beings walk, hippogryphs fly), they nonetheless all move in accordance with spatiotemporal rules as described in (i)-(v) of the previous chapter. $^{1}$

The foregoing chapter concluded by pointing to the limits of first-order coherence. While first-order coherence is necessary, it is not sufficient to account for the suspicion occasioned by incoherent phenomena, viz. the suspicion that Leibniz thinks we would feel were we to sense-perceive fictional phenomena, such as a hippogryph. To explain why cognizant agents react suspiciously to certain phenomena but not others, we need an account of second-order coherence, which regards the determination of species within the genus 'body'. The motivating idea here is that suspicion is produced owing to the cognizant agent's sense-perception being about a hippogryph, rather than merely a body. The cognizant agent who is suspicious in seeing a hippogryph must, therefore, possess resources for recognizing and evaluating the possible/impossible existence of what they experience even before they have the relevant analytic tools for pursuing their enquiries, viz. concepts.

The relevant question therefore becomes: what kinds of distinctions within the general genus 'body' are cognizant agents capable of apprehending, and by which

1 For an analysis of the codependence between corporeality and the work of the imagination, see Meier-Oeser (2011), especially where he argues that "having a body" is something related to "being an intentional object of the imagination". I think this is partially true. If bodies are fourdimensional entities, then bodies are ideal too. I think, however, that bodies - the intentional objects of the imagination - track something mind-independent, i.e., changes expressing forces. For discussion, see chapter III. 
mechanisms can they account for more specific, albeit still pre-conceptual, ways of categorizing beings? If cognizant agents can recognize a hippogriph, then they must be capable of some sort of categorization. My hypothesis is that types are acquired abilities to gather beings into similarity classes in virtue of observable, phenotypical resemblances. After all, the idea that concepts are "similitudo rerum" has a venerable, Scholastic tradition. ${ }^{2}$ My hypothesis is that Leibniz adopts and modifies this theory within his own philosophy of mind and language. ${ }^{3}$ An interesting upshot of this view is that, on my understanding, Leibniz takes the acknowledgement of similarities as a mere step towards conceptual knowledge, while falling short of conceptual knowledge itself. This removes any potential ambiguity in Leibniz's philosophy of mind of the kind that concepts are images, while also clarifying that Leibniz furthermore departs from Descartes' theory of ideas. ${ }^{4}$

We can begin by providing an argument for why Leibniz's notion of coherence must exceed its first-order characterization (sect. 1). To this end, we can analyze Leibniz's notion of a world and his theory of modality, arguing that it accounts for varieties of necessity (sect. 2). The analysis conducted in sections 1-2 serves, first, to flesh out our argument for why first-order coherence cannot alone provide the mind with the notion of coherence, as implied in the distinction between real and imaginary phenomena. Second, this enables us to deduce further constraints for second-order coherence, viz. sameness, difference, and similarity (sect. 3).

2 The theory of concepts as "similitudo rerum" is associated, within the Scholastic tradition to issues regarding intentionality and the theory of species. The theory of species was rejected by Descartes and the new philosophy through the introduction of ideas as intentional objects (for a reconstruction of the issues at hand, see Adriaenssen (2017); for a reconstruction of the Scholastic theory of intentionality, see Perler (2001)). Leibniz's apparent endorsement, albeit with various modifications, of certain Scholastic positions would once more reveal his suspicion towards Descartes' approach to ideas, as well as his attempt to rehabilitate the philosophy of the School.

3 That Scholastic philosophy had a great influence on many of Leibniz's philosophical doctrines - from the rehabilitation of substantial forms to his theory of possible worlds - is a well-known issue. Indeed, as we will see, it encompasses many aspects of Leibniz's doctrine, from modalities to his notion of substance. On the rehabilitation of substantial forms, see the contributions collected in Nita (ed. 2015). On modalities, see Schepers (2014), discussed below, and Mugnai (2013). On Leibniz's theory of universals and its relation to medieval theories, see Di Bella (2017) and Oliveri (2016: I.2).

4 In NE 267/A VI 6 267, Leibniz remarks that ideas that distinguish, sc. allow for recognition, such as the confused ideas of colors, are not per se distinct, being the criterion for distinct ideas the capacity to distinguish marks within the idea (A VI 6 255-6/NE 255-6): "Ainsi quoyque selon nous les idées distinctes distinguent l'objet d'un autre; neantmoins comme les claires mais confuses en elles mêmes le font aussi, nous nommons distinctes non pas toutes celles qui sont bien distinguantes ou qui distinguent les objets mais celles qui sont bien distinguées c'est à dire qui sont distinctes en elles mêmes et distinguent dans l'objet les marques qui le font connoistre, ce qui en donne l'analyse ou definition; autrement nous les appellons confuses." That images are not reliable in categorizing species is evident from the fact that someone can bring a plant from the Indies that looks exactly like another plant we know, and yet the plant from the Indies is from a different species. For a discussion of historical theories regarding the distinction between images and language as mental content, see Meier-Oeser (2004: 312-42). 
The main conclusion of this chapter is twofold. On one hand, the relation between types and modalities will prove that the logic of imagination cannot provide agent with logical necessity but only with a lower degree of moral certainty. This observation has important implications for what we argued in the foregoing chapter. Having expanded Leibniz's empirical principle, we have argued for another reason why Leibniz's philosophy of mind, and more specifically his theory of intentionality, are committed to a pre-conceptual form of knowledge. Indeed, it is this that explains why Leibniz thinks that both human and non-human animals share a gray area of knowledge. This kind of knowledge is close to being rational. It is, however, distinct from properly rational processes, which, on my understanding, require concepts, or what Leibniz calls "distinct notions", resting upon intellectual principles. The logic of the imagination that we have highlighted thus far does not rest upon intellectual principles (sect. 4). It is this claim for which I will argue in this chapter. The work laid down in this chapter will furthermore serve to explain how cognizant agents learn types (chapter VI), while helping to clarify why types fall short of conceptual knowledge (chapter VII).

\section{FIRST-ORDER COHERENCE AND ITS LIMITS}

First-order coherence is necessary but not sufficient in accounting for why cognizant agents are able to distinguish between real and fictional phenomena. To flesh out Leibniz's argument, we must consider the relation between first-order coherence and what Leibniz calls a "world". Whenever we feel suspicious in experiencing a phenomenon, such as if we were to see a flying hippogryph, our reaction would amount to a pre-conceptual evaluation of the phenomenon as unfit for the world. A world is not something we can experience in its totality: it is the apprehension, by the agent, of phenomena as regularly connected. This apprehension rests upon cognizant agents' capacity for considering the world as composed of beings whose modifications correspond to states of the world from which other states follow. In this way, cognizant agents are almost always in the business of evaluating new phenomena as either being fit or unfit for the world in which they live. The imagination is involved in this process insofar as it contributes to constructing the idea of a world and, thereto, in evaluating the conformity of objects and events as being compatible or incompatible with parts of the world.

Leibniz defines "world" ("mundus") as "the aggregate of all bodies, which, if it is infinite, is not one being as an infinite straight line or the biggest number ( $n u-$ merus maximum) is not [one being L.O.]" (Omnes cognitabile est vel ens, vel nonens, A VI 4 B 1509). The world - considered as the totality or aggregate of bodies - contains bodies insofar as it contains the past, present, and future states of bodies. Past and future states do not exist unless there also exist cognizant agents who conceive of the present as connected to the past and future. Therefore, the world is ideal and imaginary, like a straight line represented spatiotemporally: 
Prior in time is what is incompatible with the position of something else, and it is simpler than this. The other one is said posterious in time. Simultaneous are those things whose supposition is co-necessary, a supposition which is posited by the series of things. Time is an imaginary being, as it is space, qualities, and many others. We know because of the unifomity of change whether one is prior, or posterior, but as many different changes are simultaneously uniform, there is a cause for that simultaneity and priority: clocks indeed do not determine priority and posteriority; they just point at them (Definitiones notionum metaphysicarum atque logicarum, A VI 4 A 629).

The gist of this passage is that cognizant agents determine the priority and posteriority of states in virtue of the connections thereby established between states, and not simply because clocks mark out the succession of events in time. The composition of states, as categorized into prior, simultaneous, and successive states (for which we require the notion of causation that produces this order) is a world.

The notion of a world, as that of a body, requires the capacity, on the part of the cognizant agent, to represent bodily states as compatible in both their synchronous and diachronous existence. What does this mean? It means, for instance, that my left hand cannot simultaneously be both open and closed, as in a fist. These two states cannot be simultaneous parts of a world as modifications of the same body (my hand). They can, at most, be diachronic states. Cognizant agents expect the hand to be modified in one way or another - not both simultaneously. By the same token, a mug can be five inches above the table because I am holding it in my hand. If I open my hand, then I expect the mug to fall because I see the mug and hand as connected. Indeed, insofar as the mug is in my hand, the hand and the mug are a compositum, that is, two parts of a composite body, respectively determined by compatible and incompatible states. To illustrate, the suspended mug while my hand is open constitutes an incompatible combination. When Leibniz says that we have a notion of a world, he does not mean that we have to presently imagine all the states that exist in a given moment of the world. He simply means that we have rules for isolating local conditions, considering them as connected to other states and events, and as fitting into a more general structure, which is provided first of all by space and time. However, while necessary for constructing the notion of a world (construed as an ordered totality of phenomena), space and time are insufficient for isolating the necessary preconditions for beings' states, as well as their connections to other states, as we are going to argue.

The general notion of a world is further distinguished into a world in general and a world "with respect to us and our place", viz. the actual world as conceived in accordance with the cognizant agent's viewpoint. The actual world is divided into transidereus (beyond the stars), and sidereus (the visible, or aspectabilis). The latter is constituted by parts: coelus and tellus (Omnes cognitabile est vel ens, vel non-ens, A VI 4 B 1509). The visible, actual world therefore "consists of more solid and coherent bodies, of elongated bodies like stars [...] of liquids" (ibid.). Moreover, in Definitiones cogitationesque metaphysicae, Leibniz claims that:

The collection of all bodies that are conceived (intelliguntur) as being in space, i.e. those that have mutual situation, is called the world, and there are various states of the world at various times. Each state however proceeds from another in compliance with a certain law, which it is 
for physics to treat, so that from present states we may infer past and future ones to life's advantage. For he who can finally make predictions with success must be said to make progress in nature. (A VI 4 B 1399/LoC 242 translation slightly modified)

Here, "a world" is an ideal object of cognition that collects all bodies and their states into a whole. As such, a world is neither something given in experience, nor something we really imagine. It is rather an ability of a cognizant agent to consider experienced bodies as collections of states; objects that must furthermore fit into a bigger picture, with both synchronous and diachronous aspects, that is, as parts of a whole. As we have seen, the basic structure of a world is given spatiotemporally insofar as these structuring conditions enable the construction of connections between bodily states. Therefore, the notion of a world is related to the topic of prediction, and, consequently, to both imaginary and real phenomena, as Leibniz claims in On the Method of Distinguishing between Real and Imaginary Phenomena. Here, he affirms that even if the visible world were a well-ordered dream or phantasm, we could nonetheless claim its reality if we had a way of predicting phenomena:

Yet the most powerful criterion of the reality of phenomena, sufficient even by itself, is success in predicting future phenomena from past and present ones, whether that prediction is based upon a reason, upon a hypothesis that was previously successful, or upon the customary consistency of things as observed previously. Indeed, even if this whole life were said to be only a dream, and the visible world only a phantasm, I should call this dream or this phantasm real enough if we were never deceived by it when we make good use of reason. [...] [A]ny phenomena which conflict with those that we judge to be real, and likewise those whose fallacy we can understand from their causes, are merely apparent (A VI 4 B 1503/L 644).

Reality regards existence in the actual world. If real phenomena are those phenomena that may (although they do not necessarily) exist in the actual world, then we can be said to have an idea of the actual world if and only if we have ways of predicting and expecting possible features of this world. This prediction may be based on reasons or hypotheses (that is, propositional forms of knowledge that are based on logical inference). Otherwise, it can hinge on "the customary nature of things", as Leibniz claims in his closing remarks about the hippogryph. Let us recall this passage in the light of what we have argued thus far:

A phenomenon will be coherent when it consists of many phenomena, for which a reason can be given either within themselves or by some sufficiently simple hypothesis common to them; next, it is coherent if it conforms to (consuetudinem servat) the customary nature of other phenomena which have repeatedly occurred to us, so that its parts have the same position, order, and outcome in relation to the phenomenon which similar phenomena have had. Otherwise phenomena would be suspect, for if we were to see men moving through the air astride the hippogryph of Ariostus, it would, I believe, make us uncertain whether we were dreaming or awake. (L 363-4/ A VI 4 B 1502; my italics)

As we argued in chapter III, Leibniz's reference to "customary nature" in connection to the parts and movements of a phenomenon suggests that these kinds of prediction rest on the logic of the imagination, which apprehends perceptible wholes qua shapes that have parts that can change place over time. Here, we complete our 
analysis by inspecting the role that similarity and comparison play (vis-à-vis previous phenomena and the idea of a world) as cognitive prerequisites for such predictions. In order to predict and expect, cognizant agents must be capable of breaking the world down into its constituent parts - individuals and their modifications collected into types - while still considering those parts as limbs of an ordered whole. ${ }^{5}$

The idea of a world is, hence, a complex phenomenon implying the capacity to imagine phenomena as connected and ordered by rules, the most basic of which are spatiotemporal, governing the physical movements of bodies. ${ }^{6}$ Even when cognizant agents only implicitly know the rules by which phenomena behave (for neither a child nor a dog has any clear understanding of space and time, but they are still capable of predicting events), that they follow those rules is evident, on Leibniz's view. This is because they manifest attitudes and expectations towards phenomena and their states, which accordingly guide their actions. ${ }^{7}$ Space and time, as very

5 As I have argued, the dialectic between wholes and parts is derived from the Platonic idea of discursive reason, which structures each degree of knowledge, as described in MKTI (what Leibniz calls "perfect intuitive knowledge"). Roughly, the point is that to achieve any form of knowledge, a cognizant agent must be capable of analysis and synthesis as co-dependent moments, in "seeing" the whole while considering the part, and "seeing" the part while considering the whole. In this way, the mind is in the business of recognition, distinction, and order, which are required for clear and distinct knowledge. See Oliveri (2020).

6 Given the scope of this chapter, I can remain neutral on how we are to understand a world. One reason for this is that the notion of "world" implied here is one that finite minds can form. It is not the notion of a metaphysically-possible world, as in the mind of God. Furthermore, even if we can distinguish three main approaches among scholars on what a world $i s$, none of these interpretations denies that the notion of a world requires connections of some sort, whereby those connections are ruled by laws (whether logical, physical, or metaphysical), as each interpretation respectively claims. Logical approaches claim that worlds are sets of compossible individuals and states, insofar as conjunctions of those individuals and states do not produce a contradiction (Rescher 1979; Mates, 1986). Compossibility is hence modelled on possibility as the absence of contradiction. Other scholars (e.g., Hintikka, 1975; Wilson, 2014) object that the notion of compossibility as the absence of contradiction is not appropriate for capturing compossibility. Compossibility regards the compatibility of individuals and events based on physical laws that govern the world. According to a given set of laws, there will be events that can be part of the world, and events that cannot. Packing strategies (McDonough, 2010), on the contrary, reject both logical and lawful approaches, and assume that worlds are collections of substances. The more substances the world entails, the more perfection the world exhibits. This collection has nothing to do with laws, only with the basic properties of substances. We can compare substances to tiles that must fit into a given space (the world). Those tiles are compatible insofar as they tesselate within the given space. Even though McDonough's point is rather intuitive, I still do not understand how a tile can fit into a space determined by other tiles if there are not certain rules governing their relations, even if they are simply the geometrical rules of space and time. Despite these differences in interpreting what kind of connections are proper to the notion of a world, none of these interpretations denies that the notion of world entails connections of some sort.

7 The topic of affects or passions - e.g., suspicion, love, fear - as conative/cognitive attitudes that shape cognizant agents' responses to worldly and non-worldly oriented states, has as-yet not received due attention among Leibniz scholars, although it was a common topic for early modern authors. Some work can be found in Roinila (2015), Di Bella (2005) and Oliveri (2016: 
general rules inhering in sense-perception, explain why we consider bodies as being in agreement in space, as well as for appearing successively. Therefore, if we can imagine a world as a collection of bodies and their states, then this representation rests on first-order coherence.

While space and time are decisive indicators of the reality of phenomena, they alone cannot explain the sense of suspicion that cognizant agents would feel were they to see a hippogryph. Owing to this, space and time cannot alone account for predictions and the reality of phenomena as part of the actual world. Why? Because, based alone on spatiotemporal rules, a flying hippogryph is possible, compatible, and coherent with spatiotemporal rules. For, I can well imagine it moving coherently with space and time. Thus, first-order coherence cannot be the reason for our suspicion towards certain phenomena. If whatever I imagine is spatiotemporally coherent, then space and time alone cannot provide reasons for why what I imagine cannot be part of the world. Such phenomena are only impossible if we take into account something exceeding merely spatiotemporal constraints, viz. its coherence or compossibility with the types of phenomena that exist, or may exist, in the actual world. This is what Leibniz calls the "customary nature of things".

To understand second-order coherence, we need to clarify the relation between spatiotemporal constraints and Leibniz's theory of modality, showing thereby that, while first-order coherence provides some constraints, these are inapposite for capturing phenomena's respective reality or fictionality. In experiencing the incoherence of a certain phenomenon, I consider the phenomenon incompatible (sc. impossible) with a set of phenomena that I consider proper to the actual world. This sort of impossibility - I argue - is physical and weaker than logical impossibility. This is because it rests on hypothetical necessity, not logical necessity. Spatiotemporal coherence is to existence what contradiction is to true propositions: a mere condition of their possibility, not a proof of their existence/truth. ${ }^{8}$

\section{FIRST-ORDER COHERENCE AND MODALITIES}

The topic of coherence in relation to an actual world raises the question of the kind of modality involved in connecting phenomena through predictions and expectations, which is based on imagination. In his letter, The Elements of Geometry of the Duke of Bourgundy, Leibniz evaluates the relation between spatiotemporal rules and eternal truths:

Uniformly ordered continuity [space and time, L.O.], although it is only a supposition, forms the basis of eternal truths and necessary knowledge, and is the object of the divine understanding, whose rays illuminate our understanding too. It is no more a substance or actual thing outside the mind than is abstract and ideal number, and yet time and space ground sciences made up of truths which act as rules for existing things, since the divine understanding, whose

1.2-5). For Leibniz on love, see Leinkauf ([2004: 275-301] 2012); Brown (2011) and Goldenbaum (2009).

8 See, for instance, Generales Inquisitiones PLP 64/A VI 4, 761. 
objects they are, is the source of existing things (Leibniz to Sophie, 31 October 1705 LSS 329/II 4 353).

Space and time, which are the conditions of ideal continuity, can ground the sciences because they act as rules for connecting existing things, as well as providing a basis for eternal truths. In On the Method of Distinguishing Real from Imaginary Phenomena, Leibniz clarifies that predictions based on hypotheses, and on "the customary nature of things", cannot provide metaphysical certainty because they cannot be demonstrated via a reduction ad absurdum:

We must admit it to be true that the criteria for real phenomena thus far offered, even when taken together, are not demonstrative, even though they have the greatest probability; or to speak popularly, that they provide a moral certainty but do not establish a metaphysical certainty, so that to affirm the contrary would involve a contradiction. (L 644/A VI 4 B 1503)

To explain why predictions are only probable, and why the logic of the imagination cannot provide knowledge of eternal truths (and thereby no metaphysical certainty, only moral certainty), we have to first look into Leibniz's project of reforming modality.

Leibniz thought of modalities as distinguished into four interrelated, yet fairly distinct, notions, which form two couplets: possibility-impossibility; and contingency-necessity. ${ }^{9}$ The first couplet is framed in logical terms: possibility consists in whatever does not entail a contradiction, and, consequently, can exist. Whatever entails a contradiction is logically impossible, and therefore cannot exist necessarily. Logical possibility is therefore the condition for possible existence, and is related to the second couplet, which is framed in existential terms: whatever exists, but whose non-existence can nonetheless be conceived without contradiction, is contingent; whatever exists, but whose non-existence cannot be conceived without contradiction, is necessary. ${ }^{10}$

9 Schepers (2014: 18-41) insists on this distinction, which has been routinely overlooked in the literature. Despite the lack of scholarly attention to this distinction, it is relevant because impossibility is a strong kind of necessity, viz. logical necessity, albeit only one form of it. There are, furthermore, metaphysical necessity and physical necessity, the latter being weaker than the former. Metaphysical necessity is weaker than logical necessity but stronger than physical necessity. On Leibniz's notion of modality, see also important works by Poser (1969: 436-51) and (2016); on modality see also Nachtomy (2011) and Bender (2016).

10 A VI 4 865: "Possibile est quod non implicat contradictionem, c on $t$ i nge ns quod non esse non implicat contradictionem. Impossibile quod implicat. Necessarium quod non esse implicat contradictionem." A VI 3 126-7 (trans. Nachtomy, "Leibniz's Theory of Modality", in The Continuum Companion to Leibniz, ed. Look C., Brandon (London/New York: Continuum, 2011) 163): "Necessarium ergo illud vocabo, cuius oppositum implicat contradictionem, seu intelligi clare non potest; Ita necessarium est ter tria esse novem, sed non est necessarium me loqui, aut peccare. Possum enim intelligi esse Ego etsi non intelligar esse loquens, sed ter tria intelligi quae non sint novem, est ter tria esse, quae ter tria non sint, quod implicat, idque numeratio, id est reductio utriusque termini in definitionem, unitates scilicet, ostendit. Contingentia sunt, quae necessaria non sunt. Possibilia sunt, quae non est necessarium non esse. Impossibilia sunt, quae possibilia non sunt, vel brevius: Possibile est, quod intelligi potest, id est (ne vox potest in possibilis definitione ponatur) quod clare intelligitur, attendenti. Impossibile, 

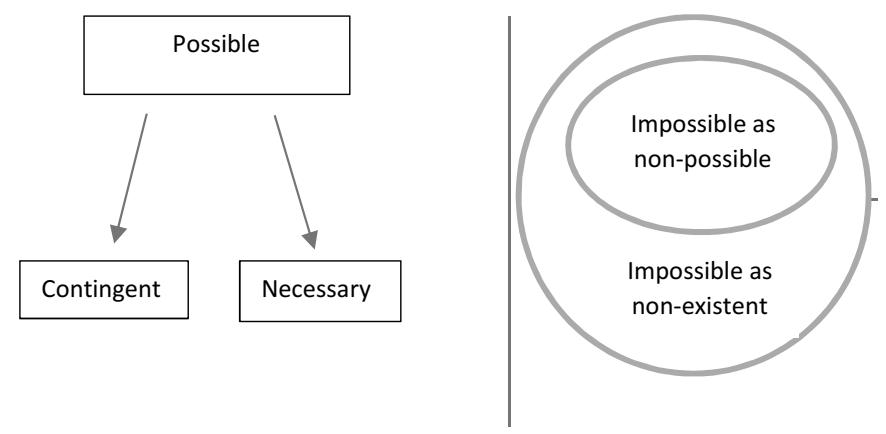

The first couplet is the strongest, in epistemological terms, because it is intrinsically related to logical necessity. The logical couplet typically concerns propositions and holds that, if denying a proposition yields a contradiction, then it follows that the proposition is a necessary truth. Leibniz was adamant that there is a set of necessary truths that rests on the logical couplet. Identity is a necessary truth, for instance, because denying an identity claim yields a contradiction. However, on Leibniz's understanding of modality, there is another notion of impossibility that is related to existence. According to this kind of modality, in supposing the existence of a set of things or conditions, we can deduce the existence or non-existence of something else. Contrary to logical impossibility, the supposed thing or event is not impossible per se: it rests on the principle of sufficient reason, which means that the denial of existence does not yield a contradiction. It is therefore impossible only on the supposition that something else exists, and that this is connected to existence either empirically or by way of reason: ${ }^{11}$

Absolute necessity is when we cannot conceive of a thing otherwise, as it implies a contradiction in terms, e.g., three times three equals ten. Hypothetical necessity is when we can conceive of a thing otherwise per se, but per accidens, if other things outside it are presupposed, it is necessary, e.g., it was necessary that Juda would have sinned, if we assumed that God had foreseen it[,] or $(\mathrm{vel})$ if we assumed that this Juda was considered to be the best. The series of things is not necessary of absolute necessity. Many other series are indeed possible, which is conceivable (intelligibiles), as from this act [of conceiving L.O.] their "execution" does not follow. (A VI 4 B 1377)

Logical necessity differs from hypothetical necessity. In virtue of the difference between necessity and impossibility (the former capturing logical relations, the latter existential connections), other worlds are possible. This split notion is therefore crucial for resisting necessitarianism, that is, the idea that the actual, existent world

quod possibile non est. Necessarium cuius oppositum impossibile est, Contingens cuius oppositum possibile est."

11 Di Bella (2005: 67-95) reconstructs a terminological cluster deployed by Leibniz to capture ontological dependence, which includes concepts such as requisites, inference, illatum, series, and connection. 
is the only possible world. In freeing the notion of possibility from that of existence, thereby rendering it merely logical and distinct from contingency, Leibniz hoped to provide a framework for arguing for the (logical) possibility of infinite possible worlds: whatever finite human minds can conceive of without contradiction can exist regardless of existential conditions. ${ }^{12}$ The conceivability of other possible worlds can provide a premise to argue for the contingency of the actual world, and hence for God's freedom in choosing the world.

I shall now reconstruct this argument according to Schepers (2014: 3-18), who presents the transformation of the two couplets from Aristotle's De Interpretatione and Metaphysics through Scholastic authors, such as Thomas Aquinas, Roger Bacon, and Abelard. As Schepers argues, the very distinction between contingent and possible stems from logical treatises concerning entailment. What we learn from his reconstruction is that a neat separation of possible from contingent (the former defined by logical relations, the latter by temporal relations of existence, i.e., intraworld connections), allows Leibniz to treat necessity and contingency as formally equivalent. Anything that exists can be considered as contingent per se, because its non-existence does not produce a contradiction, as well as hypothetically necessary, since, on any given set of premises, we have sufficient conditions to infer the thing's existence with a certain degree of necessity. ${ }^{13}$ Thus, the actual world is both contingent and necessary (Schepers, 2014: 18-41). As Schepers further notes, this account of modality paves the way for a more fine-grained treatment of truth: when dealing with contingent truths, the same thing might and might not have been; it is simply more or less probable. ${ }^{14}$

12 GP III 573-74: "le seul meilleur existe, mais non pas que le seul meilleur soit possible, ou bien c'est changer la signification des Termes. J'appele possible tout ce qui est parfaitement concevable, et qui a par consequent une essence, une idée: sans considerer, si le reste des choses luy permet de devenir existant."

13 Interestingly enough, Schepers (2014: 18-41) begins his contribution by observing that Leibniz's theory of modality and notion of contingency seems to challenge the idea that everything is either true or false: tertium non datur. Schepers deny that this is the case for Leibniz, and he is right. Nonetheless, we can say that, from the perspective of the finite, human mind, Leibniz's epistemology of modality opens up a gray area of probable events that are either true or false, in strict logical terms, although they are not parts of the world. Therefore, the chief task of Leibniz's epistemology consists in "an investigation of the conditions that enable human beings to acquire them" (Bolton, 2016).

14 To prove that probable truth were among Leibniz's main concerns, consider that, in presenting his universal language to Herzog Johann Friedrich in Februar(?) 1679, Leibniz stresses (among the many advantages of the calculus) its utility in helping us to achieve truth not only in those fields where we can rely on "raisonnement, par une espece de calcul infallible", but also in what is simply probable: "Car par la nous pourrions estimer les degrés de probabilité, ce qui est une chose également importante et negligée dans la morale et dans les affaires" (A I 2 122). Similarly, during the Fall of the same year, Leibniz writes (L 260): "We need a new logic in order to know degrees of probability, since this is necessary in judging the proofs of matters of fact and of morals, where there are unusually good reasons on both sides and we are concerned only to know on which side to tip the scales. But the art of weighing probabilities is not yet even partly explained, though it would be of great importance in legal matters and even in the 
Given this framework, the argument runs as follows. Cognizant agents can imagine states of affairs without having experienced them. I can imagine myself not writing this book, for instance. A possible non-existing state of affairs can be considered part of another non-existent, yet possible, world. Therefore, other worlds are possible. For God could choose between many different worlds, each of them wellformed and internally consistent, but He must have a reason to create only one world. God's reason is that only the best possible world can exist. God chooses the best among all possible worlds because - given His goodness and goals - there is only one world that fits the description of being the best world. The other worlds are simply incompatible with God's goals, although they are not in contradiction with God's understanding. Insofar as other worlds are still logically possible and capable of existence, God is not forced to choose the best. He would be forced to choose the best, as Leibniz argues, if the best world were also the only logically possible world, such as would be the case on the necessitarian theory (where possible is declined in temporal terms and rendered equivalent to the series of things that have existed, do exist, or will exist). Hence, the proposition "God could have not not-chosen the best of all possible world" is morally, but not logically, necessary. It is logically possible and contingent; therefore, it is not impossible. ${ }^{15} \mathrm{We}$ can surmise that Leibniz simply distinguishes between the true and the good. What is good regards existence and is not determined by logical rules alone. That which is alone determined by logical rules are abstracta. Identity and contradiction, as we shall soon see, concern concepts and abstract essences; what exists is only compatible with logical principles. Thus, whether or not we accept the foregoing argument, we can nevertheless appreciate the impact that a split-notion of necessity has on epistemology, as well as on the human mind's employment of modal arguments. This is because the distinction produces varieties of both necessity and of the ways that minds may conceive of those varieties.

In De Summa Rerum (1675), the young Leibniz, contrasting what he believed to be the widely-held notion of modality, already endorses the split-notion of necessity. The necessitarian notion of modality conflates what is possible with its temporal understanding: Only what was, is, or will be is possible.

"Impossible" is a two-fold concept: that which does not have essence, and that which does not have existence, i.e., that which neither was, is, nor will be because it is incompatible with God, or, with the existence or reason which brings it about that things exist rather than do not exist. One must see if it can be proved that there are essences which lack existence, so that it cannot

management of business." The idea of estimating the "degree of probability" was much-discussed in Leibniz's time, and goes back to the mathematical work of Pascal and Bernuoille. It is further reflected in Leibniz's mathematical work, especially regarding the establishment of a national pension system.

15 As Schepers (2014: 14-41) observes, what is decisive for the success of Leibniz's argument is the formal/logical equivalence of contingency and necessity. God does not choose what he wills, like Descartes' God, but what he understands to be best. Owing to this, his choice is morally necessary, albeit still contingent because other worlds are equally equivalent on his logical understanding. 
be said that nothing can be conceived which will not exist at some point in the whole of eternity. All things which are, will be, and have been, constitute a whole. Whatever is incompatible with what is necessary is impossible. There is a reason which brings it about that this, rather than something else, exists. The origin of impossibility is twofold: one from essence, the other from existence or positing as actual. (DSR 7/A VI $3463-4$ )

I can conceive of unicorns and yet they do not exist. The fact that I can conceive of them is proof of the possibility of the essence "unicorn". ${ }^{16}$ I can collect natural evidence that makes me conclude, with some certainty, that unicorns have never existed and are therefore impossible in the sense of the existent - they were not, are not, and will not form part of the chain of beings that populate the actual world. In a parallel fashion, there are things whose impossibility I can conclude just from considering their essences, and others that I can conclude simply on account of a set of conditions obtaining. Consider the following statements: "it is impossible that three times three equals ten"; "it is impossible for this fire to burn my hand because it is too far away from my hand". Both are impossibility claims, but, as Leibniz suggests, they imply a different variety of impossibility and, hence, necessity. This is because the latter statement is only contingently necessary, that is, it offers a reason for why the state might not obtain in the world. ${ }^{17}$

If I understand Leibniz's overall point correctly, then things that exist, will exist, and have existed form a chain that we can label "the actual world". From the point of view of cognizant agents, the world is composed of existing phenomena. How can the agent know which phenomena can exist, sc. are real? Leibniz's answer is that the agent has means for predicting which phenomena can fit into the world. The cognizant agent learns to connect a set of existing and experienced states to other states that follow from that set. This set of phenomena functions as an antecedent in a hypothetical conditional, ${ }^{18}$ although the kind of connection implied may take various forms. For, it may be of a strong kind, that is, resting on reason and knowledge of essences; it may be based on a selection of properties considered as requisites for the existence of another thing; or they may be merely empirical connections based on an inclination to expect another state when experiencing a given one. In any case, it is worth noticing that the antecedent, which is, in all cases, something existent, is necessary because "what was done cannot be undone" (DSR 8/A VI 3 464). The necessity of the antecedent warrants some degree of certainty of the consequent, although the likelihood of error depends upon whether the premises are empirical or a priori:

However, a human being, insofar as he does not act empirically but rationally, does not rely solely on experience, or a posteriori inductions from particular cases, but proceeds a priori on the basis of reasons. And this is the difference between a geometer, or one skilled in analysis, and an ordinary user of arithmetic teaching children, who learn arithmetical rules by rote but

16 In a letter to an unknown correspondent (October 1707; forthcoming in II 5), Leibniz clarifies that all species exist in God's mind as an ordered chain of distinct ideas. We will discuss this topic in the next chapter. A similar idea is also proffered in NE 307; 474/A VI $6307 ; 474$.

17 For a discussion of necessity in relation to contingent necessary truths, see Bolton (2016).

18 NE 447/A VI 6 447. For discussion, see Di Bella (2005) and Bolton (2017). 
do not know the reason for them and consequently cannot decide questions that depart from what they are used to; such is the difference between the empirical and the rational, between the inferences of beasts and the reasoning of human beings. For even if we experience many successive examples, we still are never confident of lasting success, unless we discover necessary reasons, from which we may conclude that the matter cannot be regarded differently. Thus brutes (as far as we can observe) do not acquire knowledge of the universality of propositions, because they do not understand the ground of necessity. And even if empirics are sometimes led by inductions to universally true propositions, this nonetheless happens only accidentally, not by the force of entailment (RSB $\S 14 /$ Dutens 232).

To summarize, cognizant agents have various resources for connecting things and events whose knowledge requires empirical data. The means used to reach stable predictions affects degrees of certainty, and thereby the kind of necessity the connection involves. A cognizant agent's degree of certainty regarding their predictions impacts their practical life insofar as they tend to plan their actions in accordance with those predictions, as well as in accordance with the degree of probability of their expectations. The more successful cognizant agents are in making predictions, and the more they can be said to know the actual world and what can exist, the better they can act. De Summa Rerum expresses this very thought in arguing that "existence" is not simply "to be sensed": things exist that "are consistent, or that our predictions about them are true, as our predictions of eclipses [...] We appear to prove their existence insofar as they follow from our sensations as either a necessary or a probable consequence" (DSR 8/A VI 3 464). The foregoing reference to the eclipse is one of Leibniz's favored examples for explaining the distinction between simple empirical knowledge - such as when we expect the sun to rise - and scientific knowledge. Our prediction of an eclipse is indeed the result of a geometrical and mathematical calculation based on the existence of certain entities and their states: the sun; the earth; the moon; and the sun's revolution. Mere empirical relations become necessary to our understanding via a translation or expression of those entities' existence and relations, known via experience. The first translation consists in a geometrical representation of the solar system (geodic bodies that move regularly in elliptical orbits), and then, by virtue of this translation into geometrical objects, into a mathematical calculus predicting movement. Let us not forget what Leibniz says to this end: "Physics is subordinated to arithmetic or algebra insofar as it concerns magnitude; to geometry insofar as it concerns situation; to metaphysics insofar as it concerns resistance, i.e. action and passion" (A VI 4 B 1394/LoC 242). Through expression, the necessity of the prediction is warranted by the formality of the calculus and the geometrical means for making the prediction. Since the connections within the calculus are necessary as warranted by logical principles (such as identity and contradiction), if we predict the eclipse in virtue of a calculus, then the degree of necessity of the prediction cleaves closer to logical necessity. ${ }^{19}$

19 As Leibniz explains at A VI 6 478-9/NE 478-9: "Je tiens que l'invention de la forme des syllogismes est une des plus belles de l'esprit humain, et même, des plus considerables. C'est une espece de Mathematique universelle dont l'importance n'est pas assés connuë. Et l'on peut 
This is, however, not the only way to predict phenomena. Indeed, Leibniz refers to "things as they follow from our sensations", the text affirming our capacity to predict bodily behavior (e.g., we can predict what might follow from a perceived environmental state) without the deployment of formal-logical or mathematical means, which are respectively based on deduction as well as propositional knowledge of concepts and essences. Our predictions first achieve a lower degree of probability by referring to "the customary nature of things", which is furthermore grounded in the logic of the imagination, which accounts for spatiotemporal relations between bodies and their parts. After all, the passage's chief message is that existence is more than the mere sense-perception of a being. Rather, it is an implicit judgment/expectation that the nature of the being is coherent with the set of phenomena we know to be part of the actual world. It is coherent simply because we can form expectations. This does not preclude our having diverse means for connecting and predicting states.

Predictions can rest upon various kinds of necessity that are not of a logical kind. The presence of such variety gives us cause to hypothesize that, regarding the order of discoveries (about which we will elaborate shortly), cognizant agents may access some degree of modal reasoning without full-blown logical understanding of the logical modal couplet and, thereby, of necessary truths. In other words, we can grasp some form of contingency/necessity based on imagination and experience. This knowledge, however, is not equivalent to that of a stronger logical/metaphysical kind. If space and time are insufficient for determining phenomenal connections, then the imagination must rely on other constraints that permit the interiorization of things' common natures.

\section{SECOND-ORDER COHERENCE AND ITS CONSTRAINTS}

Although first-order coherence is not sufficient for distinguishing between real and imaginary phenomena, the consideration of what can exist vis-à-vis space and time allows us to deduce those other constraints of the imagination: sameness; difference; and similarity. These constraints - which are parasitic upon space, time, and causation - are involved in the interiorization of more specific types of bodies.

We have argued thus far that space and time are involved whenever we segment two bodies by enclosing them into a shape. We saw from our analysis in chapter II that segmenting shapes corresponds to the act of coperceiving bodies and making

dire, qu'un art d'infaillibilité y est contenu, pourvû qu'on sache et qu'on puisse s'en bien servir, ce qui n'est pas toujours permis. Or il faut savoir que par les argumens en forme, je n'entends pas seulement cette maniere scholastique d'argumenter dont on se sert dans les Colleges, mais tout raisonnement qui conclut par la force de la forme, et où l'on n'a besoin de suppléer aucun article. De sorte qu'un Sorites, un autre tissu de syllogismes qui evite la repetition, même un compte bien dressé, un calcul d'Algebre, une analyse des infinitesimales, me seront à peu prés des argumens en forme; parce que leur forme de raisonner a esté prédemontrée, en sorte qu'on est seur de ne s’y point tromper.”. See also Rabouin (2017) and Bolton (2016). 
them available for qualitative and quantitative comparison. In so doing, we see that two bodies are similar or dissimilar with respect to quality or size, or congruent, which is when their borders perfectly overlap. I would now like to focus on what Leibniz says about the apprehension of perfect congruency. This will help us to deduce constraints constituting second-order coherence:

Now with the aid of time and place we can also distinguish individuals, and decide which are the same and which are different; for example, if I have to eggs in front of me that are similar and equal throughout, and I want to distinguish them, we must either make some mark on them by which they will be rendered dissimilar, or we collect them together in some fixed place, for example, with one above and the other below; or finally, if they are to be left free, or if something allows them to move, as when they are floating in water, then it remains only to follow their movement with the eye, which appears a succession in time changing situation, and we certainly never find the same body simultaneously in different places, nor from one place in another if it does not go through intermedium situations. Furthermore, the collection of all bodies that are understood to be in space, i.e., those that have mutual situation, is called a world, and there are various states of the world at various times. (A VI 4 B 1397/LoC 243 translation slightly changed)

Spatiotemporal rules dictate how things may or may not exist, giving us a glimpse into how things can or cannot possibly exist. Two bodies, although they might appear similar, while being co-perceived (sc. apprehended simultaneously in senseperception as occupying two different places) cannot but consist in two distinct bodies, not one and the same body. By the same token, the same body that occupies two different positions at the same time is considered impossible because the agent does not conceive of it as one and the same body. ${ }^{20}$

From these reflections regarding what first-order coherence permits us to imagine, we can deduce that there is at least one necessary truth we cannot learn on account of the imagination alone: identity and contradiction. For, whatever is senseperceived as occupying a different position in space at the same time is apprehended by the imagination as always distinct from any other coperceived body. Indeed, if all acts of the imagination rest on coperception: the act of comparing two, perfectlyalike bodies is never sufficient for inferring that the two bodies are one and the same. Neither can one infer identity from experience, i.e., coperceptibility cannot be the act by which cognizant agents apprehend identity relations. The kind of sameness the imagination accounts for is sameness as either coincidence or as permanence over continuous change.

Sameness as coincidence, and difference as non-coincidence, are respectively matters of the phenomenal presentation of shapes and the overlap of their borders. Coincidence is therefore related to geometrical similarity, that is, to something we can visualize. Consider what Leibniz writes in the paper Elementa Nova Matheos

20 I would like to stress that Leibniz has in mind concrete beings, like two leaves, not abstract mathematical entities. It can surely be the case that I draw two circles on a paper, perfectly alike, and consider them to be identical. Nonetheless, I need to draw two circles and senseperceive the two figures, which are distinct on the paper. To exist as images, they need to be the result of two distinct chains of productive events. 
Universalis after having argued that different, simultaneous locations of two, perfectly-alike things constitutes a valid epistemic criterion for their distinct existence:

When also things do not differ even in number, so they differ by chance in our expression or they appear different from different respects, these are said to be coincident. In this way, the ellipsis sectioned from the cone coincides with the ellipsis sectioned from the cylinder, and this appears evident when the cone and the cylinder are conceived to cut themselves obliquely. (A VI 4 A 514-15)

Sameness and difference are principles distinct from identity and contradiction, as the latter ground conceptual containment. ${ }^{21}$ Indeed, only the latter constitutes principles for structuring thought and grounding necessary truths; thought does not consist in the sensory presentation of phenomena, but in the propositional apprehension of essences. Owing to this, we can add to the list of spatiotemporal constraints, which govern the imagination, the grounds for second-order coherence. These constraints must be understood as limits on the imagination when dealing with existing phenomena, i.e., what the imagination cannot cognize/imagine vis-à-vis obtaining phenomena. These constraints are not necessary principles, however (that is, their denial does not produce a contradiction). We cannot imagine two bodies as occupying the same place. We do not know whether it is logically impossible for two bodies to occupy the same place. Let us reframe these limits more positively as follows:

(vi) Difference: whichever two bodies the mind apprehends simultaneously in space are apprehended as different and distinct, i.e., as two;

(vii) Sameness: whatever body the mind apprehends as moving continuously is apprehended by the mind as being the same;

(viii) Similarity and dissimilarity: two bodies, which are coperceived as having the same shape or being congruent, are considered to be similar or the same insofar as their borders coincide.

That which can or cannot be imagined as existing depends on how that which becomes apparent via sense-perception is then processed in accordance with spatiotemporal constraints, as outlined in (i)-(v) (see chapter IV), and furthermore according to the above-listed second-order constraints. The capacity to imagine is related to modality insofar as imagining is the act by which agents can expect and predict what will or will not exist.

The constraints on the imagination that we have deduced point to an important tenet within Leibniz's theory of imagination. Imaginative processes do not directly rely on the principles of identity and contradiction. Indeed, this is the reason why the imagination may lead us astray, causing us to believe contradictions. Contingency, as something that is in agreement with spatiotemporal rules, and possibility, as that which is contradiction-free, rest upon distinct principles: sameness/difference, on the one hand, and identity/contradiction, on the other. The connection between possibility and contingency is established by the fact that whatever exists,

21 Mugnai (2016) and Rabouin (2018) have argued for a distinction between these two notions of identity. See also Malink \& Vasudevan (2019) 
whether necessarily or contingently, cannot but be contradiction-free. However, not everything that is free from contradiction actually exists. To prove that identity and contradiction cannot be derived from the empirical concepts of sameness and difference, consider Leibniz's reply to Locke, who, by contrast, believes it to be possible to abstract the principles of contradiction and identity from the proposition, "the same is not the different":

I cannot really see how the proposition the same is not the different is the origin of the principle of contradiction, and "easier" than it: for it appears to me that one goes further in asserting that $A$ is not $B$ than in saying that $A$ is not non- $A$; and it is because $\mathrm{B}$ contains non- $\mathrm{A}$ that $\mathrm{A}$ is prevented from being $B$. Furthermore, the proposition that the sweet is not the bitter is not "innate" in the sense we have given to the term "innate truth"; for the sensations of sweet and bitter come from the outer senses, so that the proposition is a mixed conclusion (hybrida conclusio), in which the axiom is applied to a sensible truth. But as for the proposition "the square is not the circle": it might be called innate, for in thinking it one applies the principle of contradiction to materials which the understanding itself provides, as soon as one becomes aware that these ideas - which are innate - contain incompatible notions (NE 82-3/A VI 6 82-3).

This is, to be sure, a complex passage, and it is difficult to appreciate the extent to which it brings grist to our mill. So, let me explain how we should understand it. Leibniz here distinguishes the proposition "the same is not the different" from the principle of contradiction, "A is not non-A". This is because, he claims, the former is thornier than the latter. "A is not non- $A$ " is "easier" than "A is not B" because it is self-evident and simple. "Easier" here must be read as meaning 'simpler' or 'less complex', as suggested by the rest of the passage regarding conceptual containment. When we say that two things are the same, or that they are different, we convey more than a claim regarding self-identity, i.e., the fact that there are two things (A and $\mathrm{B}$ ), rather than one - these two things being non-identical. As illustrated by the example of the square and the circle, Leibniz argues for the distinction of the two principles from the perspective of conceptual containment. Leibniz's explanation is that if we analyze B (a concept, like SQUARE), then we will find out that B contains a conceptual mark, $\mathrm{C}$, that remains in contradiction with another conceptual mark of, A, where A is another concept, like CIRCLE. B, however, contains many other conceptual marks, e.g., D, E, and G. Therefore, saying "A is not B" means more than "A is not non-A."

Non- $\mathrm{A}$ is contained in $\mathrm{B}$ in the sense that $\mathrm{B}$ has conceptual marks that remain in contradiction with the conceptual marks of A: A has no-C (sc. "no angles") and $\mathrm{B}$ has $4 \mathrm{C}$ (sc. "four angles") amongst its characteristic marks. Therefore, contradiction is produced not by visualizing A and B as different but rather by analyzing the two concepts into conceptual marks that are mutually-exclusive: "has four angles" means "has angles", while "absence of angles" means "has no angles". "A is not non-A", or "the circle is not non-circle", is therefore simpler than saying "the square (B) is not the circle (A)."

Moreover, the proposition "the square is not the circle" is innate, Leibniz argues, because it rests analytically on the principle of contradiction. Indeed, it presupposes it. It is moreover because the concepts are innate: CIRCLE and SQUARE are "materials which the understanding itself provides". There are many ways for 
us to comprehend the sense in which these concepts are innate, but I shall leave that discussion for chapter IX. The important aspect for our present discussion is that, if the rational agent is capable of decomposing both concepts to find conceptual marks that contradict one another, then the cognizant agent can be said to have a concept.

Leibniz's appraisal of the simplicity of intellectual principles, such as identity and contradiction, is especially informative when read with regard to his distinction between the order of discovery, i.e., the temporal and developmental order according to which a subject discovers and acquires truths, and a natural order of knowledge, i.e., the logical and epistemic dependence of truths and propositions on intellectual principles independently of their order of discovery. Furthermore, regarding the order of discovery, more complex knowledge is related to sense-perception. Owing to this, a subject's attention is attained even before she acquires the capacity to attend to more abstract and intellectual principles:

The truths that we start by being aware of are indeed particular ones, just as we start with the coarsest and most composite ideas. But that doesn't alter the fact that in the order of nature the simplest comes first, and that the reasons for particular truths rest wholly on the more general ones of which they are mere instances. And when one wants to think about what is in us implicitly, before all awareness, it is right to start with the simplest. For general principles enter into our thoughts, serving as their inner core and as their mortar. Even if we give no thought to them, they are necessary for thought, as muscles and tendons are for walking. The mind relies on these principles constantly; but it does not find it so easy to sort them out and to command a distinct view of each of them separately, for that requires great attention to what it is doing, and the unreflective majority are hardly capable of that (NE 83-4/A VI 6 83-4).

This means that the proposition "the same is not the different" can be apprehended before the proposition "A is not non-A", the former being primary in the order of discovery. However, the former proposition is not equivalent to contradiction. Although things that are different are so because they have parts that remain in contradiction, saying that two things are different is not tantamount to saying in what respect those two things are in contradiction. In the logical order, then, the principle of sameness and difference depends logically on contradiction only insofar as, for any two distinct things, if we can provide an analysis of the conceptual marks composing the concepts respectively associated with those things, then we are, perhaps, capable of locating those contradictory marks.

Although analytical understanding of difference depends on the principle of contradiction in the natural order of knowledge, rational subjects can understand and apprehend two things as being different before they are able to give reasons to explain their differences. From this perspective, truths about facts, such as "the sweet is not the bitter", can be elevated to a degree of necessity even if only in virtue of a "mixed conclusion", which rests on both sensory apprehension and certain innate ideas. $^{22}$

A "mixed conclusion", as I understand it, consists in an implicit judgment about the difference between two things or properties apprehended as different through 
non-logical, non-analytic means, which is then expressed as being different through logical and analytical means, such as language.

Thus, in seeing a square and a circle drawn onto a piece of paper, for instance, we apprehend them as different owing to the logic of the imagination: we are capable of apprehending the two shapes as different in an act of coperception. The shape therefore functions as a reason insofar as it sense-perceptually expresses what is later made analytically distinct via certain conceptual intensions: the presence or absence of angles. Only when we finally have more analytic reasons to see why the circle is not the square, we thereby also apprehend the necessity of the statement "the square is not the circle." This truth is said to be innate on Leibniz's view, and is opposed to the example of the sweet and the bitter, because the concepts SQUARE and CIRCLE are not derived from experience, while suit and bitter are.

In like fashion, we can distinguish the sweet and the bitter on account of senseperceiving them as different. In tasting the sweetness of a pineapple and the bitterness of a lemon, we can tell the two sensations apart. However, to consider sweetness and bitterness as general properties instantiated by diverse bodies, more is required, viz. identity and contradiction. This is why the conclusion is mixed.

Sweet and bitter are, for Leibniz, sensations of the confused kind. This means, amongst other things, that they cannot be analyzed into further conceptual marks, as with the concepts of CIRCLE and SQUARE. Therefore, our reasons for distinguishing between them is owing to differences we experience in sense-perception. As I have argued elsewhere (Oliveri, 2016a), despite the contents of sensations being unanalyzable, cognizant agents can form, and denominate, general notions of sensations. However, the fact that we have a name for general notions still fails to provide us with concepts. The act of distinguishing conceptual marks within the content is necessary for having a clear and distinct notion, which is a concept, and this act differs from distinguishing extended parts into a whole. ${ }^{23}$ Yet, rational agents deal with them as if they were concepts because they are represented by means of general names. We have general names for them in the same way as we have general names for "man" or "chair" or "circle". In giving sensations a general name, we treat them as ideal entities: as something over and above their inherence in concrete existing bodies, and hence as abstract and general essences that determine what sweetness and what bitterness are. When we form the proposition, "the sweet is not the bitter", sweet and bitter operate as abstract names, and, in dealing with abstracts, we enter the ideal realm of essences, as governed by the logical principles of contradiction and identity. ${ }^{24}$

23 I think it is, following NE 267/A VI 6 267. Scholars usually feel more liberal on this point, arguing that generality of content is sufficient for having a concept. Bolton (2011b) argues that sensations are concepts, but they are not distinct (a similar view is proffered by Barth (2017)). This disagreement is, however, irrelevant to point at stake. The only important aspect here is that we cannot distinguish within the content of sensations, a point on which scholars are unanimous.

24 In Oliveri (2016a), I argue that we do not have a concept for sensation: we rather have a name that functions as a blind thought. In having a general name for the sensation, we treat it $a$ if it 
If this separation between imaginative and logical principles is correct, then imaginatively-grounded forms of reasoning are performed in agreement with, and yet independently of, an explicit grasp of logical-propositional forms of reasoning and inference, whilst also allowing for forms of pre-conceptual relations and connections among phenomena. Imaginative forms of reasoning do not amount to thought, for this requires logical forms of reasoning that are based on concepts. Concepts require conceptual containment and hence identity and contradiction. If 'logical' means whatever affords the stable knowledge of necessity, then they are not the only source of knowledge.

Thus, sameness, difference, and similarity structure the imagination in performing its groundwork of segmenting shapes and apprehending perceptible wholes. Through these synthetic acts, the imagination spontaneously compares wholes, taking them as being the same and different in terms of shape and size, i.e., something perceptible as the sweet and bitter, or the square and the circle. Moreover, the continuity of space and time guarantees that the imagination further apprehends the successive changes of a body as changes of the same body thanks to its moving through continuous transformations. The continuous movements can be apprehended as such because shape is used for considering the body to be the same body. At each moment, the body does not change shape. If it does, as when I take a tomato and turn it around, these changes amount to continuous transformations in compliance with geometrical-perspectival laws. In this way, the consistency, or coherence, of changes explains why one is able to track the movements of a tomato and take them as changes of the same body, even if the tomato changes shape. This moreover explains why one would be surprised if the tomato suddenly turned into a red square. In experiencing a sudden discontinuous change, one would doubt whether the thing experienced remained the same.

Sameness, difference, and similarity - along with spatiotemporal rules and associative causation - act as constraints on the imagination. Indeed, they are important because they give us a framework for overcoming the limits of spatiotemporal constraints as grounding first-order coherence. The spatiotemporal logic of the imagination is required for determining the set of things that can exist qua embodied. Indeed, this grounds first-order coherence. However, the set of things that can exist per se is wider than the set of things that can exist in the actual world. The former set allows for "unicorns", "hippogryphs", and "heavy bodies moving upwards when suspended in the air", but these are not part of the set of things that can exist in the actual world. While these phenomena are imaginable with regard to first-order coherence - that is, they cohere with space and time - a cognizant agent has no such phenomenal expectations in the actual world.

were a concept. However, what we have is simply a general name that refers to instances of sensations. Recognition and generality alone are not sufficient marks of conceptual knowledge, for which we require distinctness, or the analysis of notions into intensions. For a different view, see Barth (2017). He argues that sensible qualities, like redness, undergo a conceptualization (Verbegrifflichung). 
It is at this level that Leibniz introduces the notion of coherence to the customary nature of phenomena. Only when we consider the common nature of the type "body" can we say that bodies - as they customarily behave in the actual world, and of which we have experience in virtue of sense-perception and the constraints on the imagination - do not move upwards when suspended in the air. When we consider the world to be a totality of the types of things that can actually exist, we do not expect to see hippogryphs and unicorns. We do, however, expect glass to fall and shatter when dropped from a height.

In other words, sameness, similarity and difference are used to interiorize what types of bodies there are and to recognize presently perceived bodies as types. Only when one has the ability to recognize a body as an instance of a type, one can also locate that type in a world and form more detailed predictions of how that body will interact with other presently co-perceived bodies. The next chapter will provide an analysis of how types are interiorized.

\section{CONCLUSION}

First-order coherence, which is based on spatiotemporal constraints alone, is insufficient for capturing the notion of coherence to which Leibniz refers in the context of distinguishing between real and fictional phenomena. This is to say that space and time ground a first-order coherence. There is then a second-order coherence, which is parasitic upon space and time, and is moreover grounded on other imaginative constraints, viz. sameness, difference, and similarity. These further constraints allow the cognizant agent to capture things' nature and interiorize things as types. Through the filter of types, cognizant agents determine the set of things that can exist as natural phenomena in the actual world, owing to which they rightfully expect and predict what kinds of phenomena - given a set of experiential conditions - can or cannot form part of the actual world.

Having now fortified our understanding of the logic of the imagination and its principles, we are finally ready to turn to how cognizant agents interiorize types. 
Franz Steiner Verlag 


\section{SIMILARITY, MOVEMENT, AND THE INTERIORIZATION OF TYPES}

What we have described thus far - especially through chapters II to V - are the three moments that constitute the development of a cognizant agent's apprehension of their perceptual environment. The first moment consists in the exercise of agents' synthetic capacity to segment sensations - which are afforded by the senses - into shapes. In so doing, individual beings are expressed as perceptible wholes. As explained in chapter II, perceptible wholes consist in an amalgam of sensations, and therefore constitute a kind of confused perception, which must become distinct.

The process by which confused perceptions of perceptible wholes become distinguished or distinct perceptions constitutes the second moment. This consists in tracking perceptible wholes through spatiotemporal variations, which involves comparing them in acts of coperception, thanks to which wholes may appear close to one another in space at the same time. Spatiotemporal tracking is the basis to apprehend wholes as bodies, that is as sets of states that are compatible or incompatible with other states of the world. This framework allows cognizant agents to compare beings as similar or dissimilar, owing to which they can start performing various associative activities, and through which they are able to store information about how a body (qua an expression of a nature common to many individuals) changes. By apprehending the common nature of various phenomena, cognizant agents interiorize types.

Types represent the third moment in a process of sensory apprehension by cognizant agents. Types are abilities for considering actually-experienced phenomena as instances of a class of phenomena that are associated in virtue of their similarity. This association of phenomena enables cognizant agents to recall information, as well as form expectations of how a phenomenon may change from one situation $\left(t_{1}\right)$ to another $\left(t_{2}\right)$. On account of this process, originally-confused perceptible wholes become a distinct kind of perception because (i) the cognizant agent learns to distinguish between the relevant parts and properties of phenomena qua phenomenon of that type; (ii) this distinction within the phenomenon enables the cognizant agent to form expectations and predictions; and (iii) the cognizant agent forms an idea of a world, through which she learns to see phenomena as either fitting or not fitting parts of the world, whereby "world" can at first be limited to combinations of experienced phenomena, about which I shall elaborate shortly.

This chapter is divided into two parts. The first part highlights Leibniz's theory of how we learn types and the importance of similarity. The second part addresses some difficulties raised by his theory.

Part one is dedicated to similarity and argue that cognizant agents' capacity to detect similarity of shape constitutes an initial, albeit fallible, grasp on the individ- 
ualization of things' common nature (sect. 1). It is limited to the sensory apprehension of bodies qua instances of a common nature. The reason why cognizant agents first interiorize types for bodies, and only then types for properties, is the imagination's proclivity for apprehending shape over other aspects of bodies that are likewise imaginatively available. In other words, types are first and foremost ways of sorting sense-experienced individuals into similarity classes, and then, through comparison, constitute ways of non-conceptually analyzing bodies qua bodily types into their constitutive parts and properties. Through a survey of New Essays, I will argue that a cognizant agent's capacity to detect types is exercised spontaneously and before her capacity to apprehend individuals (sect. 2). This aspect will turn out to be a decisive constrain on the imagination and its combinatoric work, as it emerges in the second part.

Part two highlights why what we called perceptibility is a kind of conceivability (sect. 3). In keeping with the idea that there are varieties of necessity, so too are there varieties of conceivability that account for the apprehension of relations. Indeed, types are rooted in the apprehension of beings' similarity, and hence depend on the kind of conceivability Leibniz calls "perceptibility", i.e., an apprehension of sensorially-experienced phenomena as existing. The imagination's capacity to detect relations constitutes its combinatoric and synthetic character. Therefore, we shall move on to the productive nature of the imagination (sect. 4). Despite working closely with what the senses put forward in perception, the imagination is a combinatoric faculty, which enjoys freedom in its activity of combination. The freedom of the imagination consists in drawing inferences by imagining combinations of phenomena that it has not yet experienced. However, because the intrinsic spontaneity of the imagination may lead cognizant agents astray, they therefore need experience to enhance their ability to reliably predict real phenomena. The analysis put forward in part one will provide an answer to why cognizant agents are mostly in the business of re-enacting the past, rather than entertaining new unexperienced combination.

\section{HOW DO WE INTERIORIZE TYPES?}

We have argued thus far that a type is an acquired ability to perceive a phenomenon in a distinct way. Types are moreover interiorized via the processing of sensory experience through the cognizant agent's innate powers, which we have labelled the "logic of the imagination". The perception that a phenomenon is distinct transpires when either of three conditions obtain: (1) when a cognizant agent is able to distinguish parts or properties within the actually sense-perceived phenomenon, thereby recognizing the phenomenon as being of a certain type; (2) when a cognizant agent is able to evaluate the phenomenon as either existent (by predicting/expecting how the phenomenon/its parts are likely to change); or (3) as non-existent, namely in being surprised when perceiving a phenomenal change. Distinctly perceiving a phenomenon is more than simply apprehending the appearance of a perceptible whole, as Leibniz explains: 


\begin{abstract}
We understand under the name of "thing" (res) what appears, or (vel) from this it can be understood, that, in acknowledging the deception and error, we would say that something appeared, but we nonetheless didn't have the right to say that it did exist [when it appeared L.O.]. The nature of a thing is in the same thing the cause of its appearances. From where the nature of a thing differs from its phenomenon as a distinct appearance differs from the confused one; as the appearances of the parts differs from the appearances of the situation or $(\mathrm{seu})$ of the relations to external things; it differs as the perspective on a plain of a city from the rooftop of a tower placed perpendicularly in the middle [of the city] differs from its infinite horizontal views which pleases in diverse ways the eyes of the travelers arriving from one or the other venue of the city. This similarity is suitably strong for understanding the distinction between nature and accidents. (Specimen demonstrationum de natura rerum ex phenomenis A VI $2303-$ 4/L 142 slightly modified)
\end{abstract}

The beginning of this passage harmonizes nicely with the example of the hippogryph that we read in On the Method of Distinguishing Real from Imaginary Phenomena. If one believed for a moment that they had seen a hippogryph, then they would still not have the right to claim that that hippogryph exists because its existence contrasts with other subjectively-held expectations, which respectively rest on the nature of the phenomena in relation to the actual world. In short, simple appearance is no sufficient criterion to claim something's existence, which in turn rests on the apprehension of the thing's nature. As Leibniz remarks, nature is "the cause of the appearances", and, in describing it, he invokes the metaphor of a city and its multiple views. Each appearance is simply one of many perspectives on the city, while the nature of a phenomenon corresponds to perceiving the connections between those appearances, such as when we observe the city from the top of a tower. Leibniz is so fond of the similitude between these viewpoints and the city-map that he employs the analogy multiple times in highlighting the relation between nature and its accidents, essences and nominal definitions (NE 294), and God's epistemic relation to the world and the mind's epistemic relation to it (Monadology; PNG). All of these uses hinge upon Leibniz's notion of expression, insofar as one item (whether nature, a real essence, or God) expresses the totality and unity of a multitude (multiple appearances, an infinite number of nominal essences, the world). Types, as interiorized capacities to recognize things' natures, are nothing but cognizant agents' acquired abilities to reach the metaphorical rooftop of the tower from which they can visualize the connections and structures of a city that is otherwise only partially given in sense-perception. This ability consists in unifying or synthetizing phenomenal appearances by apprehending them as multiple manifestations of the same, common nature. Thus, in explaining how we interiorize types, I shall also provide an answer for how cognizant agents reach the top of the tower. I proceed in two parts. First, I outline what I take to be Leibniz's theory regarding how we learn types. I then bring in textual evidence to corroborate my interpretation. To this end, I focus on what Leibniz says about the abstraction of general ideas in the third book of NE. 


\section{SIMILARITY AND THE INTERIORIZATION OF TYPES}

The interiorization of types begins with coperceiving beings' shapes as similar or common. Shape is taken as a sign of those individuals' common nature and functions as a sign for associating changes in movements and properties over time to a shape taken typical of a class of individuals. In experiencing a constant and habitual association between a shape and the ways in which a perceptible whole changes, the cognizant agent's memory stores pieces of information associated with that shape. The more a cognizant agent experiences, the more she enhances her knowledge of things' nature, and thereby the more accurately she recognizes, predicts, and expects phenomenal change. On this view, cognizant agents apprehend types for concrete beings and individuals before (or concomitantly with) types for properties.

To illustrate, let us imagine a child, ${ }^{1}$ or someone in an early phase of life, sitting in a room where there are objects of three different shapes: cubes; spheres; and cylinders. There are many cylinders, cubes, and spheres, and all differ between one another in terms of size, color, tactile qualities, and materials. If we want to explain how the child interiorizes types for cylinders, cubes, and spheres, then we should tell the following story. First, the child segments bodies by detecting their shapes. Each shape is an appearance of a complex whole; it is never isolated. Shapes are always given in a complex act of co-perceiving other bodies and their shapes. The reason why bodily shape grabs the attention over other aspects of the body is that shape is more distinct than other sensations and because it provides the child with a unity, as we argued in chapters I and II. Shapes are furthermore subject to other imaginative constraints, especially similarity. As a constraint on the imagination, similarity spontaneously causes the child to compare shapes' appearances, and pay more attention to those that resemble one another. Moreover, in grasping the body and moving it, the child learns to associate sensations provided by other sense-organs - touch, taste, and sound - to the shape. Its ability to track the shape as the same, homogeneously-moving body, while also comparing bodies to one another, allows the child to further distinguish parts and properties within the shape, and associate, the shape's various states and movements. The tracking of shapes is interiorized as a body having states that differ in time and from the kind of body we are dealing with: a sphere rolls, while a cylinder remains at rest (if not acted upon by a force). Movements spark attention and are taken as characteristic of the body's shape because they are affine to the fourth dimension of bodies: time. Once this connection is established, when perceiving the shape "sphere", the child expects the sphere to roll.

1 Leibniz often compares children to non-human animals, as in Nova methodus discendae docendaeque iurisprudentiae, A VI I 269: "Cum autem primis annis infantes parum à brutis differant (ratione sese ob defectum experientiae tanquam materiae in qua exerceatur, linguaeque seu symbolorum per quae exercentur, parum adhuc exerente), et pueri quoque adolescentesque (ne quid de viris dicam) sensibus affectibusque ad instar brutorum plurimum regantur [...]." 
If the child learns to associate types of movement with types of shape (rather than to, say, the tactile qualities of the body), then this is because the association between rolling and the shape constitutes a more constant association than that which exists between its ability to roll and its tactile qualities. Spheres will roll regardless of whether they are rough or smooth. And so, through comparison, the child learns that two bodies may have different shapes and proportions. In comparing them, the child further learns that modifications in each shapes' quantity can occur without there also being modifications in quality. A cylinder, for instance, may change size without changing shape.

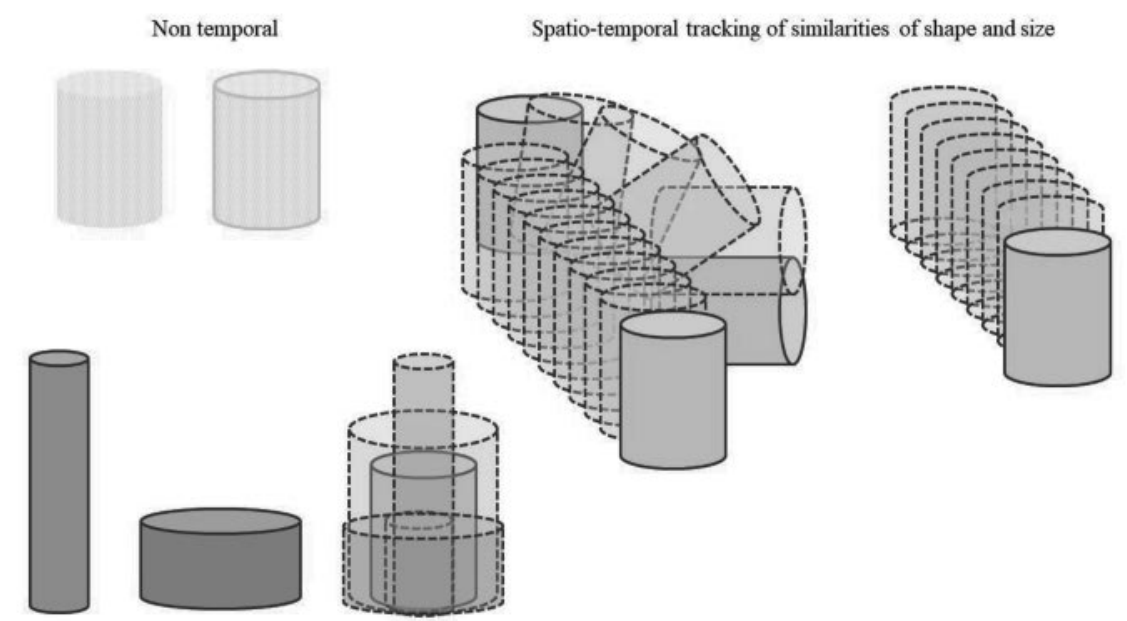

What I have described thus far simply repeats what Leibniz says in describing the logic of the imagination, as in Elements of a new mathesis (A VI 4 A 513, quoted and discussed in chapter II). Indeed, as Leibniz already held in his Ars Combinatoria (1666): "we have also [...] a unique way of penetrating into the arena of nature. This is because the more one has perceived the parts of a thing, the parts of its parts, and their shapes and arrangements, the more perfectly one can be said to know the thing". ${ }^{2}$ Indeed, even if Leibniz revised his position by arguing that direct experience of things is insufficient for giving cognizant agents either "perfect knowledge of a thing", or knowledge of the logical necessity that things are subject to, as argued above, he never denies that exprience is necessary for knowledge of natural kind: "the essence of gold is what constitutes it and gives it the sensible qualities that let us recognize it and which constitute its nominal definition" (NE 294). ${ }^{3}$

2 In De arte combinatoria (1666) A VI 1 187-8, quoted and translated in Mugnai (2017: 177).

3 See also MKTI, A VI 4 A 589-90/L 293: “a posteriori vero, cum rem actu existere experimur, quod enim actu existit, vel extitit, id utique possibile est. Et quidem quandocunque habetur 
Therefore, in tracking bodies via their shapes (and thereto their similarity or dissimilarity, i.e., their observable qualities), the child cancels out inequalities between perceptible properties, and, in so doing, interiorizes a type for the class of similar things. In other words, she learns that there are bodies in her environment that conform with, or are similar to, a cylinder-type and others that are similar to a cubetype (which are hence dissimilar from a cylinder-type). A type is not an image, but more abstractly a kind of skeletal or deep-body-structure that makes a body a body of a certain type because it is the expression of a formal cause (viz. inner constitution). In detecting a common shape and its qualities, cognizant agents track a formal cause or a substantial form. Through this, an agent can interiorize a type as the expression of a common cause, that is the nature common to similar things.

How can we say that someone possesses a type? Because in sense-experiencing an actual body, they expect changes accordingly to the type of body. The disposition to expect certain changes over others signifies that the agent recognizes the thing as a certain type of thing. In seeing a sphere, for instance, the child has a type insofar as the detection of a shape disposes her to expect certain changes but not others. The child, for instance, expects the sphere to roll when placed on an inclined plane but not to roll when submerged in water - expectations she would not have in perceiving a cube. Moreover, only when an agent learns to distinguish one body-type from another, thereby forming associative expectations of that body-type, does the agent begin to compare different bodies qua types, owing to which she is able to distinguish between typical and accidental changes. A lemon is expected to be yellow and a tomato red. Human bodies typically have two arms and two legs, while snails do not. In comparing bodies and finding differences between them, the child analyzes bodies into parts and properties and, in so doing, she abstracts those parts and properties from the whole to which they belong and considers them as such. In this way, she acquires types for parts and properties, too. For these become elements that constitute corporeal substances, which can be recombined and rearranged by the imagination thanks to its productive and reproductive spontaneity (more on this soon).

The process outlined above implies a dialectic between similarity and difference. Similarity between bodily shapes predominates because similitude grasps the agent's attention more than dissimilarity. Even if I do not have a type for tomatoes, my attention is nevertheless grasped by a similarity of shape when I see two tomatoes. If I do have a type for tomatoes, then, in seeing two tomatoes - one violet and

cognitio adaequata, habetur et cognitio possibilitatis a priori; perducta enim analysi ad finem, si nulla apparet contradictio, utique notio possibilis est. An vero unquam ab hominibus perfecta institui possit analysis notionum, sive an ad prima possibilia ac notiones irresolubiles, sive (quod eodem redit) ipsa absoluta Attributa Dei, nempe causas primas atque ultimam rerum rationem, cogitationes suas reducere possint, nunc quidem definire non ausim. Plerumque contenti sumus, notionum quarundam realitatem experientia didicisse, unde postea alias componimus ad exemplum naturae." The next chapter deals with the distinction between types and concepts. 
one red - my attention is sparked by the violet color of the first tomato. This preponderance of similarity over dissimilarity in interiorizing types qua an expression of things' common natures is decisive for making sense of a few pages in the NE where Leibniz discusses (vis-à-vis Locke) the origins of general names. It is therefore a passage that offers a textual basis for corroborating what we have argued thus far. $^{4}$

\section{SIMILARITY, ABSTRACTION, AND GENERAL NOTIONS}

Despite his declared goal of discussing general names, the discussion in Book III of the New Essays on Human Understanding - Leibniz's critical response to Locke's An Essay Concerning Human Understanding - focuses on the abstraction of a general idea to which a name is then appended. The context of the discussion is relevant because it is in this text that Leibniz aims to resist the new empiricist philosophy, according to which all our knowledge can be derived from experiential data provided by the senses. Within an empiricist framework, the role played by the similarity of shapes, as well as the frequency of experiential data and associations that constitute habits, are decisive aspects in the explanation of how minds abstract general notions. Surprisingly enough, Leibniz does not dismiss the importance of similarity and habits in making contrasts between his and Locke's theory. Indeed, he ascribes to them a different value that is afforded by a different way of understanding abstraction.

On Locke's account, abstraction is an operation of the reflexive mind which, in experiencing many similar individuals, distinguishes and abstracts properties common to the class to which those individuals belong. Abstraction for Locke therefore operates in virtue of similarity. ${ }^{5}$ Those properties are then gathered into a general idea, to which the mind gives a name. In the act of abstracting and giving a name, the idea becomes general, and so too does the name. "Man" is a general name because it is a sign of a general idea enclosing qualities like "being rational", "being an animal", "having two legs", and "being capable of laughter".

Although Leibniz agrees with Locke's overall thesis, viz. that names are general because they signify general notions, ${ }^{6}$ Leibniz and Locke disagree on the precise process by which general notions are abstracted. While, for Locke, abstraction proceeds through an analysis of individual properties, and then the synthesis of

4 I outlined a similar analysis already in Oliveri (2016) and Oliveri (2016a). Both works, however, lack the analysis of types that I offer here. Indeed, the analysis provided here is decisive for fully understanding the passage.

5 As a further proof, consider the discussion in A VI 6 234-5/NE 234-5, in which Leibniz and Locke discuss whether we would recognize as "man" an animal, like a parrot, that shows rationality, although we would be inclined to call a "man" an animal of the shape of a human being that nonetheless does not show any sign of rationality.

6 The term "idea" must here be understood as a "notion" or "concept", viz. an intentional, mental item referring to what renders several individuals members of the same species. 
common properties into a general idea, Leibniz, by contrast, tells a different cognitive story; one that moves from synthesis to an analysis of things in terms of their parts and properties. Synthesis is, for Leibniz, easier than analysis. ${ }^{7}$

As we have outlined thus far, the groundwork of the imagination is to synthetize an amalgam of sensations into perceptible wholes, that is, shapes as having a size. Concrete beings are therefore given in experience as the appearances of shapes. We further argued that perceptible wholes are mere appearances when they are not objects of distinct perception. Recall that having distinct perceptions requires cognizant agents to undertake a process of comparing wholes and then to apprehend them as similar. Since the imagination is first and foremost sensitive to shapes' similarities, the imagination is spontaneously driven to collect individuals based on the similarity of shapes. Therefore, on whatever the imagination exercises its cognitive powers, the result is a synthesis of properties and parts into a shape, or of individuals into a class. This is because shape is spontaneously taken by the imagination as exemplary of a class of individuals. More specifically, when a cognizant agent is presented with a multitude of similar individuals, she spontaneously takes the shape as a sign of something more general that the individuals share, viz. a common nature.

Agents' cognitive states essentially rest on generality. Indeed, Leibniz rebuts Locke (who claims that general names are an improvement of language) in claiming that they are "required for their [languages'] essential structure" (NE 275). In the remainder of Book III Ch. 1-3, Leibniz gathers his observations about the constitution of languages with the aim of refuting Locke's claim that we begin abstraction thanks to being directed to ideas of individuals. That we do not have ideas of individuals, Leibniz argues, emerges from an etymological analysis of proper names. Proper names have their origins in general names, which are used as an appellative or distinctive mark for that individual. Brutus, for instance, is given his name as a distinction for his stupidity, while Caesar takes his name from the fact that he was born via an incision. ${ }^{8}$ What this observation points to is that, if we had ideas of individuals before those of general entities, then nomination should reflect this order and proceed from proper to general names. But etymology shows that the correct order is the other way around: we first have names of general entities before we have the names of individuals. Therefore, we cognize generality before individuality. When we say that abstraction begins with particular things, particulars are not individuals because, if they were, as Leibniz notes, then:

we would not be able to say anything. This is because new ones are being encountered at every moment - new individuals and accidents and (what we talk about most) actions. But if by 'particular things' you mean the lowest species (species infimae), then, apart from the fact that it is often difficult to determine them, it is obvious that they are themselves universals, founded on similarity. And then, since it is just a matter of more or less widespread similarity, depending

7 See De arte inveniendi in generale, A VI 4 A 358.

8 See NE 275/A VI 6275 and NE 289/A VI 6 289. Here, Leibniz argues that etymological research on proper names proves that proper names originally are general terms. They are latterly used as distinguishing mark for individuals and used as proper names. 
on whether one is speaking of genera or of species, it is natural to mark all sorts of similarities or agreements, and thus to employ terms having every degree of generality. (NE 275/A VI 6 275; my italics)

There is a cognitive reason why agents do not begin abstracting from ideas of individuals. If they did, then ideas of individuals would need to be present already to cognizant agents as particular mereological compounds of qualities. Since every individual is unique, individuals will be a unique compound of qualities. If individuals were given as unique mereological compounds of qualities, and if generality were the product of a process, which began by comparing mereologically-unique compounds (which, from the very beginning, were apprehended as bearers of a multitude of particular qualities that are constantly changing), then cognizant agents would simply be overwhelmed by the differences manifested by individuals, even when they compared individuals of the same class. Cognizant agents would fall into a state of insurmountable stupor - similar to that of stupefied souls deprived of cognitive filters, as explained in chapter IV. "We would be able to say nothing", Leibniz remarks in the quoted passage. His solution is to reframe the notion of abstraction thus:

I do not deny that abstractions are used in that way, but it involves an ascent from species to genera rather than from individuals to species. You see, paradoxical as it may seem, it is impossible for us to know individuals or to find any way of determining the individuality of anything except by keeping hold of the thing itself. For any set of circumstances could recur, with tiny differences which we would not take in; and place and time, far from being determinants by themselves, must themselves be determined by the things they contain. The most important point in this is that individuality involves infinity, and only someone who is capable of grasping the infinite could know the principle of individuation of a given thing. (NE 289-90/A VI 6 289-90)

We are now familiar with the idea that in order to determine a particular sensory content, such as a color or tactile sensation, we do so only "by keeping hold of the thing", viz. by actually experiencing the color or tactile modification. We also know that this kind of knowledge is confused. This means that it does not present any distinction between parts and properties. Therefore, when Leibniz says that "it is impossible for us to know individuals or to find any way of determining the individuality of anything except by keeping hold of the thing itself', I interpret this passage as saying that an individual, such as Peter or Claire, can be distinguished insofar as we have a sensory presentation of either Peter or Claire, but this presentation is a confused kind of knowledge. It is an appearance: a confused synthesis of sensations that is enclosed by a shape, as we described in chapter II. The reason why cognizant agents need to first express individuals as perceptible wholes is that any particular thing encloses infinity, and infinity cannot be the object of a finite mind unless it is expressed via a finite cognitive surrogate.

Since individuality encloses infinity, if the human mind abstracted, through analysis and selection, the common qualities of different individuals, moving on to the synthesis of those common qualities into a general idea, then it would be impossible for the mind to move forward in the process of abstraction, since the act of selection would be overly complicated and long, while the cognizant agent would 
not be able to consider one thing as being the same over time. ${ }^{9}$ Indeed, attention and memory have so much information to process and compare that it would be impossible to tease out resemblances. Even space and time cannot help in the determination of such differences because, qua ideal entities, they are rendered different or alike owing to the things that they contain and are considered different or alike. $^{10}$

Leibniz's hint about similarity (and about "an ascent from species to genera") is a reference to the logic of the imagination as reconstructed thus far. Leibniz thinks that we begin with something general, from a synthesis of a multitude of traits that the agent forms spontaneously, in virtue of her expressive power, like in senseperceiving. The synthesis is a shape that functions as a surrogate that she then moves to analyze into those parts and properties that make themselves remarkable to her cognitive capacities because they occur with more frequency than other traits or are more distinct than others. Cognizant agents begin with a general idea of $n a$ ture, that, to follow the example of how the child learns a general notion "human being", it is found in the specific constitution of their mother and father. A child is then able to ascend to more general notions (like "animal") or descend to individuals, albeit with a structured order. To generalize, cognizant agents start by apprehending individuals as similar and dissimilar (in virtue of the similarity of shape). They can then move onto isolating parts and properties that are typical of those individuals. This is because agents apprehend them not as appearances but as phenomena with a common nature, i.e., as sharing a common cause for their appearances.

Thus, against Locke - who argued that we form ideas of individuals as if they were images in our head, and then, by abstracting from space and time (and indeed anything particular), we form the general idea MAN, to which we attach a name "man" - Leibniz replies:

When the child proceeds by abstraction from observing the idea of man to observing that of animal, he has arrived at the idea of human nature from the more specific idea which he observed in his mother and father and other people. That he had no precise idea of the individual is shown by the fact that he could easily be deceived by a moderate resemblance into mistaking some other woman for his mother. (NE 290/A VI 6 290)

In short, the child, in observing the common, outer appearance of her mother or father, already has an expression of "human nature". From the very beginning, the child works with an expression of common nature, not an expression of individuals. Therefore, in abstracting, she proceeds from a general idea "man" to abstract a genus as "animal". She does so by observing outer appearances. This insistence on

9 On this topic, cf. also the paper by Nachtomy (2006).

10 A VI 6 230/NE 230: "Le precis de l'identité et de la diversité ne consiste donc pas dans le temps et dans le lieu, quoiqu'il soit vrai, que la diversité des choses est accompagnée de celle du temps ou du lieu, parce qu'ils amenent avec eux des impressions differentes sur la chose. Pour ne point dire que c'est plutot par les choses qu'il faut discerner un lieu ou un temps de l'autre: car d'eux mêmes ils sont parfaitement semblables, mais aussi ce ne sont pas des substances ou des realités completes." 
appearances is relevant to explaining what Leibniz says at the end of the passage: the child does not have an idea of the individual, which would imply an idea as a sum of mereological properties, which respectively characterize the father or mother.

Proof that the child does not have access to idea of the individual - i.e., a notion present in the mind as a bundle of properties that the child is capable of distinguishing in the idea and abstracting away from it - Leibniz argues that the child would be deceived in seeing an individual perfectly similar to her father. What does Leibniz mean by this? He means that the "idea" is first present as a shape - an image of an individual - and that is the reason why, if the child stood before her father's doppelgänger, then she would be deceived by this sense-perception because she would expect this man to be her father and act as such. Therefore, the child does not compare individuals thanks to their qualities. Rather, they immediately see individuals as similar in shape, whereby they take the shape to be an expression of the common nature of those individuals. Accordingly, abstraction does not consist in selecting properties and forming them into general notions, which can then be expressed by names. It rather consists in sorting individuals into similarity classes and then distinguishing into their general nature properties and parts.

To summarize, when the child sees many individuals of the same species simultaneously, she spontaneously notices the similarity of coperceived shapes. This similarity inclines the child to take those individuals as individuals of the same class to which it can attach a name - whether "human being" or "cat" - and, in so doing, the child begins the process of associating differences to the (as-yet confused) general notion "human being". In comparing similar individuals, the child detects dissimilarities and hence is able to isolate common and contingent parts, properties, and changes. In short, the child renders the experienced perceptible whole an experience of a distinguished kind by interiorizing an associated type. The type has such associations thanks to habitual interactions with things of a common nature that are detected via shape (we shall elaborate on this shortly).

It is important to note that the term "general idea", as used by Leibniz in those passages from the NE, is not an image and cannot be consciously entertained. As an expression of nature, a general idea is a type, i.e., an interiorized ability to understand diverse appearances as possible ways that a class of things can or cannot be. Possibilities are inferred from the resemblance borne by individuals of that class to one another, and types express "possibilities inherent in the resemblances" (NE 323). Shape therefore functions as a "cognition caeca" - a blind cognition - for collecting information and for activating the type. In being presented with a body that has the shape of a human, if the child is already acquainted with this type of body, then, in seeing the body, she will spontaneously process it as similar to those seen previously, and, in so doing, the type is simply activated - recalls stored information and saves new one. This recognition of the actually-perceived body as a type does not consist in a mental representation. There is no internal mental representation over and above the agent's capacity to believe in the thing's actual existence, as manifested by assent to phenomenal appearances and expectations of the phenomenon's next state. Types are an acquired ability to predict things' behavior 
in the context in which they are perceived, and to act in compliance with one's beliefs and expectations about the thing in question. In this way, the type controls attention and memory, rendering them more selective: in seeing a sheet of paper on my table, I do not expect it to burn because the conditions in which I experience the sheet of paper are not sufficiently like those that I usually experience when I see paper burning. Since paper is not associated with fire, I do not expect it to burn. If it does, then I am surprised and look upon the phenomenon with suspicion, i.e., in need of a reason/explanation. I do not feel suspicious, however, if the paper burns when thrown into a fire. Types are so means built by the agent's capacity to control new experienced phenomena by reducing them to known structures.

Types may also play a role in societal interactions. They for instance extend beyond the representation of things' nature by becoming ways of processing signs. Gestures, or things that we say or do, can become expressions or signs of an agent's present state or beliefs. This is because these gestures produce in others expectations regarding how the gesturing agent may or may not act. Consider a simple gesture like waving. When the regular oscillatory movement of the hand becomes an expression of "greeting someone", a peer can learn to recognize the gesture and act accordingly. "Waving" is, however, conventional. This is because it changes across cultures, meaning that human beings establish it as exemplary or typical of the mental state "greeting someone". ${ }^{11}$

Types are also ways of enhancing our proficiency in processing phenomena and storing new pieces of information. When a type is active in the way described, new experiences thereafter enhance the information stored in typical form. In this way, we spot and compare a given, perceived body through the filter of information that has been stored from previous experience. This information is presented as normalized behaviors of the body qua type: changes or states the body can or cannot manifest. Thus, in processing an experience as being "normal" or "typical", we become more proficient in detecting non-normalizable, supervening changes. To use an analogy, when we acquire types, our experience becomes similar to walking down the same road to reach the office every day at the same time. You do not even need to pay attention to all the details; a simple glimpse towards a house or a tree is sufficient for gaining one's bearings. Attention and memory are much less stressed by sense-experience because the agent expects what she actually experiences. This makes her more reactive to unpredictable changes: a fallen tree, or a new color on a door, may capture her attention. This is because comparison makes her conscientious about details that differ from prior experience. Our sensitivity to these comparative differences is stored in types and becomes spontaneously activated through triggering experiences that are grounded in similarity. Consider this passage from New Essays, in which Leibniz argues that we implicitly rely on acquired "habitudes", that is habits translated as dispositions:

11 I outlined Leibniz's theory of how human peers establish linguistic meaning in Oliveri (2016: Part III.1-2), and Oliveri (2016b). On the topic of linguistic meaning, see also Dascal (1987), Gensini (1991), and Meier-Oeser (1997). 
Our gifted author seems to claim that there is nothing implicit in us, in fact nothing of which we are not always actually aware. But he cannot hold strictly to this; otherwise his position would be too paradoxical, since, again, we are not always aware of our acquired dispositions [habitudes] or of the contents of our memory, and they do not even come to our aid whenever we need them, though often they come readily to mind when some idle circumstance reminds us of them, as when hearing the opening words of a song is enough to bring back the rest. (NE 53/A VI 6 53)

Now consider the effect of habits on oblivion and unawareness. In describing the work of minute perceptions, Leibniz remarks that:

when they are combined with others, they nevertheless have their effect and make themselves felt, at least confusedly, within the whole. This is how we become so accustomed to the motion of a mill or a waterfall, after living beside it for a while, that we pay no heed to it. Not that this motion ceases to strike our sense-organs, or that something corresponding to it does not still occur in the soul because of the harmony between the soul and the body; but these impressions in the soul and the body, lacking the appeal of novelty, are not forceful enough to attract our attention and our memory, which are applied only to more compelling objects. Memory is needed for attention: when we are not alerted, so to speak, to pay heed to certain of our own present perceptions, we allow them to slip by unconsidered and even unnoticed. (NE 53-4/A VI 6 53-4; my italics)

Consider the claim: "memory is required for attention". Now imagine a world in which human beings typically moved by jumping. You would not pay much attention to a human being jumping once thereby acquainted, because any time the imagination encloses a shape that you recognize as a human being, you also remember the expected behavior of that type of body. The fact that it jumps is therefore considered to be typical or normal. Things that are typical do not grasp the attention. You would, however, be surprised if a human being in this world suddenly moved by walking. "Typical" is therefore what we have been routinely exposed to. What we experience as typical does not, however, guarantee that we have a stable grasp on the essence of a thing, viz. on how things really are. They are nonetheless necessary for establishing habits and constitute a first glimpse into the nature of things.

On Leibniz's account, habit is "an easiness in acting, generally it is asked whether there also is a habit in being acted upon? I think so" (A VI 4 B 1434). Habitus, moreover, is defined as "an acquired permanent readiness to act" ("agendi promptitudinem acquisitam permanentem") (A VI 1 266). Habitus can either be corporeal, such as when we learn to practice an art, ${ }^{12}$ or intellectual, such

12 Nova methodus A VI I 266: "Studiorum ratio est species quaedam rationis status, id est, modus perveniendi ad statum actionum perfectarum. Status autem dicitur Habitus"; Ivi 267: "Subjectum habitus est quicquid actionis capax est." Ivi 281: "Habitus corporis vel sunt circa actionem relinquentem $\alpha \dot{\pi} \sigma \tau \varepsilon \dot{\lambda} \varepsilon \sigma \mu \alpha$, vel sunt facti transeunt. Artes opus relinquentes vel naturam promoventem, applicando agens et patiens, et deinde cessando, uti agricultura, horticultura, ars pastorita ..." and moreover, the ars medica, ars veterinaria, ars pittorica. However, the body is only a medium for the execution of those arts (A VI I 283). Consequently, the soul's habits are more important for humans and those habits hinge on memory, discovery, and judgment (A VI I 277). Owing to this, even if animals could suffer addictions (assuefatio), they do not for that 
as in performing sciences, or experiencing, as we argued, or using a language. ${ }^{13} \mathrm{~A}$ habit is a certain acquired disposition of a subject to act, and be acted upon, based on the capacity for spotting typical behavior. Indeed, when we recall that action and passion are relations among how things exist (more on this soon), we are able to understand the extent to which the imagination bears a connection to metaphysics, viz. insofar as predicting a change is a way of predicting a change in underlying substantial forces and how they are connected to other existing substances, including our own.

Types hence control know-how: in predicting how a body will behave, we act, or expect to be acted upon, accordingly. Thus, in seeing a fire, I prescind from touching it, or, in seeing ice on the sidewalk, I walk with more care. In this sense, types constitute further layers of our mental sieve - to recall the metaphor used in commenting on Mariotte's theory of the mind quoted and discussed in chapter IV. The sieve's metaphorical layers help us to better understand how parts of the world can act on us through our own organic bodies. Knowledge of what our body can do, as well as what other bodies can do (both kinds of knowledge being stored as types), controls memory and attention, rendering these functions spontaneous in selecting what to focus on in any given situation. If our reconstruction is correct, then types function as filters that enhance cognizant agents' proficiency in processing information and making inferences.

Despite the range of capacities types account for, they fall short of being concepts, about which we will elaborate in the proceeding chapter. Before moving to the distinction between types and concepts, we shall draw some conclusions of distinct perceptions and provide a reason for why the imagination does not lead us systematically astray.

\section{SIMILARITY, ABSTRACTION, GENERAL NOTIONS IN NEW ESSAYS}

Following this long excursus into the logic of the imagination, modality, and its relation to existence, we now better understand why conceivability is central to Leibniz's notion of a being. Many of Leibniz's papers - especially those dealing with metaphysical distinctions - connect the notion of being to conceivability: a being is what can be conceived distinctly, viz. whose concepts can be conceived

reason have habits, which are further per institutionem (Ibid. "It remains to say about the cause of the habits proper of human beings: institution").

13 A VI 4 603: "Habitus intellectuales quidam sunt, id est in mente sunt, etiam cum non animadvertuntur; experientia, intelligentia, scientia, opinio, ars. Exprimere cogitationes est loqui, docere, discere, interrogare, espondere, etc. Haec omnia etiam intus fieri possunt, sed his adde pronuntiare, et scribere quae externa sunt. Hoc est efficere signa quae sunt literae, soni articulati seu voces, variaeque orationis et scriptionis partes." 
without contradiction. ${ }^{14}$ When we conceive of a being, we consider it from the perspective of an essence expressed through the concept that we form of the being. Conceiving is therefore different from both perceiving and the act by which cognizant agents evaluate the possibility of a being's existence. I report a passage of Leibniz re-elaboration of Nova methodus. To help the reader visualizing Leibniz's changes, I will signalize the original, changed text in this way; and what is added with bold font. From this, it will emerge an interesting systematic substitution of the terms sensus and sensibilitas through perceptio and perceptibilitas. This change is consistent with an unpublished list of definitions, where Leibniz claims that "Essence is a distinct cogitability. Existence is a distinct sensibility. I can substitute conceptibility and perceptibility to cogitability and sensibility" [Essentia est cogitabilitas distincta. Existentia est sensibilitas distincta, pro cogitabilitate et sensibilitate possis substituere conceptibilitatem et perceptibilitatem. $]^{15}$ The text of Nova methodus on Learning and Teaching Jurisprudence is:

Quicquid autem habet Qualitates sensibiles hujusmodi seu quicquid est sesibile perceptibile, illud dicitur Ens, . Et haec est perfectissima Entis definition quae est nominalis quodammodo Entis definitio seu ab effectu : quoties enim probare volumus aliquid existere, probamus ex eo quo quia nos vel alii sensering vel perceperint, aut ipsummet, sensione immediata; aut saltem per aliud, quod sine ipso esse non potest, quae est sensio mediata. Et ex qualitates simul sunte

14 On the Method of Distinguishing Real from Imaginary Phenomena (A VI 4 B 1500/L 336): "Ens est, cujus conceptus aliquid positivi involvit sive quod a nobis concipi potest, modo id quod concipimus sit possibile nec involvat contradictionem, quod cognoscimus tum, si conceptus sit perfecte explicatus nihilque involvat confusi, tum compendio, si res actu extiterit, quod enim existit utique est Ens vel possibile. Quemadmodum autem Ens explicatur per distinctum conceptum, ita Existens per distinctam perceptionem, quod ut melius intelligamus videndum est quibus modis existential probetur. " [A being is that whose concept involves something positive or that which can be conceived by us provided what we conceive is possible and involves no contradiction. We know this, first, if the concept is explained perfectly and involves nothing confused, but then in a shorter way, if the thing actually exists, since what exists must certainly be a being or be possible. Just as being is revealed through a distinct concept, so existence is revealed through a distinct perception.] Also see De ente, existente, aliquo, nihilo et similibus (1685-6, A VI 4 A 570: "Ens est positivum quod distincte concipi potest. Existens est quod distincte percipi potest. [...] Res est phaenomenon congruum. Phantasma seu Apparens est phaenomenon incongruum." [A being is something positive that can be distinctly conceived. An existent is what can be distinctly perceived. [...] A thing (res) is a congruent phenomenon. A phantasm or an appearance is an incongruent phenomenon.] The text is part of De abstracto, concreto, substantia, accidente, substantivo, adjectivo, et similibus (1685-6, in A VI 4 A 569). We can find the same definitions in another series of metaphysical definitions, close to De mutationibus (1705, LH IV, 7C Bl. 85-86. 1 Bog. 2o. 4 Sp in VE VI, 4, N. 55). Leibniz begins the text by writing: "Ens est quicquid distincte concipi potest. Existens est quod distincte percipi potest." However, as the critical edition shows, he erases this distinction and begins with a definition of "terminus". Five other, short manuscripts, however, begin with the same distinction and their content is very close to De mutationibus, see Metaphysicae Definitiones (1703, LH IV, 7c B1. 89-95). Another interesting text, which presents the same distinctions, is LH IV 7c Bl. 76.

15 The text is a pre-edition of VI 5 and it is entailed in: LH IV 8 Bl. 102. 1 Bl. 2o. $1 \mathrm{Sp}$. According to the editors, it is to be dated around $1690-4$. 
(seu imagibilitas) constituunt Essentiam, sensibilitas Existentiam, Ut adeo nostri respectu dici possit Essentiam rei nobis esse conceptibilitatem (seu imaginabilitatem) ejus distinctam. Existentiam ejus perceptibilitatem (seu sensibilitatem) distinctam. Nempe Qualitatum simul sumtarum compositum seu conceptibilitas constituit rei essentiam ; perceptibilitas (ut scilicet per rem non stet quominus actu sentiatur) existentiam ejus probat. Sumitur hic autem late sensio et imaginatio, pro omni perceptione et conceptu. (A VI 1, 285/ revised version after 1700 )

\title{
Translation:
}

\begin{abstract}
That which has sensible likewise qualities, or is perceptible, is called a being. This is the mest perfect definition of being, this is a certain nominal definition of a being, for whenever we wish to prove that something is, we do so by the fact that we or others sense or perceive it either in itself, by immediate sensation, or mediated by the sensation of something else which cannot be without it. Qualities taken together at the same time (or imaginability) constitute essence; sen-

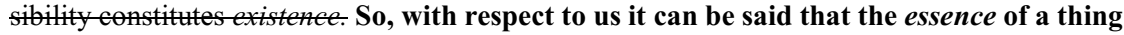
is for us the distinct conceptibility (or imaginability) of that thing, and the existence the distinct perceptibility (or sensibility) of it. Indeed, the compound of the qualities assumed simultaneously, that is conceptibility, constitutes the essence of a thing; perceptibility proves its existence (as evidently it is not a thing's fault that it is not actually sensed). We assume here sensation and imagination in a broad way for any perception and concept. (Partially L 89 and 91)
\end{abstract}

From 1667 to 1700 Leibniz decides to change his terminology and "sensation" is substituted with perception/perceptibility. Through the years, Leibniz developed more fin-grained distinctions between degrees of "perception", as we argued, and perceptibility become a more complex operation of the cognizant agent. Likewise, the definition of "being" defined as "the most perfect" in 1677 is now a kind of nominal definition, and nonetheless, the distinction between the evaluation of essence and existence is maintained. The act by which a cognizant agent simultaneously considers qualities as inhering in an essence and evaluates them as contradiction free is that by which the cognizant agent conceives of a concept (conceptibility). If, for instance, I simultaneously consider the notion of a square circle, then I see that the concept entails a contradiction and is impossible. Remarkably, Leibniz also uses the word "imaginability" to label the act by which we evaluate concepts. The use of "imaginability" could appear in contradiction to what we have argued thus far, viz. that the imagination is involved in the sensory presentation of beings. I think, nonetheless, that it is not in tension with what we have said, especially when we recall that, in the act of reflecting, the cognizant mind needs an object which cannot be an idea of the essence (chapter I). The object of reflection is an expression - a cognitive surrogate such as a figure, diagram, word, or indeed anything perceptible and therefore imaginable, which encodes information that the mind reflectively extrapolates. Consider, for instance, the string of signs " $\mathrm{A}$ is A", which Leibniz uses to express self-identity. In interpreting the string as an identity claim, one has to sense-perceive the two As as distinct, and this act falls to the imagination, as we have argued. The A before the "is" is not the same as the "A" after the "is". Nevertheless, the sequence taken as a unity is considered an expression of selfidentity, which says "A is identical to A, that is identical to itself". This is an interpretation of that string, which hinges on an intellectual reflection regarding what 
identity is, as well as on habitual or conventional ways of representing identity. That very string of signs may have signified something else.

This is important because it means that figures, diagrams, and words can all become vehicles of distinct thoughts, not only of distinct perceptions. That why Leibniz remarks at the end that sensation and imagination are assumed broadly to cover any perception and concept. This implies that rational minds can also express things that are not subject to the imagination by means of imagistic surrogates. Rational minds deploy imagistic surrogates in order to visualize relations between the marks of a concept (as argued in chapter I and as we are going to argue in chapter VII). Nonetheless, conceptibility remains an act that is distinct in nature from perceptibility. Perceptibility is the act by which the cognizant agent implicitly assumes the existence of a being based on the fact that they actually perceive, or can perceive, that very being as coherent. Consequently, an agent can be said to be in the business of conceiving when she considers an essence, but she is in the business of perceiving when she considers the existence of a being regardless of the representative vehicles she deploys in performing these acts. As Leibniz remarks:

Whatever can be distinctly perceived exists; otherwise it will be a simple appearance. Essence is what can be thought distinctly in a thing. Existence is the distinct perceptibility or sensibility of a thing. (A VI 4 A 28)

I think we are now able to understand what "distinct perceptibility" consists in. Perceptibility is not a simple apprehension of a thing's appearance at a given time. Rather, acts of perceptibility entail an evaluation of something's existence, such as when a cognizant agent apprehends a body as a type of phenomenon inscribed in a world governed by spatiotemporal laws, or where specific types of beings - dogs rather than hippogryphs - are expected to exist. Perceptibility does not entail an analytic understanding of concepts that express essences. In apprehending the existence of a dog, a cognizant agent is not in the business of evaluating whether the concept DOG is consistent. She perceives the dog, first, as a sensory presentation of a body, that is, as a being with parts and properties, which vary in accordance with what we have called first- and second-order coherence. The relation between possibility and contingency, as explained in the foregoing chapter, is the reason why there is a connection between perceptibility and possibility: if something exists, then it is possible; therefore, a cognizant agent can learn to infer the possibility of a concept from the existence of its instances. ${ }^{16}$ Nevertheless, the act by which a cognizant agent apprehends existence, and the act by which she apprehends essences, are distinct. The important aspect that we need to bear in mind is that perceptibility provides knowledge of a clear kind because it accounts for things' recognition, connection, and prediction. It also accounts for knowledge of a distinguished kind, since it allows for mereological distinctions of bodies as whole-parts. In spite of this, it does not constitute clear and distinct thought nor, thereby, knowledge of

16 De illatione veritatis atque de terminis (A VI 4 A 1822): "Quod existit est Ens seu Est possibile. Existit quod percipitur consentienter seu ita ut non inferat contradictionem cum aliis quae percipiuntur. Ens est quod concipitur consentienter, seu ita ut non implicet contradictionem.” 
essences, as expressed in virtue of concepts into definitions. Conceptual evaluation in fact hinges upon a diverse act of conceivability, viz. what Leibniz calls conceptibility, intelligibility, or imaginability, which respectively require contradiction and identity, principles that are distinct from those constituting the logic of the imagination: similarity and difference, as we argued in the foregoing chapter.

As a consequence of this, we can deduce that these unusual terms - perceptibility, imaginability, conceptibility - are invoked to distinguish between various intentional objects and the acts by which cognizant agents apprehend them. For, perceptibility gives access to bodies qua existents, while conceptibility affords access to concepts qua essences. Depending on the object that one is conceiving, the cognizant agent may infer diverse kinds of relations to which those objects are subject, owing to which the agent can attain to different forms of knowledge. Moreover, conceivability of various kinds is the act by which agents compare a multitude of things simultaneously, putting them into relations, which involves attention and, therefore, memory:

A relation is that according to which two things are simultaneously thought. As we say, relation is the simultaneous being-thought of things, so action and passion is the simultaneous existence of two things. Relations indeed consist in this, that is, some exchange. (A VI 4 A 28)

To notice (advertere) (i.e., to perceive with attention or with relation to something else) is to consider a relation to something else. (A VI 4 A 57)

There are different kinds of conceivability, each of which accounts for diverse kinds of relation, furthermore depending on the kinds of things to which the mind is directed. For instance, the comparison of essences reveals different kinds of relation than the comparison between beings qua embodied:

From the thought of many beings taken together there arises relations or affections of beings. From co-imaginability or coessentiality there arises comparison, between same and different, similar, dissimilar, and opposite, genus and species, universal and singular. From co-sensibility or coexistence there arises connection, between the whole and the part, order, one and many; necessary, contingency, connection, and cause, etc. From this grows metaphysics in general, to which the doctrine of quantity and quality in their widest sense can be referred in logistics and the art of combinations respectively. The former deals with propositions and their calculus (and hence with the one and the many, the whole and its parts ${ }^{17}$ ), the latter with forms (or similarity and orders of determination) (Nova methodus discendae docendaeque jurisprudentiae (revised version 1695-1708, A VI 1 284). ${ }^{18}$

According to the foregoing quotation, in order to apprehend relations the mind needs to perform some act by which many beings are considered together at once. The kind of conceivability involved determines both the way in which we conceive

17 The logistics of whole and parts refers to Leibniz's attempt at a mereological calculus, see Mugnai (2017). "Wholes" and "parts" refer here to propositional and conceptual containment and not to perceptible wholes, to which Leibniz immediately refers afterwards as "forms" (formae). Therefore, the passage does not contradict what we have said thus far.

18 The text is a passage from Nova methodus discendae docendaeque jurisprudentiae, partially taken from L 90. 
of something - as a sensory presentation of bodily parts rather than a concept composed of conceptual marks - and the sort of relations the mind can apprehend through that act.

Co-imaginability and co-essentiality are acts by which the mind compares essences, such as when they are judged for their relation vis-à-vis genus and species. These mental operations are at work when the mind inspects, for instance, the concept ANIMAL and the species HUMAN BEING, as well as when the mind considers universality and singularity (for instance, in conceiving of this man as an instance of HUMAN BEING). Coperceptibility is the act by which the mind compares beings and their whole-part relations (order, many, contingency), and causal relations. It corresponds to the act of segmenting, comparing, and tracking existing beings, as we have described thus far, and culminates in the capacity for predicting beings' changes vis-à-vis causal relations.

On this view, types constitute a way of ordering information in relation to one mode of presentation - the common nature of beings as expressed through their bodies, rather than essences of beings as expressed through concepts in definitions. Each format, whether the presentation of bodies or essences, encodes diverse pieces of information, some of which are available only through a single mode of presentation (i.e., a body presented through sense-perception compared with a concept expressed by a definition). Others, however, can be transferred from one mode into another. Since types regard the common nature of phenomena based on their physical states (as discussed at the beginning of chapter IV), types are connected to phenomena's appearances and therefore with the logic of the imagination.

Towards the end of the passage, Leibniz claims that the apprehension of different kinds of relation grounds metaphysics in general. The science of "quality and quantity" may be distinguished into logistics (that is, the study of propositions) and combinatorics (that is, the study of forms, a distinction that is again in keeping with a pre-propositional stage of relations' apprehension between figures, or what Leibniz calls wholes, which, hence, rest on coperceptibility). In the same years as when he revised the above text, Leibniz remarks to Locke's spokesman in NE:

The scheme of the categories is a very useful one, and we should think of improving them rather than rejecting them. It might be that all that is needed are five general headings for beings - namely substance, quantity, quality, action or passion, and relation - together with any that can be formed from those by composition. (NE 343/A VI 6 343)

It seems to me that what we have argued thus far comports with the attempt to reduce the number of categories to five: two ideal categories (quality and quantity); two metaphysical categories (substance and action/passion); and relation. The act of coperceiving whole-parts depends on the imagination, which is the combinatoric faculty, further resting on the categories of quality, quantity, and relation. In the next section, we focus on Leibniz's claim that perceptibility is related to an act of combining elements. 


\section{IMAGINATION AS A COMBINATORIC FACULTY}

If there are two arts, viz. the art of combination and the art of logistics, as Leibniz writes in the above-quoted passage, then the imagination accounts, first and foremost, for the combinatoric art which - considering the importance Leibniz's attributes to it from his earlier project of a characteristica universalis ${ }^{19}$ - is a task still connected to logistics. It means that the imagination is inherently active in invention and discovery in two ways. On the one hand, it is connected to discovery because it accounts for expressions or a synthesis of information into a medium that differs ontologically from how things really are. In this way, pieces of information are collected, encoded, and stored into unified and orderly expressions, which are ready to be extracted whenever attention and memory are directed to those expressions. On the other hand, in virtue of its expressive power, the imagination contributes to data mining, or the extrapolation of information, because expression permits it to visualize relations that would have remained hidden to the cognizant agent absent the expression. The classical example of a regional map helps to illustrate the overall point here. A map allows for measurements that would be impossible, or at least very difficult to make, without the expression of the map in two dimensions. On Leibniz's account, however, the reassessment of information at a level more accessible to the cognizant agent is a double-edged sword of sorts: while it can function as a point of discovery, it can also prove to be a great source of agential failure. The imagination can infer new relations by presenting the cognizant agent with as-yet unexperienced combinations, which, however, can easily turn out to be impossible combinations.

Leibniz often points to the shortcomings of the imagination by reporting the existence of a division between the imagination and the intellect. Cognizant agents tend to invent arguments that satisfy the imagination and fool the intellect. When the imagination is satisfied, cognizant agents tend to believe that they have formed a perfectly reasonable argument, when, really, they have not. ${ }^{20}$

19 In On Universal Synthesis and Analysis or the Art of Discovery and Judgment (1679), Leibniz introduces the notions of synthesis and analysis, remarking: "I have said more about this in my little treatise on the Art of Combinations, which I brought out soon after my adolescence" (L 229-30). Soon after he writes: "Saepe notavi ingenia inventionis capacia, alia magis analytica, alia magis combinatoria esse. Combinatorium magis est sive syntheticum alicujus rei usum et applicationem invenire, ut data acu magnetica cogitare de applicatione ad pyxidem." (A VI 4 A 545/L 233). See also De arte inveniendi in generale, A VI 4 A 81: "Methodus quaerendi duplex est vel Synthetica seu Combinatoria vel Analytica. Ex quibus Analytica est difficilior, Synthetica longior. Analytica interdum per naturam rerum exitum reperire non potest, synthetica semper."

20 Leibniz to Bulchard De Volder, December 5, 1702: "Quae differunt debent aliquo differre seu in se assignabilem habere diversitatem; mirumque est manifestissimum hoc axioma, cum tot aliis ab hominibus adhibitum non fuisse. Sed vulgo homines imaginationi satisfacere contenti rationes non curant, hinc tot monstra introducta contra veram philosophiam. Scilicet non nisi incompletas abstractasque adhibuere notiones sive mathematicas, quas cogitatio sustinet, sed quas nudas non agnoscit natura, ut temporis, item spatii seu extensi pure mathematici, massae 
In conceiving of atoms, for instance, we can imagine particles of matter that are not further divisible, and are perfectly alike, distinguished only by their different spatiotemporal locations. However, as we argued in chapter V, even if the imagination - owing to its constraints - takes two bodies (which may even be perfectly alike) as two bodies distinct in number (simply because they are coperceived in distinct locations at the same time), the fact that we can imagine it does not mean that two bodies may be distinct solo numero. Therefore, the idea that there are atoms that differ only because of their locations is rejected by Leibniz as something that satisfies the imagination but does not respect metaphysical principles. Without entering into the details of this argument, the gist is that we can imagine things that are perfectly in agreement with the imagination while contradicting intellectual principles. To conceive of intellectual principles, cognizant agents require a different level of abstraction and reflection, which imaginative processes typically do not require. To assist in making our point, we can borrow Putnam's thought experiment regarding water in a twin world. ${ }^{21}$ If, on first intuition, a cognizant agent takes twin-water and actual world-water as being the same in virtue of their phenomenal appearance, then a more considered reflection regarding the essence of water will lead the cognizant agent to revise her belief. Although water and twin-water are not the same for the intellect (which can consider their essences), these two liquids are perfectly alike with regard to the imagination. Owing to this, there is no way for us to distinguish between the two types. The imaginable world and the intelligible world may come apart, and it is the task of intellectual reflection to understand why things are sometimes different from how they appear. ${ }^{22}$

By considering the work of the imagination from this perspective, it seems that the imagination constitutively leads us astray. If this is true, then how can cognizant agents be successful in the business of making predictions based on types, if types themselves hinge upon the imagination? More specifically, if types are so intimately related to the work of the imagination, and the imagination constitutively

mere passivae, motus mathematice sumti; etc. ubi fingere possunt homines diversa sine diversitate, exempli gratia duas lineae rectae partes aequales, quia scilicet linea recta aliquid incompletum abstractumque est, quod doctrinae causa spectare oportet; at in natura quaelibet recta a qualibet distinguitur contentis. Hinc fieri nequit in natura ut duo corpora sint perfecte simul aequalia et similia. Etiam quae loco differunt, oportet locum suum, id est ambientia exprimere, atque adeo non tantum loco, seu sola extrinseca denominatione distingui, ut vulgo talia concipiunt. Hinc corpora vulgari modo sumta, veluti Atomi Democriticorum, globuli perfecti Cartesianorum, dari non possunt in natura, neque aliud sunt quicquam quam incompletae cogitationes philosophorum non satis rerum naturas inspicientium." (A II 4 131/LDV 258-9).

21 Leibniz designed a similar thought experiment in NE 245/AVI 6 245. He imagines a perfect duplicate of the actual world, inhabited by persons exactly alike, who even have the same kinds of conscious states. As he remarks, we could not tell these worlds apart.

22 To distinguish between human and non-human animals, Leibniz often points to the human animal's capacity for understanding whether something is going to happen even when the circumstances appear similar to previously experienced situations, see NE 50-1/A VI 6 50-1; NE 271/A VI 6271. 
fails to correspond with intellectual principles, thereby leading cognizant agents astray, do types provide a kind of knowledge that structurally exposes them to error by causing agents to imagine the impossible?

In order to refute this claim, we ought to recall the notion of split-impossibility that we put forth in chapter $\mathrm{V}$. There, we argued that impossibility, understood as a split-notion, can take two forms: something can be logically impossible because its essence implies a contradiction. Or, it can be impossible in the sense that, while it might not exist in the actual world, it may exist in another, possible world. Let us focus on this latter kind of impossibility because these kinds of mistakes can be corrected by the imagination, while logical impossibility requires the assistance of the intellect and intellectual principles. In short, the imagination does not constitutively lead us astray in becoming preoccupied with the second kind of impossibility claim, viz. that owing to existence. ${ }^{23}$ If the imagination leads us astray in the case of logical impossibility, then this is simply because it goes beyond its limits: it tries to imagine those notions of the intellect that constitute metaphysics, which are necessarily beyond its scope, for they rest on principles that do not straightforwardly constrain the imagination. ${ }^{24}$

As we argued in the last chapter, an impossibility claim may be about the internal possibility of a phenomenon, or about the possible existence of a phenomenon. Impossibilities of the former kind are based on a logical evaluation of the absence of contradiction within the notion. Impossibilities of the latter kind are based on an evaluation regarding whether or not the phenomenon fits into a world. What follows is an example of impossible existence.

Consider a human body. It is made up of parts, such as hands, a head, and feet. These parts can appear to move autonomously, meaning that we can see a hand moving without noticing movement in the rest of the body. Nonetheless, the movements of a hand depend on the rest of the body. For example, a hand cannot occupy a distance away from the torso that is twice the length of the arm. To illustrate, imagine that you are sitting at your desk. You would like to grab the cup of coffee on the kitchen table, which sits five feet away. Deeply immersed in your leisurely afternoon tasks, you imagine extending an elastic arm towards the kitchen table and grabbing the cup. But, of course, you cannot. If you made such an attempt and it worked, then you would feel a sense of suspicion and incoherence in looking at the cup as it approached your mouth. Suspicion constitutes a confused state of mind that expresses the cognitive fact that what the mind sensorially perceives or imagines contrasts with certain mental expectations. This renders the phenomenon im-

23 It is worth noting that Leibniz holds the view that sense-perception is always veridical. The source of error is judgment. For a discussion of this claim, see Di Bella (2016: 713-25), and Favaretti Camposampiero (2016).

24 We have already read the passage in which Leibniz remarks that: "Human beings have the natural tendency to explains via the imagination also what is not subject to it" (A VI 4 A 890). Moreover, writing to Sophie Charlotte in BSI, Leibniz claims that intellectual notions are not subject to the imagination. 
possible, albeit only physically impossible. The suspicion you would feel constitutes an implicit judgment regarding the impossibility of the phenomenon experienced, which rests on a typicality. Typically, I am not capable of extending my arm five feet. Therefore, the phenomenon is incompatible with the world in which I reside. The impossibility claim is not the result of a logical evaluation of an alleged contradiction between the concept ARM and the property "being-extensible by five feet". Even when you become an adult who is capable of logical thought and mathematical proofs, you nonetheless respond to the enquiry about whether you can reach the cup from the desk simply by running through the scenario in your head, which involves a simple evaluation of distances and your body. It seems, then, that this sense of suspicion in sense-experiencing phenomena rests on interiorized rules about how this particular type of body, i.e., your body, moves. "Type" here means that your predictions rest both on a general representation of a nature that the object in question shares with other existing things, and on expectations regarding how that type of thing typically behaves. Thus, all things of that type act in that way, and that is how they typically behave. It is not the case, however, that they could not behave otherwise.

Moreover, types are not deducible from spatiotemporal rules per se, as we argued in chapter V. For, I can draw a body that shows a body stretching an arm towards the table; I can also imagine it. Indeed, nothing can stop me from imagining that the arm might have moved in that way, except for the fact that it contrasts "with the customary nature of the phenomenon". That is not how human arms move in the real world. At this stage, the only reason I have to expect that an arm cannot stretch that far is the fact that I have never experienced it. Indeed, when I try to do so, I soon realize that it cannot actually be done.

The fact that we can also imagine what was, is, or never will be given in experience points to the productive character of the logic of the imagination. In experience, cognizant agents unpack phenomena into parts and properties, and, in collecting the elements, spontaneously start combining them. The imagination's spontaneity and anarchy constitute its essential attributes since they provide the ground for extending our knowledge beyond the limits of what we have experienced. In virtue of the productivity of the imagination, cognizant agents can infer what is asyet unknown but probable from what they already know, thanks to experience. In other words, cognizant agents infer what might be from what is or has been, i.e., they form hypotheses that must be tested. The risk they run, however, consists in believing that something impossible is also true of the actual world. Yet, such a risk is also a decisive mechanism for controlling information and predicting phenomenal states.

The imagination produces (non-propositional) inferences by combining known elements in unknown combinations. Therefore, in the act of producing new things on account of known traits, the imagination trains the mind to enhance its capacity for predicting and expecting possible phenomenal behavior, beginning with a certain 'given' or imagined state: 


\begin{abstract}
Knowledge can be taken even more generally, so that it is involved in ideas and terms before we come to propositions and truths. If someone looks attentively at more pictures of plants and animals than another person, and at more diagrams of machines and descriptions and depictions of houses and fortresses, and if he reads more imaginative novels and listens to more strange stories, then he can be said to have more knowledge than the other, even if there is not a word of truth in all that he has seen and heard. That is because the practice he has had in portraying in his mind a great many actual, explicit conceptions and ideas makes him better educated, better trained, and more capable than someone who has seen and read nothing - provided that he takes nothing in these stories and pictures to be true which really is not so, and that these impressions do not prevent him in other contexts from distinguishing the real from the imaginary, the existent from the possible. (NE 355-6/A VI 6 355-6)
\end{abstract}

On my reading of this passage, the more we experience, the more we train the imagination, and the more efficient and reliable are we at predicting what may, or may not, obtain in being presented with new scenarios. Thus, for example, having experienced that paper near a flame burns, I am better able to imagine that wood near a fire likewise burns. The mind does not have to experience a certain combination in order to imagine it coherently; once the logic is apprehended, the mind can autonomously begin to combine elements. Indeed, in so doing, it proceeds by trial and error. A cognizant agent may expect ice to burn as paper does when it is held near a flame. Agents are nonetheless able to revise their expectations when they experience that combining fire and ice produces a different result than with paper. This constitutes another reason why agents need to be taught through experience which changes are real and which are imaginary, thereby distinguishing imagining from believing in the possible existence of what we imagine. Our capacity to express concrete beings as perceptible wholes puts us on the right track for gaining knowledge of phenomenal nature. However, it also exposes us to the error of imagining what is impossible.

This analysis, however, is not entirely correct. The imagination would lead cognizant agents astray were it structurally productive, that is, as constantly being in the business of combining known elements into unknown combinations. This is not the case, however. The imagination is not completely free in its combinations and is not anarchic. Its structural dependence upon sensory inputs limits its combinatoric power to that which is typical or more likely to happen, as based on the evaluation of similarity between previously-experienced and given situations. The imagination is first and foremost in the business of reenacting the past by means of types: stored information about what we learned about things.

If, as we argued so far, types rest on detecting beings' similarity, similarity functions as a key constraints on what the imagination entertain as possible existent and inexistent. The cognizant agent has no control over seeing two things as similar. If she intends the shape as expressing a nature common to other, similar things, this act is not arbitrary because, as we have seen, the imagination is constrained by space and time, as well as by relations of similarity between the formerly- and presentlyperceived conformity between situations and things. The imagination neither invents nor creates fictions, which would provide cognizant agents with scenarios independent of experience and without having first been furnished by the senses. 
The imagination becomes a productive faculty because it is by nature a combinatoric and synthetic faculty, working jointly with the senses. The relation between the imagination and the (im)possible provides us with an understanding of the nature of the imagination as a synthetic rule-giver, which orders phenomena and its nature productively. In so doing, it leads the mind beyond what obtains by imagining what does not, or even cannot, exist, but it has also means to sort out what is merely imaginary and what can be part of the world.

\section{CONCLUSION}

Types are more than rules for tracking phenomenal movements, as based on spatiotemporal constraints. Types are, first and foremost, a way of sorting phenomena into similarity classes. Therefore, the process we described is not as linear as our foregoing description suggests. What we have called moments - the acts of segmenting, tracking, and interiorizing types - are not always temporally-successive; they are rather intertwined. Once we interiorize types, types control memory and attention and may be credited for enhancing our capacity for segmenting, tracking, and predicting phenomenal behavior in relation to other, co-existing things. In other words, cognizant agents, for as long as they experience phenomena, continue to improve upon their types. However, agents thereafter form prejudices in the form of implicit judgments, owing to which they less readily revise the order they expect to find in the world, which has been constructed from their experientially-informed viewpoint. Agents tend to act and behave according to the empirical principle, viz. "what has happened, will happen again". In order to force a revision in types, cognizant agents must develop concepts (what Leibniz calls distinct thoughts, i.e., ways of selecting more compelling reasons to falsify a theory). Distinct thoughts hinge upon reflection and intellectual principles. These principles, however, do not perfectly correspond with those that constrain the imagination. Indeed, in the next chapter, we shall enquire into why types are not concepts and what concepts uniquely allow us to do as cognizant agents. 
Franz Steiner Verlag 


\section{WHY TYPES ARE NOT CONCEPTS}

In the previous chapter, I argued that, within Leibniz's theory of human cognition, the imagination functions to express particular existing beings through similarity classes. The imagination is sensitive to similarities in shape and size. Moreover, owing to these parameters, it functions to construct and track phenomena across spatiotemporal variation. This tracking is the reason why the imagination can interiorize what I have called types: general rules that become active through habitual interaction with bodies in the phenomenal world. The background work of types in the act of perception permits cognizant agents to: (i) recognize the phenomenon as a phenomenon of a certain type (whether a body or property); (ii) predict the behavior of the body-type or property-type across spatiotemporal variations; (iii) develop a sense of coherence for phenomenal behaviors, which grounds our capacity for telling apart the real and the imaginary (i.e., phenomena that can obtain in the actual world versus phenomena that can be only imagined as obtaining in other, possible worlds). This latter capacity is something upon which we improve constantly: the more we experience, the better we are at predicting what can and cannot (in all likelihood) transpire.

As human minds interiorize types, they engage in imagine-that cases. They learn to imagine both possible and impossible scenarios, evaluating whether those scenarios can or cannot obtain. This capacity for the mental modelling of images is essential for putting structure into the world, and for obtaining a first-level abstraction and ordering of phenomena based on type-similarity.

Similarity, however, is not sufficient for grounding necessary truths, Leibniz argues. The limits of the imagination in the derivation of necessary truths is clearly stated in a passage of On the Elements of Geometry of the Duke of Burgundy (1705). There, Leibniz reports and discusses an argument against the mortality of human beings that is based on induction. The argument, as reported by Leibniz, casts doubt upon the idea that, because we know that our ancestors died, then we also know that we ourselves are going to die. Our ancestors' deaths bear no causal relations to our own lives, so their deaths cannot provide evidence for our own mortality. Leibniz observes that, in criticizing the argument based on induction, the author does not address the proper relation between the premises and the conclusion upon which the argument is constructed. Evidence for my own mortality is in no way provided by a causal relation that my ancestors' deaths bore on my own life. Rather, the similarity that characterizes my ancestors and I signifies that there must be a reason for this similarity. The reason consists in a common nature that is also the cause of our deaths. Since common nature belongs to all similar things, we can track analogical behavior in things that are similar. For instance, in our acts of tracking and expecting spherical objects to roll, so too we expect that human beings die just as our ancestors did, not because our ancestors did. What the mind establishes is not a causal relation between individuals, but an analogy: 
The problem is that we resemble them [our ancestors L.O.] a little too much, in that the causes of their death also subsist in us. For the resemblance would not be sufficient to draw certain consequences without the consideration of the same reasons. (Leibniz to Sophie Charlotte June 1702 LSS 243/A I 21 343; my italics)

Only the acknowledgment of a great similarity causes us to infer a common, formal cause for all similar individuals. Leibniz's final remark is decisive for understanding that the imagination is not the source of necessary truth. The similarity of beings is only a sign, which the rational agent must interpret by means of other tools, viz. innate intellectual principles. These principles enable agents to envisage a reason that can count as a cause for this or that phenomenal behavior. The reason found is something implied by the similarity of my ancestors and I, but similarity per se is not the reason for our deaths: the fact that we have a body that decomposes - subject to physical and biological laws - are the prerequisites of that being's nature, which all similar beings share, and functions as the reason for the states of that being. Only the intellect can locate these requisites, viz. the causal links between those properties and various states of the being. Without the preliminary work of the imagination, which consists in an initial ordering of things based on similarity, the intellect would not seek out reasons. This is because, without the simplification work operated by types, the intellect would be groping in the dark, not knowing what to search for. Thus, while similarity serves as the basis for necessary truths, it is not their ground. Necessary truths are grounded in the mind's innate ideas. Similarity explains how a cognitive subject learns necessary truths; not why truths are necessary. To this end, thinks Leibniz that we need a further kind of knowledge: concepts.

In this chapter, I address the question of what concepts are and the extent to which concept-based reasoning differs from type-based reasoning. If our analysis is correct, then, in delineating the logic of the imagination, we will have attained a very important and systematic distinction within Leibniz's epistemology and theory of human cognition, viz. the distinction between types and concepts, that maps onto his distinction between perception and thought. First, however, we need to offer a proof that types and concepts truly are two different kinds of acquired cognitive abilities. In arguing for this, I shall use a two-step argument.

The first step consists in showing that types and concepts correspond to two different cognitive mechanisms. Types are collections of individuals; concepts are not. The main argument that Leibniz provides for this claim is that our capacity for detecting similarity enables the gathering of particulars into classes. Similarity classes can be understood as sets: sets have identity conditions extensionally in virtue of their members; instances do not provide identity criteria for concepts.

The second step consists in arguing for the irreducibility of types to concepts. Unlike types, concepts, for Leibniz, are structured networks of terms that express essences in the mind of God, thereby capturing the structure of possible world(s). Within Leibniz's framework, concepts express possibilities that we may conceive of on the basis of similarity classes, which consist in interiorized ways of expressing the nature of a certain kind of object, or certain kind of property, through a variety of nominal definitions. Concepts, however, are not abstracted from types. Concepts and types are two different kinds of cognitive tools that fulfill different tasks. While 
types support imagistic forms of reasoning (based on the manipulation of spatiotemporal images), concepts enable the manipulation of propositions and the evaluation of reasons that ground their truth.

Once we have distinguished between the kinds of cognitive tools that types and concepts are, I shall argue for the irreducibility of the first-acquired kind (types) to the second-acquired kind (concepts). There are tasks that we cannot perform through conceptual thought alone. Owing to this, we need types. However, there are likewise tasks that types are unable to fulfill, owing to which we need concepts. Types are not transformed into concepts: they spontaneously accompany all forms of conceptual reasoning. Concepts provide something that types cannot give us: identity criteria for individuals.

Based on types, cognizant agents can consider members of a similarity class as similar but not as identical. Only concepts can provide identity conditions for their members. In the act of taking a particular object as an instance of a concept, one proclaims the identity of the structure/analogy of the object with the concept. The concept is defined by some properties that map onto the ontological structure of the object, thereby reducing it to an abstract essence. One does this as if the individuality of the object can be reduced to the universality of the essence, as expressed by the concept. Even if this knowledge is often provisional and hypothetical, Leibniz claims, it nonetheless allows us to predict phenomenal behavior with a higher degree of certainty, or even with necessity. This level of knowledge cannot be reached via types. ${ }^{1}$ It moreover rests on innate, necessary truths. This latter claim shall be argued for at length in chapter VIII.

\section{TYPES VS. CONCEPTS - EXTENSION VS. INTENSION}

Against Locke, Leibniz at several points emphasizes that concepts are only based in resemblances between particulars. They do not consist in particulars' resemblances. If concepts were constituted by the relation of the resemblance that individuals bear to one another, then concepts would amount to collective wholes of individuals. Recently, Stefano Di Bella (2017) has argued that, since his edition and commentary of Marius Nizzolius's Antibarbarus (1671), Leibniz developed his theory of concepts (traditionally called "universals") through critical confrontation with the theory of universals understood as collective wholes.

The so-called "collective wholes theory of universals" has its roots in the Scholastic tradition, whereby it is simply called collectio. ${ }^{2}$ Collective wholes have their identity criteria in their members. A universal, say "man", differs from another universal, say "lion", because it is a collection of different individuals. As a corollary,

1 See Bolton (2017: 220-25).

2 For an introduction, see Klima (2017) and Di Bella-Schmalz (2017: 1-9), for a discussion of the relation between medieval and early modern issues. 
this theory sees universals being explained extensionally: a universal is (i) a collection of individuals; and (ii) a general term referring collectively to the individuals of that class (Leibniz's technical terminology is that the term refers "in concreto", that is, to concrete beings). In what follows, I shall build upon the insights reached in Di Bella's work. ${ }^{3}$ For, while I am in-tune with Di Bella's work on Leibniz's theory of concepts, I nevertheless argue that, amid Leibniz's criticisms of a theory of concepts understood as a collection, he does not deny that human minds make use of collective wholes. Types can be understood as collective wholes, but collective wholes are not concepts. Concepts, however, can gain an extensional interpretation in virtue of a corresponding type.

I shall moreover argue that Leibniz equates collective wholes to Locke's theory of general terms. Following Bolton's (2017) lead, I shall conclude that Leibniz rejects Locke's theory of ideas because Leibniz understands Locke's ideas as general images that can be explained extensionally. On his view, Locke's ideas are not concepts, and they cannot help to further the sciences. This is because Lockean ideas suffer from the same problems as the theory of collective wholes.

The endorsement of a nominalist ontology seems to lead straightforwardly to the acceptance of a theory of concepts understood as collective wholes. Nominalists only accept individuals in their ontology, Leibniz maintains. ${ }^{4}$ Anything that is not an individual - for instance tropes and abstract terms, such as "redness" or "humanity", or kinds, like "man" or "virtue" - are merely general names. These general names are used as compendia: abbreviations to refer to aspects or properties inhering in the only things that we have in our ontology: individuals. So, when I say:

(1) Every man is mortal,

I simply collectively refer to all of those individuals in the ontology that bear the property of "being a man" (M) and bear the property of "being mortal" (G). (1) claims that $(\mathrm{M})$ and $(\mathrm{G})$ are co-extensional. Sentence (1) has a further meaning. If sentence (1) is true, then it claims that there are individuals in our ontology that bear $(\mathrm{G})$ if they have $(\mathrm{M})$, and that both properties are co-extensional within a certain collection of individuals that we call "men".

Compare proposition (1) with the particular proposition:

(2) Socrates is mortal.

This sentence simply claims that there is an individual, Socrates, and that this individual is mortal. It is true iff (i) Socrates exists and (ii) Socrates instantiates the property of "being mortal". Now consider the further proposition:

(3) Every mammoth has four feet.

3 Di Bella (2004: 15-48; 2017: 198-219).

4 For a reconstruction of how to understand Leibniz's nominalism, see Mugnai (1990); Mates (1986). Bolton's argument (Bolton: 1996) for Leibniz's nominalism: abstracta cannot exists because they are incomplete entities. 
This sentence (3) claims that the property of "being a mammoth", (F), is co-extensional with the property of "having-four-feet", $(\mathrm{H})$. Nonetheless, there are no mammoths in our ontology, for they are extinct; there is no individual bearing properties $(\mathrm{H})$ and $(\mathrm{F})$. There is no co-extensionality between $(\mathrm{F})$ and $(\mathrm{H})$. Therefore, $(3)$ is false.

Even if the reading of concepts as collective wholes were plausible, Leibniz argues that the interpretation of (1) - (3) exhibits inconsistency. First, consider sentence (1). What is the reference of the quantifier "every" in the expression "every man"? If we assume concepts to be collective wholes, then they consist in a collection of existing individuals designated by a general term, "man". Therefore, "every" collectively refers to all men existing at a certain time in the actual world. However, if this is true, then every time a member of the class perishes we get a different concept. ${ }^{5}$ This is implausible, however, because the truth of (1) is grasped independently from acquaintance with the individuals to which it refers.

The theory of collective wholes perhaps fairs better with particular sentences, such as (2). The truth-value of (2), however, seems to be susceptible to temporal changes as well. If (2) is true as long as Socrates exists, then it is false as soon as he dies. This seems to contradict our intuition that "Socrates is mortal" is true independently of Socrates' actual or continuing existence. Sentence (3) faces a similar difficulty, for it contradicts our intuition about mammoths. We perfectly understand (3). Indeed, we assent to it. However, on an extensional understanding of concepts, (3) is false, for mammoths do not exist. The sentence below, (4), is subject to the same difficulties as (2) and (3), because it appears to be true in summer but false in the winter (when it is impossible to find Carnations):

(4) Carnations smell good.

Let us now return to Leibniz. In a passage of NE, he argues that Locke's account of the idea of substances is existential. Locke argues that our ideas of substances are always inadequate since there are no corresponding essences in the world (archetypes). Indeed, if there were, then we could not know them. ${ }^{6}$ Given the absence of real references for our ideas, general names denote collections of individuals. That is to say, general terms refer collectively to individuals in our ontology. In spite of their being inadequate, ideas of substances can either be real or chimerical. They are real when they signify a connection of ideas to which something in the world corresponds. They are chimerical when nothing in the world corresponds to that connection of ideas. ${ }^{7}$ If this is true, Leibniz argues, then when we talk of carnations in winter, we are talking about something inexistent and therefore chimerical. This conclusion is absurd because we grasp the truth of sentences like (4) independently of the existence of the individuals to which they refer. Leibniz presents Locke with the same difficulties suffered by the theory of collective wholes:

5 This argument is not new. It is also reported in Zimmermann (1854). We will analyze the text below.

6 EHU 361-6.

7 EHU 369. 
If one takes what exists as one's only guide, one will needlessly diverge from accepted ways of speaking; for these do not allow one to say that someone who speaks of roses or carnations in winter-time is speaking about a chimera, unless he thinks that he can find such flowers in his garden. (NE 266/A VI 6 266)

Given these difficulties, Leibniz believes that Locke's theory of concepts cannot ground science. For, consider the sentence:

(5) Every body falls at a rate of $9.8 \mathrm{~m} / \mathrm{s}^{2}$

On the collective wholes reading, (5) is true iff all bodies falling at a given time descend with a rate of acceleration of $9.8 \mathrm{~m} / \mathrm{s}^{2}$, which is absurd. Sentence (5) is meant to be true independently of actually-existent, falling bodies and, perhaps, even independently of the existence of bodies tout court. Even if bodies did not exist, on Leibniz's view, their possibility in different possible worlds holds true. ${ }^{8}$ As Leibniz writes in NE 301/A VI 6 301: "The real existence of beings which are not necessary is a matter of fact or of history, while the knowledge of possibilities and necessities (the necessary being that whose opposite is not possible) is what makes up the demonstrative sciences." Here, "possibilities" and "necessity" refer to essences. Indeed, what Leibniz means by the fact that essences or possibilities do not depend on instances is clarified in another passage of NE, in which he explains that there are two modes of predication: one being extensional, the other intensional:

The common manner of statement concerns individuals, whereas Aristotle's refers rather to ideas or universals. For when I say Every man is an animal I mean that all the men are included amongst all the animals; but at the same time I mean that the idea of animal is included in the idea of man. 'Animal' comprises more individuals than 'man' does, but 'man' comprises more ideas or more attributes: one has more instances, the other more degrees of reality; one has the greater extension, the other the greater intension. So it can truthfully be said that the whole theory of syllogism could be demonstrated from the theory de continente et contento, of container and contained. The latter is different from that of whole and part, for the whole is always greater than the part, but the container and the contained are sometimes equal, as happens with reciprocal propositions. (NE 486/A VI 6 486)

In this passage, Leibniz distinguishes between (i) a use of general names that maps onto relations of containment between concepts and (ii) the use of names as referents for existing individuals and their modes of modification. ${ }^{9}$ Intension can therefore be understood as a mark of a concept that can either entail, or be entailed by, other intensions. Notice also the conclusive remark that conceptual containment is not equivalent to whole-parts relation: if the whole is always greater that his parts, the container and the contained can be equivalent (or equipollent, if we use Jungius'

8 An extensionalist might say that, in this case, the extensional reading could be analyzed in temporal terms. For all falling bodies that have existed, exist now, and will exist, it is true that they fell, fall, or will fall with an acceleration of $9.8 \mathrm{~m} / \mathrm{s}^{2}$. I suppose, however, that this reading would render truths dependent upon time. Moreover, it cannot provide any account of the necessity of the connection between bodies and their physical states.

9 On the relation between intensional and extensional predication see Lenzen (1983: 129-148); also Mugnai (1976). 
terminology), that is they can be synonymous. This theory, which is known as "conceptualism", can erase the difficulties faced by the theory of collective wholes - or so Leibniz argues.

A conceptualist position holds that concepts express possibility, or what is classically called essence, consisting independently of (1) a mind's actual knowledge of them, and (2) actually-existing instances. On this view, a concept expresses something's possibility if and only if the definitional marks composing the concept do not result in contradiction. A possibility is expressed by an ordered cluster of general terms that can be given by definitions. For theoretical and logical reasons (related to demonstrations), we assume that for each essence there is a cluster of terms individuating that essence alone. In this sense, a cluster is complete even if we are not capable of completely unpacking it. Each cluster is moreover separate from the existence of its instances.

Despite the fracture between essences and existence, Leibniz thinks that concepts can either be real or chimerical:

Possible ideas become merely chimerical when the idea of actual existence is groundlessly attached to them - as is done by those who think they can find the philosopher's stone. (NE 265/A VI 6 265)

The same is true of those who think they can find carnations in their gardens in winter. In other words, we can still make a distinction between those concepts expressing essences that are instantiated in the actual world, and those that express essences that are not instantiated in the actual world. And yet, we can say that truth does not depend on the existence of instances, but on the possibilities that conceptual reasoning permits us to grasp. The sentence "Carnations smell good" is not true just in virtue of carnations existing: it depends on the compatibility of CARNATION (qua concept) and the property of smelling good. Concepts depend on purely intensional entailments, and the networking of simpler concepts that are expressed into the network of terms belonging to a system of signs, which are in turn ruled by semantics and syntax. ${ }^{10}$ A system of signs can equally constitute a natural language and an artificial language, such as a characteristica universalis. The networking and entailment among concepts constitute a structure that allows: (i) a greater degree of abstraction, and hence of logical and metaphysical analysis, than that permitted by types, since we can form expressions that are hyperintensional; ${ }^{11}$ (ii) a

10 The relation between logic and grammar was a discussed topos in late Scholasticism in light of questions related to the order of Aristotle's Organon. If the Organon is an introduction to reasoning, then what is its first book? Is it the Categories (about predication), or is it On Interpretation (about language)? It seems that the correct interpretation of a sentence is a constitutive part of the logician's work, and, at the same time, the truth of the sentence seems to precede language and its interpretation. See Oliveri (2014).

11 Leibniz does not use the word hyperintensional, but he is aware of terms and sentences that are equivalent in terms of extension, since they refer to the same individuals, but are not logically equivalent because they cannot be substituted in a discourse without changes in truth-value. See Nolan (2014: 149-60), who defines hyperintensional as follows: "The twenty-first century is seeing a hypterintensional revolution. Theoretical tools in common use carve more finely 
different kind of conceiving from that permitted by types. If imagining based on types is to some extent a matter of mental imagery, and, as we saw in the preceding chapter, it is not subject to identity and contradiction but only to agreement with those principles, then conceiving based on concepts is independent from imagery, and subject to identity and contradiction, although it is not therefore completely independent of the imagination. Signs, or indeed other kinds of vehicles, are required for this kind of conceiving.

Leibniz concludes that the difficulties faced by extensional theories of concepts, such as Locke's, can be avoided through a form of conceptualism. Before considering in detail why Leibniz believes his theory fairs better with cases like (1)-(5), let us examine the assumptions characterizing conceptualism.

\title{
2. LEIBNIZ'S CONCEPTUALISM
}

Although Leibniz criticizes the nominalist theory, he provisionally defines himself as a nominalist. At the same time, however, he does not feel comfortable with realist positions, since they make nature "too profligate" in claiming the impossibility of "vacuum among forms", i.e., the claim that every possible essence must exist: ${ }^{12}$

\begin{abstract}
Also, we could not exaggerate nature's 'liberality'; she goes beyond anything that we can devise, and all the dominant compatible possibilities are made real on her great Stage. Philosophers used to have two axioms: the realist one seemed to make nature profligate and the nominalist one seemed to declare her to be stingy. One says that nature permits no gaps, the other that she does nothing in vain. These are two good axioms, as long as they are understood: nature is like a good housekeeper who is sparing when necessary in order to be lavish at the right time and place. She is lavish in her effects and thrifty in the means she employs. (NE 323/A VI 6 323)
\end{abstract}

Leibniz's criticism of realist positions is directed at the claim that every possible essence must exist. Therefore, there cannot be any lack, or gap, in nature: everything has an essence and the essences known by human rational beings are nature's real essences. On the contrary, Leibniz is sympathetic to Locke's idea that, if there are real essences, then these do not straightforwardly correspond to the essences we, as finite human beings, are capable of knowing. Our knowledge of essences is often limited and provisional. It would be absurd to pretend that nature and God are constrained by what we can conceive (NE 64). Leibniz, however, thinks that the assumption of the impossibility of a vacuum among Forms, proposed by realists, is valid, at least if it is not limited to the actual world. Any essence of which we can

than by necessary equivalence: two pieces of language can apply to the same entities across all possible worlds but not be equivalent; thoughts can be necessarily equivalent in truth value but not synonymous." See also Berto-Nolan (2021).

12 This passage must be read in relation to Leibniz's discussion about the impossibility of vacuum formarum, that is, a vacuum of forms (NE 307/A VI 6 307). On his view, this principle is valid, but the denial of a vacuum of forms does not imply that every form must necessarily exist. There are species incompatible with the series of existing ones that are nonetheless possible. 
conceive is possible, even if not every essence is instantiated in the actual world. There are other possible worlds, which are structured according to essences that are possible but different from those instantiated in the actual world. Therefore, the continuity between Forms is maintained by Leibniz. Indeed, it is actualized in his theory of possible worlds and not constrained by only one existent. Concepts, henceforth, refer to the human mind's apprehension of essences, regardless of whether they are instantiated in the actual world. This remark leads us to the discussion of what interpreters have called Leibniz's conceptualism.

Even in early interpretations of his work, Leibniz's position is reduced neither to realism nor nominalism. Among these interpreters are Zimmermann (1854) (who was a Professor at the University of Vienna and a contemporary of Franz Brentano and Alexius Meinong), Schepers (2014), Mugnai (2000), and Di Bella (2004; 2017).

Schepers (2014: 227-231) notes that Leibniz's conceptualism must be read along the line of Ockham's theory of a mental language. According to Schepers, concepts are for Leibniz, as for Ockham, termini nullius linguae, terms that do not belong to any spoken or written language, which naturally refer to things. Termini nullius linguae are concepts proper to a mental language. Schepers assumes that all concepts are innate. However, a closer look at some passage of Ockham suggests that his account of concepts consists in the mind's capacity to grasp the similarity between things and, through this, the concept is abstracted. This abstraction, Ockham claims, is an occult operation of the mind. ${ }^{13}$ Since similarities are real and

13 Ockham's position about lingua mentalis is in fact more complex and debated than Schepers' presentation would lead us to believe. From the following passage, in which Ockham describes the formation of general notions, it is evident that notions are in the soul not innately, but rather as a way of cognizing the actual world, which is naturally present in rational souls: "[...] iste est processus quod primo homo cognoscitur aliquo sensu particulari, deinde ille idem homo cognoscitur ab intellectu, quo cognito habetur una notitia generalis et communis omni homini; quo existente in intellectu statim intellectus scit quod homo est aliquid, sine discursu. Deinde apprehenso alio animali ab homine vel aliis animalibus, elicitur una notitia generalis omni animali, et illa notitia generalis omni animali vocatur passio seu intentio animae sive conceptus communis omni animali” (William of Ockham, Summa logicae III-2 cap. 29, OP I, 557.) The process of concept-formation is described as a hidden (occultus) process, neither observable nor consiously perceived by the mind: "natura occulte operatur in universalibus, non quod producat ipsa universalia extra animam tamquam aliqua realia, sed quia producendo cognitionem suam in anima, quasi occulte - saltem mediate - producit illa universalia, illo modo quo nata sunt producit. Et ideo omnis communitas isto modo est naturalis, et a singularitate procedit, nec oportet illud quod isto modo fit natura esse extra animam, sed potest esse in anima" (William of Ockham, In I Sent. (ordinato), d. 2 q. 7 (OT II, 261)). Interpreters, however, tended to assimilate Ockham's lingua mentalis to Fodor's language of thought and, hence, to understand concepts as innate to the mind, that is, they cannot be acquired via experience. Lenz $(2008,309)$ argues against a mainstream interpretation of Ockham as an innatist, thereby denying that there is an inborn mental language, or a systematic capacity to form sentences. For a reconstruction of Ockham's theory of "mental language", see Perler (2004) and Schierbaum (2014). I am grateful to Stephan Meier-Oeser for making me aware of the passage. 
mind-independent, they are grasped in the same way by all man, and are, for that reason, natural.

This reading has some affinity to Leibniz, as proven by the following passage of NE 485: "Insofar as you conceive the similarities amongst things, you are conceiving something in addition [to the things themselves], and that is all that universality is. You will never clearly present any of our arguments without making use of universal truths." Conceiving of a universal, however, does not give a definition or a concept of the universal. So, what Schepers says is only partly true. Similarity is what enables us to conceive of a universal; it does not thereby provide us with knowledge of that universal. To have knowledge, we need to form a concept, that is understanding intensional relations among terms that define the concept.

A more detailed and pregnant account of Leibniz's conceptualism is given by Zimmermann (1854). Remarkably, Leibniz's conceptualism is discussed in light of the recent (at in Zimmermann's day) finding of a fragment on the reconciliation between nominalism and realism through conceptualism. The fragment is known by the title "De generibus et speciebus", erroneously attributed to Abelard. ${ }^{14}$ Conceptualism is defined as a mixture of the positive characteristics of both nominalism and realism, with the virtue of avoiding their respective pitfalls. Conceptualism considers concepts to be collections (Inbegriffe) of real individuals that are collected thanks to similarity in nature. Given this real ground of concepts, they are neither mere names - which are only in the mind of subjects - for they represent real essences, nor real things, since what exists are individuals. ${ }^{15}$

Following this first definition of conceptualism, Zimmermann notes that it does not apply to Leibniz's philosophy. If it did, then Leibniz's philosophy would suffer from the same problems as those inherent in nominalist positions that Leibniz himself critizes, viz. that a change in the number of individuals designated by a name would force a change in the concepts. To avoid this problem, Zimmermann argues, Leibniz understands concepts as collections of essences. Essences are instantiated materialiter by the individuals they represent and, therefore, do not exist in nature. However, because there is a relation between the material constitution of individuals and essences, as manifested in the similarities between

14 The Manuscript was first published in 1836 by Victor Cousin as part of a more extensive text collected by a Manuscript held at the Bibliothèque nationale de France (lat. 12268) under the name "Fragmentum Sangermanense de generibus et speciebus" and attributed erroneously to Abelard. The study of Peter King shows that the fragmentum published by Cousin points to four different treatises: 'Totum integrum'; 'De destructione Socratis'; 'Si quelibet duo puncta'; 'De generibus et speciebus'. 'De generibus et speciebus' is, however, an independent treatise and cannot be attributed to Abelard. Working with two different manuscripts (Bibliothèque nationale de France, lat. 13368 and Orléans, Bibliothèque Municipale, 266, pp. 153a-166a), King reconstructed the complete text. The provenance of the text remains, however, controversial. Recent studies tend to attribute it to Joscelin de Soissons, or to one of his pupils. For a discussion of the text, see Tarlazzi (2013, 104-9; 182ss.). This aspect is not directly relevant to our discussion since Zimmermann believed that the author was Abelard.

15 Cf. Zimmermann, 1854 (2010), 24-25. 
existing individuals, concepts can be collections of essences and have an extensional interpretation.

Although Di Bella $(2004 ; 2017)$ does not refer to Zimmermann directly, we can use his work to clarify what Zimmermann meant by concepts as "collections of essences". Di Bella points out that Leibniz's philsophy is developed against the backdrop of an ontological distinction between essences, beings, and terms. Terms (often used by Leibniz as a word for concepts) represent essences because they consist in "formalitates", i.e., intentional distinctions within the concepts that are not straghtworwardly extensional distinctions among beings. ${ }^{16}$ Through this operation, Leibniz detaches concepts from instances and considers them mere possibilities, as determined by the intensions of which they are composed.

Leibniz's conceptualism entails a further assumption (Mugnai 1990; Schepers 2014). We can only know essences as abstracta. As such, essences cannot but exist in God's mind. Essences are conceived by God eminenter, i.e., in a way incommensurable when compared to the human mind. ${ }^{17}$ Only God can conceive of essences as real constituents of individuals. Therefore, as we shall see, there is a place for realism in Leibniz's view: the existence of individuals. Individuals, however, do not have to exist in the actual world. They exist in God's mind as complete concepts of individuals belonging to different possible worlds (Schepers, 2014: 227-231).

I shall argue that an account of Leibniz's conceptualism must explain how concepts, that is human grasping of essences in the mind of God, have extensions, that is apply to indisiduals, whilst keeping extension "outside" the concept of a concept. On our view, types qua cognitive processes distinct from conceptual processes, account for the extensional interpretation of concepts. Following Di Bella and Zimmermann, I shall maintain that Leibniz's conceptualism does not have straightworwardly extensional interpretations. Concepts can obtain extensional interpretations when they are associated with types detecting beings' similarity. Similarity is a sign to interpret a concrete being as befitting under an essence, and hence to grasp it by means of a concept. Concepts, however, express possibilities, not individuals, nor their similarities.

Concepts are learned thanks to a first ordering on account of types. Therefore, they can acquire an extensional interpretation. However, I align with Bolton's

16 Di Bella $(2004,39)$. The passage Di Bella is referring to is a note to Temmik, presented in the Vorausedition (VE 1082), which says: "Albus Socrates, et Musicus Socrates, sunt unum idemque nam etsi Socrates qua Musicus bene canant, et qua albus non canant, verum tamen est album Socratem canare et quicquid de Musico Socrate, etiam de albo dici potest, nisi quod praedicationes hic excludimus reduplicativas, quibus formales rationes praedicatorum albedo scilicet et Musicae peritia distinguuntur. Et sane revera Socrates qua Musicus bene canit est enuntiatio praegnans constans ex his Socrates canit, Socrates est Musicus, et Nisi Socrates esset Musicus non bene caneret. Itaque non semper alius est Musicus et alius albus, ac proinde non sunt disparata."

17 Mugnai (1976; 1990); Schepers (2014); Antognazza (2015). Bolton (1996) argues that abstract, incomplete entities are compatible with Leibniz's account. 
argument that concepts are not abstracted from individuals in virtue of similarity. ${ }^{18}$ Similarities can help in forming types, but they cannot give us concepts. Concepts are acquired in virtue of necessary truths and, especially, the principles of contradiction, identity, and sufficient reason. When we conceive of not just what is common to similar beings but also of relations among conceived universals, such as inclusion (as in the case of "animal" and "man") or identity (as in the case of "man" and "rational animal"), we form a concept.

Following this reconstruction of the literature, we are now in a position to pinpoint some general traits characterizing conceptualism. In the remainder of the chapter, I shall test these claims and launch my theory of the co-indispensability of concepts and types. Conceptualism claims that:

(i) Concepts are human ways of cognizing essences or possibilities in God's mind;

(ii) Concepts are determined intensionally by their definitional marks, that is, their intensions;

(iii) Intensions are expressed via terms: signs or words that are used not in concreto - to refer to instances straightforwardly - but in abstracto - to capture essences' structures. In short, there is a difference in the use of the word "mortal", as in (2) "Socrates is mortal" and in (1) "Every man is mortal". In spite of the "every", (1) means that "mortal" is contained in "man"; 19

(iv) Concepts and their definitional marks remain in a network and are acquired in a network (Bolton 2011). ${ }^{20}$ This network grounds the systematicity of thought over associations, as permitted by types, as well as the analysis of conceptual entailment and conceptual connection, which vouch for the derivation of new propositions from a given one or from a set of propositions;

18 Do we abstract notions from individuals owing to their likenesses? On this matter, see Bolton (1996), who distinguishes two kinds of abstraction and denies that we can abstract general notions from individuals. A first kind of abstraction consists in separating some properties from the existing thing; a second kind of abstraction consists in the use of general terms that are necessary for hypothetical truths and therefore for science. Contrary to what Mate (1986) proposes, Bolton points out that Leibniz refuses only the former kind of abstraction, but not the latter. I agree with Bolton and build on her account in showing that the acknowledgment of similarities among individuals helps a particular mind to direct attention and the intellect to apply innate turths. It is thanks to the support of innate truths that we can acquire knowledge. This position is also supported by Bolton $(1990 ; 2018)$. For discussion about the determination of similarities, see Barth $(2014,287)$.

19 That is unless the singular proposition (2) is treated as universal, whereby "Socrates" refers to the complete concept Socrates and "mortal" is a mark of this concept: "But it is as well to notice that singular propositions are counted, so far as their form goes, among universal ones. For although there is indeed only a single Apostle Peter, it can still be said that anyone who was the Apostle Peter denied his Master. Thus the syllogism: 'St Peter denied his Master, St Peter was a disciple, so some disciple denied his Master', although it has only singular premises, is deemed to have universal affirmative ones, which puts it into the third-figure mood Darapti." (NE 485/A VI 6 485).

20 Bolton (2011a). 
(v) The systematicity of thought can be expressed via the systematicity of a system of signs structured by syntax and semantics, when the parts of the language are used in accordance with (ii) ${ }^{21}$

(vi) Concepts may acquire an extensional interpretation, but they are not explained extensionally.

In order to ground his theory of concepts, argues Di Bella, Leibniz introduces into his ontology a distinction between essences and beings, on the one hand, and possibility and existence, on the other.

While we can divide beings into possible and existent, we can divide essences into possible essences and essences that are instantiated in the similarities between existing beings. However, as Di Bella and Mugnai highlight, this distinction is only made possible by the Leibnizian approach to reality, which claims that "there is a great difference between how we divide things (res), and how we divide terms". ${ }^{22}$ I shall flesh out this claim by analyzing (i) - (vi), thereby showing to what extent concepts differ from types. To this end, the thesis I seek to defend is that the "great difference" in how we divide things and concepts relies on the profound difference between the cognitive processes that support tasks of recognition and those supporting conceptual reasoning. As I shall argue, the former is based on types, the latter on concepts.

\section{ALIA EST RERUM, ALIA TERMINORUM DIVISIO ${ }^{23}$}

In order to analyze the Leibnizian motto, we have to contextualize it within Leibniz's ontology. As explained in the introduction, Leibniz distinguishes between beings, terms, and essences. Let us briefly reiterate this distinction.

Leibniz defines "being" as the ontological bearer of primary and secondary qualities. A being is something that either exists or possibly exists. Since Leibniz endorses a nominalist ontology (albeit only "provisionally"), beings are not particular substances, i.e. monads, but countable beings (Rutherford 2008). Particulars are concrete insofar as they have - or are imagined as having - a body. By contrast with contemporary usage, the term "concrete" seems to be a property of both possible and existing individuals. Sherlock Holmes - in spite of being a fictional character - is concrete insofar as he is a possible existent being, imagined as having a body that bears primary and secondary qualities. ${ }^{24}$

Essences are not beings but collections of definitional marks. First of all, they are abstracta, which means that they are incomplete or ideal, lacking thereby the capacity of being real or existing. The essence of a square, for instance, is an abstract, while the drawing of a square is a concrete. In other words, it seems that for

21 I argued for this view in Oliveri (2016: III.2).

22 This motto is the title of a text partially edited by Mugnai (2010: 257).

23 See LH 4 7c 76-78 partially published in Mugnai (2010: 257-70).

24 For an overview of contemporary theories, see Rosen (2020). 
Leibniz the difference between abstracta and concreta lies in the fact that the letter can be embodied. Now, also a square can be embodied, but it does not count as a concrete because, as Leibniz writes to Arnauld, abstracta "contains only eternal or necessary truths, whereas the concept of an individual contains, considered as possible, what in fact exists or what is related to the existence of things and to time" (A II 245 ). ${ }^{25}$ An essence, therefore is detached from the notion of existence or possible existence, and we have an essence when we are capable of conceiving the union of some marks as being free from contradiction and as having some logical relations. The essence of MAN, for instance, is defined through the marks ANIMAL, RATIONAL, CAPABLE OF LAUGHTER, and so on. By contrast, BEE cannot be defined as both a FLYING and NON-FLYING ANIMAL. This is not possible, and therefore, does not correspond to an essence, since essences consist in the unities of compossible conceptual marks, that is marks that when unified do not result into a contradiction.

Leibniz is adamant that beings and essences are distinct. If an essence were a being, he argues, then this would lead to an infinite regress. For, if any essence were a being, then there would be an essence of that essence. Again, the latter would be a being too, so there would be an essence of an essence of an essence - and so on, ad infinitum. ${ }^{26}$ Let us not forget that, for Leibniz, there are individual essences (qua complete concepts of individuals) in the mind of God.

To sharpen the distinction between an essence and a being, we can add that the essence HUMAN BEING and a concrete individual, Claire, differ ontologically. This is because the latter actually has a body modified in a determinate way owing to various causes, while conceptual changes are not the result of causal changes. This ontological distinction, as we will see, raises the question regarding the relation between the concept and its instances. If I know that the concept HUMAN BEING has, among its intensions, the property of HAVING A BODY, then I can infer that Claire (qua human being) also has a body. In reverse, the concept does not give me the ability to recognize Claire as human being. For this recognitional act, I need to experience the individual Claire and form a type about the kind of changes Claire may be subject to that I label as HUMAN BODY. Claire, qua a concrete human being, has a particular shape and she is subject to causal changes, while no particular "shape" belongs to the concept MAN, nor can the concept undergo causal changes. In other words, concrete beings qua embodied are bearers of primary and secondary qualities. They are first known via experience and subject to the logic of the imagination which, as we have seen, does not respond to the principles of contradiction and identity, which, in turn, govern concepts that express essences.

This distinction offers an initial grasp of what Leibniz means in saying that "there is a great difference between how we divide things and how we divide

25 Thanks to Richard Arthur and Martha Bolton for inviting me at making this point explicit.

26 A VI 4 A 994: "An Essentia est Ens? Ita sane si philosophi scholae consequenter loqui volunt. Ergo Essentia habebit etiam essentiam, et sic in infinitum, inutili reciprocatione." The same argument is offered by Lowe (2008: $23-48)$. 
terms". If the term "thing" refers to concrete beings, then the division we perform when dealing with beings may either be: (i) distinctions of wholes into parts; or (ii) distinctions of individuals into similarity classes. As we discussed in chapters IIVI, these two possible ways of dividing beings are supported by the work of the imagination and do not correspond to concepts. Thus, the motto seems to suggest that conceptual distinctions are not of the same kind as a mind's act of gathering individuals into similarity classes. If the recognition of instances as being of a certain type and the formation of concepts are governed by different logics, then how can we learn to recognize an individual, say Claire, as an instance not of a type, but of a concept? That is, on what grounds am I permitted to attribute to Claire properties that belong to the concept HUMAN BEING?

Leibniz's solution is that we can learn to take certain phenotypical appearances of something as a sign of the concept which, better than others, express the thing from the point of view of an abstract essence. In particular, in dealing with natural kinds, the external shape of beings, which is used to interiorize type, seems to provide the link between the common nature detected via beings' similarity, on the one hand, and a general abstract essence, on the other. The type therefore mediates between things and concepts. Indeed, the reason for this lies in the fact that even if concepts do not consist in similarities, they are nonetheless formed by experiencing beings' common nature, as interiorized by the type. As outlined at the beginning of this chapter, whereby we discussed Leibniz's criticism of the argument concluding that human beings are mortal (based on data-collecting our ancestors' deaths), similarity is not the reason why beings are instances of the same essence; similarity is the reason why the intellect must search for a common reason explaining why similar beings will be subject to similar changes. If cognizant agents did not first group individuals into similarity classes, then they could not search for common reasons explaining those beings' states. Moreover, since the job of a type is to track beings' common nature, the type is spontaneously active in the formation of a concept and is therefore spontaneously associated with a concept expressing that common nature in a clear and distinct manner, viz. from the perspective of an essence. It is important to keep in mind that Leibniz distinguishes between nature and essence: the former constitutes a 'middle way' between necessary and contingent states of things, depending on how beings interact in the world (subject to physical laws), while the latter consists in the rigid cluster of those properties necessarily belonging to a thing. In explaining the difference, Leibniz uses the example of water. If we can say that, given certain physical conditions that obtain on some parts of planet Earth, the status of being fluid is natural to water, then we are not permitted to say that fluidity is essential to it. However, a human being born on the moon, in which nowhere to be found are those physical conditions necessary for the fluidity of water, would believe that water is essentially solid, and that it is unable to undergo any change in physical status. This example proves that, when dealing with natural kinds, it is difficult to isolate which properties essentially belong to a particular kind (see NE 433-4). However, we can still use nature as a guide. The next section will further analyze the case of water in order to show in what sense nature, as detected 
by types, can provide initial guidance for postulating an essence and hence for forming a concept.

\section{FROM TYPES TO CONCEPTS}

To explain the move from having a type to forming a concept, let us take into account the distinction between water and ice, as discussed in Leibniz's NE. Water and ice have a common nature, for they are two different phenomenological appearances of the same kind. And yet, we cannot detect any phenomenal similarities between ice and water. We observe that water changes its shape as soon as it is poured into a container. We observe it flowing in seas and rivers. On the other hand, ice does not change shape so easily; it does not flow in rivers and seas. Given these phenomenological differences, we form two different general words, "water" and "ice", because we have pragmatic reasons for having two different general names for two different phenomenal appearances.

Nevertheless, the case of water and ice seems to give us a good example of when appearances lead us astray. As Leibniz mentions to Locke, despite having two names and two phenomenological appearances, we are not allowed to infer that ice and water are two different species. As Leibniz explains: "A great deal of care and experience is needed if one is to mark out genera and species in a manner which comes fairly close to nature" (NE 310/A VI 6 310). This means that observations of appearances' similarity permit an initial distinction of phenomena into similarity classes. Given the different appearances of "ice" and "water", aligning with Leibniz's theory of the imagination, we actually form two different similarity classes for these phenomena. However, once we learn to recognize "ice" and "water", we observe that the former can undergo grandual and continuous spatiotemporal changes, which transforms it into something resembling water. On the other hand, we can observe that the latter can also be gradually and continously transformed into ice under certain conditions. The continous tranformations of one phenomenon into the other is the reason why, following extensive observation, we take water transformed into ice as being the same thing changing. When we thereafter conceive of something persisting in spite of phenomenal change, we advance the hypothesis that ice and water are two different manifestations of the same nature. In other words, we claim:

(6) Ice is water.

What is meant by this proposition? It is an identity statement produced by the spontaneous application of what Leibniz calls "truths of reason". To prove this, consider that the proposition cannot be a statement claiming the phenomenological coincidence of ice and water, for their phenomenological dissimilarity is the reason why we take them as two different things. In claiming "ice is water" we utter an identity statement, which is informative both on the side of the extension, and, more interestingly, on the side of the intension. In claiming that "ice is water", I am saying that two phenomena share the same essence (water), which can be manifested 
phenomenally as "fluid water", as well as in the phenomenological appearance "ice". I am not identifying the phenomenology of water with ice. What we are claiming is that there is a genus, whereby both water and ice are its particular manifestations. When I use the word "water" to refer to this genus, and not to a particular phenomenological manifestation, I make an initially-confused reference to the essence of water. As Leibniz writes to Locke: "Insofar as you conceive the similarities amongst things, you are conceiving something in addition [to the things themselves], and that is all that universality is" (NE 486/A VI 6 486).

What remains to render the confused apprehension of an essence as being of a distinct kind is to distinguish it into its constiutive intensions. This is done by means of terms that remain in regulated relations to the general term "water". The capacity for considering relations between terms as non-contradictory is the human mind's way of conceiving of essences. Indeed, it is an act distinct from imagining, at least as we have characterized it thus far. Imagining is subject to spatiotemporal rules, like those deployed to track transformation in ice into water, while conceiving responds to principles of identity and contradiction (which are not imaginative). What Leibniz calls conceptibility as conceiving concepts and their marks therefore equips the rational, cognitive agent with a new tool of discovery: demonstrations based on definitions, which are provided by the reduction of terms to identity claims, such as "man is a rational animal".

The use of identity statements as the foundation for the sciences (both mathematical and empirical) is advocated by Leibniz in several places in the NE. For instance, in this passage, Leibniz distinguishes between primary truths of reason and facts:

The primary truths which we know by 'intuition' are of two sorts, as are the derivative ones. They are either truths of reason or truths of fact. Truths of reason are necessary, and those of fact are contingent. The primary truths of reason are the ones to which I give the general name 'identities', because they seem to do nothing but repeat the same thing without telling us anything. (NE 361/A VI 6 361)

Examples of Identities are "What is, is; Each thing is what it is, and as many others as you want: $A$ is $A$; $B$ is $B$;..." (ibid.). Identities can also be negative statements, for instance, "I now turn to negative identities, which derive from either the principle of contradiction or from 'disparities'. Stated generally, the principle of contradiction is: a proposition is either true or false." The reason why Leibniz lingers on the matter of disclosing the variety of identity is that he wants to prove their use to Locke in demonstration. Since identities are truths to which we assent without the need for demonstration, they are axioms, that is, things worth taking as true:

All these can be established with certainty, without any proof, i.e., without bringing them down to an opposition (i.e., down to the principle of contradiction), when the ideas are well enough understood we do not need any analysis at this point. When that is not the case one is liable to error: someone who said The triangle and the trilateral are not the same would be wrong, since if we consider it carefully we find that three sides and three angles always go together [...]. Someone who has been listening patiently so far to what I have just been saying will finally lose patience and say that I am wasting time on trivial assertions and that identities are all useless. But this verdict would result from not having thought enough about these matters. The 
inferences of logic, for example, are demonstrated by means of identities, and geometers need the principle of contradiction for their demonstrations by reductio ad absurdum. (NE 363/A VI $6363)$

When we claim that "water is water" or "water is ice", we are not repeating the same thing. Rather, we are fixing the word "water" in its technical use to refer to an abstract essence WATER, which can then be specified through its relation to other definitional terms. Terms, as we will soon see, are the tools used to express essences. A concept, therefore, is an acquired capacity to form expressions consisting in the connection of terms that refer to essences. ${ }^{27}$

Leibniz returns to the topic of axiomatic identities in Book IV, this time underlining the difference between imagining and conceiving. He begins by claiming:

[...] the principle of principles really amounts to making good use of ideas and of experiments; but if we take this a little deeper we will find that what it involves, so far as ideas are concerned, is nothing but the connecting of definitions by means of axiomatic identities. (NE 450/A VI 6 450)

The idea of axiomatic identity is explained a few lines later, using as an example Euclid's axiom that straight lines only meet once and - most salient of all to our analysis - Leibniz opposes it to the confused ideas of the imagination:

Euclid, for instance, has included in his axioms what amounts to the statement that two straight lines can meet only once. Imagination, drawing on sense-experience, does not allow us to depict two straight lines meeting more than once, but this is not the right foundation for a science. And if anyone believes that his imagination presents him with connections between distinct ideas, then he is inadequately informed as to the source of truths, and would count as immediate a great many propositions which really are demonstrable from prior ones. This is something which has not been properly thought out by many people who have found fault with Euclid: images of this sort are merely confused ideas, and someone who knows a straight line only by means of them will be incapable of demonstrating anything about it. Euclid had no distinctly expressed idea of a straight line, i.e., no definition of it (for the one he offers provisionally is unclear, and useless to him in his demonstrations), and so he was obliged to have recourse to two axioms which served him in place of a definition and which he uses in his demonstrations: the one, that two straight lines do not have any parts in common, and the other, that they do not enclose a space. Archimedes gave a sort of definition of 'straight line' when he said that it is the shortest line between two points. But in his demonstrations, when he uses elements such as Euclid's, founded on the two axioms I have just referred to, he tacitly assumes that the properties spoken of in those axioms are possessed by the line which he has defined. (NE 451; my italics)

How do we know that two straight lines do not meet more than once? If we imagine them, then we can see them with our mind's eye. These confused ideas, however, cannot provide the foundation for science. A definition can do this job, although, if we are unable to find a real one, we can select observable properties of something that does the same work as a definition. This is what Euclid did: he assumed that two straight lines have no parts in common and do not enclose any space. In tacitly

27 See also Bolton (2017). 
assuming that the essence we are defining has those properties (although we cannot say why), we provide nominal definitions which, albeit only provisionally, assist in the advancement of knowledge. These ideas are distinct because they are based on terms that are themselves distinct, as shall be explored in the next section.

\section{TYPES, CONCEPTS, AND TERMS}

If types are abilities for recognizing, tracking, and predicting phenomenal appearances and connections, then concepts consist in the ability to form expressions of essences through the connection of terms. A term refers to an intensional distinction within an essence, which can be entailed by, or entail, other intensions. When we use names, such as 'man', as terms, the name does not refer to a concrete or possible being, but to an essence determined by other sub-conceptual marks that remain in a regulated relation. If I utter the sentences "That man is tall", and "man is rational animal", man is not used univocally. In the first case, it has an extensional interpretation, on which account the sentence is true if there really is a tall man. In the second case, it has an intensional interpretation and is true if and only if "rational" and "animal" constitute a conjunction of possible intensions, that is (i) if, when unpacked into their constituents, there is no contradiction entailed, and (ii) if their conjunction does not produce any contradiction. I do not need to know whether a man exists to know that the essence is possible.

A rational agent can be said to possess a concept when she has the ability to express an essence through the connection of terms in a definition, which can either be nominal or real. A real definition, as we pointed out in Chapter I, is one that puts us in a position to demonstrate the possibility of an essence, or to derive other things that we can demonstrate about the essence. A nominal definition consists in a selection of properties that we conceive of as pertaining to the essence - either through observation of its instances or by hypothesis - in spite of the fact that we have no way of demonstrating that they essentially pertain to the thing. Since concepts are an acquired ability to connect intensions, distinguished using the help of representative vehicles, ${ }^{28}$ intensional distinctions and their relations through terms render concepts forms of distinct knowledge of essences, and, therefore, of a different kind by comparison with clear and distinct perceptions, such as types. The intensional distinctions we use to define a concept are distinctions that do not change the extension of those concepts: they introduce divisions into what we can imagine as "epistemic space". 29

Let us illustrate with an example. If I say that "every tree is a plant", then this sentence is not informative regarding the extension of the concept TREE. It may be informative about the extension of the concept PLANT, because if I did not know

28 To this end, we have focused on the terms within a language. Leibniz, however, was adamant that we can also employ other tools, such as numbers, diagrams, or indeed anything that can be divided into parts, connected in virtue of rules.

29 Mugnai (1976); Di Bella (2004). 
that trees are plants, then once I grasped this proposition, I would know that when I see a tree, I thereby see a plant. Information regarding the extension of concepts, however, is only indirectly deduced from intensional distinctions. This is because we assume that concepts refer to individuals and their worldly modifications, and that there is an inversion relation between intensions and extensions: the more intensions a concept entails, the less individuals it refers to, the less general it is. In arguing that the distinction introduced by concepts is not extensional but intensional, Leibniz brings in the example of co-extensional concepts.

Co-extensional concepts are designated by different terms that can be substituted within a sentence "salva veritate", that is, without changing the truth-value of the proposition. ${ }^{30}$ To this end, trilateral and triangular are among Leibniz's examples. Although all triangles are trilateral, and these terms therefore both refer to the same geometrical essence, there are contexts (like the reduplicative context (Mugnai 1990)) in which "triangular" and "trilateral" cannot be substituted "salva veritate". This is because they refer to two distinct aspects of the same thing, which explains why some scholars, like Ishiguro (1972) and Mugnai (1990), observe that the "salva veritate" principle is a criterion for the identity of concepts/terms, rather than the identity of the thing designated by the name:

Someone who said The triangle and the trilateral are not the same would be wrong, since if we consider it carefully we find that three sides and three angles always go together. And if he said The quadrilateral rectangle and the rectangle are not the same he would be wrong again, since it turns out that only a four-sided figure can have all its angles right angles. However, one can still say in the abstract that triangularity is not trilaterality, or that the formal causes of the triangle and of the trilateral are not the same, as the philosophers put it. They are different aspects of one and the same thing. (NE 363)

When we consider a being not through its appearance, but as a collection of essences (to use Zimmermann's characterization), or formalitates (since Leibniz remarks above that they are formal causes; see also Di Bella (2004)), we simply consider the thing in the abstract, i.e., through its essence. In so doing, while we distinguish aspects that exist together in one being, these aspects are distinct from the perspective of essences.

Another example are terms that are co-extensional and yet be two distinct essences. "justice" and "wisdom". If it is true that a wise man is a just man, (viz. that

30 Elementa ad calculum condendum A VI 4 A 154: "Si a est b et b est a, potest unum pro altero substitui salva veritate. Subjectum substitui potest in locum praedicati seu si a est b, et b est c, etiam a est c."; Calculus ratiocinator A VI 4 A 275: "Idem est quod ubique in alterius locum substitui potest salva veritate. Ex. gr. aequilaterum aequiangulum quadrangulum, et: aequilaterum rectangulum quadrilaterum, et denique quadratum, haec tria sunt idem, et unum pro altero substitui potest. Nam eadem res quae quadrata est etiam aequilatera rectangula quadrilatera est et contra." Specimen calculi universali A VI 4 A 282: "Eadem sunt quorum unum in alterius locum substitui potest, salva veritate, ut Triangulum et Trilaterum, Quadrangulum et Quadrilaterum.” The topic of the salva veritate criterion of truth for propositions is a focus of discussions about Leibniz's logic. Scholars, including Russell, have interpreted the principle as a necessary assumption for an analytic account of truth. 
the terms are coextensional, because, on Leibniz's view, a wise man cannot be unjust), then they are nonetheless two different terms. This is because their intensional analyses differ (Di Bella, 2004). Therefore, if both terms refer to one and the same being, then they divide what is ontologically one (a being) into many aspects that nonetheless belong to the same individual. However, those terms, when used as marks for essences, hold for two different essences, viz. WISDOM and JUSTICE, which precludes us from inferring that justice is wisdom, an identification that would have given us a logical ground for claiming that "a just man is also a wise man". Based on essences, however, we have no reason to infer that wisdom and justice are logically connected. ${ }^{31}$

The idea underlying these examples is that, in order to express essences, the terms tokened in the sentence must evidence some kind of connection that differs from causal or ontological connection. The relation must be one of conceptual containment or exclusion, that is, what Leibniz calls formal causation, which consists in a relation between forms, or what Leibniz calls "possibilities", that are based on the reduction of terms to identity claims and contradictions. Even though it may be true that every just man is wise, based on their possibilities, the logic of essences does not allow for this inference. However, logic does not exclude the possibility that justice and wisdom are ontologically related. This is because, as Leibniz seems to argue, it is true that it cannot be the case that there exists a just man who is not also a wise man, and yet the fact that a wise man is also a just man is still contingently true (as there is no logical necessity involved). Possibilities and existence are not the same thing: if two properties inhere in the same being, then it is not the case that in the abstract they must inhere in the same concept, or that they must be logically related. If there is any relation between essences, then it is also our task to determine what kind of relation this is. As we will see in the next chapter, this relation will boil down to either a metaphysical, physical, or logical connection.

Before focusing on the reality of distinctions, we need to complete our enquiry into Leibniz's conceptualism, in particular by spelling out its answer to the issues raised against nominalist theories. Surprisingly, the first step in providing such an answer involves conceding one of the nominalist's central claims: when we use conceptual distinctions to express ontological modifications of beings, we use a fiction, because we reduce something concrete, complex, and multifaceted to its aspects, whereby we consider these aspects as if they were identical to our concept

31 See De abstractis A VI 4 A 573-5. This distinction is relevant to Leibniz for theological reasons. If the relation between wisdom and justice is of logical containment, then God is necessarily wise and just, such that it is impossible (read: logically impossible) for God to condemn an innocent. If, on the other hand, there is no logical relation between them, then it seems that it is not impossible for God to condemn an innocent even if it cannot be the case that God condemns an innocent. "God cannot condemn an innocent" is then contingent, whereby the impossibility is of a moral, not a logical, kind. See De libertade a necessitate in eligendo A VI 4 B 1453, where Leibniz writes that the damnation of innocents is logically possible, but impossible in existence. See also Griffin (2013: 64) for a discussion. 
of that modification or property. ${ }^{32}$ This fiction, according to Leibniz, consists only in treating the concrete being as if it were an ideal essence or a collection of several abstracta, but terms, on Leibniz's account, are not fictional as they are on so-called 'ultranominalist' accounts, such as the theory of collective wholes. For this latter, general terms are themselves fictions because they refer to non-existing, mind-dependent entities, viz. essences abstracted from individuals. It is this - not Leibniz's interpretation - that jeopardizes the sciences, reducing them to knowledge of names rather than things. On Leibniz's account, for example, when we reduce a man to the concept MAN and, in turn, to RATIONALITY, we consider not the particular, but the essence, which qua possibility is mind-independent insofar as the connections that defines it are not constructed by minds; they are only apprehended by minds as possibilities. ${ }^{33}$ The essence is real insofar as it exists in the mind of God, but not even God has the power to arbitrarily construct it. Essences qua possibilities are there to be grasped by God's intellect. ${ }^{34}$ While God can grasp them immediately and directly, human minds have to reconstruct the realm of possibilities a posteriori, inferring it from observation of what actually exists.

Furthermore, through this fiction (or, better yet, analogical reasoning, since we consider abstracta "as if" they existed in concreto or concreta as if they were $a b$ stracta), we decompose complex beings into more simple aspects, which are easier to analyze by a finite mind. When we consider one aspect over others, this is because, in unpacking via conceptual containment those aspects, we are able to derive other characterizing facets, which is to say that the aspect we select is more informative about the thing with respect to what we want to know about it. The necessity of the connection between terms is provided by the principle of contradiction and identity, and not by the actual states of the thing. This means that if I can consider Claire as an instance of HUMAN BEING, and I further know that HUMAN BEING is CAPABLE OF LAUGHTER, I will believe that Claire can laugh. The process Leibniz has in mind is similar to what we do with numbers. If I have

32 Through this fictive reduction, I shall argue, finite human minds acquire necessary knowledge about the world and, in so doing, can navigate the world's variety with a greater degree of certitudo. Moreover, conceptual knowledge is the ground for intercourse between minds, the constitution of a moral society, and membership in God's kingdom of grace.

33 Already in Dialogus (1679), Leibniz argues against Hobbes' ultranominalism, claiming that definitions do not consist in knowledge of names because they express connections between ideas, which are independent from how we name them. The same idea was expressed in $D e$ mente, de universe, de Deo (1675) and will be repeated in NE against Locke. There, Leibniz adds a "realist" note, claiming that essences are eternal in God's intellect, for He cannot choose those that are possible, but only those that can be instantiated and exist in the actual world. On this, see Mugnai (1990), Schepers (2014), and Bolton (2018).

34 This piece of theory is a response to Descartes' Universal Possibilism. According to Descartes, God chooses necessary truths. This means that if God had so desired, it could have been the case that a necessary truth, like $2+2=4$, would be false (see, for instance, Saint-Germaine, 2016). On Leibniz's understanding, such a claim is equivalent to affirming the superiority of God's will over His intellect, viz. that truths depend on God's choice. Leibniz responds that even God cannot choose what it is true, since this depends upon the possibilities that God grasps in accordance with necessary principles, such as identity, contradiction, and sufficient reason. 
apples, count them, and find that they add up to five, then I also know that I need five more apples if I want 10 of them. I know this because the reduction of apples to the number five is the reason why I can count $5+5=10$ (or $5 \times 2=10$ ). When we operate with the concept, we do something along the lines of calculating with terms about essences, which subjects our inferential capacity to too many variables, thereby jeopardizing our success in alethic inferences. One way of overcoming this is to find a mechanical way of controlling risks by finding a language capable of showing conceptual containments. Indeed, as is well-known, this was precisely Leibniz's project of a scientia generalis, as constituted by an alphabet of human thoughts, that is, a compendium of well-defined terms. In effect, this scientia generalis consisted in an encyclopedia encompassing a division of sciences and up-todate information regarding their knowledge-status. Meanwhile, Leibniz's characteristica universalis consisted in the invention of a formal language that permitted calculation and deduction. People often overlook the fact that a formal language without the two other parts simply amounts to a formal-logical tool, which alone is unproductive of truth. Nevertheless, the reduction of a subject matter to a formal procedure, which captures essences, really does expand our inferential powers, thereby making us less prone to error. To this end, the next chapter offers a fullyfledged theory of error.

I want to emphasize that it is the act of considering a concrete being as an ideal, abstract essence that is fictional, not the connection present in essences (notwithstanding questions about how they are established, e.g., those found in natural kinds are likely less certain than connections established in mathematical essences). This view is therefore compatible with a nominalist ontology. That theory states that there are actual attributes and modifications of individuals that determine them to some states rather than others - to some actions over others - which we then abstractedly categorize as distinct in concept terms like WISE or JUST. It nonetheless tries to avoid the pitfalls of nominalism, claiming that essences are nominal (to use Locke's words) because they are mere connections of names. Terms that are connected in virtue of concepts constitute distinct knowledge of essences. This will become clearer in the next chapter, where we shall tackle the question of why our knowledge of essences is not fictional.

For now, let us focus on the advantages of Leibniz's conceptualism. The attribution of many different properties to one and the same individual would be impossible were human minds incapable of grasping distinctions in essences and considering those essences as distinct from one another, even though the states we categorize as instances of an essence altogether inhere in one and the same individual. In other words, finite minds can conceive of a logico-epistemological space, which is independent of how individuals are sorted into similarity classes, but is nonetheless related to those classes (recall the example of water and ice). When rational agents divide that space into conceptual regions, which reflect the relations between concepts, individuals and their states can be housed in those regions because they can be expressed from many perspectives: as belonging to a species or genus, viz. as instantiating properties. The apprehension of the similarity between individuals is only a ladder that we use to reach a level of abstraction, which permits the mind 
to apply necessary and innate truths to the materials afforded by the senses, which the imagination synthetizes into a format befitting limited human minds, which are bound to generality. When the mind acquires conceptual distinctions, it also gains a better way of predicting reality. It nonetheless has a cognitive interest in retaining that ladder, for there are tasks that involve needing to return once again to instances.

Concepts are, therefore, not sets of individuals, as in the theory of collective wholes. They are individuated by intensions, which are respectively structured by the entailment relations between terms. Our capacity for relating some terms to others by means of definitions is what we call a concept. It is worth noticing that the mere aggregation of intensions would be insufficient for drawing up criteria for conceptual individuation. For this requires identity criteria, provided by a predicamental structure, as in a Porphyrian tree. ${ }^{35}$ A different structure may produce a different concept. Consider, for instance, that our concept is an ability to connect the intensions PLANT and TREE in a regulated way. Unless we know the kind of predicamental relation that exists between those terms, we cannot say which concept we have, and thereby which essence we thereby express. The sentence "every plant is a tree" would express a different essence and hence constitute the manifestation of a different concept of PLANT from the one we have. In our system, PLANT is a genus entailing other species, like TREE. On this view, "every tree is a plant" but not "every plant is a tree". Concepts are capacities to express essences as the absence of contradiction between connected terms, which are structured in predicamental trees.

If this is correct, then the Leibnizian motto "alia est rerum, alia terminorum divisio" refers to two different kinds of distinction: one based on individuals and similarity; the other on concepts and their relations, supported by two different kinds of cognitive processes. The first kind of cognitive process relies on types, while the other relies on concepts. In other words, Leibniz's hypothesis is the following: there is a substantial difference between the real attributes of beings and the divisions of essences. In spite of this great difference, conceptual distinctions and their relations map onto beings' distinctions and changes across worlds. This mapping comes at the price of a loss of determinacy, which is, however, payed back in terms of conceptual distinctness, which permits a more stable grip on world(s). If we were God, then we would know the world in all its detail. Since we are not, however, we can only know regions of the world distinctly by reducing them to essences. The imagination and the senses bound us to one actual world.

35 Porphyrian trees are not only structured logically but ontologically. Leibniz was actually critical of the ontological implications of Porphyrian trees, as Di Bella (2005: 36-55) discusses in detail. In the next chapter, we will see that Leibniz divorces logic from ontology. This leaves Porphyrian trees as valid logical tools for conceptual organization, but they assuredly refer to essences, not beings and their ontological constitution. 


\section{THE CONCEPTUALIST RESPONSE}

We now know all the elements for proving how the extension of a concept can exist outside of the concept of a concept: types provide concepts with an extension. Consequently, concepts are not grounded in their instances, but on possibilities conceived logically as the absence of contradiction between terms.

Similarity is simply a sign for subsuming an individual under a concept; it does not constitute the concept. In distinguishing existence from the mere possibility of an essence, Leibniz reveals himself to be adamantly against Locke's idea that concepts do not depend on their instances:

If you take ideas to be actual thoughts, you are right. But I see no need to apply your distinction in connection with the very form or possibility of those thoughts; and that is what we are concerned with when we separate off the ideal world from the existent world. The real existence of beings, which are not necessary, is a matter of fact or of history, while the knowledge of possibilities and necessities (the necessary being that whose opposite is not possible) is what makes up the demonstrative sciences. (NE 301)

If concepts depended on their instances, then Leibniz's theory would be subject to the same difficulties faced by nominalist theories, such as Locke's or Nizolius's. The distinction between beings and essences represents Leibniz's solution to the issues raised by collective wholes. Understanding concepts as expressions of essences (instead of expressions of individuals) allows us to consistently argue that true statements are independent of the actual existence of instances. If truth depends only on the relations of entailments and connections of concepts, then the existence of individuals does not bear any influence on those relations. On this picture, propositions like

(3) Mammoths have four legs

(7) Pegasus is a winged horse

(8) The sum of the angles of a triangle is $180^{\circ}$

are all true because they simply state that if triangles exist, then the sum of their angles is $180^{\circ}$; if Pegasus exists, then it has the property of being a horse with wings; if mammoths exist, then they have four legs. These are propositions about fictional essences, extint species, and mathematical essences, which do not differ from a purely analytical perspective. ${ }^{36}$ In this way, Leibniz's theory preserves our intuition about the propositions that we can form and consider to be true, even if they are about non-existing entities. Nevertheless, it seems to leave us with a bitter taste, for we feel like there is a difference between what those statements claim. There is a difference between real and fictional beings, for instance, while, if we follow this analysis, then anything I can conceive of as being free from contradiction is also true. The next chapter will offer an error theory and present certain restrictions on our capacity for producing distinctions. On this occasion, this restriction cannot be 
internal to the subject: it must be "real", that is, it regards what Leibniz calls metaphysical and physical genera.

\section{CONCLUSION}

Against Locke's worries regarding the notion of essences, Leibniz argues that the limitations of our knowledge of essences are not sufficient for causing us to relinquish this notion. In order to rehabiliate a notion of essence that capably explains why human knowledge is necessary (albeit often only hypothetically), Leibniz propounds a form of conceptualism. I have argued that conceptualism has the aim of contrasting what is traditionally called the "collective wholes" theory of concepts. On this theory, concepts consist in sets of individuals and suffer from difficulties that can be overcome by understanding concepts as structured clusters of intensional distinctions, which represent essences rather than individuals. However, Leibniz's conceptualism implies that concepts cannot play this recognitory role. For this reason, Leibniz must draw a distinction in kind between types and concepts: types are active in the cognitive process of recognizing individuals qua individuals of a certain type. This recognition moreover forms the basis for acquiring concepts: concepts may be activated in the process of recognizing individuals. When we claim that a certain individual is an instance of a concept, however, we are performing a different mental act: we implicitly assume that the intensional distinctions of the concept map onto real attributes and modifications of that individual. In so doing, we are capable of inferring some universal, contingent truths about the individual. This is true even if the nature of the instance is not as rigid as we assume the essence to be. This "mathematization" of the world allows human beings to better navigate the variety of the world, and to imitate God's intellect, thereby gaining entry into the realm of grace. 


\section{CONCEPTUALISM, REAL DISTINCTIONS, AND ERROR}

The preceding chapter clarified the distinction between types and concepts. There, it was argued that, for Leibniz, these distinct cognitive abilities correspond to two different logical analyses: the former are classes referring to particular beings or modifications, while the latter are clusters of contradiction-free intensions. We furthermore established that, if type-acquisition did not precede concept-formation, then (1) rational agents could not form concepts, and (2) concepts could not obtain an extensional interpretation. The distinction between types and concepts, I argued, is invoked by Leibniz in order to solve issues raised by nominalist theories insofar as they seek to determine the truth of universal, contingent propositions. On an extensional interpretation, some true propositions turn out to be false. Leibniz's conceptualism avoids this consequence. Still, it is not clear how Leibniz's solution can avoid a particular form of arbitrariness about kinds, as raised by Locke's spokesman in NE. Even if essences in the mind of God are the metaphysical ground of concepts, the human ability to conceive of essences still depends upon experiencing individuals and their similarities. This aspect of Leibniz's theory of concepts subjects it to the set of challenges raised by Locke against our alleged capacity to know real essences in his Essay.

As anticipated, Locke's criticism insists on a gap between the varieties that characterize instances, ${ }^{1}$ and a sort of freedom in the stipulation of properties that necessarily belong to a being in order for it to be considered an instance of a certain kind. The cluster of properties selected as essential to a kind are often not coextensive with their instances: a man can become irrational, or may never manifest rational competences. ${ }^{2}$ As we have seen, Leibniz responds to this issue by separating the extensional from the intensional analysis of concepts. Concepts are abilities to form clusters of intensions grounded in the logical possibility of an essence, which they express through definitions. Concepts are, therefore, not abstracted from instances; they map onto existing beings in virtue of their association with types. If concepts are not abstracted from instances, then Locke's criticism is circumscribed but not thereby surmounted. Rational agents, in fact, do not have direct knowledge of essences, Leibniz thinks, because they can conceive of essences a posteriori, viz.

1 Lenz (2009) uses the expression "varieties of standards", meaning that experience offers various possible ways of categorizing particular instances.

2 EHU 545-6: "in vain therefore shall we endeavor to discover by our ideas; (the only true way of certain and universal knowledge,) what other Ideas are to be found constantly joined with that of our complex Idea of any Substance: since we neither know the real constitution of the minute Parts, on which their qualities do depend; nor, did we know them, could we discover any necessary connexion between them, and any of the secondary Qualities: which is necessary to be done, before we know their necessary co-existence." 
following their acquaintance with beings' similarities. The separation between intension and extension is then only the logical counterpart of a solution that entails various metaphysical commitments. Indeed, as Zimmermann notes, "logic and metaphysics are in their development inseparably intertwined" (Zimmermann 1854). The last piece of analysis that sees Leibniz's theory succeed is an enquiry into the metaphysical commitments that such a logic of concepts entails, namely what Leibniz calls a distinction between real and logical genus, a distinction that functions as a sort of error theory for the conceivability of essences. Our enquiry's output will, then, consist in a metaphysical explanation for why essences do not exist in their instances, owing to which they cannot be abstracted from empirical experience.

Our analysis begins by stressing the role of experience and types for conceiving of essences. To this end, we shall probe more deeply the relation between language, types, and concepts (sect. 1). In so doing, we individuate a gulf between the formation of general names and the conception of essences: it is not the case that an essence corresponds to any general name that we may form for pragmatic reasons (sect. 2). Essential distinctions are metaphysically more fundamental than the gathering of individuals into classes. Indeed, in order to understand what they are, we need to study Leibniz's distinction between real and logical genera (sect. 3). The contrast between real and logical genera is the key to arguing that Leibniz remains faithful to his antirealism about essences. On his view, there are no real essences that exist in the being that makes that being a being of that kind; a substance modified in accordance with permanent attributes constitutes a being. If essences are not real, then they cannot be abstracted. They can, however, be constructed as logical devices, viz. concepts that "mathematize" the world, better enabling predictions than types, which are based in the logic of the imagination (sect. 4). We conclude our chapter with an error theory (sect. 5).

The main upshot of this chapter is that, when we categorize natural kinds, we do so by tracking modifications of a physical genus, what Leibniz calls the "matter" of a concept. Categorization expresses this physical genus by dividing it into physical species that are then mathematized via rigid definitions, which capture essence as clusters of conceptual marks. In this way, Leibniz secures the autonomy of scientific enquiry from metaphysics, and, at the same time, the regulative role that metaphysics plays with regard to the sciences. To this end, hypotheses and explanations are true if they are simpler than other candidate hypotheses and explanations, which require assumptions grounded in real beings or substances, a conclusion based on Leibniz's methodological nominalism (Mugnai 2018). Whether or not we find Leibniz's theory palatable, it nonetheless contains certain striking intuitions, which we will discuss in our conclusion.

\section{GENERALIZATIONS AND NATURAL LANGUAGES}

At no point does Leibniz deny that our distinctions of beings into kinds depends on experience. In Epistolica de historia etymologica dissertatio (1712?), a text that presents insights into the relationship between language and thought (as well as 
their mutual evolution), ${ }^{3}$ he proposes what sounds like a developmentalist account of language and cognition. This is based on the idea that, normally:

the denominations of those things easier to cognize, and the simpler opinion of the people come first. (ED § 23, Gensini 1991: 229)

In the Epistolica, Leibniz uses etymological studies to prove the historical and cognitive dimension of languages. Languages are transformed and expanded on an ongoing basis through the speech acts of communicative, rational agents. More precisely, etymology proves that the words of our language, which are now used to refer to abstract entities or metaphysical categories, were originally established to refer to more concrete physical entities. The word "spirit", for instance, originally signified "warm breath", and was later deployed figuratively to denote "life", or "that which keeps us alive", viz. the soul. This move away from concrete to abstract entities reveals the general rule undergirding cognition, viz. human minds cognize, and consequently (1) denominate first things that fall under the knowledge domain of the senses, and (2) later in time they categorize and give names to more abstract entities. $^{4}$

Transposed onto the level of categorization, this view implies that the observable properties of bodies and their outer appearances are used as a primitive guide to divide beings into natural kinds. General names hence first refer to beings' appear-

3 For an analysis and transcript of the text, see Gensini (1991). I analyze the text in Oliveri (2016: III.2 and 2016c).

4 As argued in Oliveri (2016: III.2) and Oliveri (2016b), Leibniz uses etymological enquiries to establish that metaphysics and the moral sciences were developed following the establishment of a language employed for mundane purposes, which moreover subjects metaphysics and morality to historical development. More precisely, to be capable of communicating about abstract matters (which are proper to morality and metaphysics, such as the notion of the soul, justice, and the good) rational peers must impose names onto these abstract subjects. But words are established in speech acts that are first directed towards objects and states that manifest a relation between the organic body and a mind. As a consequence, human beings' first acts of denomination begin by imposing names onto concrete things. This makes it natural for linguistic peers to use existing words in the establishment of new meanings when they need to denominate abstract entities. Known words are used with a meaning that bears an analogical relation to the context and its semantic precedent. In processing a word that is being used in a slightly different way, the peer to whom the linguistic act is addressed seeks a new meaning, through which the word acquires reference to an abstract subject matter. When we use the word "spirit" (whose original meaning is "intangible breath") in a context that has nothing to do with "breath" (such as when it is used to describe what keeps us alive, viz. the soul), we extend the meaning of the word, which thereby comes to signify the soul. Figurative speech is hence a cognitive tool (rather than a merely ornamental facet of languages) and can be responsible for shifts in meaning. The origins of names used for metaphysical discourse, however, subject metaphysics and morality to the imagination, after which it is prone to superstition. As names first refer to imaginative and concrete beings, human beings tend also to express those things that are not subject to the imagination via what it is subjected to, and are prone to mistakes because the figurative use of speech inclines them to understand what they say literally. Thus, they wrongly imagine that the soul has a seat, or that space and time are concrete beings. 
ances, upon which rests recognition. If our analysis of types is correct, then it follows that the origins of general names are tied to types before names are to concepts, and are used to refer to essences, which results in a fallible and provisional division of natural kinds. The same thought is expressed in NE. There, Leibniz agrees with Locke that cognizant agents distinguish between beings by giving them a general name well before they have any precise, scientific knowledge:

PHIL. Languages were established before sciences, and things were put into species by ignorant and illiterate people.

THEO. That is true, but the people who study a subject-matter correct popular notions. Essayers have found precise methods for identifying and separating metals, botanists have marvelously extended our knowledge of plants, and experiments that have been performed on insects have given us new routes into the knowledge of animals. ${ }^{5}$ However, we are still far short of halfway along our journey. (NE 319)

If Leibniz accepts human dependence on experience for categorization, then how can he reject Locke's criticism? In separating beings into species, rational agents first rely on empirical data and outer appearances, which can lead them astray or present them with borderline cases that challenge the reality of our categorizations, warns Locke. Divisions between species seem to result from rational-agential agreement, rather than the representation of real essences, as evidenced in borderline cases (such as monsters). Despite their ancestors belonging to the species "human being", monsters do not look like their ancestors and show no signs of rational thought, which casts doubt upon whether they can be considered instances of the species "human being." If there are real essences and we know them through definitions that consist in collections of properties (variously subdivided into species, genus, and more specific differences, such as "man is a rational animal"), then what makes nature so liberal in the creation of a monster ${ }^{6}$ In other words, if there are real essences and, moreover, if our definitions represent those real essences, then every man must be rational, and there is no room for anomalies like monsters. Borderlines cases seem to prove the arbitrariness of natural kinds. ${ }^{7} \mathrm{We}$ can recast Locke's worry thus: how can we say that the divisions we project onto nature (based on similarities) correspond with real divisions? What licenses us to infer that a real essence corresponds to our ways of dividing beings?

5 Leibniz regularly refers to the discovery of the generation of insects (thanks to the microscope) as proof of the thesis that nothing is ever destroyed or newly created; everything is borne from seeds that develop and envelop according to physical laws. See Monadology $\S 74$ (1714, GP VI 619); Considerations on Vital Principles and Plastic Natures by the Aauthor of the Principle of Pre-Established Harmony (GP VI 540-1/ L 588-9).

6 EHU 404: "The frequent productions of monsters, in all the species of animals, and of changelings, and other strange issues of human birth, carry with them difficulties, not possible to consist with this hypothesis; since it is as impossible that two things partaking exactly of the same real essence should have different properties, as that two figures partaking of the same real essence of a circle should have different properties."

7 Cf. EHU 416. 
Although he rejects the arbitrariness of our categorizations, Leibniz nevertheless agrees with Locke that our species-genus distinctions are provisional and, indeed, prone to error. This is especially true when we are dealing with natural and social kinds, rather than ideal entities, such as in mathematics. ${ }^{8}$ Our limitations, however, are not a sufficiently good reason to doubt that there are essences, since we have strategies to make our distinctions more precise, namely by grounding them in more stable truths and axioms. To implement this strategy, Leibniz first denies that concepts are abstracted from their instances, as we began to see in the previous chapter. The second step constitutes a more 'classical' move, namely, we need to argue that there are higher genera that ground more specific modifications, owing to which beings can be sorted into genera and species. In short, rational agents have ways of understanding which distinctions are more fundamental than others and, hence, of putting constraints on which distinctions can be accepted as possible and real owing to their conformity with the possible modifications of a genus. By including a species into a genus, and then this genus into another, we determine which genus is more inclusive of other genera. In so doing, our distinctions track something more fundamental or, to use a contemporary expression, they carve reality at its joints. ${ }^{9}$

8 See also Bolton (2017).

9 Even early on in his philosophical career, Leibniz thought to reduce beings to their higher genera and then ordering them in chains of definitions, see On Universal Synthesis and Analysis, or the Art of Discovery and Judging (1679? A VI 4 A 538-9/L 229): "Cum puer Logicam discerem, et solerem jam tum altius inquirere in rationes eorum quae mihi proponebantur, objiciebam praeceptoribus, cur non, ut praedicamenta habentur terminorum incomplexorum, quibus ordinantur notiones; ita et praedicamenta fierent terminorum complexorum, quibus ordinarentur veritates; ignorabam scilicet hoc ipsum facere Geometras, cum demonstrant, et propositiones ita collocant, prout aliae ex aliis dependent. Videbatur autem mihi res universaliter fore in potestate, si haberentur prius praedicamenta vera simplicium terminorum et ad ea obtinenda constitueretur quoddam velut Alphabetum cogitandi, seu catalogus summorum (vel pro summis assumtorum) generum, ut a, b, c, d, e, f, ex quorum combinatione fierent inferiores notiones. enim est genera sibi mutuo differentias praestare; omnemque differentiam posse concipi ut genus et omne genus ut differentiam; et tam recte dici animal rationale, quam si fingere licet, rational animale. Cum vulgaria vero genera species sua combinatione non exhibeant, concludebam non recte constituta esse. Et quidem genera summis proxime inferiora, forent biniones: ut ab, ac, bd, cf. Genera tertii gradus forent terniones, ut abc, bdf, et ita porro. Quod si summa genera, vel pro summis assumta essent infinita, ut in numeris (ubi numeri primitivi possunt assumi pro summis generibus, nam omnes pares possunt dici binarii, omnes per tres divisibiles possunt dici ternarii, et ita porro, et numerus derivativus exprimi potest per primitivos tanquam genera, ita senarius omnis est binarius ternarius), saltem ordo summorum generum, ut in numeris esset constituendus, et ita ordo quoque appareret in inferioribus. Et proposita qualibet specie ordine enumerari possent propositiones de ea demonstrabiles, seu praedicata tam latiora, quam convertibilia, ex quibus memorabiliora seligi possent." Leibniz pursues this strategy throughout his career, as demonstrated by the numerous tables of definitions for various sciences (physics, metaphysics, natural sciences, and morals). In light of the analysis we have conducted here, we can nonetheless conclude that if, in his youth, Leibniz thought that the highest genera consist in simple notions (or the attributes of God), then it seems that, in his mature philosophy, he abandons this idea for solving terms in abstract and concrete, which are then reduced to three irreducible genera: logical, metaphysical, and physical. 
We begin by elaborating on why the separation between the extension and intension of a concept constitutes a response to Locke's formulation of arbitrariness of natural kinds, after which we propose a new form of arbitrariness. Thus, the question is not about whether our distinctions have a fundamentum in re owing to their grounding in similarity: ${ }^{10}$ the question is about whether our distinctions are fundamental; whether they carve reality at its joints. Recognizing this new challenge, Leibniz sets out to avoid it by way of his theory of real and logical species.

\section{GENERALIZATIONS AND ESSENCES}

For Leibniz, Locke's attempt to cast doubt on the species-genus distinction bears all the hallmarks of a nominalist revival, such that "universals" are mere names resulting from human agreement, while general concepts are nothing but collective wholes with extensional referents. For this reason, single cases that do not befit our concept of the species reflect the arbitrariness of human distinctions of beings into species and genus. Unsurprisingly, Leibniz channels most of his theoretical might into revealing that Locke addresses the wrong target: concepts are not grounded in individuals and their existence; individuals are distinct from concepts, although their outer appearances are signs that those individuals are better expressed by one concept over another:

So far no rational animal has ever been discovered with an outer shape much different from our own. That is why, when there was some question of baptizing a child, its pedigree and its shape were never regarded as more than signs from which to judge whether or not it was a rational animal. So theologians and jurists had no need to give up their consecrated definition on this account. (NE 320)

In chapter VIII, we explored the sense in which Leibniz believes that - on the nominalist theory - propositions about natural kinds are always contingently true. Leibniz's solution is to make concepts expressions not of individuals and their states, but of possibilities or ideas in the mind of God. In spite of his solution, there are two respects in which experience is relevant to concept-formation:

(1) experience is necessary for conceptual acquisition, for it allows us to distinguish concepts into those that are real and those that are chimerical;

(ii) the intensional structure of concepts captures the structure of the real world, that is, our conceptual apparatus, when accurately unpacked, carves reality at its joints. ${ }^{11}$

To reiterate, general essences are conceived of by finite minds as "possibilities inherent in the resemblances" among beings. This means that experience of actuallyexisting individuals and their similarities (tracked by the logic of the imagination)

10 On this aspect, also see Mugnai (1976; 1982).

11 The metaphor of carving reality is a reference to Plato's Phaedrus 265c-266b). For an interpretation of Plato, see Campbell, Rourke, Slater (2011). Leibniz's relation to Plato is wellstudied and complex, see Belaval (1975), Mercer (2008), Leinkauf (2009). 
are the primary resources of the human mind for grasping the realm of ideas in the mind of God. By contrast with his contemporaries, Leibniz denies that a direct vision of ideas in the mind of God (cf. Malebranche) or an intuition of some innate ideas (cf. Descartes) is the way in which finite, human minds grasp essences. ${ }^{12}$ As highlighted in chapter I, "grasping" means that, in virtue of experience and a mind's innate constraints, a cognizant agent is able to form expressions and use them to conceive of identity conditions between things whose appearances are not perfectly alike (as in the case of water and ice), but which are thought to share a common nature, such as when similarities between human beings are captured as "human nature". Cognizant agents can then use words, diagrams, and anything else that can function as cognitive surrogates (albeit organized into a coherent system) as signs for intensions, the conjunction of which express the identity conditions for essences that exist in God's mind.

Since concepts are formed in close dependence with types, types are associated with concepts, through which concepts acquire an extension. Even if propositions expressing conceptual entailments first refer to essences (that differ ontologically from real beings), concepts may nonetheless refer extensionally to real (or possible) beings thanks to their being preceded by, and associated with, types. In this way, the predicamental structure of concepts maps onto possible world(s) and can be used to carve world(s) at their joints.

Leibniz is, however, aware that Locke is right in claiming that our categorizations often lose their grip on what there is, owing to which they do not really seem to carve reality at its joints. The reason for human fallibility is that thought depends on language, the latter of which is established before we have more stable scientific knowledge. Examples of this fallibility include believing in what is not possible (thanks to an intrinsic, undetected contradiction entailed in the concept), and believing in existent possibilities that may obtain in other possible worlds (such as when we groundlessly attach existence to a logically possible essence, which renders the concept chimerical). And yet, thinks Leibniz, the risk of error is worth taking because, as he stresses, the route to grasping essences is necessarily one of trial and error, while abstract knowledge promises greater success in predicting events and changes. Even if we are incapable of reducing our risks to zero, there are always methods available for controlling risk-factors, which tend to cause us to go astray. For instance, grasping metaphysical necessity (at least in the way that Leibniz understands it), or what there is at a fundamental level, can provide rational minds with a more robust understanding of what can or cannot exist. Indeed, the distinction that we are about to canvass between physical, metaphysical, and logical genera has this function.

To understand what there is at a fundamental level, Leibniz thinks that we need to understand the mechanisms through which we form general names, based on observation. In this way, we can tease out the relation between general terms and

12 As I highlight in Oliveri (2016: II.1), Leibniz is deeply influenced by the Arnauld-Malebranche controversy about the Cartesian claim that we have ideas and we know them intuitively. Recently Barth (2020) has insisted on Malebranche's influence on Leibniz. 
concepts, thereby showing that it is not the case that an essence corresponds to any general name. This is another reason why Locke is wrong to argue that an idea is simply a general name defined through properties considered as belonging to a being necessarily.

As we have argued thus far, types account for generality before and in absence of a concept. Given that cognizant agents are spontaneously attracted to similarities between beings, their attention and memory are first directed to general, common traits between beings that are compared in acts of co-perception. Indeed, this is the reason why types consist in interiorized rules for recognizing and predicting things' common behavior. If types are acquired in relation to experiencing actually-existing beings, and concepts do not rest on individuals, then Leibniz's strategy has the consequence of denying that concepts perform recognitory work. "The objects of abstract, incomplete ideas do not suffice to pick out the entities that are involved in all the actions of things", Leibniz points out to Locke (NE 313/A VI 6 313). This is the reason why Locke has trouble with particular cases, for he attributes a task to concepts that they simply cannot perform.

At the same time, however, Leibniz firmly claims that universals are envisaged as "possibilities inherent in the resemblances" (NE 323/A VI 6 323). This means that the essences we can conceive of depend on our empirical experiences. The dependence of the human mind on things' appearances is the reason why our distinctions are not as precise as those obtaining in nature. Despite their provisional or hypothetical status, our distinctions are always grounded in the reality of things and, therefore, there are pragmatic reasons for adopting them. For instance, we can have reasons for coining generic words to refer to instances that present as similar. Indeed, at the pragmatic level, generalizations based on types, and universals based on essences, come apart: not every generalization based on a similarity carves reality at its joints, and "popular" notions of species and genus ("folk concepts") need theoretical amelioration by scientists and philosophers, as Leibniz claims in the above passage from the NE.

Generalizations based on types may represent essences, but they do not have to. As explained in chapter VI, interiorizing phenomena as types (based on similarities in shape, or properties shared by particular beings) is a cognitive process that minds engage in spontaneously. The strengths (as well as the limitations) of this process are that we continually exercise interiorization. In co-perceiving phenomena, we spontaneously find similarities between them, the reason being that the human mind is bound to generality, as individuality is beyond human mind's reach.

To illustrate, suppose you enter a room and find five items. Each of them represents one Platonic solid. Suppose, furthermore, that they are all green. You simply consider them to be a class of beings, even though what they have in common cannot be taken as a distinction in species between these solids and those of a different color (say, purple). Further, suppose that (for some reason) you need to refer to the green solids collectively in order to distinguish them from the class of purple solids. You can form names like "purple solids" and "green solids" to discriminate between these different classes. 
The formation of "purple solids" constitutes a cognitive operation that is equivalent to the formation of an accepted genus-species distinction, such as "rational animal". It is equivalent because the cognizant agent finds a genus, or "common matter", that is shared by those beings. In our example, the fact that they are solids is the "common nature", and what distinguishes one class of solids from the other, in our example, are the properties of being purple, on the one hand, and green, on the other. And yet, "purple solids" and "rational animals" are not ontologically equivalent. Notice, moreover, that their difference is not logical either, because logic is indifferent to the content of concepts or the properties rational beings select as falling under the notions of genus and species. Once cognizant agents establish a class and denominate it, they can proceed with an intensional analysis, thereby treating the denomination as expressing an essence. One can, for instance, consider the concept "solid" as the genus included in "purple solid". Likewise, one can consider the concept "animal" as the genus included in "rational animal". These operations are both logically valid, since it is not the job of logic to determine which distinctions are metaphysically sound. "Purple solid" can be an empirical concept whose possibility is demonstrated a posteriori simply by ascertaining the existence of a collection of terms. Since one can recognize purpleness as existing on a solid surface, an agent can thereby assume that "purple solids" is a logically possible combination of terms. ${ }^{13}$ The reason for claiming a difference between "rational animal" and "purple solid" cannot, therefore, be logical in kind; it must be an ontological difference, which makes us claim that some collections of beings say something more about the world, as in the case of "rational animal", while other collections are simply the result of linguistic economy, as in the case of "purple solid".

Despite those general terms resting on distinct ontological grounds, I insist that there is no substantial difference in the cognitive act through which we form the two general names for those classes. "Purple solid" is a general term referring to a collection of beings that I need to address. It rests on linguistic economy, although it does not refer to a division that carves nature at its joints. "Rational animals" may have been established for similar reasons as "purple solids" by "illiterate people", as Leibniz claims in the NE, who imposed and employed a string of words merely for linguistic economy, to refer extensionally to a class of beings. On further observations, however, cognizant agents took the division as saying something substantial about things that exist in the actual world, and so they made the name a cognitive surrogate for an essence. The imposition of a general name may serve as a

13 It is worth remembering what Leibniz says in MKTI (A VI 4 A 589-90/L 293): "Patet etiam, quae tandem sit Idea vera, quae falsa, vera scilicet cum notio est possibilis, falsa cum contradictionem involvit. Possibilitatem autem rei vel a priori cognoscimus, vel a posteriori. Et quidem a priori, cum notionem resolvimus in sua requisita, seu in alias notiones cognitae possibilitatis, nihilque in illis incompatibile esse scimus; idque fit inter alia, cum intelligimus modum, quo res possit produci, unde prae caeteris utiles sunt Definitiones causales: a posteriori vero, cum rem actu existere experimur, quod enim actu existit, vel extitit, id utique possibile est. Et quidem quandocunque habetur cognitio adaequata, habetur et cognitio possibilitatis a priori; perducta enim analysi ad finem, si nulla apparet contradictio, utique notio possibilis est." 
staircase for referring to abstract subject-matter, essences expressed by relations between terms. ${ }^{14}$ In this way, after being established and having a reference in concreto, names can be re-used as expressions for abstracta insofar as they are reassessed through relations capturing conceptual containment rather than reference to individuals or external traits, which are used to recognize instances of a class.

In a text that we will analyze in more detail below, Leibniz exemplifies the distinction between concrete and abstract use with the term "warm". In saying "Warm is a quantity", one is defining and using "warm" abstractly. The difference with its use in concreto is evident insofar as, when one says "this man is warm", one is not claiming that "this man is a quantity". ${ }^{15}$ While abstract predication determines what warm is (that is, the properties that constitute the essence "warm"), in its concrete usage we are not ascribing all of the abstract properties to what instantiates the property of being warm. We interpret "this man is warm" as saying that "man" has a certain quantitative degree of warmth, since we know that warmth admits of degrees. ${ }^{16}$ Furthermore, in transforming a reference from concrete to abstract, the selection of intensions defining an essence changes: from outward, perhaps accidental properties, we move onto selecting more essential properties, viz. those that do not change, such as quantity.

Leibniz's approach has much in common with the classical distinction between a shell of accidental properties and a core of essential ones. Indeed, this is what our final analysis on mathematical species (sect. 4) will confirm. For now, what I want to stress is that the core of essential properties has neither the function of recognizing nor of determining the existence of instances of an essence. None of the essential properties of a natural kind can be ascribed to what exists on a metaphysical level, and, as we will see in section 3, this is a consequence of Leibniz's rejection of realism about essences.

Let us begin with recognition. Denying that recognition is a task fulfilled by a concept is an extremely important theoretical point because it renders Leibniz's theory of concepts and definitions immune to criticisms regarding typicality effects. Criticism based on typicality effects in some way mirrors Locke's strategy, since it claims that failure to recognize instances qua instances of a certain natural kind proves the nominalism - not the realism - of definitions, since they fail to provide a robust criterion for recognizing instances as instances of a natural kind. To remind the reader of the typicality effect: the basic assumption here is that "not all instances of concept are on equal footing". ${ }^{17}$ For instance, robins are more easily recognized and categorized as BIRD than chickens, while apples are more readily considered FRUIT than olives. Thus, if definitions are what provide rational agents with a criterion for recognition, then this difference should not take place, since the definition to which we appeal when we recognize robins as BIRD is the same as that which

14 I argued for a similar position in Oliveri (2016: III.1) and (2016a).

15 See De Mutationibus (1705) LH IV, 7C B1. 85-86. 1 Bog. $2^{\circ} .4$ Sp. / VE VI, 4, N. 55.

16 Ibid.

17 For an introduction to the classical theory of concepts as definitions and typicality effects, see Margolis \& Lawrence (1999: 25). 
we appeal to when we have to categorize chickens as BIRD. In the latter case, however, we fail. But if, with Leibniz, we argue that the role of definitions is to capture precise categorizations, rather than providing cognizant agents with a clear set of features for recognizing their instances, then typicality effects constitute a critique of types, not concepts. Indeed, Leibniz thinks that this is exactly right.

Leibniz can explain typicality effect and argue that types account for instances' recognition, and, insofar as types depend upon experience and habit, habits may prevail over conceptual reasoning. Olives are, for instance, eaten alongside savory foods, while fruits are usually sweet and eaten for dessert. Robins fly - indeed, this is generally considered a defining trait of birds - while chickens do not. Reasoning based on similarity/dissimilarity (in both cases), combined with temporal and spatial association (as in the case of olives), prevails when we need to categorize those instances. This is because that is how we experience those beings. For, typically, we are neither botanists nor ethologists: our categorizations are contextually and pragmatically grounded. This does not mean that our categorizations cannot contradict experience and thereby our intuitions regarding natural distinctions. To use another example, whales were once considered to be kinds of fish thanks to their living in oceans and swimming like fish (Ishiguro 1972). We nowadays know that whales are mammals, and yet people may mistakenly believe that whales are a kind of fish. By incorrectly judging that whales are kinds of fish, people inadvertently swap the type for the concept: they believe that they are reasoning in virtue of the concept, while they are relying on things' outward appearances, which are governed by the logic of imagination. Their mistakes, however, are grounded in the cognitive mechanism that we rely on for navigating worldly varieties, viz. via a form of fast reasoning which, despite its limitations, largely produces reliable knowledge. Slow conceptual or "reflective" reasoning, by contrast, requires time and practice for its mastery. That is why it is important to have types and concepts as distinct cognitive mechanisms, which are respectively based on distinct logics. Recognition operates via the imagination and habit, while scientific knowledge requires a more stable ground for its distinctions, which may thereby depart from folk categories. In this way, Locke's worries are well-founded: our divisions are provisional because they cannot provide the ground for beings' internal constitution:

It is true that we cannot define a species in terms of something which is unknown to us [that is, its internal constitution L.O.]; but the outer features serve in place of it, though we recognize that they do not suffice for a rigorous definition, and that even nominal definitions in these cases are only conjectural and sometimes - as I have already pointed out [NE 300] - merely provisional. (NE 311)

Human agents may have limited resources vis-à-vis determining divisions. Indeed, it may be the case that agents need to select one among many different methods of categorization. Each method may produce a difference in categorization, since methodology determines the way in which we compare beings. And yet, each method bears a relation to nature and therefore has a fundamentum in re. We simply need to choose the method that seems to provide the best, most stable ground for 
acts of comparison, just as botanists select plants' procreation as a main criterion for determining differences between species:

\begin{abstract}
My point was that if this theory proved to be true, and if we learned more about how plants are generated, I have no doubt that the differences we observed amongst them would provide a foundation for very natural divisions. And if we had the acuity of some of the higher Spirits, and knew things well enough, perhaps we would find for each species a fixed set of attributes which were common to all the individuals of that species and which a single living organism always retained no matter what changes or metamorphoses it might go through. (Reason is a fixed attribute of this kind, associated with the best-known physical species, namely that of humans; reason belongs inalienably to each individual member of the species, although one cannot always be aware of it.) But lacking such knowledge, we avail ourselves of the attributes which appear to us the most convenient for distinguishing and comparing things and, in short, for recognizing species or sorts; and those attributes always have their foundation in reality. (NE 310; my emphasis)
\end{abstract}

The above discussion is instrumental to showing that, if scientific categorizations constitute the perfection of our capacity for comparing and collecting beings into similarity classes, then cognizant agents constantly appeal to this capacity to form classes for pragmatic reasons: I ask my husband to look through "the clothes in the closet", or I ask my sister not to wear "black t-shirts". To be sure, these terms are general, since they rest on grasping the similarities of shared properties. They are not, however, distinctions that "carve reality at its joints".

The formation and use of general names do not therefore provide sufficient reason for either inferring that the cognizant agent possesses a concept for the thing named, or that an essence corresponds to that general name. General names are simply ways of collectively referring to a class of items, while essences are something ontologically more robust and fundamental than the collections of beings to which we refer by way of linguistic tools. Nonetheless, there may be a use of linguistic expressions based on types, which does not necessarily exemplify that a concept (viz. that which expresses essences) corresponds to a general name. This means that we can learn to use a language to describe and refer to beings in the world(s) based on types, through which we are capable of what Leibniz calls distinct thoughts, all before we learn to express an essence by means of nominal definitions. This latter act requires the use of terms as abstract, that, as we have seen, is different from the use of a term in concreto, which refers to existent beings: "When an abstract [term] is predicated of another abstract [term], the predication is an essential one, and there is no room for changes. Like when I say that 'warm is a quantity' or that 'justice is a virtue' as the subject could not remain if we removed the predicate" (De Mutationibus). What Leibniz means is that there is a difference in saying "Socrates is a musician" and "warm is a quantity". Socrates can lose the property of being a musician and still be Socrates. Such an act of predication is not rigid as in the case of warmth: if one denies that warm is a quantity, she thereby removes the subject itself, for she has denied an essential quality of the subject. Coherently with the nominalist/empiricist picture, language per se is not a proof of conceptual reasoning, since we can use general words based on some imagistic representation of beings and still lack the capacity of defining an abstract essence. 
This is a narrow way of using the term concept and, perhaps, something particular to Leibniz's theory that departs from a more common use of the term "concept", through which one signifies an element composing a meaningful proposition or a general representation. I take Leibniz to have this narrow use of the term in mind when he insists on the necessity of true definitions for the sciences and metaphysics: not every name we use is a term for a concept. Nonetheless, any general name we can form is grounded in similarities that are "out there" and not completely arbitrary. When we do science or metaphysics, however, we are in the business of searching for those concepts that better carve nature at its joints, i.e., which capture an essence. Similarity is only a sign - a trace - that we can follow in order to infer what exists at a fundamental level. This is the reason why certain folk distinctions and impositions of names - based on outer appearances - may overlap with scientific distinctions, although this is not necessary.

This gulf between language and metaphysics therefore calls for reconciliation. In order to provide one, we need to focus on the division of labor between types and concepts. Even if generalizations are natural tendencies of human minds, rational agents have cognitive resources for determining certain distinctions to be more fundamental than others. What does fundamental mean here? It means that we have reasons to think that our distinctions track something on a substantial level (sc. at the level of substance). So, the more fundamental we go, the more accurate our distinctions will be. One reason to consider a distinction more fundamental than another is its metaphysical simplicity: its assumption explains a wider range of modifications than another distinction, for instance. Fundamentality is proved by reducing a species to a genus and the latter to another genus, which sets boundaries on the possible modifications we can fathom therein, while tracking something persistent. The result is a distinction between metaphysics, physics, and logic, whereby metaphysical beings or true unities ground both physical and logical changes, without assuming any direct causal relations between them, nor a perfect correspondence, as shall be argued shortly.

Approaching essences in terms of higher (or more fundamental) genus shifts the issues concerning arbitrariness. Definitions are not judged as arbitrary on account of their capacity to pick out instances: their being arbitrary is decided based upon their fundamentality. The question, then, is whether similarity can help us to detect those distinctions that carve reality at its joints.

As we saw in previous chapters, and especially in chapters III and VII, a first step in detecting true distinctions is to use the similarity of shape as a guide, at least for natural kinds. Not just any kind of similarity will do. The similarity of shape or constant transformations (as in the case of uncountable things, like water and ice) give us reasons for distinguishing individuals into types, after which we form concepts of those types. The appearance of shape can be taken as a sign of a common formal cause (as Leibniz also claimed in NE 320, quoted above). Owing to this, the tracking of shape constitutes an initial ground for dividing things into classes that correspond with confused representations of natural distinctions. This theory of Leibniz's comes with strong metaphysical commitments: a formal cause always 
corresponds with our capacity for tracking similarity. In the remainder of this chapter, we shall elaborate on Leibniz's metaphysical commitments by arguing that the theory of formal cause couples with a theory of reducing changes to modifications of three different genera: metaphysical, physical, and logical. This separation will allow us to argue that species-genus distinctions are logical expressions of categorization based on the apprehension of physical modifications of beings that are not metaphysically committed to the existence of real essences, in which essential properties necessarily inhere. What exists metaphysically is substances that we can only nominally label "man" or "animal", although we need to keep in mind that there is no identity relation between the abstract essence and the substance. Thus, what exists metaphysically as a man, for instance, may stop being a man, but it does not stop being a substance of a rational kind, viz. a rational soul.

In other words, Leibniz divorces metaphysics from epistemology, and understanding from prediction. Our knowledge of logical essences allows us to reduce beings to mathematical-like entities, thereby ameliorating the kinds of predictions that we can make about contingent truths. Nonetheless, cognizant agents cannot have any understanding of how (at the metaphysical level) changes categorized by appealing to essences are produced. They only have reasons to presume that there is something at the ontological level that produces those changes. And yet this lack of understanding does not undermine their knowledge of nature, nor the reliability of their predictions, since predictions are still grounded in the logical possibility of necessary truths, like identity and contradiction. To prove that there is this divorce (albeit reconciled by harmony) we need to understand Leibniz's distinction between logical, metaphysical, and physical genus.

\section{LOGICAL, METAPHYSICAL, AND PHYSICAL GENUS}

In the foregoing chapter, we used the example of ice and water to explain how types help us in conceiving of concepts. There, we argued that when one conceives of a third item (which is abstract and therefore can neither exist in water- nor ice-form, but which is nevertheless water), one conceives of an essence thereafter as defined by conceptual marks. Thus, we can now ask: what do we presuppose when we claim that there is something homogeneous between ice and water, calling this the essence of water? Leibniz says that we presuppose a physical genus, a homogenous matter that can be transformed into different phenomena, like water and ice. In an early essay, Leibniz says that the matter of a concept or an essence is what first comes to mind:

The matter of a concept of something positive or real or an essence is what first occurs to the mind; anything we perceive convenes into this [matter]. This something is what we call being, or thing or subject, only after this we come to conceive of substance or the ultimate subject; Thereby it seems that we first conceive something's presence (praesentia), or what it is now, and anything that is observed by the mind actually is believed to exist, unless experience teaches us to tell apart the mere appearances of the imagination and dreams from real phenomena. In those things that exist now we observe a certain variety. In this way we take notice of 
the diverse, the many, the simultaneous. As when I perceive a bull and a horse, I notice that the bull is not the same as the horse, but they are diverse, although they convene in something, i.e., that they are many animals or beings. The same, hence, is what can be substituted salva veritate. As $\mathrm{A}$ is $\mathrm{D}$, and $\mathrm{B}$ is $\mathrm{D}$, and $\mathrm{C}$ is $\mathrm{D}$, and $\mathrm{A}, \mathrm{B}$, and $\mathrm{C}$ are the same, D will be one. Are $\mathrm{A}, \mathrm{B}$, and $\mathrm{C}$ singles and diverse, they will be many, from which numbers derive. (Divisio terminorum ac enumeration attributorum 1683 - 1685? A VI 4 A 561)

We can better understand this passage if we begin from the end. When we are presented with diverse beings, as in the case of a horse or a bull, we can consider them as diverse, and so as many, or as one with respect to something that the bull and horse both share, viz. a genus like "animal". When we consider the common nature of beings, we conceive of the matter of an essence or a concept, that is, a substratum on which all modifications converge. The "matter" is that which remains notwithstanding change. Owing to this, matter is what we take to exist, because the fact that we are actually perceiving something proves something's existence, as explained in chapters V and VI. Given its connection to perception, "the matter" of a concept or essence constitutes the first aspect that minds cognize.

The notion of matter or genus is controversial. Indeed, in a later text, De Mutationibus (1705), Leibniz grapples with the question of what persists through change, thereby criticizing the Democriteans who argue that concrete matter underlies changes. ${ }^{18}$ On Leibniz's view, if matter is the ultimate subject of modifications, then there is a coincidence between matter and substance; the latter being something concrete, it cannot provide any criterion of identity for what persists through change. So, the ultimate subject of change, Leibniz argues, must be a substance or something that differs from matter, even if we only conceive of substances after considering the underlying physical substratum of change. Leibniz discusses some examples, like the distinction between virtuous and non-virtuous, on the one hand, and water and ice, on the other. He observes that there are modifications of beings that can be transformed into one another, and so produce changes in a subject. A man for instance can be virtuous and become vicious. Being-virtuous - as a transitory modification - must inhere in something that persists or "survives" (superesse) the change, and this is the subject "man" of which those are possible modifications. A man like Appius may be virtuous or vicious, but his being a man (and his being Appius) persist through change. On a metaphysical level, the idea of something persisting while changing has various implications, for instance, "man" or "Appius" cannot themselves be modifications of matter. Thus, there must be a substance that does not simply persist in those changes: it is moreover indestructible (I will return to this point below). ${ }^{19}$ By contrast, Democriteans, who think that there is nothing over and above matter and its changes, differ from realists about essences, the latter

18 See Di Bella (2015) for a more detailed study of the text and a deeper analysis of Leibniz's reinterpretation of hylomorphism.

19 Leibniz often claims that not only the soul but a small animal (a soul with an organic body) remains after death. As he writes to Sophie: "not only the soul but also the animal always subsists. Also, nature never proceeds by leaps, and does not pass from one kind to another [...]" (Leibniz to Sophie, Hanover, 6 February 1706 in: A I 25 426/LSS 348. 
making nature profligate, to use Leibniz's words in NE (322/A VI 6 322). Realists think that essences exist in nature and that there is a core of essential properties of a being that persists through change. On this point, Leibniz compares the case of the virtuous and vicious person to that of water and ice:

As it can be done that the same passes from [being] a man to [being] an animal, or (aut) if, according to Democritus, it didn't remain anything distinct from matter, the predicament of substance would be only of concrete, and concrete would be more persistent than substance. Water and ice differ less with respect to virtuous and non-virtuous when we consider the easiness of transformation; they differ more with respect to the similarity we find in the first species, ice differs barely from crystal whose difference form water is great. When we treat of substances in philosophical terms, we will locate only species in the predicament of substances as lasting beings per se one. So, we notice that if the virtuous can be produced from the nonvirtuous, there is something that persists that we say be the man. But when we transform water into ice, we cannot designate anything that persists beyond the same resistant thing or the body in general. (De Mutationibus)

The passage highlights two important points. The first is that when we talk about the "matter" of a concept as something persisting, we cannot reduce this "matter" to a physical substratum of change. There must be a substance that remains distinct from the physical substratum. The second point is that there is a difference between what persists when a true unity, like a man, changes, and what persists when those things that lack true unity, like water or artefacts, e.g., a clock, change. If, in the first case, we must assume that a particular kind of substance, i.e., a soul, corresponds to one true unity, then we are not allowed to claim the same for aggregates, which are composed of corporeal substances. ${ }^{20}$ Leibniz advocates that true unities, or substances, are the ultimate subjects of changes; that "actiones sunt suppositorum", as he wrote in Discourse de metaphysique. ${ }^{21}$ Activities require a subject of the activity, and true subjects of activity can only be that which remain active throughout, viz. substances. In a way, then, this approach to substances is Leibniz's reinterpretation of nominalism as a method, as Mugnai (2018) writes:

To properly understand the further developments of Leibniz's philosophy, it is important to note that he represents nominalism as a point of view suggesting a method rather than as a doctrine concerning ontology (i.e., what there is). Leibniz does not say that a nominalist has to abstain from referring to universals and real forms because nothing real corresponds to them, but because it is possible to have a simpler explanation of phenomena without employing them.

In light of Mugnai's explanation, I understand the reduction of beings to substances in Leibniz's philosophy not as a denial of the reality of phenomena, nor of their existence, but as a claim about the unity and simplicity of explanation at which

20 See Divisiones A VI 4 A 576: "Ens est aut reale aut apparens, Reale ut sol, imaginarium ut parhelius vel iris aliave phaenomena. Omnis Res est aut Ens per se, aut Ens per Accidens; Ens per se quod revera unum est, ut Homo, Animal, Ens per Accidens, quod et dicitur Ens per aggregationem, ut multitude hominum, strues lignorum; Machina. Si animalia sunt Machinae, si corpora carent forma substantiali, erunt Entia per Accidens, imo tandem ostendi potest posito corpus omne esse Ens per accidens, corpus fore rem imaginariam seu phaenomenon ad instar iridis."

21 Discours de metaphysique A VI 4 B 1540/L 307. 
metaphysics aims, understood as an autonomous, philosophical enterprise. If the various sciences have as their proper subject-matter the variety of nature considered from different viewpoints - including dynamics and the physics of bodies, natural sciences, medicine - then metaphysics seeks a univocal explanation that explains being qua being. Therefore, if various sciences deal with specific manifestations of beings, then metaphysics can be said to seek the unifying ground of that variety.

Therefore, as Mugnai - at least on my understanding - remarks, "Leibniz does not say that a nominalist has to abstain from referring to universals and real forms because nothing real corresponds to them". ${ }^{22}$ Real beings correspond to abstract terms, but we do not thereby need to pursue the illusion that real beings exist as we conceive of them in the abstract, that is, that essences exist. As Mugnai writes, "it is possible to have a simpler explanation of phenomena without employing them", which amounts to saying that there is a real being corresponding to the essence we express via abstract terms, even if we cannot assume that that true being exists with all the properties that we distinguish in the essence. We can explain phenomena in virtue of simpler, metaphysical explanations by grounding them in substances as principles of changes and - to draw a parallel with chapter III - we can say that as motion requires force because matter constantly changes and does not remain one, all transitory modifications of a physical being require something more substantial that persists while the concrete being changes, i.e., a substance.

In other words, the individuation of a physical genus provides a clue for determining the ontological constitution of what we first observe and assume to be the matter of an essence. What Leibniz calls "matter" is just a substratal bearer of the possible modifications of a being qua being of a certain kind (whether a dog, human being, etc.). In reducing species (DOG) to genus (ANIMAL) and genus, in turn, to an ultimately metaphysical genus, viz. substance, Leibniz thinks that we can find ways of determining which modifications of a being are transitory and those that are permanent. Transitory and permanent modifications - and this is the important point for our purposes - do not correspond with essential or accidental properties of a being (qua being of a certain kind). The upshot is that we can claim that a substance has permanent modifications without endorsing realism about essences. Specifically, we can endorse the thesis that a substantial form "man" constituting Appius, always persists, without being committed to the thesis that a man must always be rational, have two legs, or be capable of laughter, in order to be a man. The real being "man" exists metaphysically, in Leibniz's jargon, as a spirit, which is a particular kind of substance whose modifications are not identical to those manifested and used to categorize him into the kind HUMAN BEING, or as Appius. Only per analogiam can we say that the substance corresponding to Appius is MAN, or ANIMAL. This is because the ways that those distinctions are implemented at the metaphysical level are different from the signs we use to infer that there are such differences. In expressing the world, minds operate a transformation eis allo genos, that is, rendering what there is into a world quoad nos. To unpack 
this thought, we need to look at the NE, where Leibniz deploys a distinction between metaphysical, physical, and logical genus.

Leibniz introduces his discourse regarding physical, logical, and metaphysical genus in order to argue against the thesis that God could create thinking matter. The question can be recast as follows. We have significant words like "thought" and "matter": can these be joined up to form a concept that expresses an essence, such as THINKING MATTER, as we do with RATIONAL ANIMAL? Posed in this way, our question instantiates a more general issue that we have already broached, viz. how we can eliminate those distinctions that seem logically possible (since we can detect no contradiction thereby) but which are not real. To help explain this puzzle, it is worth analyzing Leibniz's argument for the claim that thinking matter cannot exist. He begins by drawing a distinction between modifications and attributes:

Modifications must be distinguished from attributes. The faculties for having perception and for acting, together with extension and solidity, are attributes, i.e., permanent main predicates; whereas thought, impetus, shape, and motion are modifications of these attributes. (NE 63)

According to Leibniz, attributes consist in the "permanent main predicates" of a substance. His unspoken assumption is that substance refers to the specifically Leibnizian notion of a substance, which crucially differs from Locke's use of "substance", which denotes a general name for a cluster of ideas. ${ }^{23}$ "Substance", for Leibniz, is a metaphysical rather than a logical category. Perceptions, actions, solidity, and extension are permanent attributes of substances, while thought, motion, and shape are modifications of their attributes. This results in a distinction between attributes: those constituting a metaphysical and physical genus, and those that constitute more specific modifications, which result in phenomena that rational agents categorize into physical and logical species (about which we will elaborate in section 5, below). Physical genus differs from logical genus insofar as the latter encompasses logical and abstract categories, such as space and time, which rational agents use to grasp and put order into the world, although what exists does not exist as we conceive of it in abstracto. The target of this distinction is the same that will engage Leibniz some years later with Clarke, viz. the denial that space and time are substances modified into concrete bodies and their changes. Indeed, Leibniz begins the discussion by explaining what it means to be of a homogeneous genus:

[One] should distinguish between physical (or rather real) genus and logical (or ideal) genus. Things which are of the same physical genus, or which are 'homogeneous', are so to speak of the same matter and can often be transformed from one into the other by changing their modi-

23 See EHU 425: "The common names of substances, as well as other general terms, stand for sorts: which is nothing else but the being made signs of such complex ideas wherein several particular substances do or might agree, by virtue of which they are capable of being comprehended in one common conception, and signified by one name." 
fications - circles and squares for instance. But two heterogeneous things can belong to a common logical genus, and then their differentiae do not consist in mere accidental modifications of a single subject or of a single metaphysical or physical matter. (NE 63)

Since this is a convoluted passage, its examples may mislead the reader. Thus, to better comprehend it, we need to grasp the underlying cognitive operation for considering two things as being homo- or heterogeneous. Two things are homogeneous if and only if we can transform one into the other. For example, if I have a circle, then I can mentally entertain ways of transforming it into a square. This mental modelling is similar to having a stuff, such as gold, which can be modelled into different shapes. The underlying "matter" is what remains throughout its alteration, and we call this its genus. Leibniz explains the same process in De Mutationibus. There, he calls the genus the matter or body that persists over change. If there is not a way of transforming one thing (like an hour) into another (like a meter), then the two things are heterogeneous; they can nonetheless inhere in an abstract logical genus like continuous quantity.

This mechanism of "abstraction" can be applied to almost anything. For instance, I can conceive of variations with regard to "hair", like color, length, and shape. "Hair", sc. that which is homogeneous, persists in spite of its alteration. Thus, I may call "hair" a genus. However, Leibniz argues in the NE that the most fundamental genera are of three kinds: physical, metaphysical, and logical. The idea is that anything we can conceive of as a substratum of change can be further reduced to both a more general physical genus, which consists in the physical matter underwriting the change, which can, in turn, be reduced further to either a logical or metaphysical genus. Physical genus is the "matter" or "body" of change (for instance, when deprived of any phenomenal appearances, the matter of water may exemplify a modification of a physical genus). Modifications of a physical genus are expressed by the mind through space and time which, by contrast, instantiate logical genus, viz. "continuous quantity." Space and time qua ideal quantities (as argued in chapter II) are ideas that the cognizant agent relies upon in tracking beings and their modifications. Modifications are then interiorized as types and categorized through concepts, which are defined via conceptual marks. What exists cannot exist as abstractedly cognized through the concept. On the other hand, a physical genus may be reduced to a metaphysical genus, that is, as a change requiring a true unity or substance. When I consider Appius to be a man who moves from being virtuous to vicious, I posit - as a condition of possibility - a substratum for his actions: an enduring substance.

The distinction between logical and real genus is introduced to highlight that not every distinction we are able to draw (such as that between space and time) presupposes the existence of that which we distinguish. While rational agents need space and time in order to cognize beings, it is not thereby the case that they exist as real substances:

[Time] and space are very heterogeneous things, and it would be a mistake to think that they have resulted from modifications of who knows what real common subject, characterized only by continuous quantity in general. Yet their common logical genus is continuous quantity. (NE 64/A VI 6 64) 
This remark of Leibniz offers us a clue in understanding the function of these distinctions. "Logical" means that the genus is proper to the mind, but cognizant agents are not permitted to say that something concrete exists merely in virtue of being abstractly conceivable. Space and time constitute continuous, ideal quantities: what they track cannot exist as being itself continuous, but only as a physical genus. We now see how this distinction of genera maps onto the distinction between essence and existence, which we have argued for thus far. Space and time are innate ideas that are spontaneously deployed by cognizant agents in tracking phenomenal changes in relation to existence, that is, to actual modifications of a real attribute, viz. matter. In sense-perceiving actual changes, cognizant agents track a body, viz. the ideal representation of a corporeal substance whose unity across time is provided by a true unities or substances. The divisions of matter that we can observe (aggregates of corporeal substances) are expressions of changes at the level of metaphysical attributes, which pertain to perceptions and endeavors. In this way, when the mind tracks a body as a type and then as an instance of an abstract essence, all the mind actually does is track what that region of the world - unified by substances as expressed by the mind in terms of minute perceptual changes - can do. In this way, the mind employs different resources for anticipating and predicting how that region of the world may change or behave.

The distinction of the three genera, therefore, simply demarks that our logical categorizations map onto something that does not fully accord with our conception of it. To become objects of finite minds, things must be transformed or expressed, and this implies that they do not exist in the way that we imagine or conceive of them. Nevertheless, our expressions track physical genus - the matter composing bodies - as well as a metaphysical genus, which maps onto those substances that correspond ontologically with observable, phenomenal changes.

Metaphysical genus therefore refers to something existing as a substance. Leibniz also calls this "a true unity": something that is not in the mind as an idea, as bodies determined by space and time. Metaphysical genus, Leibniz argues, is the other attribute characterizing real beings - what exists as an object of possible experience in a human mind, that is, true substances that are associated with corporeal substances. Metaphysical genus consists in those modifications that remain permanent in a substance. As is well known, Leibniz's view is that permanent properties of substances consist in perceptions and appetites; striving forces bring about substantial change. "Substance" is a genus because it can undergo modifications in the attribute of perception. Perception can be modified into thoughts, sensations, images, giving rise to the degrees Leibniz enumerates in MKTI. On the contrary, the attribute of matter, which constitutes the corporeal substance associated with true unity, can be modified into shape, size, and motion. 
Real Genus

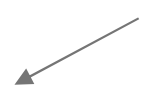

Metaphysical

Genus

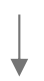

Attribute of

perception

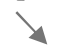

True unity modified

in perceptions and endevours

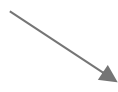

Physical

Genus

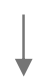

Attribute of

extension

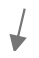

Corporeal substances

modified in shape and

size
Mind

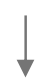

Logical

Genus

Continuous

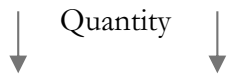

Space

Time
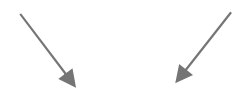

Bodies as types

Real existing beings

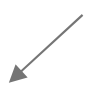

Thus, this distinction, as presented in the NE, aims to rule out the possibility of "thinking matter". Thinking matter should be understood as a physical genus whose modifications can bring about thoughts, although thoughts are not possible modifications of matter. This is because matter belongs to a physical genus, which is distinct from a metaphysical genus, the sole capable of receiving changes that can produce thoughts. ${ }^{24}$ If matter and perception are permanent attributes of real beings, and they are heterogeneous (because they belong to different genera, even though they cannot exist as distinct), then there cannot be any modification brought about in shape that transforms a shape or motion into a thought just because the modification does not belong to the proper attribute. ${ }^{25}$ Just as one cannot produce any change in gold that transforms it into a statue of clay, so too one cannot bring about a change in matter that produces thought. Leibniz's conclusive remark is important for our discussion:

Perhaps people will laugh at these philosophers' distinctions: two genera, one merely logical, the other real as well; and two matters, one physical (which is that of bodies), the other merely metaphysical or general - as if someone were to say that two parts of space have a single matter, or that two hours share a single matter. (NE 64/A VI 6 64)

24 Notice that the argument coheres with Monadology $\S 17$, where, through the example of the mill, Leibniz argues that modifications in shape, size, and motion cannot produce a perception. For discussion of the argument, see Lodge (2014).

25 Leibniz refrains this argument in Monadology $\S 17$ using the example of the mill. 
And, while these distinctions may sound like redundant "philosophers' distinctions",

[...] these are not merely distinctions among terms but among things themselves, and they seem very apposite here, where confusing them has led to a false conclusion. These two genera share a common notion, and the notion of real genus is common to both matters. (NE 64)

In addition to the specific use that Leibniz makes of the distinction in the NE to argue against "thinking matter", the distinction between real and logical genus, on the one hand, and metaphysical and physical genera, on the other, is telling with regard to how we have to understand distinctions between natural kinds. As we have argued, bodies (or modifications of corporeal substances) are first cognized by minds, thereby culminating in the interiorization of types. In the preceding chapter, we argued that after we have interiorized types, bodily similarity is then categorized through clusters of intensions, which are in turn structured by logical genus and species (secundae notiones), and finally expressed through definitions.

If this is correct, then we primarily track the modifications of a physical genus. Our first, intentional objects are not true unities, since they are possible objects neither of the senses nor of the imagination, while corporeal substances are possible objects. ${ }^{26}$ Thus, when we follow the transformations of bodies and thereby infer a common genus (as in the case of WATER or ANIMAL), we are inferring a physical species that can be defined through logical relations between a logical genus and a specific difference, as in "MAN is a RATIONAL ANIMAL". It is at the level of abstract, logical genus that modifications come to be either essential or accidental. Exactly as space and time, natural kinds genera and species are logical and there are no essential or accidental modifications at the level of real genus, whereby changes are only permanent or transitory modifications of substantial attributes.

As attested to in the passage of De Mutationibus, Leibniz thinks that any time a rational agent detects a common nature and arrives at a species for its classification, they may infer that the species belongs to a metaphysical being, viz. substances. However, none of the intensions that constitute the concepts of the species belongs to the real being. In saying that a substantial form corresponds to changes that we can observe in the corporeal substance (expressed as a body in space and time), we are not thereby permitted to say that the substances cause the changes (for we do not comprehend how that could be), any more than we can say that what we attribute to the corporeal substance is thereby a property of the substance itself. The ascription is without identity. What does this mean? It means that, if I say that Appius has the substantial form of being that individual man, "Appius", then I am not allowed to infer that any of the intensions of the concept inhere in the substantial form, Appius. Appius, viz. the historical individual who exists in a certain spatiotemporal frame, is rational, virtuous, capable of laughter, but the corresponding substance is not. The substance, indeed, is indestructible and immortal: it does not survive with all the properties of Appius - not even those we consider essential. By

26 Bolton (2006) argues that monads, understood as simple beings lacking parts, cannot be objects of sense-perception. 
contrast, the complete concept of Appius will entail all the properties of Appius, even those that are not cognizable by finite minds.

This theory of Leibniz's is coupled with a central tenet of Leibniz's metaphysics of substance, viz. that substances are never destroyed, but are simply transformed through envelopment and development into different, larger or smaller animals, although they never disappear:

[T] here are sorts or species such that if an individual has ever been of such a sort or species it cannot (naturally, at least) stop being of it, no matter what great events may occur in the natural realm. But I agree that some sorts or species are accidental to the individuals which are of them, and an individual can stop being of such a sort. Thus one can stop being healthy, handsome, wise, and even visible and tangible, but one does not stop having life and organs and perception. I have said enough earlier about why it appears to men that life and thought sometimes stop, although really they continue to exist and to have effects. (NE 305/A VI 6305 )

This means that Appius remains a man even when the physical Appius dies, and no parts of his body remain visible or discernable as parts of Appius' body. Moreover, as we saw in chapter IV, a well-formed organic body, when attached to a soul capable of rational activities, explains why the indestructible and eternal soul passes from a state of stupor to having distinct and conscious cognitive states. This means that even when Appius dies and his soul shrinks in a body that lacks the proportions and organs that we would perceive as being Appius' human body, the soul of Appius still exists and remains rational, although, owing to its new constitution, it is in a state of stupor and is temporarily incapable of rational thought. None of the properties I assume as constitutive of Appius qua historical man persist; a substantial form whose main attributes can receive the modifications that characterize the historical Appius, when developed into an organic human body, always persist. The properties of the historical man, whom human rational agents can conceive of and discern when they experience Appius, constitute the essence MAN (or the essence APPIUS), but the essence does not exist. What exists is the substance. Leibniz is therefore right to reject realism about essences.

Thus, metaphysical enquiries into substances do not aim to determine what man or Appius is; they rather aim to provide a unifying explanation for the variety of observable phenomena. We want to know what unifying ground all phenomena share. From this point of view, we seek a simple cause. For Leibniz, the answer comes in the form of substance. This implies that all one can say is that a substance constitutes Appius; but one cannot derive any particular claim about specific substance beyond certain general claims regarding the constitution of substances more generally. On Leibniz's understanding, metaphysics is a general science, owing to which it is able to infer certain general truths about substances. The reason why metaphysical knowledge is possible, albeit necessarily limited, is that human rational agents are themselves substances and, through introspection and analogical thought, they can deduce what a substance, in rigore metaphysico, must be. In our experiencing a variety of things, for instance, we can infer that a variety of things 
exist. And, just as we experience change in ourselves, we can thereby claim substances to be the principle of such changes, and, moreover, that they must also be found in other beings. ${ }^{27}$

Our aim here, however, is not to survey Leibniz's arguments regarding substance, the validity of which remains questionable. I rather want to highlight Leibniz's overall approach to this question (which is interesting in its own right) and the impact it has on his epistemology. Indeed, Leibniz does not contradict Locke insofar as our conceptual apparatus is the product of finite understanding, owing to which it is fallible and provisional. He in fact agrees with Locke that we cannot know the real constitution of things. With this, however, he means something different. We cannot know how the metaphysical level yields change at the physical level, and any knowledge of this would require an infinite mind, such as the mind of God.

If our analysis is correct, then we reached a decisive aspect of Leibniz's philosophy: the natural sciences and metaphysics are autonomous, despite their being intimately intertwined insofar as metaphysics is the foundation of everything. This means that scientific and metaphysical knowledge are distinct enterprises. A botanist need not also be a metaphysician to distinguish species, nor must an essayer know the metaphysical constitution of substances to recognize gold. And indeed, already in Specimen Dynamicum, Leibniz gives a warning to those who misinterpret his reintroduction of substantial forms: substantial forms are necessary to philosophize about, but not to explain, phenomena. We should not assume that occult causes are acting within something in order to explain their visible effects. ${ }^{28}$

27 This move is used, for instance, in the Monadology, as explored in chapter V. Leibniz to Gottlieb Samuel Treuer, June $1^{\text {st }} 1708$ (Oliveri (ed.) 2019: 103-4): "Every substance by its true name is simple, or a Monad; the compositum is not a substance, but an aggregate or a plurality of substances. Furthermore, any substance must act, intimately from its nature or an internal act (as just one can demonstrate); and the internal act of the simple substance, insofar as it refers to a multitude to be found outside [the substance], entails the representation of those things. And this very act is what I call a perception, a representation of the multitude in the one or in the monad. This is what we experience in our minds; this is what must necessarily be inferred to be in other monads, even if consciousness and reason are not present in them. And as all aggregates consist of monads or substantial atoms, it is necessary that there are perceptive beings everywhere, although with different degrees of perfection. We must say about monads as the true substantial atoms what the Democriteans claim about their corporeal but fictitious atoms: once they are created, they always subsist and cannot perish because of a natural cause. And when I say that an organic body is added and always corresponds to each monad, although it [the organic body] must change, augment, diminish or transform, this does not happen in the way of the soul, but rather of the animals themselves or other similar perceptive beings, [and] they always subsist."

28 Specimen Dynamicum (L 436): "I agree with those who deny that forms are to be used in investigating the specific and special causes of sensible things. This I must emphasize to make it clear that in restoring to the forms their proper function of revealing the sources of things to us, I am not trying to return to the word battles of the more popular Scholastics. A knowledge of forms is necessary, meanwhile, for philosophizing rightly, and no one can claim to have grasped the nature of body adequately unless he has paid some attention to such things and has come to 
If knowledge of forms was necessary for scientific enquiry, then any scientific enterprise would be doomed to failure, since perfect knowledge regarding how the metaphysical constitution of beings leads to changes in the visible world is offlimits for finite minds. Despite this limitation, however, the transformations of a physical genus that we can track may yield inferential grounds from which we can know essences, whose knowledge provides a more reliable basis for predicting how worldly regions may or may not change, although predictions remain only provisional. A better understanding of the natural world, moreover, is the main entrypoint to understanding what there is at a metaphysical level, although our knowledge of it remains of the utmost generality. Metaphysical knowledge - even if it is not strictly required for scientific discoveries - serves as a guide for the acceptance or rejection of scientific theories or argumentation. Our understanding of the distinction between logical and real genus, for instance, provides us with a reason as to why space and time cannot be substances nor the ultimate substrata of change, ${ }^{29}$ nor, moreover, why the world cannot be constituted by purely material, hard bodies, such as atoms, ${ }^{30}$ nor why extension cannot exist. ${ }^{31}$ If science has the scope for determining what there is at the fundamental level, then scientific hypotheses will need a metaphysical test via metaphysical principles like the principle of sufficient reason or the identity of indiscernibles.

\section{MATHEMATICAL AND PHYSICAL SPECIES}

If metaphysics deals with the categories of permanent and transitory modifications, that is, it asks the question of what substances are (such that they are understood to be the ultimate constituents of reality), then the natural sciences are concerned with phenomena, that is, with what appears or can be observed. In other words, if the

understand that the crude concept of a corporeal substance which depends only on sensory imagery and has recently been carelessly introduced by an abuse of the corpuscular philosophy (which is excellent and most true in itself) is imperfect, not to say false."

29 As proven by the controversy with Clarke on Newtonian gravity and the existence of space and time. On this, see Ariew (2000). As argued in the fifth letter to Clarke, space and time as substances violate the principle of the identity of indiscernibles.

30 Consider Leibniz's exchange with Hartsoeker, especially the letter from October 30, 1710 in GP III 507. There, Leibniz says that the notion of atoms as perfectly-alike constituents of bodies, which differ only in shape, size, and motion, satisfies the imagination, but is inadequate to the intellect ("Les Atomes sont l'effect de la foiblesse de nostre imagination, qui aime à se reposer et à se hater à venir à une fin dans les sousdivisions ou analyses; il n'en est pas ainsi dans la nature qui vient de l'infini et va à l'infini. Aussi les Atomes ne satisfont ils qu'à l'imagination, mais ils choquent les raisons superieures.") According to our analysis of the logic of imagination, this means that atoms violate some metaphysical principles, viz. the principle of the identity of indiscernibles.

31 Leibniz argues against Descartes that extension is an abstract idea, owing to which it cannot be a substance, viz. something subsisting ontologically per se. For discussion, see sect. 5 On Error, below. 
substance Appius always is Appius or a man (owing to the impossibility of substantial destruction), then there is a limited window of time in which we are able to observe and categorize that substantial form through the abstract essence MAN, viz. while Appius is capable of being tracked spatiotemporally by our sensory faculties (perception and imagination). During this time span, Appius changes constantly because he is attached to a body that itself undergoes constant alteration. Nonetheless, we still seek a stable criterion for understanding what makes Appius different to a lion, or what makes being Caucasian different from being virtuous. To this end, we need to draw a distinction between Appius's accidental and essential properties, that is, we produce a fiction that treats Appius - or, indeed, any modification of a physical genus - as a logical species of the logical genus ANIMAL.

Introducing the distinction between logical and physical genus, Leibniz writes:

one should distinguish between physical (or rather real) genus and logical (or ideal) genus. Things which are of the same physical genus, or which are 'homogeneous', are so to speak of the same matter and can often be transformed from one into the other by changing their modifications - circles and squares for instance. But two heterogeneous things can belong to a common logical genus, and then their differentiae do not consist in mere accidental modifications of a single subject or of a single metaphysical or physical matter. (NE 63)

Leibniz here introduces a distinction that he reprises in addressing matters of mathematical and physical species. The crux of his distinction is that one can consider two different things, e.g., a circle and a square (or Peter and Claire), as two accidental modifications of an underlying physical genus. By imaginatively modelling them, I can think of ways of transforming one thing into the other. For, I can model Peter's face into Claire's, and thereby conceive of something that persists in spite of the change. We call this something HUMAN BEING. However, in order to understand what HUMAN BEING is, I need to treat it as a logical genus, that is, I need to characterize it through a cluster of conceptual marks that I take to be rigid. Here, 'rigid' means that any change in conceptual marks - or introducing a new mark in a logical genus - produces a new essence. The addition of a new conceptual mark, like RATIONAL, to a genus, like ANIMAL, produces a cut in the genus, giving a species, MAN, and another indefinite one produced by the opposite of the mark, NON-RATIONAL. In other words, it produces order and affords distinctions within a realm of logically possible essences. In conceiving of a logical genus that is distinguished into species through the introduction of differences, we conceive of species logically or mathematically, by contrast with modelling instances in the mind, which yields only differences in physical form. ${ }^{32}$

This discussion about physical and mathematical species corroborates the distinction between types and concepts, on the one hand, and, on the other, the idea that concepts are constructs of the human mind, which take the actual modifications

32 Through a detailed analysis of MKTI, in Oliveri (2020) I argued that Leibniz uses the Platonic method of collection and division as a criterion for making concepts distinct, as well as for giving a logical basis to genus-species distinctions. 
of a physical genus as if it were a modification of an essence-expressing logical genus. In this way, agential minds forge a more stable ground for their predictions and can be said to have scientific knowledge of the observable world.

The distinction between physical and mathematical species is used by Leibniz to overcome Locke's criticism regarding essences and definitions. If there is something like essences in nature, Locke argues, then how do we explain deviance from the standard to which we believe nature conforms? Leibniz's way of answering this difficulty is to argue that mathematical species do not depend on their instances, while physical species do:

All this trouble arises from a certain ambiguity in the term 'species' or 'of different species.' When that ambiguity is removed, there will be no further dispute except perhaps about the name. One can understand 'species' mathematically or else physically. In mathematical strictness, the tiniest difference which stops two things from being alike in all respects makes them 'of different species'. It is in that sense that in geometry all circles are of a single species, because they are all perfectly alike, and for the same reason all parabolas are of a single species; but the same does not hold for ellipses and hyperbolas, for there is an infinity of sorts or species of these, each containing an infinity of members. (NE 309/A VI 6 309)

When we use the term "species", we may be referring to two very different things. If we take the term mathematically, then "man" refers to an essence expressed by a structured cluster of conceptual intensions that are organized in relation to genus, species, and specific difference. The cluster is rigid, meaning that any change in the intensions produces a new and different essence. This thereby produces a change in the identity of the concept. Now let us say, for instance, MAN is RATIONAL ANIMAL. Here, the terms are rigid and fixed because any change in the intensions defining RATIONAL and ANIMAL would designate a different essence (assuming that there is no contradiction in the set). The essence becomes possible as soon as it is not contradictory, although one cannot infer that the essence maps onto individuals existing in the actual world merely from the fact that the essence is possible.

Mathematical species can be exemplified by circles. Any circle is perfectly similar to another circle. While circles can get bigger or smaller, their geometrical similarities remain. If I change the proportions of a circle so that it looks like an oval, the result is a different figure. Likewise, the number of intentions composing the concept MAN may be wider or narrower: I can limit myself to the intensions RATIONAL ANIMAL or extend it to RATIONAL ANIMAL CAPABLE OF LAUGHTER AND SPEECH. Here, the two concepts remain the same because they are similar; the latter is only wider vis-à-vis intension. If I change the structure of the cluster, however, as when I substitute RATIONAL with NON-RATIONAL, the result is a different essence, whereby intensions contained in RATIONAL become impossible modifications of the new essence.

Physical species do not present the same kind of rigid, mathematical similarity and can be exemplified by ellipses in mathematics. Any modification of an ellipse 
produces an ellipse, although of a different kind. ${ }^{33}$ Ellipses are individuated by the ratios between their foci. Any variation in this ratio produces a variation in the species to which a particular ellipse belongs. Even though we can still call them "ellipses", they are not the same individual ellipses. What Leibniz calls "physical species" exemplifies the relation between categorization and their instances, while what he calls "mathematical species" exemplifies the relation between concepts and essences. Instances may vary and still preserve a similarity sufficient to enable our recognition of this individual as an individual of that type (such as Claire and Peter). This similarity is translated into a rigid, mathematical species that does not admit of such flexibility and variety, thanks to it being a rigid cluster whose identity criterion consists in an overlapping of intensions derivable via analytic entailment and semantic inferences. The rigid mathematical species no longer refers to individuals, but to the essence to which individuals are reduced. Only when we conceive of essences can we consider Claire and Peter as if they were identical (not similar) to each other as HUMAN BEINGS, as instances of an essence. According to the logic of the imagination, we could conceive of them only as different when spatiotemporally perceived, or as similar, but we could not conceive of them as one and the same. As objects of the imagination, they are necessarily different and distinct. We thereby recognize them as two distinct individuals. Nonetheless, the intellect overcomes phenomenal appearances and conceives of them as identical. To highlight this point, Leibniz argues that, if physical species were like mathematical species, then any modification in a particular being would make it of a different species:

Two physical individuals will never be perfectly of the same species in this manner [in the manner of mathematical species, L.O.], because they will never be perfectly alike; and, furthermore, a single individual will move from species to species, for it is never entirely similar to itself for more than a moment. But when men settle on physical species, they do not abide by such rigorous standards; and it is for them to say whether stuff which they themselves are able to restore to its previous form continues to be of the same 'species' so far as they are concerned. And so we say that water, gold, quicksilver, and common salt remain such, and are merely disguised, in the ordinary changes they undergo. (NE 309/A VI 6 309)

We recognize particulars as similar even if they are not similar in the mathematical sense. However, concludes Leibniz, it would be impossible for us to conceive of particulars if the term 'species' were as rigid as its mathematical counterpart. If it were, then we would simply not be capable of conceiving of particulars, because we would not have general species to which particulars are opposed. Physical species correspond to our ways of considering individuals as individuals of a certain type - a confused way of considering an abstract common essence. Physical species are therefore distinct from mathematical species because they rely on different mental processes: the former based on types, the latter on concepts.

Therefore, when we claim that a being or its modification is an instance of a certain concept, while we are relying on a type to recognize the instance, we are

33 The contrast between circles and ellipses in explaining the difference between general species and species infimae, i.e., individuals, is typical of many Leibnizian writings. For discussion, see Di Bella (2005: 217). 
claiming something different. We are claiming an identity relation between the individual and the concept. In claiming, "Mary is a human being", I do not simply recognize Mary as a human being: it is as if Mary is identical to HUMAN BEING, owing to which I attribute to Mary some of the properties that I can also attribute to HUMAN BEING. ${ }^{34}$ This fictional reduction of Mary to the conceptual-structural clusters of conceptual intensions permits the derivation of contingent, necessary truths about Mary, as based on the properties that mirror the modifications Mary is capable of undergoing. As we will soon see, there is a great complication in this theory: nature (that which all existing individuals have in common) is not as rigid as we have been supposing in framing this conceptual-epistemic space, based in turn on essences. ${ }^{35}$ Deviance from our rigid designations are possible. Indeed, when deviance goes beyond a certain range of frequency or limits, as when it exhibits contradictions with our concepts, we have to reframe our concepts. ${ }^{36}$ As Leibniz insists, conceptual distinctions are presumtions:

I have distinguished earlier [NE 308ff] between the various meanings of the word 'species'. In the logical, or rather the mathematical, sense, the least dissimilarity is enough, so that each different idea yields a new species, whether it has a name or not. However, in the physical sense, we do not give weight to every variation; and we speak either unreservedly, when it is a question merely of appearances, or conjecturally, when it is a question of the inner truth of things, with the presumption that they have some essential and unchangeable nature, as man has reason. So the presumption is that things that differ only through accidental changes, such as water and ice or quicksilver in its liquid form and its sublimate, are of a single species. (NE $323)$.

When we consider species mathematically, we treat them as mathematical or rigid essences. Essences are individuated through conceptual intentions and their relations (as captured by the medium expressing them, that is, a system of signs ruled by syntax and semantics). The structured relations between concepts define the essence. Any change in the structure causes a change in essence. Once we learn to postulate logical genus and species, i.e., to divide concepts into logical classes defined in virtue of the properties they share, we learn to identify the species not with its phenomenology, which is recognized in virtue of a type: we reduce the essence

34 As Leibniz says in De Mutationibus, one cannot attribute all the properties bore by abstracts to concretes. It would be a mistake to say that "a man is a quantity" because I can say that "a man is warm" and I know that "warm is a quantity". The distinction between how things exist and how things are conceived in relation to essences helps us to avoid these mistakes.

35 As Leibniz writes in A VI 6 314/NE 314: "Les imbecilles manquent de l'usage de la raison; mais comme nous savons par experience, qu'elle est souvent liée, et ne peut point paroitre, et que cela arrive à des hommes, qui en ont montré et en montreront; nous faisons vraisemblablement le meme jugement de ces imbecilles sur d'autres indices, 'est à dire sur la figure corporelle. Ce n'est que par ces indices, joints à la naissance que l'on presume que les enfans sont des hommes, et qu'ils montreront de la raison: et on ne s'y trompe gueres. Mais s'il y avoit des animaux raisonnables d'une forme exterieure un peu differente de la notre, nous serions embarassés. Ce qui fait voir que nos definitions quand elles dependent de l'exterieur des corps, sont imparfaites et provisionelles."

36 See A VI 6 324/NE 324. 
to a logical or mathematical possibility, which belongs to the realm of ideas in the mind of God. This is because what exists metaphysically does not exist as we conceive of it. When we form a concept of a species defined via a structured cluster of intentions expressed through linguistic (or any other kind of cognitive) tools, we express God rather than the historical world, because we are imitating God's intellect. $^{37}$

Therefore, the distinction between logical and physical species, Leibniz believes, allows him to surmount Locke's criticism that rigid, mathematical species do not refer to anything in reality. Given the dependence of the human mind on the relation of similarity for conceptual formation, a type is associated with a concept. Moreover, the type - not the concept - is responsible for the recognition of an individual as an instance of a concept. In other words, the concept MAN and the type "man" are closely related because, as highlighted, even if concepts are not abstracted from individuals, the generalization types allow for nonetheless constitutes a first step in seeking a reason for beings' similarity. All the type does, however, is to idealize modifications of a substance as expressed by a physical genus, and not as modifications of a metaphysical genus. In other words, according to the law of harmony, we know that something substantial must correspond with the common nature tracked by the type and conceived of as an essence via the concept, which distinguishes between essential and accidental properties. Yet, we are not allowed to attribute to a substance any of the properties we track via types, or that we conceive of as essential owing to the concept. If essences do not exist in re, then they cannot be abstracted. What there is at the metaphysical level can neither be deduced from the outer appearances of temporal beings, nor from the ideality and abstractness of essences. To conceive of what exists at the metaphysical level, we need innate ideas, as we shall argue in the next chapter. The correspondence between those genera nonetheless warrants the reality of our distinctions and categorizations.

\section{ON ERROR}

The distinction between types and concepts can provide a general diagnosis for possible sources of error and thereby fashions a strategy for avoiding them.

Error arises when cognizant agents exchange types for concepts, deploying the logic of the imagination instead of invoking intellectual principles. As we have argued, when cognizant agents make similarity between beings explicit by organizing conceptual intensions into predicamental, logical structures, the logic they rely upon is that of the intellect (based upon identity and contradiction), not that of types governed spatiotemporally. Concepts are structured via logical principles of identity and contradiction. Given the association between type and concept, when the type "human being" is active (thanks to our sense-perceiving a shape recognized as the body-type of a human being), through memory we recall information about the

37 As Leibniz says in the Monadology, this is a peculiar feature of rational substances. 
type, and, thereto, the concept associated with the type is more promptly accessed by the mind. On the other hand, when I reason about HUMAN BEING and recall the concept, my imagination spontaneously activates a type. The type naturally inclines me to associate images through reasoning. The consequence is that rational agents can run types and concepts together, believing that they are reasoning about the concept, while they are instead imagining instances based on types. The consequence of this exchange of principles governing our reasoning is that we can believe in the possibility of things that are not possible. Leibniz levels this idea against atomism in saying that atoms perfectly satisfy the imagination, while they do not provide a valid theory for the intellect. With this claim, Leibniz alludes to the fact that atoms contradict the principle of the identity of indiscernibles, viz. that different locations in space and time are sufficient for claiming a real distinction between two things. As we saw, spatiotemporal distinction suffices for the imagination, but it is not sufficient at the level of the intellect. The latter recognizes space and time as ideal and abstract, and hence demands a more substantial difference between atoms, viz. substances. In appealing to its innate ideas and principles, the intellect cannot be satisfied by atoms as the ultimate constituents of nature. ${ }^{38}$

Another source of error is what Leibniz calls obreption and chimerism. As we saw, the human mind sometimes uses the same name in abstracto and at other times in concreto. This habit of the mind - of taking names as signs of concrete beings implants in it the belief that something concrete always corresponds with general names. In short, obreption is a sort of category mistake, which takes something abstract for concrete. The consequence of obreption is chimerism, or the groundless belief in the existence of instances of a concept, while nothing corresponds to it in the actual world. In some preparatory drafts of the NE (A VI 6 30-31), Leibniz explains the two mistakes, invoking Cartesian extension as an example:

Concerning this [the error of the mind L.O.] we must consider that there are in definitions two kinds of abuses that we can commit in forming ideas: one is what the excellent Jungius called 'obreption', the other is what I call chimerism; for example, if someone reasoned in this way: it is permissible to combine some ideas and to confer a name to the result of the combination. Let us take for instance the idea of substance that contains nothing but extension and let us call it a body; therefore, the bodies that we find in nature have nothing but extension; in this reasoning, we have at once these two errors. The obreption consists in the fact that we conferred to the name 'body' the definition that appears good to us, which is arbitrary to some extent, and we apply it to what other people call by the name 'bodies'. It is as if in geometry one defined ovals as ellipses. [...] The chimerism is to have done an impossible combination, since it is not possible to have a substance which does not have anything but extension. (A VI 6 30-1, my trans.)

As Leibniz emphasizes, obreption and chimerism are typical in metaphysics ${ }^{39}$ (as evidenced in the very target of this quotation, viz. Descartes' notion of res extensa

38 See fn 30. In the next chapter, we will return to the role of innate ideas.

39 Obreption corresponds to what, in the Wolffian tradition, is called "subreption", an operation also recognized by Kant as the cause of paralogisms. On this topic more generally, see BirkenBertsch (2006). 
as a substance), although they can be extended to natural kinds or concepts in general. Leibniz indeed agrees with Locke that we may misrepresent reality by conceiving of possible essences and attaching "existence" to them. We may take a structured cluster of intensions to be instantiated in the actual world, when, indeed, the cluster is impossible either because it results in a contradiction on a more detailed analysis, or because nothing existent corresponds with it in the actual world, as in the case of extension. When this happens, we make a mistaken judgement about the nature of things, believing existent what is not. Only in this case are concepts chimerical, Leibniz claims, because existence is groundlessly attached to them. Despite the risks of relying upon mathematical species, there are still certain advantages in postulating rigid mathematical essences. For instance, the presupposition of such essences allows us to form new hypothesis and thereby to test them.

The general rule we need to follow, Leibniz claims, can be labelled the Human Conceivability Principle, which states that:

What we can conceive is not a measure of God's power, but our conceptivity is based on nature: everything which is in accord with the natural order can be conceived or understood by some creature. (NE 65/A VI 6 65)

From our discussion, we can recast the principle as follows:

Human conceivability principle: conceptual distinctions grasping essences allow human beings to carve reality at the joints.

This principle has the following corollary: everything God has created can be conceived by a human mind, but not everything a human mind can conceive of can therefore be created by God. Mistakes are possible. This does not mean that God is a deceiver because He made cognizant agents fallible. Like Descartes, Leibniz thinks that God is no deceiver, albeit for different reasons. For Descartes, God is no deceiver because He provides human minds with an infallible intellect. When dealing with ideas, the intellect has the power to grasp them in a pure way - without error. For Leibniz, God creates finite minds, which can express what exists from $a$ finite point of view. In making the world quoad nos, we need to operate a metabasis eis allo genos which - of necessity - changes what there is at the ontological level (which is otherwise inaccessible to us) into a surrogate that our finite minds can conceive. Expression is therefore an intrinsic activity of the human mind understood as a unity of soul and body that is then unfolded onto various degrees. This constant construction of a world proportioned to finite human minds is the reason why we are prone to mistakes. However, it is also the reason why, among existing creatures, minds are more similar to God. God is no deceiver not because he made minds infallible but because he made them such that they can correct themselves through their own activity. They are therefore perfectible and free. The result is that we can conceive of the impossible, which may become a resource for the human mind to construct tools for overcoming its finitude, as in the case of the infinitesimal in mathematics. 


\section{CONCLUSION}

In the preceding two chapters, I argued that Leibniz has a story to tell about the origins of our conceptual distinctions. This story explains how human beings evolve from perceiving particular beings to conceiving of them as instantiations of abstract general essences. To this end, types constitute the connection between existence and essence.

Human minds naturally tend to represent discrete matter in continuous space. They reduce phenomena to shapes and sizes, tracking their variations spatiotemporally. In so doing, human minds interiorize types: rules for tracking and predicting natural, phenomenal behavior. Indeed, types are a first form of abstraction, which express beings' common nature, owing to which they can be understood as a confused expression of abstract essences. Essences are expressed confusedly by types because types are not the right kind of cognitive state to produce distinctions within abstract essences. The connection between types and essences, however, explains how human minds can move from confused representations of essences to distinct representations of essences, viz. through conceptual distinctions. This process is facilitated by, and supported through, a change in the use of names: from general referents to denotations of the similarities between concrete beings, names become terms used to refer to conceptual marks structured into definitions that express essences. Types explain how finite minds are able to mentally modify phenomena, thereby predicting which kinds of modifications a type can undergo without effecting a change in type. Through abstraction and mental imagery, minds can conceive of modifications in types that preserve a material substratum, which is conceived as common even for beings of different types. This common substratum is what becomes the genus grasped as an essence when logically defined through terms and their relations based on identity and contradiction. Because the formation of concepts is intimately bound up with types, concepts obtain an extensional interpretation through their association with types, a fact that renders human beings liable to error.

Another important result of this enquiry is the separation of real and logical genera. While a real genus can be of a physical or metaphysical kind, logical genus is proper to the mind and is used in grasping real modifications. The result is a necessary transformation of real genera by means of expressions that, while making those changes available to a finite mind, also idealize them. Modifications of a physical genus are apprehended by the logic of the imagination, which are then expressed via conceptual distinctions captured by identity and contradiction. On the other hand, modifications of metaphysical genus are proper to substances understood as true unities, resting on principles that are innate, like the principle of indiscernibles. To conclude our enquiry, we shall address various issues concerning Leibniz's theory of innate ideas, which are taken to be constraints on thought. 
Franz Steiner Verlag 


\section{LEIBNIZ’S INNATISM}

Our enquiry into the logic of the imagination has revealed that sense-perceiving and conceiving are, for Leibniz, two distinct kinds of cognitive modes. While sense-perception and conceptual reasoning correspond to distinct logics, there is not, for that reason, discontinuity between them. For both consist in imagining wholes divided into parts, although the nature of parts and the rules governing their connection change radically from one logic to another. ${ }^{1}$ The logic of the imagination concerns extended parts, which are opaque to the principles of identity and contradiction. Conceptual logic concerns intensional "parts", which are expressed by terms responding to identity and contradiction. Syntax and semantics, rules that preside over languages, are used for composing definitions and discourse. Languages are not the only vehicles for conceptual reasoning: diagrams and images can also become vehicles for concepts, insofar as their parts can be arranged to express relations respecting identity and contradiction. Leibniz himself develops a linear calculus to express conceptual containment. ${ }^{2}$

The separation between the two logics is decisive for arguing that animals have a form of empiric knowledge, governed by the logic of the imagination, while denying that they can develop a robust form of conceptual reasoning, through which they might acquire knowledge of necessary truths. If our analysis is correct, and the two logics are indeed separate as we have shown, then Leibniz is well positioned to attribute to sensitive, non-rational agents a shadow of reasoning, without thereby being committed to attributing to them thought or conceptual reasoning. ${ }^{3}$ Although Leibniz follows Hobbes in attributing to non-human animals some mental capacity for connecting events, as explained in the introduction, he finds another way to distinguish between human and non-human cognitive agents: while the former possess innate ideas, which transforms the ways in which they sense-perceive and cognize

1 The fact that both types and concepts can be analyzed as mereological wholes, albeit being composed of different kinds of parts, is important to avoid violating the continuity principle, see Jorgensen (2009).

2 Cf. De la methode de l'universalité (1674; A VII 7 118/C 125), where Leibniz writes "mais commes ces chose ne sont gueres intelligibles sans figures et examples" and he proposes a calculus comprised of segments. A similar procedure can be found in Schèmes linéaires des syllogismes (C 248) and De forma logicae comprobatione per linearum ductus (1986, C 292).

3 See NE 51/A VI 6 51. The same thought is also present in PNG (GP VI 600), as well as in NE 175/A VI 6 175, where Leibniz describes a wild boar who notices a hunter and flees. This must prove that the wild boar has some knowledge of the hunter and has expectations regarding the consequences that may follow from the presence of the hunter, although he denies that the wild boar has an intellect and knowledge of necessary truths. 
the world, non-human cognizers lack those innate constraints, owing to which their expressive capacities remain circumscribed to the level of types. ${ }^{4}$

Non-rational animals must, however, possess some of the constraints we have highlighted. For instance, they must be capable of the following: the capacity for spatiotemporally-apprehending bodies; the ability to detect causal connections, or connections of similarity; and the capacity for forming types. Non-rational animals lack intellectual innate ideas, owing to which they also lack the capacity for developing their cognitive processes into rational-conceptual ones. On my understanding, the absence of intellectual ideas, such as identity, contradiction, and substance, explains why animals process sense-perceptual information differently to human beings. Consider this passage of NE, in which Leibniz says that animals are not capable of considering that which is common to many things apart from their actual presence in sense-perceived beings:

They [non-human animals L.O.] apparently recognize whiteness, and observe it in chalk as in snow; but this does not amount to abstraction, which requires attention to the general apart from the particular, and consequently involves knowledge of universal truths, which beasts do not possess. (NE 142/A VI 6 142)

A lack of ideas is the reason why non-human animals are incapable of considering common, general nature apart from its particular instances. Animals therefore lack the capacity to develop a conceptual apparatus, as enjoyed by human rational agents. We will elaborate on this shortly.

Just as types influence concepts, so too concepts influence types. Once mastered, concepts change the way that rational agents experience the world, namely by enhancing their capacity for societal interactions, predicting events, and planning for the future. The gradual blurring of boundaries between concepts and types causes the interpenetration of conceptual and perceptual processes, the result being that "when we come to the point that we perceive the connection among ideas, by that very act we already form a judgment", 5 that is, we express what we experience through states that either evaluate the coherence of what we experience, or we entertain propositions that affirm or deny something about something else, which are subject to truth and falsehood. The fork between the two species of cognizant agents therefore increases gradually and constantly.

Non-human animals not only lack logical notions: they further lack metaphysical notions. The notion of substance, as we saw in chapter III, is involved in constructing more stable expressions of the real world. In On Distinct Perception (our

4 A VI 6 274/NE 274: "Pour ce qui est des organes les singes les ont en apparence aussi propres que nous à former la parole, cependant il ne s'y trouve point le moindre acheminement. Ainsi il faut qu'il leur manque quelque chose d'invisible." What is "invisible", as Leibniz remarks in A VI 6 173/NE 173, is the intellect, and therefore the ideas of pure understanding: "Ainsi dans mon sens l'entendement répond à ce qui chez les Latins est appellé Intellectus, et l'exercice de cette faculté s'appelle Intellection, qui est une perception distincte jointe à la faculté de reflechir, qui n'est pas dans les bestes. Toute perception jointe à cette faculté est une pensée, que je n'accorde pas aux bestes, non plus que l'entendement." See also Pasini (1996: 152-162). Leibniz to Treuer, 21 May 1708, Lbr 939 B1. 2 in Oliveri (2019). 
focus in chapter II), Leibniz claims that judgments without negation or affirmation accompany our sensory experience of the world. By this, he means that, in the act of sense-experiencing the world, we form implicit expectations about percepts. These expectations consist in general attitudes to which the percept responds in the spatiotemporal order, viz. that it is produced by other events and consists in a (corporeal) substance or a unity of parts and attributes considered as belonging to one persisting thing. What we implicitly form is the notion of a corporeal substance rather than the metaphysical notion of a true unity. It is the imaginable counterpart of a metaphysical notion that guides us in constituting beings as stable and unified phenomena, which could not be formed implicitly if the cognizant agent did not already have some innate notion of substance (about which we shall elaborate soon). Intellectual notions are operative in experiencing the world, although they are transformed within the limits of the faculty, viz. the imagination when it expresses how the world affects the body.

If non-rational agents lack innate ideas, as Leibniz suggests, then the way in which they process sense-perceptual states differs from rational agents, who are capable of giving phenomena a more stable kind of unity than non-rational animals. The distinction between rational and non-rational animals exists from the outset. Moreover, sense-perceptual processes in rational and non-rational animals are implemented in two different ways, although they can be considered different species of the same genus, viz. sensitive souls. The difference in how they sense-perceive the world explains why human beings develop conceptual knowledge while animals do not.

This chapter will conclude with an analysis of Leibniz's theory of innate ideas, a discussion we began in chapter I. There, we explained the connection between innate ideas and expressions as outlined by Leibniz between Quid sit idea and MKTI. Here, however, we propose an analysis of NE, specifically how innate ideas guide the developmental story we have told thus far.

\section{INNATE IDEAS}

At least nominally, the doctrine of innate ideas was widely shared among early modern philosophers. The qualification here is intended to reflect that each philosopher developed her own version of the doctrine. Indeed, as explained in chapter I, Leibniz's account of innate ideas holds that they are not amenable to introspection qua intentional objects of the mind. Innate ideas are instead abilities of a cognizant agent to form expressions or cognitive surrogates, which refer either to concrete beings or abstract essences. These surrogates are intensional objects of cognitive processes. This means that expressions take the place of what early modern philosophers designate ideas, which, when deployed in reasoning, allow for the processing and extrapolation of information that would otherwise have remained offlimits to the rational agent (at least, absent the invention of expressions).

Our ongoing enquiry into the logic of the imagination has unpacked Leibniz's innatism insofar as, through it, we have established how cognizant agents acquire 
types, that is, abilities to form expressions of beings as bodily phenomena, and concepts, that is, abilities to express essences in the form of definitions. On this interpretation, both types and concepts are distinct kinds of acquired abilities insofar as they depend on experience and habit. At the same time, however, they cannot be merely acquired insofar as they are constructed through the cognitive activity of agents, activity that is spontaneously constrained by innate rules and principles that are ideal, that is, proper to immaterial substances like souls. The consequence is that types and concepts are both learned and innate.

Leibniz believes that this apparent contradiction is entailed by his theory of human cognition. He chides Locke's spokesman, "I cannot accept the proposition that whatever is learned is not innate" (NE 85/A VI 6 85). Nonetheless, he understands this contradiction to be an asset to his theory, not a sign of internal inconsistency. ${ }^{6}$ Accepting the contradiction breaches Locke's dichotomic view of the mind - from which it follows that, if a content is learned, then it cannot be innate. This dichotomy is used to dismiss the argument against innate ideas. Locke's argument rests on the mutual exclusion of what we can call "nature and nurture", a terminological pairing used as an abbreviation for the fact that there are abilities and contents we have by nature, and others that we acquire through experience, whether sense-perceptually, culturally, or socially. Abilities that are acquired (nurture) cannot be innate (nature). This exclusion is therefore ancillary to Locke's argument that the mind cannot possess innate contents.

On Locke's account, a cognizant agent can be said to possess an idea or mental content insofar as she is (or was in the past) aware of that very content. But innate ideas seem to be contents present in the mind without entailing the mind's intentional awareness thereof. On this definition, the meaning of "innate" is vague because any idea learned via experience (even sensory contents) could be said to have been innate latently in the mind (EHU 49). If there is no clear distinction between what is learned and what is innate, then there is no room for learning and experience as a source of mental contents. On the contrary, if an idea can be learned, then this proves that it is not innate. Strong of this conclusion, Locke's argument against innatism is a book-length proof, viz. Book 2, which demonstrates that the ideas commonly considered innate by philosophers, such as ideas regarding substance, power, freedom, quality, space, time, and self can be learned through experience. And so: if they can be learned, then they are not innate. However, as Leibniz claims, the matter is more complicated than this.

For starters, Leibniz's innate ideas are not - strictly speaking - contents. As we have argued, what counts as "innate" are those constraints on what the cognizant agent can or cannot perceive, imagine, or conceive. The mind can only achieve explicit knowledge of its limits by reflecting upon its own operations. Leibniz argues, then, that these constraints - latterly cognized in the form of principles and

6 Although I do not have the space to analyze it fully, I want to flag up that these words of Leibniz's echo the Aristotelian solution to the aporias of Plato's Meno. See Aristotle, APost. $71 \mathrm{a} 12-71 \mathrm{~b} 6$. 
rules - are spontaneously active whenever the cognizant agent forms expressions. When the agent has the capacity to reflect on the process of formation of expression-relations, those constraints become objects of reflection and are therefore considered to be requisites ${ }^{7}$ or principles for the formation of more specific expressions.

Space and time in general, for instance, can themselves be objects of reflection. This occurs when the cognizant agent is acquainted with particular expressions of bodies and then considers what those peculiar expressions have in common, as we argued in chapter VI. When cognizant agents reflect on the common nature of bodies, for instance, they recognize space and time as requisites for bodily expression, that is, as necessary conditions for the formation of expressions of beings as bodies. Before being explicitly grasped by minds, however, those constraints are operative in forming expressions that are the contents of certain cognitive states. Expressions bear the trace of cognizant agents' innate capacity insofar as they are the result of a synthesis between innate constraints and how a substance is harmoniously acted upon by external bodies. This synthesis of non-subjective instances and top-down constraints is possible because, as we have argued, minute perceptions and strivings, which constitute a cognizant agent's intrinsic activity, mirror changes in the external world through the law of harmony. Minute perceptions are spontaneously filtered and transformed through the cognitive filters of the agent (recall the imagery of Leibniz's "mental sieve" in chapter IV). This spontaneous filtering and transformation of data through the agent's cognitive activity is nothing but the $a c$ tion of a substance that is "clearer" than other substances, viz. a sensitive soul. Depending upon the kind of cognitive processes they can develop, substances may be called either sensitive non-rational or sensitive rational. The important point here is that, through its cognitive/conative activity, the substance always expresses and hence situates itself in the world by both expressing its body and its environment, and by anticipating and predicting states that are (im)possible within her world, either because they as-yet do (not) exist, or because they can(not) exist. Through this, the cognizant agent constructs a physical, moral, and historical point of view. None of her cognitive states is indifferent to any aspect of the world. ${ }^{8}$ Any state of hers is a response to how she is acted upon by other, cognizant agents who inhabit the world, although she may not be aware of them. Indeed, she may even misrepresent the world through errors and mistakes, as described in chapter VIII section $5 .{ }^{9}$

7 Leibniz defines "requisitum" (that is, something that is required for something else) in A VI 4 A 308: "a 'requisitum' is something prior to the nature of something, that, if it is not posited (posito), then this other thing cannot exist (requisitum est aliquid re natura prius, quo non posito ipsa existere non potest)." For a thoroughgoing analysis of the term, see Di Bella (2005).

8 A VI 6 240/NE 240: "Les ames selon mes hypotheses ne sont point indifferentes à l'egard de quelque portion de matiere que ce soit, comme il vous semble; au contraire elles expriment originairement celles à qui elles sont et doivent estre unies par ordre."

9 Phemister (2016) elaborates on the role of minute perceptions and their contribution to a cognizant agent's emotive states. 
The spontaneous activity of the cognizant agent results in a bootstrapping process through which expressions produced by the interaction of the imagination with a lower faculty are then reassessed by the imagination when interacting with a higher faculty, owing to which they are reinterpreted in accordance with principles proper to this higher faculty. "Bootstrapping" means to get oneself out of a situation using already available resources. ${ }^{10}$ This terminology captures well Leibniz's idea of the autonomy and self-sufficiency of a substance, since it shows the substance improving and ameliorating itself using its proper, internal resources, owing to which it does not "borrow" anything from the outside. At the same time, it respects what I take to be essential to Leibniz's theory of substance, viz. the interactions between all created substances. As an advancement based on lower cognitive processes, these latter mirroring the complete universe, it results that also higher cognitive states are ultimately grounded in minute perceptual changes. While each cognizant agent interprets sensory information from its own viewpoint, the actions and strivings of the substance are never isolated nor independent from other coexisting substances. The substance is not independent because it is able to develop itself independently of all other substances; it is independent insofar as it is not causally determined by other substances, although it freely and spontaneously expresses all other substances. I shall elaborate on these thoughts shortly.

An illustrative example of what I mean by "bootstrapping" consists in the reassessment of general names, which are established through social interactions and for pragmatic reasons by rational peers, when used as terms to refer to essences (see chap. VIII). As I have argued elsewhere, the establishment of a language (understood as a syntactic and regulated system of signs) requires the so-called pragmatic triangle, I-Thou-World. ${ }^{11}$ An individual cannot alone establish linguistic conventions, because the imposition of names expresses a complex relation to other peers within a context. Likewise, the expanding, semantic force of a language must proceed past accepted and established conventions. So, in using established words figuratively, such as in metaphorical speech, a speaker both acknowledges the convention and uses it to establish a new one. ${ }^{12}$ Words that are first designed to refer to concrete sensible beings are then reassessed and transformed into terms that serve a different purpose, namely to refer to different abstract objects (see chap. VIII

10 The term "bootstrapping" is currently used in psychology and linguistics to explain first language acquisition within connectionist theories. This is not how I use the term, since it is not my intention to associate Leibniz with any contemporary theory. Here, the term is used figuratively to describe a process by which a subject ascends in her degree of knowledge about a subject matter by using intrinsic, cognitive resources, which are expanded through that very process of epistemic discovery. This idea may bear certain similarities with contemporary theories, although it is not intended to. I also invoke this terminology in Oliveri (2016: III.1).

11 See Oliveri (2016: III.1-III.2.) and (2016b).

12 On the role of metaphor in Leibniz's philosophy, see Marras (2010). 
sect. 1). ${ }^{13}$ Through this process, minds acquire more abstract moral and metaphysical concepts.

It is precisely this shift in the use of language - which is aimed at expanding cognizant agents' expressive powers - that exemplifies this bootstrapping process, which relies on established knowledge as a means for broaching new epistemic horizons. It further reflects an ongoing dialectic between confusion and distinction, the sensible and the intelligible. Confused apprehensions of aspects of the world, which cognizant agents achieve through the interplay of the imagination with the senses, serves as a ladder for reaching more distinct knowledge about the world, which is achieved through the reflective interplay of the imagination and intellect. This dialectic is illustrated by Leibniz to Sophie Charlotte:

There are therefore three grades of notions: the sensible only, which are the objects assigned to each particular sense; the sensible and intelligible together, which belong to the common sense, and the intelligible only, which are characteristic of the understanding. The first and second are both imaginable, but the third are beyond the imagination. The second and third are intelligible and distinct, but the first are confused, although they are clear or recognizable. (Leibniz to Sophie Charlotte, June 1702, LSS, 2011: 240/A I 21 340).

The engine of this dialectic - I want to argue - are those intellectual ideas that Leibniz defines in NE as ideas of the pure understanding and which, in the letter to Sophie Charlotte, include "metaphysical" ideas, such as the notion of the self or substance. More specifically, on my view, innate ideas are nothing over and above the cognitive activity of a substance endowed with what Leibniz calls "pure understanding", which structures cognitive processes. Changes in the way that innate ideas structure cognitive processes are only reflected in the degrees of clarity and distinctness of cognitive acts, or in the force of evidence that enables the emergence of the principles themselves from the particular act engaging the cognizant agent's attention and memory. When the rational agent engages in reflection upon her own cognitive operations and their conditions of possibility - sc. she reflects on herself as a cognitive/conative substance - the rational agent gains a more distinct kind of knowledge since she hereby acquires knowledge of the principles governing her reasoning. To attain to this level of self-reflection, however, the agent must gradually ascend through the lower and more confused forms of cognition:

The truths that we start by being aware of are indeed particular ones, just as we start with the coarsest and most composite ideas. But that doesn't alter the fact that in the order of nature the simplest comes first, and that the reasons for particular truths rest wholly on the more general ones of which they are mere instances. And when one wants to think about what is in us implicitly, before all awareness, it is right to start with the simplest. For general principles enter

13 As I have argued elsewhere (Oliveri, 2014), it is significant that Leibniz analyzes syncategorematic terms, like prepositions, as signifying originally spatial relations which, only via metaphorical use, are rendered into signs for other kinds of relations. Importantly, the basic meaning of prepositions is spatial, since it reinforces the idea that words first signify sensible aspects of beings and later more abstract relations among them. The thesis propounded in that article is expanded and connected with conceptual development in Oliveri (2016: III.1 - III.2) and Oliveri (2016b). 
into our thoughts, serving as their inner core and as their mortar. Even if we give no thought to them, they are necessary for thought, as muscles and tendons are for walking. The mind relies on these principles constantly; but it does not find it so easy to sort them out and to command a distinct view of each of them separately, for that requires great attention to what it is doing, and the unreflective majority are hardly capable of that. (NE 84/A VI 6 84)

This passage, which echoes Aristotle's Posterior Analytics, ${ }^{14}$ claims that innate ideas are constraints that are actualized differently at each level. This is because "human beings naturally tend (conantur) to explain through things that are subject to the imagination also those that they cannot imagine." (A VI 4 A 890). The reason why rational, cognizant agents responded to this tendency, we argued, is that they need to adjust the world to their finite viewpoint. In this attempt, intellectual principles are transformed by the imagination into a format conforming to the lower faculties, like the senses. By using the product of a lower faculty as a placeholder for a successive reflective state, the agent can compare similar states from the point of view of the act, and thereby abstract and extrapolate those innate principles. In this way, innate principles are translated at a higher level of cognitive activity and the mind makes distinct what was only grasped confusedly at the lower level.

The passage further clarifies the apparently contradictory status of abilities as being both learned and innate. The contradiction is waived when one notices two kinds of dependency relations characterizing knowledge-acquisition. There is a difference between the historical and logical order of knowledge, thinks Leibniz. ${ }^{15}$ The historical order follows the temporal development of a single cognizant agent. On this order, which is vouched for even by empiricists, the mind begins its cognitive development by first apprehending those things that fall under the senses. Only through reflection on sensible states can the cognizant agent gradually apply herself to more abstract matters, such as mathematics or metaphysics. Our reconstruction follows this historical order. However, when reflections provide knowledge of the rules and principles that constitute lower states, cognizant agents surmise that there is also a logical order of knowledge according to which those principles must already be active, viz. before we become aware of them. Following the logical order of knowledge, then, the dependence relation is inverted, because more abstract and general principles are required to conceive of more concrete beings, and can be said to come first, even if on the temporal order of knowledge (on the ontogenetic perspective) they are the latter to be conceived of.

Take for instance the innate idea of substance. Cognizant agents already grasp the innate idea of substance confusedly when they sense-perceive what we have

14 Apost. 71b 35-72a 6: "There are two senses in which things are prior and more knowable. That which is prior in nature is not the same as that which is prior in relation to us, and that which is $<$ naturally $>$ more knowable is not the same as that which is more knowable to us. By 'prior' or 'more knowable' in relation to us I mean that which is nearer to our perception, and by 'prior' or 'more knowable' in the absolute sense I mean that which is further from it. The most universal concepts are furthest from our perception, and particulars are nearest to it; and these are opposite to one another."

15 See A VI 6 83/NE 83; A VI 6 412/NE 412. 
been calling perceptible wholes, such as a dog. However, at the level of sense-perception (including the imagination), the idea of substance is grasped in relation to the senses, that is to something corporeal, like our bodies. Since we are corporeal substances and are always attached to an organic body whose changes we perceive as belonging to something that persists through the changes, we project this status of substance to anything presenting itself in the imagination as being a whole having parts. With time, we will distinguish different kinds of substances and realize that an artefact, for instance, is just as if it were a substance. Likewise, when cognizant agents engage in the act of conceiving of concepts, they transform the innate idea of substance into a logical substratum bearer of conceptual marks. On both levels of cognitive activity, they do not understand the idea of substance as a true immaterial unity, principles of action and bearers of those properties such as they recognize when they engage in metaphysical reasoning. When the innate idea of substance is perceptually active through the work of the imagination, the notion of substance simply is their capacity for sense-perceiving the dog as a corporeal substance, or as a unity in spite of its having parts that can undergo alteration. More importantly, the way in which the imagination transforms the innate idea of substance when operating with a lower faculty, such as the senses, does not disappear once they increase their reflective power and are able to shift attention away from the sensory notion of substance to a notion of substance conforming with metaphysical principles. In the act of sense-perceiving, they still see the dog as a body because the imagination is still adapting the intellectual idea of substance to a sensible medium, in the same way as the metaphysical notion of substance is adapted to a logical category in conceptual reasoning. Only further reflections in light of metaphysical principles can lead cognizant agents to make intensional distinctions within the notion of a substance, conceiving of it as something that cannot have parts, be extended, and so on. In this way, they ameliorate their knowledge of substance through metaphysical enquiry, which rests on principles grasped as objects of the intellect alone. ${ }^{16}$ The result is that metaphysical principles cannot be understood fully while the agent is immersed in a logic that renders them opaque, namely the logic of imagination as it is governed by space and time. To grasp metaphysical principles, the mind must develop a certain capacity to abstract from the senses. In spite of the variety of experiences that each cognizant agent is subject to as historical individuals, there is a sort of ontogenetic development characterizing rational cognizant agents, which is guided by what Leibniz calls "innate ideas".

This understanding of innate ideas provides a way of resisting a move towards what can be called extreme innatism, while still making sense of a distinction between a restricted set of conditions necessary to the mind for implementing its cognitive processes (viz. what we have been calling "constraints"), and an acquired set of abilities that fine-grain and enhance the cognizant agent's capacity to construct specific responses to different states of the world. This acquired set of abilities comprises both concepts and types, which are both learned and innate: they are learned 
insofar as, without experience, the mind could not form the expressions that are necessary for acquiring knowledge; they are innate because they are interiorized through the activity proper to the mind.

Consider the case of knowledge about essences. Essences are expressed via concepts as clusters of conceptual marks, which either can or cannot be associated owing to identity or contradiction. Identity and contradiction are innate to the mind, and do not derive from experience. Concepts are hence grounded in the mind, not on experience, although they could not be conceived without experiential contribution. The same can be said for types, which rest on space and time, viz. rules that the mind deploys for sense-perceiving phenomena. While types depend upon sensory experience, they are innate insofar as space and time, which are requisites for their formation, are innate. Finally, the agent's set of innate dispositions is both acquired and innate, insofar as experience and reflection are necessary for forming explicit knowledge of those constraints. Although they are only known once a certain level of sensible knowledge has been acquired, once we acknowledge them we further need to recognize that they must have been active from the outset, since they explain how we are capable of certain cognitive states.

\section{A MODERATE INNATISM}

According to what we have said, we can define Leibniz as a moderate innatist. This means that he is committed to both the necessity of some innate constraints for the acquisition of new abilities, which only count as innate insofar as they depend on the set of innate constraints. To use one of Leibniz's own metaphors, the cognizant agent can only avail herself of cognitive responses that are there potentially, just as Hercules exists potentially in the marble block (NE 52/A VI 6 52).

On other scholarly interpretations, it is not so easy to draw a distinction between what is learned and innate. Owing to this, Leibniz is often interpreted against the backdrop of extreme innatism. What it would mean for Leibniz to be an extreme innatist is that every possible mental content of a cognizant agent must already be inscribed in her mind in the form of a disposition to actualize a certain content. This disposition is then activated by minute perceptions functioning as triggers of that disposition. On this level, interpreters disagree on what dispositions are, and they divide into two camps. First, there are those who claim that dispositions (and hence innate ideas) are simply identical to the minute perceptions of a substance differing only in degrees of clarity (Jolley, 1988). Then, there are those who understand dispositions to be the ideas that are necessary for forming concepts. Concepts are meaningful components of propositions and are hence individuated by categorematic expressions of a language, i.e., names. ${ }^{17}$ For any name that can be used in a

17 Categorematic signs are significant parts of a language, like names or verbs. Syncategorematic signs are those parts of a language that change the signification of the words they are associated with, and so only assume a meaning in connection with other significant words. Examples of 
sentence, there is an idea in the mind that strives to be actualized whenever it is triggered by the perceptual activity of the substance. ${ }^{18}$ More than one idea can be triggered by the same perceptual state, which brings about competitive strivings between ideas for their respective actualization. ${ }^{19}$ The idea that is strongest, or that which corresponds to a greater degree with reality, prevails. ${ }^{20}$ On this reading ideas can be complex and being actualized in sentences; they are furthermore dispositions to form expressions that are conceptual insofar as they express propositions or thoughts into languages (or other vehicles representing thoughts). ${ }^{21}$ Although my proposal is sympathetic to this latter camp of interpreters, and especially with Bolton's account, there are differences between our proposals, which I shall soon explicate. The main difference, however, is that, on the dispositional reading, all ideas are innate and these are infinite in number, while on my account there are innate ideas, on the one hand, and acquired abilities, i.e., concepts and types, on the other. Ideas, concepts, and types are respectively all learned and innate, albeit on different

syncategorematic signs are prepositions like "in", "for", and "on". Syncategorematic signs were of philosophical interest in Leibniz's time especially in the context of mental language theories, since it was unclear whether syncategorems had corresponding mental signs, or whether they were "mere" signs, that is, signs that refer to other signs. Although most Leibnizian scholars who discuss the dispositionalism of innate ideas are not explicit about this point, I think we can fairly assume that, for them, only categorems have mental counterparts, i.e., ideas.

18 Ishiguro (1972: 23-7) does not distinguish between ideas and concepts. She uses the terms "concepts" and "ideas" interchangeably and opposes them to the words of a language. On her view, concepts are dispositions individuated by the words of a language when they are used for constructing definitions. She argues that Leibniz endorses a kind of Platonic position, according to which concepts are not learned. What we learn is the mastery of a concept by expressing it into definitions. Dispositionalism about concepts is also endorsed by Mates (1976: 49). Meanwhile, Mugnai (1976 and 1982) presents a view similar to the one I seek to defend. Bolton (2011a and 2011b) cleaves terminologically closer to Leibniz's text and distinguishes between ideas and concepts. On her view, ideas are dispositions to form concepts, while concepts are themselves the mental counterparts of the words in a language. Thus, Bolton takes concepts to be individuated by words, whereby many words can refer to the same concept, which is merely actualized differently depending upon the kind of "competition" that exists between dispositions, bringing about a combination of dispositions. Bolton's account is richer in detail and has more explanatory force than Ishiguro's. Still, they agree upon two main points: (i) there are innate dispositions that account for our conceptual mental life; and (ii) there are as many dispositions as there are concepts. Barth (2020) moreover argues that ideas are dispositions to form expressions, as already argued by Bolton (2011), Leduc (2011: 582-590; 2014: 53-68), Picone (2003: 102-32; 2005: 179-99), and Oliveri (2016: 2.1-2.3. and 2016a). My view differs from the foregoing positions insofar I have already argued that innate ideas are constraints and that there is not an idea for every concept the mind can form.

19 Bolton (2011a) insists on this aspect, since Leibniz often uses the metaphor of a conflict between strivings, as in NE 39/A VI 639.

20 As Leibniz says in De Affectibus (A VI 4 B 1411, 1679): "Perfectiores sunt cogitationes quae plus realitatis involvunt."

21 Although dispositionalist views focus on languages, a charitable interpretation of their claims does not exclude the acceptance of other vehicles as expressions of conceptual reasoning. 
grounds. They are moreover individuated by the function they carry out in cognition. I will now provide a cursory reconstruction of the arguments for extreme innatism.

Arguments for extreme innatism outstrip Leibniz's simple theory of cognition, as grounded in his notion of substance. As soon as we recognize that Leibniz's substances are "windowless", that is, incapable of interacting causally with bodily phenomena, we are forced to acknowledge his commitment to extreme innatism. Substances are complete insofar as they draw what they need for their metaphysical subsistence (whether perceptions, appetites, or thoughts) from their own depths. This thesis is normally expressed through an image of the windowless monad: the monad does not have any windows, which means that it neither communicates with other substances nor with the environment. ${ }^{22}$ It henceforth follows that there is no direct communication between body and soul.

The absence of direct causation between body and mind - together with the metaphysical completeness of the monad - make a strong case for innatism. ${ }^{23}$ On Leibniz's view, cognitive changes, like thoughts, result from perceptual changes. However, if these changes have their source not in an external affection of objects on the senses (since they are produced by the mind itself), then those states must somehow already be inscribed in the mind. On this view, even the content of what you are reading right now was already in your mind: it is not caused by the words I write. Regardless of whether we understand the future mental state as only virtually there, the lack of efficient causation between the experienced environment and mental states renders those states and their contents independent of experience. They are therefore innate. ${ }^{24}$

22 Monadology § 7 (GP 6 607): "Les Monades n'ont point de fenêtres, par lesquelles quelque chose y puisse entrer ou sortir."

23 Look (2017) endorses the metaphysical argument regarding the lack of direct communication between body and soul. He further argues that another reason why Leibniz must endorse innatism of an extreme kind is that the notion of the mind as a blank slate (proper to the empiricists) violates the principle of the identity of indiscernibles. I think Look is right about this, but his solution (in arguing that each mind is furnished completely differently to others), is not the right alternative. Leibniz thinks that innate ideas and dispositions present differently in each mind because each mind possesses them with more or less power or perfection, that is, with regard to bringing about more effective cognitive states: "sunt enim quaedam in mente dispositiones primitivae quae non sunt ab externo. Itaque dicendum est Mentes ipsas per se, ex natura sua primitiva dissimiles esse inter se, contra quam vulgo putatur. Cujus rei etiam aliunde certa argumenta habeo in promptu. Ut una mens alia perfectior sit fortiorque ad resistendum externis. Radix libertatis est in dispositionibus primitivis" (Mentes ipsae per se dissimiles sunt inter se, 1689-90 A VI 4 B 1639).

24 Cowie $(1999,50)$ : "Leibniz is sometimes willing to criticize his opponents from within their own empiricist perspective, advancing on the basis of poverty of the stimulus arguments an innatism that is limited to our acquisition of certain sorts of ideas or beliefs. But in fact his own metaphysics, and in particular his view that individual substances have 'no windows', is deeply hostile to empiricism. So, where he considers them from within a properly 'Leibnizian' perspective, Leibniz argues that empiricist acquisition theories are fundamentally inadequate. $\mathrm{He}$ concludes, on these grounds, that everything in our minds is innate." The reason is this: "Since 
Moreover, this argument normally runs alongside a further thesis endorsed by Leibniz: solipsism. If a substance can summon any cognitive state from its depths, then the external world may not exist, owing to which the mind is only representing the world as if it existed (NS $\S 14$ ). On this view, I merely represent myself sitting in this office, typing up this book chapter, hearing people walking around the department as they wait for a talk, even if none of those persons and things actually exist. If this is right, then could there be a stronger endorsement of extreme innatism? The master-argument for extreme innatism is hence the absence of interactions between body and soul. But if we can refute it, then we can also reject extreme innatism.

As we have repeatedly shown throughout our enquiry, the absence of direct body-soul interactions is not an absence of a transfer of information between body and soul, insofar as body-body interactions are mirrored on the level of the soul through the activity of minute perceptions. Minute perceptions, moreover, are not simply triggers for actualizing thoughts. The layered structure of the cognitive agent's mind guarantees that there is also an elaboration in the transfer of information from one level to another. This elaboration means that each substance develops from its peculiar point of view through its own strivings. This activity may properly be called "experience", since it does not occur without the input of the senses, and is simply the expressive nature of the substance. ${ }^{25}$ If this answer excludes the idea that learning is impossible, owing to which everything is innate, it nonetheless leaves room for extreme innatism, understood as the disposition to form concepts.

The dispositional theory of ideas interprets Leibniz's extreme innatism as more palatable and is overall more faithful to Leibniz's texts. Leibniz often refers to innate ideas as dispositions, powers, and faculties. ${ }^{26}$ On this reading, it is not the content that is innate, but rather a readiness to form a concept corresponding to the

Leibniz does not accept that anything (except God) can act upon a substance since he holds that the soul has no windows he cannot accept that experience can provide the soul with ideas or beliefs" (ibid.). McRae (1995: 176), for instance, considers Leibniz's opposition to empiricism as sufficient proof of his commitment to extreme innatism.

25 Jorati (2019) has recently argued that the senses provide the opportunity for thinking about a content because they give the content of a thought. In this respect, Jorati argues that there is a correspondence between senses and the content of thoughts, and this correspondence consists in the mind's embodied cognition. I am sympathetic to Jorati's account, as is reflected in Oliveri (2016; 2016a; and 2018). There, I argue that the mind is embodied because the senses provide the occasion for envisaging a certain content. Our accounts differ, however, on one decisive aspect. On my view, the senses alone do not give any content: they provide information that limits what the mind can or cannot perceive when that information is expressed via the imagination. If the senses give content to thought, then it is not clear what the activity of the mind is. On my account, the mind constructs its own content simply because it is an expressive force. The senses are limits on what minds can and cannot perceive. Furthermore, on my view, experience coincides with the elaboration on what the senses provide. However, on Jorati's view, mental inputs remain undetermined, since it is not clear what kind of "content" the senses provide.

26 References to ideas as dispositions cannot only be found in NE but earlier in, e.g., Quid sit idea. See A VI 4 B 1370. 
ideas. More precisely, what is innate is a disposition to form concepts like DOG, CHAIR, TREE, and HYPERBOLA when perceptions present instantiations of those concepts because the sense organs of a cognizant agent are correspondingly affected by bodies categorized as such. Being aware of a concept means forming a mental content that may have a linguistic form, such as a sentence. On this view, however, what is learned and what is innate are still diametrically opposed. For, even if it is true that concepts must be learned somehow, learning would not be possible were concepts not already innate qua dispositions (Ishiguro, 1972). Therefore, ideas are the innate counterpart to acquired concepts.

It is worth stressing that the difference between ideas as dispositions and my account of innate ideas (understood as constraints) is principally a question of the number of innate ideas. One issue that may therefore be raised is at the level of those ideas' individuation. Supporters of the dispositional view individuate ideas on account of their being manifested in linguistic expressions. The view is that, for any significant name within a language, there is a concept and therefore a corresponding innate idea in the mind. On my reading, there is a subtle problem with this view. Considering the gulf we detected between general names and essences (chapter VIII), it is not the case that an essence always corresponds to the formation of linguistic expressions. In other words, the correlation between names and essences is not as transparent as dispositionalists seem to assume, which Leibniz himself notes in MKTI, arguing that complex names are non-transparent expressions because they can refer to impossible concepts to which no idea can correspond. So if dispositionalists are able to partially address questions about synonymity by arguing that different names can refer to the same essence, owing to which they can be expressions of the same thought, then it is more difficult to address the problem of conceivability errors, or those mental states by which the subject forms a name and believes it refers to a possible concept, while the name stays for an impossibility, like square circle. What sort of disposition is a disposition to err? I will return to this topic at the end of the chapter. For now, my solution to the issue is that there is a small set of constraints (or innate ideas) that are sufficient and necessary for acquiring further abilities, like types and concepts. These are abilities to form different kinds of expressions either imagistically (as when we engage in imagine that cases), linguistically, or through other signs, such as when we conceive of essences. Moreover, on my account, this small set of constraints is individuated not only through their expressions, as both language and image can become vehicles of concepts: innate constraints can be recognized only through reflective processes of reducing one truth to a more general principle on which that truth depends. This is possible because general principles are operative in more particular cognitive acts. This allows for the distinction between innate ideas, concepts and types. Ideas, concepts, and types can be said to be both learned and innate, although on different grounds, as we have explained. Concepts and types are innate because they depend upon innate constraints, which are themselves learned insofar as, without the expression of sense-perceptual processes, the mind could not produce more detailed and habitual responses (viz. types and concepts) and then reflect on its activity. It is through 
this that the mind acquires knowledge of the general rules and principles to which it is subject in reasoning.

One limitation of my view - a dispositionalist might argue - is that there is no clear textual evidence for rejecting the dispositional view. Indeed, Leibniz often remarks that we have infinite innate ideas. See, for instance, this passage of NE 52/A VI 6 52:

But reflection is nothing but attention to what is within us, and the senses do not give us what we carry with us already. In view of this, can it be denied that there is a great deal that is innate in our minds, since we are innate to ourselves, so to speak, and since we include Being, Unity, Substance, Duration, Change, Action, Perception, Pleasure, and hosts of other objects of our intellectual ideas? And since these objects are immediately related to our understanding and always present to it (although our distractions and needs prevent our being always aware of them), is it any wonder that we say that these ideas, along with what depends on them, are innate in us?

The passage reads as though Leibniz is claiming that every thought is, to some extent, innate. It can, however, be interpreted as supporting my view, at least if we insist on the fact that Leibniz calls those ideas intellectual, owing to which they themselves are innate and that anything depending on them is innate as well. From this perspective, the passage claims that there is no clear distinction between what is learned and innate. Indeed, what is learned is, in some sense, innate. Thus, while concepts and types can be considered acquired when we insist on the activity of the mind necessary for their formation, they can also be considered innate when we insist on the innate constraints they depend upon for their construction. Since the text leaves these claims rather undetermined, however, in what follows I shall discuss two analogies offered by Leibniz that seem to go in the direction of claiming a "starting set" of dispositions, which accounts for the acquisition of dispositions that are more fine-grained. Furthermore, I would like to propose two central desiderata that Leibniz's theory of innate ideas should meet, and which the theory of ideas understood as dispositions seems incapable of satisfying.

\section{THE MIND AS A DARK ROOM}

The first analogy is the well-known example of the mind as a dark room, which, on Locke's account, has only two entry-points: the senses and reflection. Leibniz modifies Locke's example thus:

To increase the resemblance [between the mind and the room, L.O.] we should have to postulate that there is a screen in this dark room to receive the species, and that it is not uniform but is diversified by folds representing items of innate knowledge; and, what is more, that this screen or membrane, being under tension, has a kind of elasticity or active force, and indeed that it acts (or reacts) in ways which are adapted both to past folds and to new ones coming from impressions of the species. This action would consist in certain vibrations or oscillations, like those we see when a cord under tension is plucked and gives off of a musical sound. For not only do we receive images and traces in the brain, but we form new ones from them when we bring 'complex ideas' to mind; and so the screen which represents our brain must be active and elastic. This analogy would explain reasonably well what goes on in the brain. As for the soul, 
which is a simple substance or monad: without being extended it represents these various extended masses and has perceptions of them. (NE 144-5/A VI 6 144-5)

Although at the end of the passage Leibniz points to the limits of the analogy, which depicts the mind as material, we can nevertheless draw a parallel here between the brain and the mind. The first thing to strike the reader here is the activity and alleged plasticity of the mind/brain, as described by Leibniz. While he does not deny that the senses and reflection constitute the two sources of ideas, what he positively points to is the "elasticity" of the brain/mind, which is constantly reacting and reassessing its structure through the accommodation of innate structures in order to acquire new affections. This results in an ongoing change in what can be considered as the innate structure of the brain/mind, which gradually becomes more finegrained (viz. as the brain acquires new folds corresponding to new abilities of the mind). As a metaphor for the mind, the passage suggests that it also has a kind of elasticity insofar as it adjusts and rearranges new pieces of information, as furnished by the senses through the activity of its innate "folds", which we have been calling constraints. The ongoing alterations affecting the body are reflected at the level of the mind through the filtering of innate constraints, and are thereby systematized and organized into types and concepts, which are nothing other than abilities to store and recall information regarding how the identified being is going to change. When new abilities are acquired, those abilities are active in future sense-perceptual states and "furnish" the mind with more nuanced responses to its environment. Types and concepts are therefore habits or facilities for conceiving of present states, owing to which we can connect them to other states that the mind either recalls or anticipates. Thus, types and concepts constitute the spontaneity and freedom of rational souls. The more we learn about the actual world, the more we are capable of predicting the future and determining ourselves to act accordingly.

The innate constraints of the mind explain how minds connect and relate events. While types provide connections, which are based on experiencing contiguous phenomena, concepts provide connections that have a more stable ground, since they can be demonstrated logically. If human animals relate events in a similar way to non-human animals in three-quarters of their life, then innate constraints enable human animals to develop other forms of connections that, very gradually, render them increasingly distinct from non-rational agents. ${ }^{27}$ The takeaway claim of the passage is therefore that general faculties, such as senses and reflection, are not

27 Leibniz's explicit reference to the brain seeks to take a stance within the scientific debate of his time. There were philosophers arguing that every thought left a trace in the brain and, theoretically, every thought could be traced back to this organ. Leibniz rejects the idea of a direct connection between the brain's modification as a material cause for a specific thought, but not the idea per se that bodily changes correspond with cognitive changes. He therefore tries to integrate the scientific findings of his time into his system. The human brain, like the rational soul, must be a more active organ; one that is capable of responding diversely to the various impressions of the senses. This diversity of the human brain is reflected at the level of the soul. Cf. Favaretti Camposampiero (2010: 115-145). 
sufficient for explaining the complexity of cognition. While Locke is not completely wrong-headed in saying that minds first and foremost respond to perceptual stimuli, he is assuredly mistaken insofar as he thinks that a subject can develop complex responses to the environment without appealing to more fine-grained cognitive constraints.

\section{THE MIND AS AN ARCHITECT}

The second analogy is that of the mind as an architect, which Leibniz invokes in his exchange with Toland. In 1702, Leibniz writes a letter to Sophie Charlotte ("On what is beyond the senses and matter"), which answers a criticism raised by Toland, namely that Leibniz's theory of substance implies the possibility of a disembodied epistemic subject. Leibniz rejects the criticism thus: "I believe that everything which happens in the soul is always expressed by what happens in the body, and vice versa, and that the soul is never without organs or without some sensation through the organs", ${ }^{28}$ a conception of the soul that we examined in chapter IV. Toland considers this answer unsatisfactory and presses Leibniz to give an account of what the senses contribute to knowledge if the mind and body do not communicate directly. Leibniz answers that the senses are necessary for filtering information such that the mind can awaken from its state of stupor, as unpacked in chapter IV. He then adds:

We have in ourselves before experience and independently of experience this internal light, from which there results intellectual ideas and truths, but if experience does not provide us with the occasion to exercise this light and to make reflection on these ideas and truths, we will be forever stupid. But it by no means follows, as the letter's author says, that there are grounds to conclude from these common progressions of the soul and the body that it is through the body and through corporeal things that the soul is what it is and does everything it does. (Leibniz to Sophie Charlotte (for Toland), November 1702, LSS 263-4/A I 21 672)

In What is beyond the external senses and matter, Leibniz expresses this thought more concisely:

However I agree that the external senses are necessary for us to think, and that, if we hadn't had any, we wouldn't think. But what is necessary for something does not thereby constitute its essence. To us, air is necessary for life, but our life is something other than air. (Leibniz to Sophie Charlotte june 1702, LSS 224/A I 21 334)

There are two possible interpretations of these passages: one weak, the other strong. On the weaker interpretation, sense-perceptual processes are simply a necessary counterpart to the mind's activity of thinking: the computer must mechanically affect my sense-organs in order for me to have a representation (for instance, a thought) that there is a computer and I am typing on it. Nevertheless, these senseperceptions are merely triggers of thoughts whose causes are already in the mind, and are generated by its own laws. This reading fits with Leibniz's conception of 
harmony, although I think he intends to say something different. For his words to Toland echo what he said to Locke, namely that "nothing is in the mind which was not previously in the senses, except the intellect itself" (NE 111/A VI 6 111). Indeed, he goes on to repeat this claim in an unsent draft to Sophie Charlotte (Leibniz to Sophie Charlotte August/November 1702 LSS 261). Just as he wrote to Sophie Charlotte in What is Beyond Senses and Matter, ideas can be categorized as either sensible, imaginable, or intellective: the latter need experience in order to be objects of thought, even if their origins are in the intellect itself. We need sense-experience to draw attention to our internal acts and mental processes, through which we focus on the rules governing them. If the senses are necessary in order to think about those ideas, then they are not essential. This means that these ideas are of a different kind to sensible notions, just as air is essential to our survival but is something apart from our lives and in no way constitutes it.

There is, therefore, a stronger way to interpret the claim that sense-organs afford only occasions for conceiving of more abstract subject-matter. Changes occur in the perceptual activity of the embodied mind because the organs function like filters for external affections: there are objects that interact differently with the various organs of my body, and this difference is expressed at the level of the rational sensitive soul through a gradual transformation of sense-perception, viz. from what we have been calling a perceptible whole to something that functions like an explanation of that experience to the mind (consisting in a type or concept). Since Leibniz describes the mind as having a dynamical structure, it is not merely passively receptive to sense-perceptions, which become heightened and more distinct; the mind actively forms and processes information bottom-up through top-down constraints, and so transforms and simplifies information (sc. it expresses it) into a format suitable to memory and attention. In being presented with something simpler than the raw material of minute perceptions, memory and attention actively contribute to constructing habits by storing information (memory) and recalling it when they are adequately triggered to do so. The more specific responses we build, the more promptly our memories and attentions are activated, thanks to which it becomes easier to respond to future states of the world. Thus, acquired abilities themselves become filters that extend the top-down constraints of minds and enhance the proficiency of substances' responses to their environments. To reprise an example from action-theory, once heavy clouds can be recognized as a sign of rain, then perceiving heavy clouds activates my type for rain, which inclines me to take an umbrella before leaving the house.

As we argued in chapter VI, spatiotemporal associations based on types - what Leibniz calls empirical action - are not the only way that rational animals can act. Rational animals are capable of finding more stable ways of analyzing and processing data. For instance, they can do mathematics and develop algorithms capable of predicting rainy days weeks in advance, when there are no signs of clouds. Agents do this by finding ways of transforming data in a way that is suitable to reasoning procedures, which are not directly related to a subject matter, but which, when appropriately translated into a formal procedure construed by logical neces- 
sity (identity and contradiction), guarantee a higher degree of certainty in the deduction and extrapolation of new information. In short, reasoning procedures that are based on identity and contradiction enhance our capacity for predicting the future. Mathematics and other forms of logical reasoning can thereby greatly enhance our capacity for interpreting signs and making estimations about the future. Concepts - and the connections they establish through identity and contradiction, rendered by means of definitions - fall under the umbrella of logical reasoning, since they allow agents (through a kind of fiction) to consider particular instances as identical to clusters of intensions, through which they can extrapolate information via conceptual analysis. Note that, if analysis is important, then conceptual construction requires an a posteriori process that informs minds about the possibilities (sc. essences) inherent in resemblances between existing beings. Even if concepts are not abstracted from instances, as we have argued, cognitive agents nonetheless need to be informed about what might or could be.

The strong interpretation therefore places an emphasis on the active, dynamical, and productive character of the mind, which invents tools for connecting truths to events. Even if "the most abstract thoughts are represented by some traces in the body by means of characters", and therefore always require sense-perception, as Leibniz explains to Toland (LSS 269), the mind is capable of initiating a "chain of thoughts" to inferentially move from one to another. This productivity relies on innate constraints of the utmost generality as well as on more specific, acquired abilities of the mind. It is through its activity, then, that the mind can become attentive not only to the content of a specific cognitive/conative state, but to the rules governing it. Indeed, it is through this attentiveness that the mind acquires explicit knowledge of rules that are in the mind, not as contents but as its own constraints and limitations. By reflecting on its own acts, the performance of which depends upon perceptual activity, the mind can contemplate itself in its operations with, and formation of, concepts. When the mind itself becomes an object of reflection, it explicitly distinguishes and acquire notions of its own innate capacities:

\footnotetext{
Indeed he [Toland L.O.] also agrees with me that there are materials in the soul which the external senses do not provide. For he makes use of the comparison with an architect. For him, the objects of the senses are like the materials of a house, and the faculty which understands sensations and uses them in its reasonings is like an architect with its rules. And one (according to him) should be distinguished from the other. Very well, and that is all I ask for. But it should be considered that, in the soul, this architect with its rules should itself be counted among the materials, that is, among the objects of thought, since we think about ourselves, and about our faculties, rules, thoughts, and reasonings. And these rules are this internal light which establishes consequences and all the necessary truths I have spoken about in my letter. (Leibniz to Sophie Charlotte and John Toland, December 1702, LSS 276/A I 21 724)
}

This response, and indeed the entire letter to Toland, echoes the words of NE, in which Leibniz insists that we must carefully distinguish the question regarding the temporal order of knowledge-acquisition from the question regarding what makes it possible that human minds are able to develop general, abstract knowledge. If, on the historical order, it is true that rational cognizant agents first acquire knowledge that pertains to the sensible domain and only later, via reflection, are they able to 
form explicit knowledge of intellectual ideas (including self-knowledge, knowledge of mathematical unity, or the principle of contradiction), then temporal order is no proof that our knowledge depends upon the senses. If sensible notions are explicitly thought before intellectual ideas, then sensible notions are not essential to intellectual ideas. On the contrary, as soon as we form explicit knowledge of innate constraints, we are compelled to acknowledge that all knowledge - even that which is sensible - rests on those innate ideas.

This architectural metaphor of the intellect and its innate constraints constitutes the most persuasive textual evidence that I know of for arguing that, although all the abilities of cognizant agents are, in a sense, innate, still there is a set of constraints that are prior and hence necessary for the development of more specific abilities. Should this account still be inadequate for convincing the reader, I conclude by discussing two desiderata that Leibniz's theory must meet, and which should incline any remaining skeptics towards my view.

\section{TWO DESIDERATA FOR LEIBNIZ’S THEORY OF INNATE IDEAS}

The first desideratum is what Leibniz calls "economy" or "the simplicity principle". This corresponds to the idea that, in creating the world, God chose the one that comprised the least number of assumptions and the greatest variety of phenomena. Why should He have violated this principle in creating spirits or minds, viz. those substances that are capable of more sophisticated cognitive states? The assumption that there is a small set of innate constraints accounting for a huge variety of cognitive states and processes, which the substance can deploy in using its own resources (i.e., the bootstrapping process, as we defined it), reflects this principle, while dispositionalist views seem to violate it.

The second desideratum is related to the question of error. If God provides minds with ideas that dispose them to form concepts when experience triggers the activation of certain dispositions to strive, then God must also have given minds impossible concepts. While this may be unproblematic with regard to concepts that express logically possible essences (viz. those that are not instantiated in the actual world, but that are possible), then what about those concepts that are contradictory and therefore logically impossible and that minds can mistakenly believe to be possible? Would God not be a deceiver if He created a substance with a disposition to err? On my view, while the mind has no such disposition to false concepts, it can still determine itself in such a way that results in error. Indeed, this is a consequence of its constitutive expressive power, which operates from a necessarily circumscribed viewpoint.

Moreover, I think there is a difference in saying that God created the substance with a disposition to form false thoughts, and saying that God created a substance that $c a n$ additionally determine itself to errors and mistakes. On the latter reading, God foresees those errors and mistakes, but he does not concur with them insofar as they result entirely from the free, spontaneous acts of the finite, expressive nature 
of a substance..$^{29}$ On the dispositional reading, this solution is unavailable because, on that account, God must have implanted in the substance a disposition to err.

To conclude, both analogies reinforce the thesis that: (a) innate ideas enter into, and constitute, every single thought, just as muscles and tendons do for movements; (b) explicit knowledge of general principles requires a greater degree of attention and reflective power; therefore (iii) an explicit knowledge of those principles, if it is ever acquired by an epistemic subject, is acquired later on in her ontogenetic life, viz. through exercise of the reflective faculties.

Now, if we return to Leibniz's other analogy, viz. of innate ideas as muscles and tendons, then we can draw a further analogy. Take an infant. Her hands are as well-formed as those of an adult, but she is not yet capable of using them as adults do. As with the adult, movement is supported by muscles and tendons, which delimits the movements that are physically possible (and which are not) for the infant's hands. In using her hands, the infant figures out which movements are physically possible, and, with time and practice, she learns to improve her use of them. In this case, do we need to say that the infant must be conscious of all her muscles and tendons in order to raise a hand or to improve upon her movements? Surely not. Indeed, knowledge of manual anatomical structures is frankly off-limits to the majority of cognizant agents. For while I know my hands comprise muscles, nerves, and tendons, I cannot name them, tell you how many there are, nor can I explain how they function. This is the kind of knowledge that a hand surgeon must have in order to execute her art, but it is not required to simply use the hand. If ideas are innate in this sense, then, as a kind of constraint that determines what the mind can and cannot think, Locke's criticism is thereby surmounted.

Consider another aspect. Suppose the infant will become a great pianist. Could we say that mastery in piano playing is "inborn" in the infant's hands? Articulated thus, the question does not make sense, although it does (in a certain respect) capture why Leibniz thinks that the question about whether a piece of knowledge is learned or innate is wrong-headed. In a certain sense, one should acknowledge that the particular configuration of the infant's hand grounds the possibility of movements that she can learn to perform. However, should the infant learn to perform those movements, then it is only on account of practice. The skill of playing the piano is potentially inborn in the hand of the child and must be acquired through exercise. Leibniz himself uses the image of a piano player to describe the habitual connections cognitive agents form between language and thought: "Most of our reasonings, mainly those involved in major issues, are performed by playing with characters, as we play the piano partly by habit, without the mind [soul] being quite conscious of it, and reflectively forming its reasons." 30

Leibniz appears to argue that the same happens with the mind and its own structure. When an infant begins to articulate her thoughts, she is probably not able to

29 On the topic of limitations, see Antognazza (2014: 176-86).

30 LH, IV, VII B 3 Bl. 16r, Niedersächsischen Landesbibliothek, Hannover (ed., transl. in Dascal 1987: VI-VII). 
perform abstract reasoning. She focuses first on what the senses present to her. But in thinking of a ball, food, and toys, there are at least some innate principles involved. While she may not know the principle of contradiction, for example, she will still need to use it if she is to learn to talk with consistency. ${ }^{31}$ If she has the occasion to do so, then the child will later acquire knowledge of logic. Contrary to Locke's suggestion, then, innate ideas are not innate contents. Therefore, Locke's criticism, viz. that, in order to be in the mind a content must have been consciously entertained by the mind, is unsound. There are models that show we can use something without being aware of how this happens: why can this not also apply to the mind itself?

One could object that Leibniz's example of muscles is inappropriate because it fails to address the premise of Locke's criticism: awareness or consciousness is an essential mark of the possession of an idea; a condition that is obviously unnecessary vis-à-vis the material parts that constitute the body. The first thing to notice here is that the comparison is specifically between something's material constitution (which puts limits on what an object can or cannot do), and mental-intellectual constitution, which puts limits on what a mind can or cannot think. The ideal space of what can be thought must then be filled through the processes we described, namely those requiring the senses, memory, and attention. Granted, the second thing to notice is that Leibniz's objective is precisely to deny the coincidence of that which we can conceive and that about which we can be aware. After all, the analogy between the structure of the mind and the body seems to push exactly in the direction of the necessity of minute perceptions as states about which the mind cannot structurally become conscious, but which nonetheless constitute its activity when properly expressed. If there are minute perceptions, then why should it be so implausible that other constraints - proper to other faculties - are also active, without thereby needing to be intentional objects of conscious mental states?

\section{CONCLUSION}

Leibniz's innatism is highly peculiar. It encompasses a sort of bootstrapping process between the mind's own resources and discovering resources anew. This bootstrapping process is possible because rational cognizant agents have an intellect structured by innate constraints, which can later be identified and analyzed in terms of intellectual ideas and principles. The presence of a set of innate constraints speaks in favor of interpreting Leibniz's theory as a form of moderate innatism. This is because it is possible to distinguish between types and concepts as acquired abilities and more detailed responses that are constructed in virtue of a mind's expressive activity (sc. experience) and innate ideas, which are those ideas and principles that are necessary for the expressive activity itself. Despite this distinction, 
both ideas and acquired abilities are innate and acquired, a piece of theory that is needed in order to resist Locke's argument against innate ideas.

Thus, although the textual evidence may be deemed indeterminate for supporting my interpretation, three analogies used by Leibniz (viz. that of the mind as a dark room, as an architect, and as a hand that has the capacity to play piano) present a dynamical model of the innate constraints of the mind. The mind qua substance is always active and changing. At the same time, however, it retains everything it undergoes. This retention of the past helps it to construct a capacity for anticipating the future and acting in the present. Moreover, there is a kind of elasticity to the mental constraints that needs to be developed through exercise in order for them to function.

The second remark concerns the ontological status of the mind and its innate constraints: there are not two entities, i.e., the mind plus its ideas, knowledge, or contents. Just as a hand is constituted by the muscles and tendons composing it (such that we cannot say that a hand is a different entity to those parts), so too the innate constraints, and the alterations the mind undergoes through the exercise of its powers, are not something added to the mind, or different from the mind itself. The mind $i s$ this dynamical activity of exercising its innate constraints in the process of expressing the world to itself. 
Franz Steiner Verlag 


\section{CONCLUSION: CONTOURING THE IMAGINATION}

The human being is an imaginative animal. The imagination is an inventory and combinatoric faculty; in virtue of these features, it is also a synthetic faculty. Its chief task is to synthetize instances provided by other faculties (the senses, the intellect, memory, and attention) and connect them into coherent cognitive processes. Without the work of the imagination, the material provided by those faculties would be of difficult, if not impossible, access by a finite spirit, like the human cognizant agent.

The infinity of minute perceptions mirroring the affection of the created universe on the organic body attached to a soul could not be available to memory and attention if the imagination did not express the variety and complexity of the actual divisions and interactions of material parts in the simplicity and finitude of the substance. The imagination expresses the world according to the affection of the senseorgans by segmenting sensations into perceptible wholes, that is shapes having size, as bearers of primary and secondary qualities (chapter II). Perceptible wholes are then interpreted as bodily or corporeal phenomena when the agent recognizes them as the same unities undergoing various spatial and temporal states. A body, we argued, is hence a four-dimensional object of the imagination (chapters IV and V).

The regular connections of phenomena would not appear to the mind if the imagination did not compare bodies, detect their similarities, and track them in their spatiotemporal variations. Through its spontaneous activity, the imagination produces a further synthesis of the varieties of phenomena into types expressing beings' common nature (chapter VI).

The ideal connections of essences could not be conceived by minds if the imagination did not use general names as terms responding to identity and contradiction, principles structuring the logic of the intellect (chapters VII and VIII). In short, without the imagination mediating between innate ideas and the senses through the invention of expressions, the cognitive agent could not construct her world and find her place in it (chapters I and IX). The information provided by minute perceptions would be overwhelming, condemning her to a constant state of stupor (chapter IV).

The products of the imagination are expressions, viz. cognitive material surrogates, whose main characteristic is to be perceivable (chapter I). They translate and encode information in a format available to $a$ cognizant agent constituted as a unity of organic bodies and cognitive faculties. Expressions are inventions of the cognizant agent not just because the agent constructs them; they are essential tools for advancement of knowledge and achieving new discoveries. The relation between imagination and invention is due to expressions that work as cognitive surrogates that allow for extrapolation of relations and information that would remain inaccessible to the finite mind were they not simplified by the expression. Improving a cognitive agent's expressive tools goes hand in hand with improving the agent's 
capacity to achieve more stable and general knowledge. The better the system, the more accurate the knowledge agents can achieve.

Cognitive tools are only one side of the story. If they can work as discovery tools, it is because the imagination has an intrinsic, tormented and complicated relation to the (im)possible (chapter VI). Its main task is to re-enact the past in light of the present in order to see into the future. For this tendency to anticipate what has not yet come to be, it cannot refrain from variations on the theme, since combinations of elements - known and new - are part of its combinatoric nature. At each level, though, its combinatoric and synthetic work is not anarchic.

At the perceptual level, the imagination has bottom-up constraints consisting in the outreach of the sensory organs that compose the body attached to the soul. Sensory functioning responds in part to mechanical interactions of the organs - composing the body attached to a sensitive soul - with other bodies. Additionally, topdown constraints subjugate the imagination while active in perceiving by submitting sensory information to the logic of the imagination constituted by those "ideas of the common sense or of the pure understanding" (NE 128/A VI 6 128). Chapters IV and $\mathrm{V}$ fulfilled the task of outlining the rules composing this logic. Perceptible wholes are instantaneous actualizations of those bottom-up and top-down processes, as we described in chapter II, and they are transformed through experience into more distinguished expressions of bodies, that is specific types of phenomena. Phenomena are constituted by spatiotemporal orders of coexistence. Their intrinsic temporality instils in the imagination the tendency to connect those instantaneous products into a larger picture we call a world.

From its intrinsic relation to time, the imagination derives its tendency to imagine combinations it has never experienced before. The imagination constantly imagines the possible by synthetizing the past with the future, insofar as it interprets the present as the effect of a past cause and the cause of a future effect. The imagination, having no voluntary control on this spontaneous association of events, learns from its conjoint work with the senses to distinguish real from imaginary phenomena, since it learns to tell apart what is the object of possible experience and what is not. The eagerness and anxiety of anticipating the future makes it a faculty involved in predictions and scientific discoveries, as well as in the envisaging of fictions, of ideal entities of mathematics, and of imaginary possible worlds. By imagining what could be, the imagination thus frees agents from the limits of their organic body. The risk is to conceive of the impossible.

To justify the actions of the imagination and to comprehend its limits vis-à-vis an intellect that, following analytic rules, is sometimes slower in finding reasons to support possibilities the imagination envisages, we must take into account the equivocity of the modal couple possible/impossible. Leibniz distinguishes (im)possible into two main couples: logical possibility and impossibility, according to which whatever entails a contradiction is necessarily false; and contingency and hypothetical necessity, according to which whatever is precluded to exist when considered from the point of view of a set of conditions, is existentially impossible. On this latter meaning of impossible, what does not exist is not necessarily contradictory and therefore logically impossible; existence simply precludes it. This split- 
notion of the (im)possible opens the path to a variety of necessity - from logical necessity to hypothetical necessity and metaphysical necessity. Hypothetical necessity is no strict logical impossibility and comes in degrees of probability (chapter $\mathrm{V})$. The imagination is involved in predictions that have only a certain law degree of hypothetical necessity given by the logic of space and time, since more stable forms of knowledge, resting on necessary truths composing logical and metaphysical necessity, are precluded to the logic of imagination. More stable demonstrations require concepts or a system resting on logical possibility whose pillars are logical identity and contradiction and whose understanding remains beyond the domain of the imagination.

Although the logic of imagination does not respond to identity and contradiction, necessary to the formation of concepts, the imagination is not passive in concept formation. It contributes to the development of these other cognitive processes by providing the intellect with perceivable expressions. Without the use of expressions, the intellect could not exercise its power. Most of a person's capacity to apply more stable intellectual principles to what is per se not subject to them depends on the capacity of the imagination to translate one subject matter into a format subject to those intellectual principles. One example of this work is the application of mathematics to nature, as in the case of predicting eclipses (chapter VI). In this translation, the imagination is thus constrained by bottom-up and top-down instances, as it is evident in the process of concept formation outlined in chapters VIII and IX.

The common nature of phenomena, as expressed by types, is a first hint towards a conception of distinctions in species and genera. These latter are constructed by the imagination, working together with the intellect, as clusters of conceptual marks denoted by terms. Terms are general names that, as signs, respond to the imagination and its spatiotemporal logic, although when used in definitions, they are reassessed and re-interpreted through top-down constraints, like the principles of identity and contradiction. To explain this aspect, we referred to the string ' $\mathrm{A}=\mathrm{A}$ ' used by Leibniz as a symbol for logical identity. Since for the logic of the imagination the two As are two distinct things because they are co-perceived at a certain distance, the cognizant agent cannot conceive of them as one and the same while resting only on the imagination, no matter how similar the two As might appear. The deployment of intellectual principles signalled by the ' $=$ ' points the agent to take the string as a unity claiming that A is identical to A, that is to itself. This grasping of an identity rests on a logic which uses the imaginative tools as a staircase to reach truths which are "beyond the senses and matter", to use the words of the letter to Sophie Charlotte, viz. intellectual (more on this soon).

Identity is the gaining of conceptual reasoning that idealizes or mathematizes the concrete world by expressing it as being composed of essences, whose interconnections are independent both from the historical world and from the language that minds establish to signify concrete beings. Their interconnections are ideal and expressed in definitions. Losing existential concreteness, expression of beings via conceptual reasoning gains in knowledge distinction through relations of composition and conceptual entailment. The result is a separation between concrete (historical) beings, subject to the logic of the imagination, and abstract essences, governed 
by intellectual principles. This separation is necessary to have a stable ground for natural sciences, as Leibniz argues against Locke, without losing a grip on the actual world. Types anchor conceptual reasoning to reality and experience, since they guarantee that our distinctions are well-grounded in the actual existence of distinguished phenomena (chapters VIII and IX).

Existing beings individuated by types and conceptualized as instances of essences are not the ultimate ground of reality. When canvassed through the lenses of metaphysical reasoning, existing beings require true unities, principles of changes or, in Leibniz's jargon, substances. Chapter VIII contributed to clarifying some "distinctions in the things themselves" (NE 64). Logical, metaphysical, and physical realms are neatly divided for Leibniz, and yet they interact through ruled correspondences that should guarantee the reality of minds' cognitive processes.

The logical realm is the realm of cognizant agents, or what Leibniz calls "sensitive souls", both rational and non-rational. Souls are substances with greater cognitive capacity than simpler substances, as we saw in chapter IV, and part of their cognitive power derives from their being attached to a more cohesive and unified organic body ("nested", in Leibniz's jargon). Despite their finitude and thanks to a body more organized than those of lower organic forms (like plants) or other nonorganic forms of lives (like minerals or artefacts), sensitive souls are capable of more complex interactions with their environment, insofar as they have some faculties that better express what corresponds to external changes. In processing minute perceptions via the diverse forms of expressions we outlined in the work, souls do what all substances are meant to do in proportion to their ontological status: they act by building habitual responses to their environment.

The mechanisms by which souls express the world are ideal, like space and time. Space and time are central to express the world from the point of view of the soul, to locate it into the constant flux of phenomena; ${ }^{1}$ and yet space and time are only ideal framework to express changes that occur at a level distinct from the logical one, what Leibniz calls a physical genus in NE. Modifications of a physical genus are variations of matter that Leibniz describes as actually infinitely divided into parts that are themselves internally divided and constantly changing through mechanical interactions (chapter III). As the organic body is part of this flux and constantly changing, Leibniz holds that bodies are constantly changing and acted upon in a way that is reflected at the level of minute perceptions that are then first synthetized into sensations. Sensations are then synthetized into perceptible wholes, and these into types through the story we now know. In so doing, the cognizant agent builds habitual and more efficient responses to types of phenomena she might encounter as they are conceived to be parts of her world (chapters V and VI).

The phenomena resulting from the operations of minds are in a sense ideal and real, as we argued in chapters III and VIII. They are ideal because cognizant agents,

1 On this aspect, see De Risi (2011: 208-16), who argues that monads locate themselves by expressing non-spatial relations as bodies in space and time. 
I insist, need to transform changes happening at the physical and metaphysical levels into expressions proportional to their limited cognitive skills. Bodies formed in virtue of types and definitions formed in virtue of concepts are therefore modifications of what Leibniz calls a logical genus, that is continuous quantity (space and time, in the case of types), then categorized through logical principles into concepts. Modifications of cognitive processes respond to these ideal constraints while corresponding to modifications of a real genus. Expressions are ideal simply because they cannot exist as minds conceive of them because - to conceive of them - minds need to appeal to ideal and abstract ideas and principles, like space and time, or identity and contradiction. Expressions, the products of minds' actions, are, however, not merely ideal because they refer to ruled and constant correspondences to what exists.

Despite the different target of the present query, our analysis contributed to bringing a little more clarity to the issue of idealism vs. realism, insofar as it shows that existence and reality are themselves equivocal terms. Substances and beings both exist and are real, but in their own peculiar ways. Substances exist as true, permanent and indestructible unities. Substances as such cannot be the intentional objects of minds, so they are not strictly speaking in time and space, and hence cannot be said to exist as countable beings or those things minds can conceive of in spatiotemporal order. Substances do not have spatiotemporal existence, but metaphysical subsistence, while beings have spatiotemporal existence but no metaphysical subsistence, unless they can be reduced to metaphysical entities, i.e. substances. In being reduced, however, beings lose their phenomenal properties, or, when they are not lost, as in the case of rationality for the human soul, they are radically transformed in their monadic subsistence. To this aim, Leibniz introduces a distinction between transitory and permanent modifications of substances. Transitory are those properties that minds can detect in a physical genus as signs of metaphysical processes. In this respect, some beings that minds perceive are ideal and depend on a certain kind of unity that the mind attributes to them, as in the case of water or the body of a human being. However, those beings are not less real or exist less than substances; they exist differently than substances. To reiterate our example, Appius's soul is indestructible and immortal; in Leibniz's view, it is always active and changing, although other souls can conceive of Appius only during the timespan in which the soul of Appius animates an organic body 'large' enough to aptly affect other organic bodies attached to souls that are capable of distinct sense-perceptual states. The way in which cognizant agents can conceive of Appius is not how Appius exists in its permanent monadic and physical life (the soul is always attached to a body, however small and insensible it might be).

What we usually call 'being' is said to exist and to be real insofar as it corresponds to physical processes that can be sense-perceived and conceived as parts of a world, i.e. insofar as minds can conceive of them as coherent and hence predict their transformations as types of phenomena. Substances do not exist in this way. They exist as true unities whose permanent and transitory changes respond neither to the logic of the imagination, nor to that of identity and contradiction. However, 
minds could not conceive of anything if changes in true substances were not expressed as bodies in space and in time. To express, minds need the mediation of physical material interactions that correspond to metaphysical changes. Something must correspond to bodies, and this something cannot be straightforwardly substances. Substances alone cannot be intentional objects of other substances, unless their modifications are carried via a medium to a soul. This medium is material modification that affects the material body attached to the soul, modifications that are expressed by the soul through its minute perceptions because of harmony. Therefore, a physical genus or matter must correspond to the cognitive expression of the world as made up of bodies. What this 'matter' is is not decided by the present work. One thing is clear, however: whatever matter is, it must be constituted by substances since it has ruled interactions with other material parts that are translated by minds into the diversity and variety of phenomena, then categorized via conceptual distinctions. The ontological status of matter is multiplicity and constitutive lack of unity; matter exists but in a way that does not have persisting unity over time if it were not constituted by substances. The result is that minds never express 'pure' matter or 'pure' substances because both could not be perceived: matter cannot be perceived without the action of forces and forces cannot be perceived without the effect transmitted by mechanical interactions on the body associated to the cognitive soul. Minds simply cannot understand how material changes can be continuously reduced to substantial changes, a knowledge proper of a divine mind (see chapter III). The result is that our distinctions and categorizations of natural kinds and modes capture changes that are transitory to substances and whose variety is more fine-grained than the abstract ideal forms in which we are capable of conceiving those changes. Those changes are what substances can produce, but they are not permanent to substances.

Constrained by their logical notions, minds can simply conceive things as either material or substantial. So, on rigorous metaphysical reasoning, only substantial changes exist. But metaphysical existence is not a truer or more real form of existence; it simply is another way of existing which is not the way in which phenomena exist, or essences exist, or God exists. Minds strive to find a stable ground for what there is, and must reckon a fundamental ground for phenomena: substances inferred by introspection to our own activity; before recognizing a true notion of substances, though, we need to go through manifold expressions of substances at diverse levels: from types to concepts. All these levels 'exist', but on different grounds. Metaphysics simply provides a unifying ground for the variety of phenomena. The order of explanation of metaphysics rests therefore on principles that are neither strictly logical, like identity and contradiction, nor spatiotemporal; they are metaphysical, like the principle of identity of indiscernibles, that cannot be analysed either through the logic of imagination, nor through logical identity, because both produce abstracts and ideal entities, while the principle of indiscernibles aims at determining the existence of maximum concrete entities: substances.

The metaphysical constitution of the world is, thus, not precluded to us. We can know what substances are, so they are not things in themselves. Nor is reality pre- 
cluded to us: expressions guarantee a perfect correspondence between the exprimendum and the exprimens, and that in cognizing we are dealing with real things even when all we have is a mental surrogate. We would make a category mistake to think that beings exist as we perceive or conceive of them, although they may have real and existing referents. Our main error is hence a form of anthropocentrism: believing that the world is made only for rational substances since it perfectly corresponds to the world quoad nos, the one we experience.

From these different notions of existence, we derived a relation between metaphysics and natural sciences. Knowledge of substances qua substances is a form of general knowledge provided by metaphysics and it is independent from scientific enterprises. The result is that in rigore metaphysico, only what acts and has unity can exist. At this level, modifications are modifications of substances. But at the ontological level, beings and their modifications exist and are real. Beings have causes, enquired by sciences independently from metaphysics. States of beings are causes and effects of other states of beings that they exist insofar as they are coherent and can be predicted by cognizant agents.

Our enquiry into the logic of imagination has further metaphysical insights into the distinction between what Leibniz calls sensitive rational and sensitive non-rational souls, since it allows distinguishing between perceiving and conceiving as two kinds of cognitive modes.

Sense-perception and conceptual reasoning respond to distinct logics and yet there is no discontinuity between them. Both consist in imagining wholes divided into parts, although the nature of the parts and the rules of their connections change radically from one logic to the other. The logic of imagination deals with extended parts that are opaque to the principles of identity and contradiction. Conceptual logic deals with intensional 'parts' expressed by terms responding to identity and contradiction. Syntax and semantics, governing languages, are used to compose definitions and discourse. Languages are not the only vehicles for conceptual reasoning; diagrams and images can become vehicles for concepts, insofar as their parts can be arranged to express relations respecting identity and contradiction. Leibniz himself develops a linear calculus or something similar to Venn diagrams to express conceptual containment.

The separation between the two logics is decisive to argue that there are infinite degrees of souls that differ in the ways they express the world:

There can be infinite degrees of souls [...]. The soul has the ability to connect together different states of the body, so that past and future exist together by its help, the past by a kind of reminiscence, the future by presentiment. And although it is true that a body also relates its past and present states, there is however this difference: In body there is nothing but a present state, even if it is an effect relating a cause of the past, and likewise, a cause relating an effect of the future. But in a soul every state is represented per se, past as past, future as future, present as present; each state not only is expressed as a consequence, but it is also represented. (There Can Be Infinite Degrees of Souls 1686 LoC 299/A VI 4 A 304)

Degrees of clarity in the way souls represent past, present, and future states is the ground for acknowledging that animals have a form of empiric knowledge, gov- 
erned by the logic of imagination, while denying that they can develop robust conceptual reasoning and acquire knowledge of necessary truths. If our analysis is correct and the two logics are separated as we proved, then Leibniz is in a good position to attribute to sensitive non-rational agents a shadow of reasoning, without being committed to attributing to them thought or conceptual reasoning. And yet a question emerges: why do rational agents develop higher forms of reasoning, while sensitive non-rational agents do not? The question is more urgent if we consider the developmental story we have outlined so far. If there is such evolution, why do rational agents develop some cognitive skills while non-rational agents do not?

Leibniz's answer is that non-rational animals lack innate ideas. Non-rational animals must possess some of the constraints we highlighted: they must be capable of some sort of spatiotemporal apprehension of bodies; of causal connections, of similarity, and they must be capable of some form of types. Non-rational animals lack intellectual innate ideas, thereby lacking the capacity to develop their cognitive processes into rational conceptual ones, differing hence in the way they represent the world. On my understanding, the lack of intellectual ideas, like identity, contradiction, substance, is the reason why animals process sense-perceptual information differently from human beings, despite being like them imaginative animals. 


\section{ABBREVIATION}

Leibniz's Texts

A = Leibniz: Sämtliche Schriften und Briefe. Edited by Preußische (later: BerlinBrandenburgische and Göttinger) Akademie der Wissenschaften zu Berlin. Darmstadt (later: Leipzig, most recently: Berlin) 1923 ff. Quoted with year, series, page.

$\mathrm{C}=$ Opuscules et fragments inédits de Leibniz. Extraits des manuscrits ... par Louis Couturat. Paris 1903 (Reprint: Hildesheim 1961 and 1966).

Dutens $=$ Leibniz: Opera omnia, nunc primum collecta ... studio Ludovici Dutens. T. 1-6. Genevae 1768.

GM = Leibnizens mathematische Schriften. Ed. by C. I. Gerhardt. Vol. 1-7. Berlin (later: Halle) 1849-1863 (Reprint: Hildesheim 1962).

GP $=$ Die philosophischen Schriften von Leibniz. Ed. by C. I. Gerhardt. Vol. 1-7. Berlin 1875-1890 (Reprint: Hildesheim 1960-1961).

$\mathrm{LBr}=$ Nieders. Landesbibliothek Hannover, Leibniz-Briefwechsel.

LH $=$ Nieders. Landesbibliothek Hannover, Leibniz-Handschriften.

English translations:

$\mathrm{AG}=$ Philosophical Essays, trans. and ed. by R. Ariew and D. Garber, Indianapolis 1989;

$\mathrm{DSR}=$ De summa rerum: metaphysical papers, $1675-1676$, trans. and intro. by G. H. R. Parkinson, New Haven/London 1992;

$\mathrm{L}=$ Philosophical Papers and Letters: A Selection, ed. by L. E. Loemker, second edition, DordrechtBoston-London, 1989;

LDB $=$ The Leibniz-Des Bosses Correspondence, trans. and ed. by D. Rutherford and B. Look, New Haven and London, 2007;

LDV $=$ The Leibniz-De Volder Correspondence, trans. and ed. by P. Lodge, New Haven and London 2013;

$\mathrm{LoC}=$ The Labyrinth of the Continuum: Writings on the Continuum Problem, 1672-1686, ed. and trans. by R. W. Arthur, New Haven 2001;

LP = Leibniz. Logical Papers, trans. and ed. by G. H. R. Parkinson, Oxford 1966;

LSS = Leibniz and the Two Sophies: The Philosophical Correspondence, ed. and trans. by L. Strickland, Toronto 2011

LST = The Shorter Leibniz Texts: A Collection of New Translations, trans. and ed. by L. Strickland, London 2006;

MKTI= Meditations on Knowledge, Truth, and Ideas (1684) in L 290-3/A VI 4 A 589-92.

$\mathrm{NE}=\mathrm{G}$. W. Leibniz, New Essays on the Human Understanding, trans. by J. Bennett and

P. Remnant, Cambridge 1996 


\section{REFERENCES}

Antognazza, Maria Rosa (2020) The Distinction of Kind Between Knowledge and Belief. Proceedings of the Aristotelian Society CXX, 3.

- . (2018 ed.) The Oxford Handbook of Leibniz. Oxford/New York: Oxford University Press.

- . (2015) The Hypercategorematic Infinite. The Leibniz Review 25: 5-30.

- . (2015) The Benefit to Philosophy of the Study of Its History. British Journal for the History of Philosophy, 23/1: 161-84.

Arthur, Richard. (2018) Monads, Composition, and Force: Ariadnean Thread Through Leibniz's Labyrinth, Oxford University Press.

- . (2018) The Labyrinth of the Continuum, in: M.R. Antognazza (ed.), The Oxford Handbook of Leibniz, online version 2013 DOI: 10.1093/oxfordhb/9780199744725.013.003

- . (2013) Leibniz's Theory of Space, Foundation of Science (2013) 18:499-528

Ashworth, E. Jennifer, "Medieval Theories of Analogy", The Stanford Encyclopedia of Philosophy (Fall 2017 Edition), Edward N. Zalta (ed.), URL = https://plato.stanford.edu/archives/fall2017/entries/analogy-medieval/>.

Barth, Christian (2020) Judgement in Leibniz's Conception of the Mind: Predication, Affirmation and Denial. Topoi 39: 689-98.

- . (2017) Intentionalität und Bewusstsein in der frühen Neuzeit: die Philosophie des Geistes von René Descartes und Gottfried Wilhelm Leibniz. Frankfurt a.M.: Klostermann.

- . (2011) Apperception in the New Essays Concerning Human Understanding. A critique of the Reflective Account. In: Herbert Breger (et al. eds.), Natur und Subjekt. IX. Internationaler Leibniz-Kongress, pp. 37-43, Berlin: Akademie Verlag.

- . (2011a) Leibnizian Conscientia and its Cartesian Roots. Studia Leibnitiana 43/1: 216-236.

Black, Deborah (2000) Estimation and Imagination: Western Divergences from an Arabic Paradigm. Topoi 19: 59-75.

Belaval, Yvon (1975) Note sur Leibniz et Platon. Revue d'histoire et de philosophie religieuses 55: $49-54$.

- . (1960) Leibniz critique de Descartes. Paris: Gallimard.

Bender, Sebastian (2016) Leibniz' Metaphysik der Modalitäten. DeGruyter: Boston/Berlin.

Berto, Francesco - Nolan, Daniel (2021) "Hyperintensionality", The Stanford Encyclopedia of Philosophy (Spring 2021 Edition), Edward N. Zalta (ed.), URL $=<$ https://plato.stanford.edu/archives/spr2021/entries/hyperintensionality/>.

Bolton, M. B. (2021) Kant's Amphiboly as Critique of Leibniz, Brandon Look (ed.), Leibniz and Kant, Oxford: Oxford University Press.

- . (2019) Theory of Knowledge: Mathematical and Natural Science, in: M.R. Antognazza (ed.), The Oxford Handbook of Leibniz, online version 2013 DOI: 10.1093/oxfordhb/9780199744725.013.18

- . (2017) Locke's Essay and Leibniz's Nouveaux Essais: Competing Theories of Universals. In S. Di Bella, \& T. M. Schmaltz, The Problem of Universals in Early Modern Philosophy (pp. 220-52). Oxford: Oxford University Press.

- . (2011a) Leibniz's Theory of Cognition. In B. C. Look, Continuum Companion to Leibniz (p. 136-158). London/New York: Continuum.

- . (2011b) Metaphysics and Psychology in Leibniz's Theory of Ideas' in Natur und Subjekt: IX. Internationaler Leibniz-Kongress, vol 4, ed. H. Breger, J. Herbst and S. Erdner (Hannover: Druckerei Hatmann) 
- . (2006) Leibniz and the Limits of Perception. In H. Breger, J. Herbst, \& S. Erdner (Ed.), Einheit in der Vielheit, VIII. Internationaler Leibniz-Kongress, Hannover, 24. bis 29 Juli. I, pp. 94 100. Hannover: Druckerei Hartmann.

- . (1996) The Nominalist Argument of the New Essays. The Leibniz Review 6: 1-24.

Bos, H.J.M. (2001) Redefining Geometrical Exactness. Descartes' Transformation of the Early Modern Concept of Construction. New York: Springer.

Brandom, Robert (1981) Leibniz and Degrees of Perception. Journal of the History of Philosophy 19/4: 447-479.

Brown, Gregory (2011) Disinterested Love: Understanding Leibniz's Reconciliation of Self- and Other- Regarding Motives. British Journal of the History of Philosophy 19/2: 265-303.

Campbell, Joseph Keim (et al. eds.) (2011) Carving Nature at Its Joints, The MIT Press.

Chalmers, David (2002) Does Conceivability Entail Possibility? In: Szabo Gendler et al. (eds), Conceivability and Possibility, pp. 145-200, Oxford: Oxford University Press.

Chavez-Arvizo, Enrique (1997) Descartes's Imagination: Proportion, Images, and the Activity of Thinking by Dennis Sepper. Isis 88/1: 143-4.

Couturat, Louis (1901) La logique de Leibniz: d'après de documents inédits. Paris: Felix Alcan.

Dascal, Marcelo (1987) Leibniz. Language, Signs and Thought. Amsterdam/Philadelphia: John Benjamin Publishing \& co.

Debuiche, Valerie (2019a) Expression and Analogie in Leibniz's Philosophy. In: Herrera Castillo, Laura (Hrsg.), Äußerungen des Inneren. Beiträge zur Problemgeschichte des Ausdrucks, 6584, DeGruyter.

- \& Rabouin, David (2019) On the Plurality of Space in Leibniz. In: De Risi, Vincenzo, Leibniz and the Structure of Sciences. Modern Perspective on the History of Logic, Mathemaics, and Epistemology, pp. 171-201, Dordrecht/New York: Springer.

- . (2013) L'expression leibnizienne et ses modèles mathématiques. Journal of the History of Philosophy 51/3: 409-439

- . (2009) La notion d'expression et ses origines mathématiques. Studia Leibnitiana 41/1: 88-117

De Rosa, Raffaella (2015) Locke's Critique of Innatism. In: Stuart, Mattew (ed.), A Companion to Locke, pp. 157-174, London: Blackwell Publishing.

- . (2010). Descartes and the Puzzle of Sensory Representation. Oxford: Oxford University Press.

- . (2004) Locke's Essay Book I: The Question-Begging Status of the Anti-Nativist Argument. Philosophy and Phenomenological Research 69/1:37-64.

De Risi, Vincenzo (2019) Introduction to: Leibniz and the Structure of Sciences. Modern Perspective on the History of Logic, Mathemaics, and Epistemology, Dordrecht/New York: Springer.

- . (2019a) Leibniz on the Continuity of Space. In: Leibniz and the Structure of Sciences. Modern Perspective on the History of Logic, Mathemaics, and Epistemology, pp. 111-169, Dordrecht/New York: Springer.

- . (2015) Introduction to: Mathematizing Space. The Objects of Geometry from Antiquity to the Early Modern Age, pp. 1-14, New York/Dordrecht: Birkhäuser.

- . (2007) Geometry and Monadology. Leibniz's Analysis Situs and Philosphy of Space, Basel/Boston/Berlin: Birkhäuser.

Di Bella, Stefano (2016). Leibniz on Error: Between Descartes and Spinoza. Will, Judgement, and the Concept of Reality. Rivista di Storia della Filosofia, 4, pp. 713-25.

- . (2006) Le 'De Affectibus' leibnizien: de la dynamique des passions à la constitution de la substance individuelle. In: Les passions à l'âge classique, edited by Pierre-François Moreau, pp. 193-208. Paris: Presses Univ. de France.

- . (2005) The Science of the Individual: Leibniz's Ontology of Individual Substance. Dordrecht/Berlin: Springer.

-. (2005a) Leibniz's Theory of Conditions: A Framework for Ontological Dependence. The Leibniz Review 15: 67-93. 
- . (2004) Multum interest inter terminos et res. On Leibniz Theory of Distinction. In: Carrara Massimiliano (et al. eds.), Individuals, Minds and Bodies: Themes from Leibniz, (Studia Leibnitiana SH 32), pp. 15-48. Stuttgart: Franz Steiner Verlag.

- . (2000) Leibniz on the Subject of Change. On De Mutationibus (Vorausedition, N. 55). In: Dutz Klaus (ed.), Individuation, Sympnoia panta, Harmonia, Emanation. Festgabe für Heinrich Schepers zu seinem 75. Geburtstag, pp. 23-48, Münster: Nodus.

- . (1998) L'astratto e il concreto: Hobbes, Leibniz e la riforma dell'ontologia. Rivista di storia della filosofia LIII/2: 235-266.

Duchesneau, François ([2013] 2018) Physiology and organic Bodies. In: Antognazza Maria Rosa (ed.), The Oxford Handbook of Leibniz, Oxford: Oxford University Press.

Favaretti Camposampiero, M. (2010) Pure Intellect, Brain Traces, and Language: Leibniz and the Foucher-Malebranche Debate. Oxford Studies in Early Modern Philosophy, 5, 115-145.

- . (2009) Conoscenza simbolica. Hildesheim/New York/Zürich: Georg Olms.

- . (2007) Filum cogitandi. Leibniz e la conoscenza simbolica. Milano: Mimesi.

- . Priarolo, M., \& Scribano, E. (2016/4). I volti dell'errore nel pensiero moderno: da Bacone a Leibniz. Rivista di Storia della Filosofia.

Fotì, V. M. (1986) The Cartesian Imagination. Philosophy and Phenomenological Research 46/4: 631-42.

Garber, Daniel (2015) Leibniz's Transcendental Aesthetic. In: De Risi, Vincenzo. Mathematizing Space. The Objects of Geometry from Antiquity to the Early Modern Age, pp. 231-254, New York/Dordrecht: Birkhäuser

- . (2009) Leibniz: Body, Substance and Monad. Oxford: Oxford University Press.

Gensini, Stefano (1991) Il naturale e il simbolico. Saggio su Leibniz. Roma: Bulzoni editori.

Goldenbaum, Ursula (2009) It's Love! Leibniz Foundation of Natural Law as Outcome of His Struggle with Hobbes's and Spinoza's Naturalism. In: Goldenbaum Ursula (ed.) The Philosophy of the Young Leibniz, pp. 189-201, Stuttgart: Franz Steiner Verlag.

Hasse Dag Nikolaus (1999) Das Lehrstück von den vier Intellekten in der Scholastik:_von den arabischen Quellen bis zu Albertus Magnus. Recherches de Théologie et Philosophie médiévales 66: 21-77.

Hight, Marc A (2008) Idea and Ontology: An Essay in Early Modern Metaphysics of Ideas. Pennsylvania State University Press.

Hübner, Wolfgang (1977) Ist Thomas Hobbes Ultranominalist gewesen?. Studia Leibnitiana, 9/1: $77-100$.

Ishiguro, Hilde (1972) Leibniz's Philosophy of Logic and Language. Ithaca, New York: Cornell University Press.

Jolley, Nicolas (1990) The Light of the Soul: Theories of Ideas in Leibniz, Malebranche, and Descartes. Oxford/New York: Oxford University Press.

- . (1988) Leibniz and Malebranche on Innate Ideas. The Philosophical Review 97: 71-91.

- . (1984) Leibniz and Locke. A Study of New Essays on Human Understanding. New York/Oxford: Oxford University Press.

Jorati, Julia (2019) Embodied Cognition Without Causal Interaction in Leibniz. In: Bender Sebastian et al. (eds.), Causation and Cognition in Early Modern Philosophy, pp. 273-95, Routledge, New York.

Jorgensen, Larry M. (2019) Leibniz's Naturalized Philosophy of Mind, Oxford University Press.

- . The Principle of Continuity in Leibniz's Theory of Consciousness. Journal of the History of Philosophy 47/2: 223-248.

Kind, Amy (2016) Introduction: Exploring Imagination. In: Kind, Amy (ed.), The Routledge Handbook of Philosophy of Imagination, pp. 1-12, London/New York: Routldge.

- . and Kung, Peter (2017) Introduction: The Puzzle of Imaginative Use. In: Kind E. et al., Knowledge Through Imagination, pp. 1-37, New York: Oxford University Press. 
Kustad, Mark. (2006) Leibniz on Expression: Reflections After Three Decades. In H. Breger, J. Herbst, \& S. Erdner (Ed.), Einheit in der Vielheit, VIII. Internationaler Leibniz-Kongress, Hannover, 24. bis 29 Juli. I, pp. 413-19. Hannover: Druckerei Hartmann.

- . (1977) Leibniz's Conception of Expression. Studia Leibnitiana 9/1: 55-76.

Leduc, Christian (2011) La doctrine Leibnizienne de l'idée. In H. e. Breger, Natur und Subjekt (p. 582-90). Hannover: Steiner Verlag.

- . (forthcoming). Imagination and Reason in Leibniz. Studies in History and Philosophy of Science (pre-print: https://www.academia.edu/12533520/Imagination_and_Reason_in_Leibniz).

Leinkauf, Thomas (2012) Einheit, Natur, Geist. Beiträge zu metaphysischen Grundproblemen im Denken von Gottfried Wilhelm Leibniz. Berlin: Trafo Verlagsgruppe.

Leinkauf Thomas (2009) Leibniz und Plato. Zeitsprünge. Forschungen zur Frühen Neuzeit, Band 13, Heft 1/ 2: 23-45.

Lenz, Martin (2009) Lockes Sprachkonzeption. Berlin/New York: De Gruyter.

Lenzen, Wolfgang (1983) Zur extensionalen und 'intensionalen' Interpretation der Leibnizschen Logik. Studia Leibnitiana 15: 129-148.

Liao, Shen-yi and Gendler, Tamar (2020) "Imagination".The Stanford Encyclopedia of Philosophy (Summer 2020 Edition), Edward N. Zalta (ed.), URL $=<$ https://plato.stanford.edu/archives/sum2020/entries/imagination/>.

Lodge, Paul (2014) Leibniz's Mill Argument Against Mechanism Revisited. Ergo 1/3 DOI: http://dx.doi.org/10.3998/ergo.12405314.0001.003.

Lodge, Paul \& and Puryer, Stephen (2006/7) Unconscious Conceiving and Leibniz's Argument for Primitive Concepts. In: Studia Leibnitiana 38/39: 177-196.

Lodge, Paul; Bobro, Marc E. (1998) Stepping Back Inside Leibniz's Mill. The Monist: An International Quarterly Journal of General Philosophical Inquiry 81: 553-72.

Lowe E. J. (2001) The Possibility od Metaphysics. Substance, Identity, and Time. Oxford: Clarendon Press.

- . (2006) The Four-Category Ontology. A Metaphysical Foundation for Natural Sciences. Oxford: Oxford University Press.

- . (2008) Two Notions of Being: Entity and Essence. Royal Institute of Philosophy Supplements 62: $23-48$.

Maat, Jaap (2004) Philosophical Languages in the Seventeeth Century: Dalgarno, Wilkins, Leibniz. Dordrecht: Springer.

Malink, Marko (et al.) (2019) Leibniz on the Logic of Conceptual Containment and Coincidence. In: De Risi, Vincenzo, Leibniz and the Structure of Sciences. Modern Perspective on the History of Logic, Mathemaics, and Epistemology, pp. 1-46, Dordrecht/New York: Springer.

Marras, Cristina (2000) Metaphora translata voce. Prospettive metaforiche nella filosofia di $G . W$. Leibniz. Firenze: Leo S. Olschki Editore.

Mates, Benson (1986) The Philosophy of Leibniz: Metaphysics and Language. Oxford/New York: Oxford University Press.

Mercer Christia (2001) Leibniz's Metaphysics; Its Origins and Developments, Cambridge University Press.

- . (2008) The Platonism at the Core of Leibniz's Metaphysics: God and Knowledge. In: S. Hutton (ed.), Platonism and the Origins of Modernity: The Platonic Tradition and the Rise of Modern Philosophy, pp. 225-38, Ashgate Press.

Meier-Oeser, Stephan (2019) Erkenntnistheorie. In: F. Beiderbeck, W. Li, S. Waldhoff (eds.), Gottfried Wilhelm Leibnz. Rezeption, Forschung, Ausblick. Stuttgart: Franz Steiner Verlag.

- . (2011) Leibniz' These von der körperlichkeit allen kreatürlichen Denkens. In H. Breger, J. Herbst, \& S. Edner, Natur und Subjekt. IX. Internationaler Leibniz-Kongress (p. 660-666). Berlin: Akademie Verlag.

- . (2007) Das Ende der Metapher von der >inneren Rede $<$. Vom Verhältnis von Sprache und Denken in der deutschen Frühaufklärung. In: Hans Erich Bödeker (ed.), Strukturen der deutschen Frühaufklärung 1680-1720, pp. 195-223, Vandenhoeck \& Ruprecht. 
- . (2004) Sprache und Bilder im Geist. Skizzen zu einem philosophischen Langzeitprojekt. Philosophisches Jahrbuch der Görres-Gesellschaft, 111/2: 312-342.

- . (1997) Die Spur des Zeichens. Das Zeichen und seine Funktion in der Philosophie des Mittelalters und der frühen Neuzeit. Berlin/New York: De Gruyter.

Mugnai, Massimo (2019) Leibniz's Mereology in the Essays on Logical Calculus of 1686-1690. In: De Risi, Vincenzo, Leibniz and the Structure of Sciences. Modern Perspective on the History of Logic, Mathemaics, and Epistemology, pp. 47-69, Dordrecht/New York: Springer.

- . (2000) 'Alia est rerum, alia terminorum divisio': about an Unpublished Manuscript of Leibniz. In A. Lamarra, \& R. Palaia, Unità e molteplicità nel pensiero filosofico e scientifico di Leibniz. Simposio Internazionale, Roma, 3-5 ottobre, 1996 (pp. 257-270). Firenze: Leo S. Olschki Editore.

- . (1999) Phänomene und Aussenwelt in der Leibnizschen Erkenntnistheory. In: Nowak Kurt (ed.), Wissenschaft und Weltgestaltung: Internationales Symposium zum 350. Geburtstag von Gottfried Wilhelm Leibniz vom 9. bis 11. April 1996 in Leipzig, pp. 145-154. Hildesheim: Olms.

- . (1990) Leibniz's Nominalism and the Reality of Ideas in the Mind of God. In A. Heinekamp, W. Lenzen, \& M. Schneider, Mathesis Rationis. Festschrift für Heinrich Schepers (p. 153168). Münster: Nodus Publikationen.

- . (1992) Leibniz's theory of relations. Stuttgart: Franz Steiner Verlag.

- . (1982) Introduzione a: Leibniz, Nuovi saggi sull'intelletto Umano. In: Mugnai, Massimo (ed.), Leibniz, Nuovi Saggi sull'intelletto umano, pp. 9-36, Roma: Editori Riuniti.

- . (1976) Astrazione e realtà. Saggio su Leibniz. Milano: Feltrinelli Editore.

Nachtomy, Ohad (2011) Leibniz's Theory of Modality. In : Look C., Brandon (ed.), The Continuum Companion to Leibniz, pp. 160-170, London/New York: Continuum.

- . Shavit Ayelet, Smith, Justin (2002) Leibniz's Organisms, Nested Individuals and Units of Selection, Theory in Biosciences, 121, pp. 205-30.

Nolan, Danile (2014) Hyperintensional Metaphysics. Philosophical Studies 171/1: 149-60.

Oliveri, Lucia (2020) The Art of Division and the Unity of the Idea: Leibniz as Scholar of Plato. In: W. Mesch, M. Städler \& C. Thein, Einhei und Vielheit metaphysischen Denkens. Festschrift für Thomas Leinkauf (65. Geburtstag), Hamburg: Felix Meiner Verlag.

- . (2020a) "Imposition". In: Encyclopedia of Early Modern Philosophy and the Sciences, Dana Jalobeanu - Charles T. Wolfe (eds.), Dordrecht: Springer. (https://doi.org/10.1007/978-3-31920791-9 221-1)

- . (2020b) "Obligation (in language use)". In: Encyclopedia of Early Modern Philosophy and the Sciences, Dana Jalobeanu - Charles T. Wolfe (eds.), Dordrecht: Springer. (https://doi.org/ 10.1007/978-3-319-20791-9 200-1)

- . (2020c) "Universal language". In: Encyclopedia of Early Modern Philosophy and the Sciences, Dana Jalobeanu - Charles T. Wolfe (eds.), Dordrecht: Springer.

- . (2019) Leibniz-Treuer Correspondence. The Leibniz Review 29: 83-106.

- . (2016) Imagination and Harmony in Leibniz's Philosophy of Language: https://repositorium.uni-muenster.de/document/miami/d88ae178-c9c1-4209-b087-2da40e328599/diss_oliveri.pdf

- . (2016a) Leibniz on the Role of Innate Ideas in Human Cognition. In: Li Wenchao (et al., eds.) "Für unserer Glück oder das Glück anderer." Vorträge des X. Internationalen LeibnizKongress, pp. 37-48, Hildesheim: Olms.

- . (2016b) Leibniz on the Cognitive Conditions for the Origins of Natural Languages. In: Li Wenchao (et al., eds.) "Für unserer Glück oder das Glück anderer." Vorträge des X. Internationalen Leibniz-Kongress, pp.467-478, Hildesheim: Olms.

- . (2016c) On Concepts and Ideas: Themes from G.W. Leibniz's New Essays on Human Understanding. In: Kann Christoph et al. (eds), Concepts and Categorization. Systematic and Historical Perspectives, pp. 141-66, Münster: Mentis Verlag. 
- . (2014) Logische und Semantische Funktion der Präpositionen bei Leibniz' Sprachphilosophie. In: Li Wenchao (ed.), Die Einheit der Vernunft und die Vielfalt der Sprache (Studia Leibnitiana Supplementa 38), pp. 55-82, Stuttgart: Franz Steiener Verlag.

Pasini, Enrico (1993) Il reale e l'immaginario. La formazione del calcolo infinitesimale nel pensiero di Leibniz, Torino: Sonda edizioni.

- . (1996) Corpo e funzioni cognitive in Leibniz. Milano: Franco Angeli.

Perler, Dominik (2004) Theorien der Intentionalität im Mittelalter. Vittorio Klostermann: Frankfurt a.M.

Picone, M. (2005) L'expérience de la pensée. Définitions, idées et charactères en 1675. In D. Berlioz, \& F. Nef, Leibniz et la puissance du language (pp. 179-99). Paris: Vrin.

Poser, Hans (2016) Leibniz' Philosophie. Über die Einheit von Metaphysik und Wissenschaft. (Wenchao Li ed.) Hamburg: Meiner Verlag.

- . (2009) Leibniz' Theorie der Perzeptionen heute. In: Erich Barke et al. (eds), Leibniz neu denken (Studia Leibnitiana Sonderheft 38), pp. 15-35, Stuttgart: Steiner.

- . (2000) Phaenomenon bene fundatum. Leibnizens Monadologie als Phänomenologie. In: Renato Cristin (et al. eds.), Phänomenologie und Leibniz (= Orbis phaenomenologicus, Perspektiven 2), pp. 19-41, Freiburg/München: Alber.

- . (1994) Analogia und Expressio bei Leibniz. In: Quintín Racionero, Concha Roldán (eds), G.W. Leibniz. Analogía y expresión (= Philosophica Complutensia 2), pp. 21-29, Madrid: Ed. Complutense.

- . (1984) Apriorismus der Prinzipien und Kontingenz der Naturgesetze. Das Leibniz-Paradigma der Naturwissenschaft, in: A. Heinekamp (Hg.): Leibniz' Dynamica (Studia Leibnitiana, Sonderheft 13), pp. 164-179, Stuttgart: Steiner Verlag.

- . (1679) Erfahrung und Essenz. Zur Stellung der kontingenten Wahrheiten in Leibniz' Ars characteristica. In: A. Heinekamp et al. (eds.), Die intensionale Logik bei Leibniz und in der Gegenwart (Studia Leibnitiana Sonderheft 8), pp. 67-81, Wiesbaden.

- . (1679a) Signum, notio und idea. Elemente der Leibnizschen Zeichentheorie. Zeitschrift für Semiotik, 1: 309-324.

- . (1969) Zum logischen und inhaltlichen Zusammenhang der Modalbegriffe bei Leibniz. Kant Studien 60: 436-451.

Rabouin, David (2018) Logic of imagination. Echoes of Cartesian epistemology in contemporary philosophy of mathematics and beyond. Synthese 195: 4751-4783

- . (2017) Les mathématiques comme logique de l'imagination: Une proposition leibnizienne et son actualité. Bulletin d'analyse phénoménologique XIII 2 (Actes 10): 222-251.

- . (2015) Proclus' Conception of Geometric Space and Its Actuality. In: De Risi, Vincenzo. Mathematizing Space. The Objects of Geometry from Antiquity to the Early Modern Age, pp. 10542, New York/Dordrecht: Birkhäuser

- . (2013) Analytica Generalissima Humanorum Cognitionum. Some Reflections between Logical and Mathematical Analysis in Leibniz. Studia Leibnitiana 45/1: 109-30.

- . (2012) Interpretations of Leibniz's Mathesis Universalis at the Beginning of the XXth Century. In: Ralf Krömer \& Yannick Chin-Drian (eds.), New Essays on Leibniz Reception in Science and Philosophy of Science 1800-200, pp. 187-201, Dordrecht: Springer.

Rauzi, Jean-Baptiste (2001) La doctrine leibnizienne de la vérité. Aspects logiques et ontologiques. Paris: Vrin.

Read, Stephen, "Medieval Theories: Properties of Terms", The Stanford Encyclopedia of Philosophy (Spring 2019 Edition), Edward N. Zalta (ed.), URL = https://plato.stanford.edu/archives/spr2019/entries/medieval-terms/

Renz, Ursula (2019) Spinozist Cognitive Psychology: Spinoza Concept of the Imagination. In: Meer Rudolf (et al. eds.), Konzepte der Einbildungskraft in 18. Jahrhunderts. Festschrift zum 65. Geburtstag von Udo Thiel, pp. 9-24, Berlin: DeGruyter.

Rescher, Nicholas. Leibniz's Interpretation of His Logical Calculi. In: The Journal for Symbolic Logic, 1954: 1-13. 
Roinila, Markku (2007). Leibniz on Rational Decision Making. PhD Dissertation.

- . (2015) Affects and activity in Leibniz's 'De affectibus'. In: Nita, Adrian (ed.). Leibniz's Metaphysics and Adoption of Substantial Forms: Between Continuity and Transformation. Dordrecht: Springer, 73-88.

Rosen, Gideon (2020) “Abstract Objects”, The Stanford Encyclopedia of Philosophy (Spring 2020 Edition), Edward N. Zalta (ed.), URL $=<$ https://plato.stanford.edu/archives/spr2020/entries/abstract-objects/>.

Russell, Bertrand. A Critical Exposition of the Philosophy of Leibniz. Cambridge: Cambridge University Press, 1900.

Rutherford, Donald (2008) Leibniz as Idealist. In: Oxford Studies in Early Modern Philosophy 4: 141-90.

- . (1995) Philosophy and language in Leibniz . In: N. Jolley, The Cambridge Companion to Leibniz, p. 224-269, Cambridge: Cambridge University Press.

Schepers, Heinrich (2014) Leibniz. Wege zu seiner reifen Metaphysik, Berlin: Akademie Verlag.

Schofield, Malcolm (1995) Aristotle on the Imagination. In: Nussbaum, Martha et al. (eds.), Essays on Aristotle's De Anima, pp. 249-78, Oxford: Oxford University Press.

Sepper, Dennis (1996). Proportion, Images, and the Activity of Thinking. Berkeley: University of California Press.

Sorell T \& Rogers G.A.J. (2005, eds.) Analytic Philosophy and History of Philosophy. Oxford: Oxford University Press.

Swoyer, Chris (1995) Leibnizian Expression. Journal of the History of Philosophy, 33/1: 65-99.

Tahko, Tuomas (2012) Boundaries in Reality. Ratio (new series) XXV/4: 406-24.

Tropper, Sarah (2019) The Importance of Imagination in Leibniz. In: Meer Rudolf (et al. eds.), Konzepte der Einbildungskraft in 18. Jahrhunderts. Festschrift zum 65. Geburtstag von Udo Thiel, pp. 25-38, Berlin: DeGruyter.

Varzi, Achille (2019) "Mereology", The Stanford Encyclopedia of Philosophy (Spring Edition), Edward N. Zalta (ed.), URL $=<$ https://plato.stanford.edu/archives/spr2019/entries/mereology/.

- . \& Barry Smith (2000) Fiat and Bona Fide Boundaries. Philosophy and Phenomenological Research 70/2: 401-20.

Weckend, Julia (2017) Leibniz on Certainty. In: Strickland, Lloyd et al. (eds.), Trecentenary Essays on the Philosophy and Science of Leibniz, Palgrave McMillan.

Williamson, Timothy (2017) Knowing by Imagining. In: Kind E. et al., Knowledge Through Imagination, pp. 113-24, New York: Oxford University Press.

Wilson, Mark (2006). Song of the Master Idea. In: Wilson, Mark (ed.). Wandering Significance: An Essay on Conceptual Behaviour. Oxford: Oxford University Press.

Yablo, Stephan (1993) Is Conceivability a Guide to Possibility?. Philosophy and Phenomenological Research 53/1: 1-42.

Zimmermann, Robert (1854 [2010]) Über Leibnitzens Conceptualismus: Ein Vortrag. Whitefish, Montana: Kessinger Pub \& co. 
STUDIA LEIBNITIANA - SONDERHEFTE

Im Auftrag der Gottfried-Wilhelm-Leibniz-Gesellschaft e.V.

herausgegeben von Herbert Breger, Michael Kempe,

Wenchao Li (verantwortlich) und Pauline Phemister.

2I. Gottfried Wilhelm Leibniz

Le Meilleur des Mondes

$\mathrm{Hg}$. von Albert Heinekamp und André

Robinet

I992. 295 S., kt.

ISBN 978-3-5I5-05764-6

22. Renato Cristin (Hg.)

Leibniz und die Frage nach

der Subjektivität

Leibniz-Tagung in Triest vom II.-I4. Mai

1992

I994. 229 S., kt.

ISBN 978-3-5I5-06230-5

23. Susanne Edel

Metaphysik Leibnizens

und Theosophie Böhmes

Die Kabbala als Tertium Comparationis

für eine rezeptionsgeschichtliche Untersuchung der individuellen Substanz

I995. 225 S., kt.

ISBN 978-3-5I5-06666-2

24. Martine de Gaudemar (Hg.)

La notion de nature chez Leibniz

Colloque organisé par le departement de philosophie de l'université de Provence

(Aix-en-Provence), le CNRS (Paris), et la

G.W. Leibniz-Gesellschaft (Hannover),

Aix-en-Provence, I3-I5 Octobre 1993

I995. 240 S., kt.

ISBN 978-3-5I5-0663I-o

25. Alexander Wiehart-Howaldt

Essenz, Perfektion, Existenz

Zur Rationalität und dem systematischen Ort der Leibnizschen Theologia Naturalis I996. XII, 223 S., kt.

ISBN 978-3-5I5-06840-6

26. Emily Grosholz / Elhanan Yakira Leibniz's Science of the Rational

I998. $107 \mathrm{~S} ., \mathrm{kt}$.

ISBN 978-3-5I5-07400-I

27. Paul Blum

Philosophenphilosophie

und Schulphilosophie

Typen des Philosophierens in der Neuzeit I998. 302 S., kt.

ISBN 978-3-5I5-0720I-4
28. Herbert Breger//

Friedrich Niewöhner (Hg.)

Leibniz und Niedersachsen

Tagung anläßlich des 350. Geburtstages

von G. W. Leibniz, Wolfenbüttel 1996

I999. 238 S. und I6 Farbtaf., kt.

ISBN 978-3-5I5-07200-7

29. Martin Fontius / Hartmut Rudolph /

Gary Smith (Hg.)

Labora diligenter

Potsdamer Arbeitstagung zur Leibniz-

forschung vom 4.-6. Juli 1996

I999. 240 S., kt.

ISBN 978-3-5I5-07602-9

30. Brandon Look

Leibniz and the

'Vinculum Substantiale'

I999. I43 S., kt.

ISBN 978-3-5I5-07623-4

3I. Andreas Hüttemann ( $\mathrm{Hg}$.)

Kausalität und Naturgesetz

in der Frühen Neuzeit

200I. 240 S., kt.

ISBN 978-3-5I5-07858-o

32. Massimiliano Carrara / Antonio-Maria Nunziante / Gabriele Tomasi (Hg.)

Individuals, Minds and Bodies

Themes from Leibniz

2004. 297 S., kt.

ISBN 978-3-5I5-08342-3

33. Alexandra Lewendoski (Hg.)

Leibnizbilder

im I8. und I9. Jahrhundert

2004. 26I S., kt.

ISBN 978-3-5I5-0840I-7

34. Daniel J. Cook / Hartmut Rudolph /

Christoph Schulte (Hg.)

Leibniz und das Judentum

2008. 283 S. mit 6 fbg. und I s/w-Abb., kt.

ISBN 978-3-5I5-0925I-7

35. Mark Kulstad / Mogens Lærke /

David Snyder (Hg.)

The Philosophy of the Young Leibniz

2009. 259 S. mit I Abb., kt.

ISBN 978-3-5I5-08098-9 
36. Paul Rateau (Hg.)

L'idée de théodicée de Leibniz

à Kant: héritage, transformations, critiques

2009. 222 S., kt.

ISBN 978-3-5I5-0935I-4

37. Juan Antonio Nicolás (Hg.)

Leibniz und die Entstehung

der Modernität

Leibniz-Tagung in Granada,

I. -3. November 2007

20IO. 278 S., kt.

ISBN 978-3-5I5-09357-6

38. Erich Barke / Rolf Wernstedt /

Herbert Breger (Hg.)

Leibniz neu denken

2009. I08 S., kt.

ISBN 978-3-5I5-09374-3

39. Thomas Kisser (Hg.)

Metaphysik und Methode

Descartes, Spinoza, Leibniz im Vergleich 20I0. I53 S., kt.

ISBN 978-3-5I5-09736-9

40. Paul Rateau (Hg.)

Lectures et interprétations des

Essais de théodicée de G. W. Leibniz

20II. 3I6 S. mit 2 Abb., kt.

ISBN 978-3-5I5-099I9-6

4I. Wenchao Li / Hans Poser /

Hartmut Rudolph (Hg.)

Leibniz und die Ökumene

20I3. 314 S., kt.

ISBN 978-3-5I5-I0309-I

42. Wenchao Li / Hartmut Rudolph (Hg.)

„Leibniz“ in der Zeit

des Nationalsozialismus

20I3. 309 S., kt.

ISBN 978-3-5I5-I0308-4

43. Christian Leduc / Paul Rateau /

Jean-Luc Solère (Hg.)

Leibniz et Bayle :

Confrontation et dialogue

20I5. 452 S., kt.

ISBN 978-3-5I5-10638-2

44. Wenchao Li (Hg.)

„Das Recht kann nicht

ungerecht sein ...“

Beiträge zu Leibniz' Philosophie

der Gerechtigkeit

20I5. I84 S. mit 3 Abb., kt.

ISBN 978-3-5I5-II2I2-3

45. Arnaud Pelletier (Hg.)

Leibniz and the aspects of reality

20I6. I49 S. mit $7 \mathrm{Abb}$., kt.

ISBN 978-3-5I5-III70-6
46. Arnaud Pelletier ( $\mathrm{Hg}$.)

Leibniz's experimental philosophy

20I6. 257 S. mit I6 Abb., kt.

ISBN 978-3-5I5-II307-6

47. Wenchao Li / Simona Noreik (Hg.)

Leibniz, Caroline und die Folgen

der englischen Sukzession

20I6. I36 S. mit 8 fbg. und $2 \mathrm{~s} / \mathrm{w}-\mathrm{Abb}$., kt.

ISBN 978-3-5I5-II383-O

48. Ansgar Lyssy

Kausalität und Teleologie

bei G. W. Leibniz

20I6. 4I7 S., kt.

ISBN 978-3-5I5-II349-6

49. Edward W. Glowienka

Leibniz's Metaphysics of Harmony

20I6. I24 S., kt.

ISBN 978-3-5I5-II482-O

50. Nora Gädeke / Wenchao Li (Hg.)

Leibniz in Latenz

Überlieferungsbildung als Rezeption

(I7I6-I740)

20I7. 262 S. mit 25 fbg. und $3 \mathrm{~s} / \mathrm{w}-\mathrm{Abb}$., kt.

ISBN 978-3-5I5-II474-5

5I. Thomas Leinkauf/

Stephan Meier-Oeser (Hg.)

Harmonie und Realität

Beiträge zur Philosophie des späten Leibniz 20I7. I99 S., kt.

ISBN 978-3-5I5-II656-5

52. Wenchao Li (Hg.)

Leibniz and the European

Encounter with China

300 Years of "Discours sur la théologie naturelle des Chinois"

20I7. 295 S., kt.

ISBN 978-3-5I5-II733-3

53. Michel Serfati

Leibniz and the Invention of

Mathematical Transcendence

20I8. 248 S., kt.

ISBN 978-3-5I5-I2082-I

54. Luca Basso (Hg.)

Leibniz und das Naturrecht

20I9. 20I S., kt.

ISBN 978-3-5I5-I2288-7

55. Maria Seidl

Pierre Gassendi und die Probleme des Empirismus

20I9. 225 S. mit 2 Abb., kt.

ISBN 978-3-5I5-I234I-9

56. Juan Antonio Nicolás (Hg.)

Körper, Geist, Monaden

Monadologie und Metaphysik bei Leibniz 2020. 267 S., kt.

ISBN 978-3-5I5-IIO30-3 
Through the reconstruction of Leibniz's theory of the degrees of knowledge, this book investigates and explores the intrinsic relationship of imagination with space and time. The inquiry into this relationship defines the logic of imagination that characterizes both human and non-human animals, albeit differently, making them two different species of imaginative animals.

Lucia Oliveri explains how the emergence of language in human animals goes hand in hand with the emergence of thought and a different form of rationality constituted by logical inferences based on identity and contradiction, principles that are out of reach of the imagination. The book concludes that the presence of innate principles in human animals transforms the way in which they sense-perceive the world, thereby constantly increasing the distinction between human and non-human animals. 